\title{
Funktionale Analyse des CC-Typ Glutaredoxin ROXY19 in Arabidopsis thaliana
}

\author{
Dissertation \\ Zur Erlangung des mathematisch-naturwissenschaftlichen Doktorgrades \\ “Doctor rerum naturalium" \\ der Georg-August-Universität Göttingen
}

Im Promotionsprogramm

"Grundprogramm Biologie“

der Georg-August University School of Science (GAUSS)

vorgelegt von

Jan Oberdiek

aus Göttingen, Deutschland

Göttingen 2018 



\section{Betreuungsausschuss}

Prof. Dr. Christiane Gatz

(Abteilung Molekularbiologie und Physiologie der Pflanze)

Prof. Dr. Jörg Stülke

(Abteilung Allgemeine Mikrobiologie)

Dr. rer. nat. Corinna Thurow

(Abteilung Molekularbiologie und Physiologie der Pflanze)

\section{Mitglieder der Prüfungskomission}

Referentin: Prof. Dr. Christiane Gatz

(Abteilung Molekularbiologie und Physiologie der Pflanze)

Korreferent: Prof. Dr. Jörg Stülke

(Abteilung Allgemeine Mikrobiologie)

\section{Weitere Mitglieder der Prüfungskommission:}

Prof. Dr. Volker Lipka (Abteilung Zellbiologie der Pflanze)

Prof. Dr. Ivo Feussner (Abteilung Biochemie der Pflanze)

Prof. Dr. Andrea Polle (Abteilung Forstbotanik und Baumphysiologie)

PD Dr. Thomas Teichmann (Abteilung Zellbiologie der Pflanze) 



\section{Erklärung}

Hiermit bestätige ich, dass ich diese Dissertationsarbeit mit dem Titel „Funktionale Analyse des CC-Typ Glutaredoxin ROXY19 in Arabidopsis thaliana“ selbstständig verfasst und keine anderen als die angegebenen Hilfsmittel genutzt habe. Alle wörtlich oder inhaltlich übernommenen Stellen habe ich als solche gekennzeichnet. Die Experimente wurden größtenteils von mir ausgeführt; Experimente die von meinem Kollaborateur Dr. rer. nat. Sven Freibert (Philipps-Universität Marburg) durchgeführt wurden, wurden als solche gekennzeichnet.

Ich versichere außerdem, dass ich die beigefügte Dissertation nur in diesem und keinem anderen Promotionsverfahren eingereicht habe und, dass diesem Promotionsverfahren keine endgültig gescheiterten Promotionsverfahren vorausgegangen sind.

Göttingen den,

(Jan Oberdiek) 


\section{Inhaltsverzeichnis}

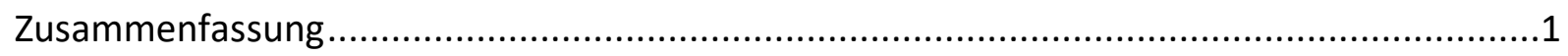

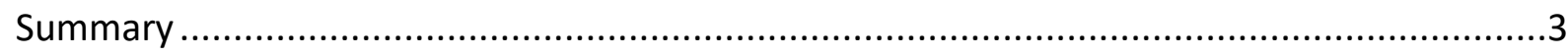

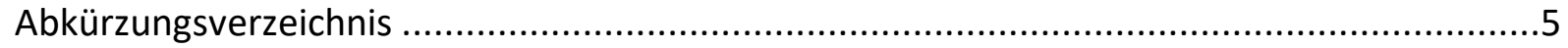

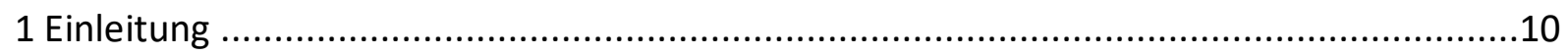

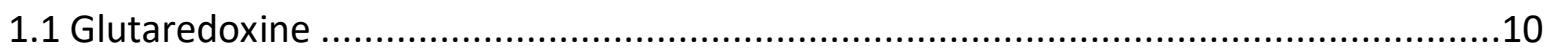

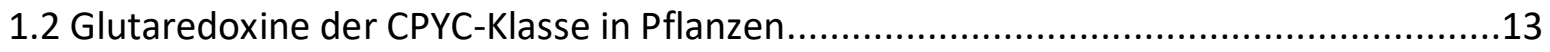

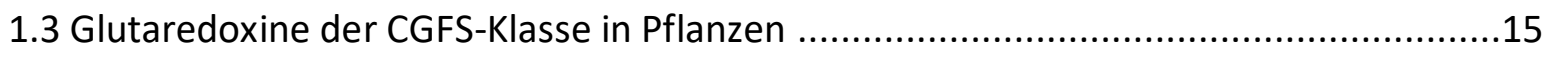

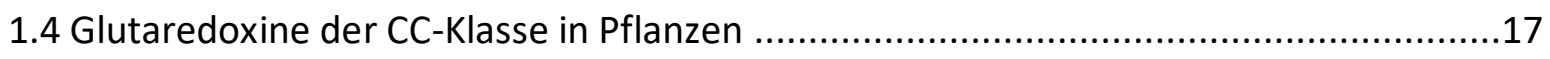

1.5 Die Bedeutung von Klasse II TGA Transkriptionsfaktoren in Arabidopsis thaliana ........20

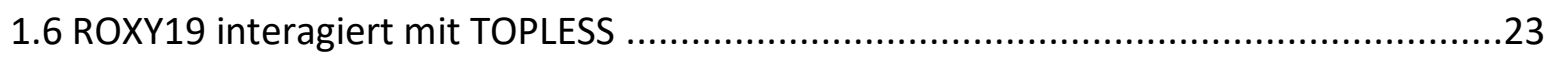

1.7 CC-Typ Glutaredoxine könnten die Bindungseigenschaften von TGA Faktoren

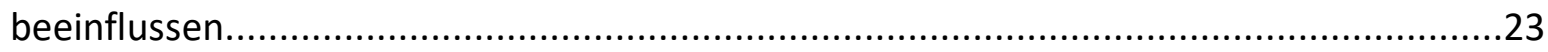

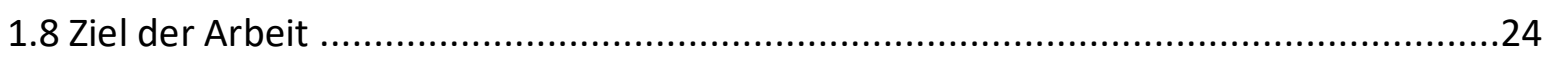

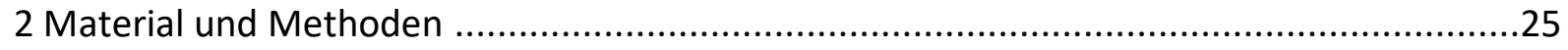

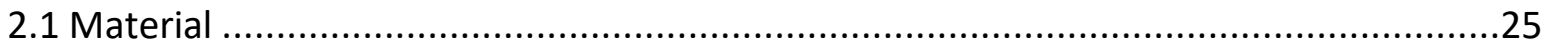

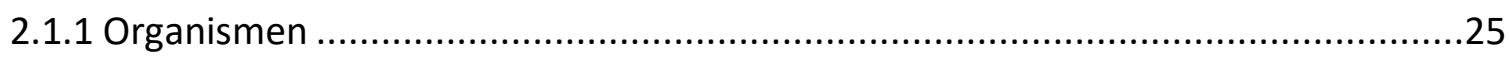

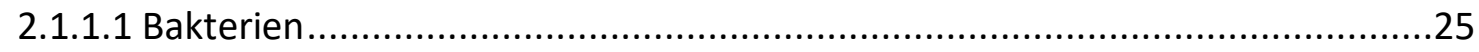

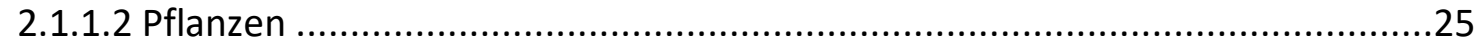

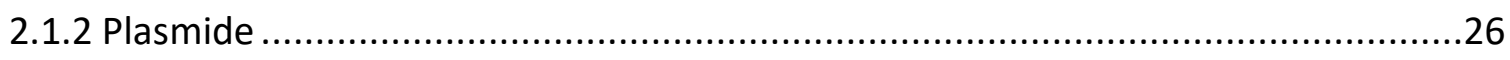

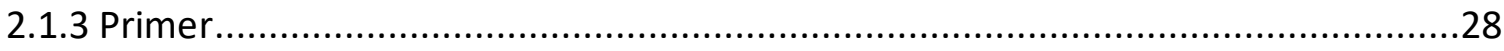

2.1.4 Chemikalien, Enzyme, Kits und Antikörper .................................................29

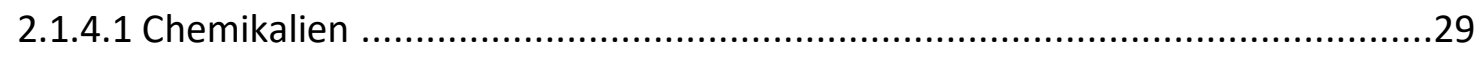

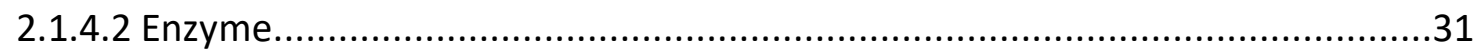

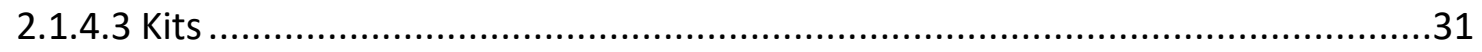

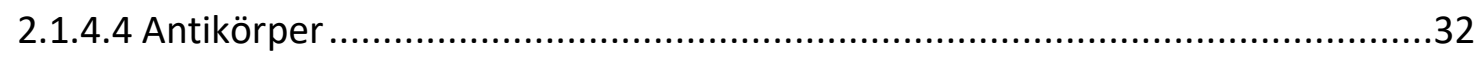

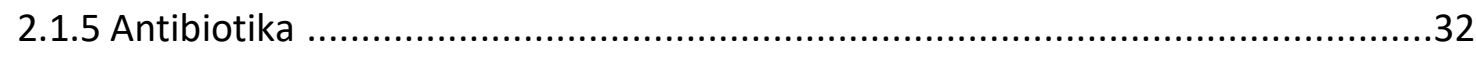

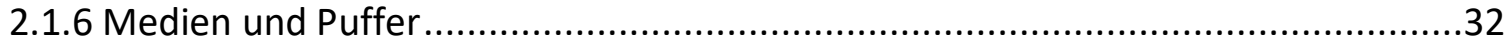

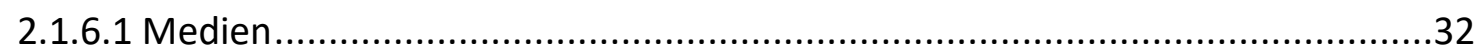

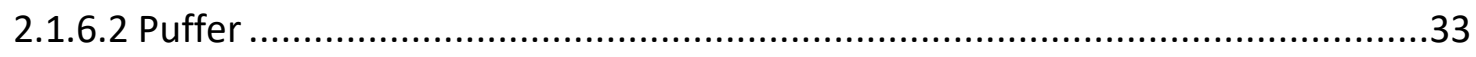

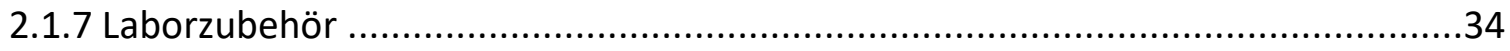

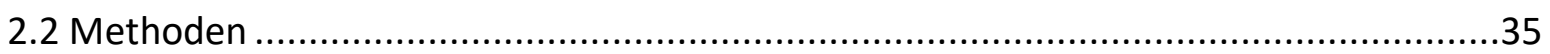

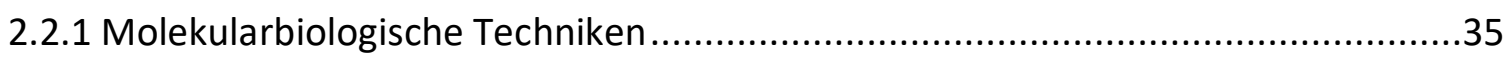




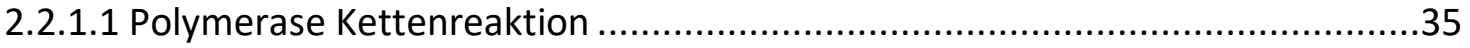

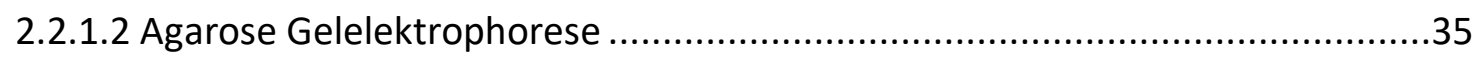

2.2.1.3 Konzentrationsbestimmung von Nukleinsäuren ......................................35

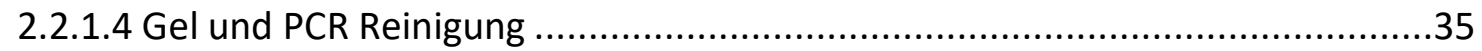

2.2.1.5 Fragmentierung von DNA mit Restriktionsenzymen .................................36

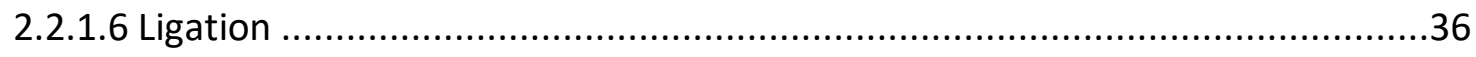

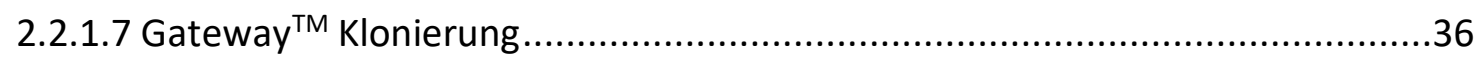

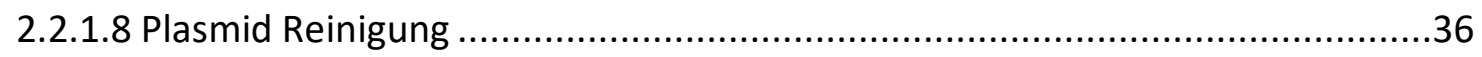

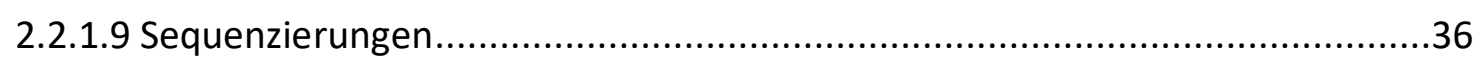

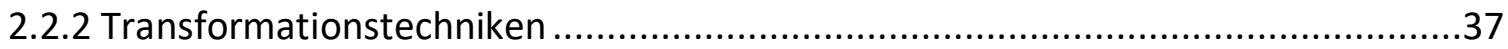

2.2.2.1 Herstellung von chemisch kompetenten Escherichia coli............................37

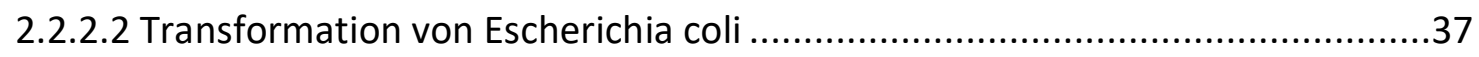

2.2.2.3 Transformation von Agrobacterium tumefaciens .....................................37

2.2.2.4 Transformation von Arabidopsis thaliana .....................................................38

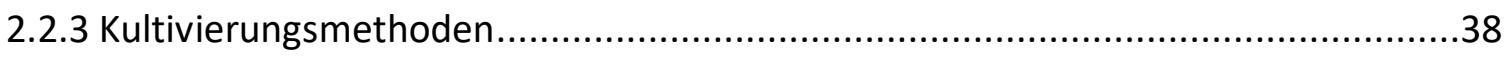

2.2.3.1 Oberflächensterilisation von Arabidopsis thaliana Samen ...........................38

2.2.3.2 Wachstum von Arabidopsis thaliana Samen auf MS-Platten ..........................38

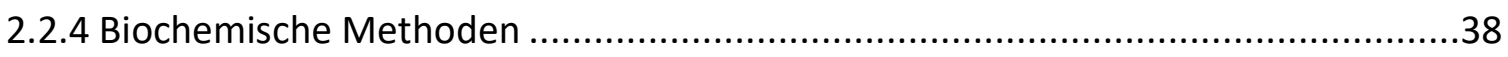

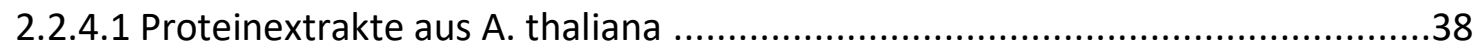

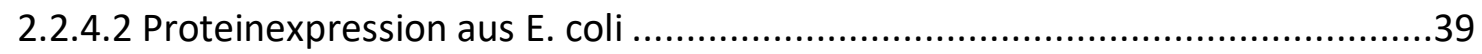

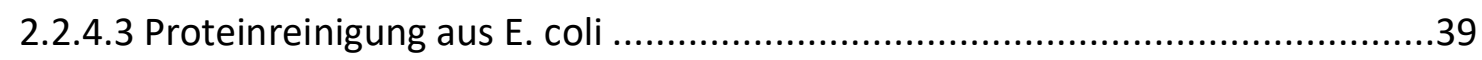

2.2.4.4 Konzentrationsbestimmung von Proteinen .............................................40

2.2.4.5 SDS-Polyacrylamid Gel Elektrophorese (SDS-PAGE) ...................................40

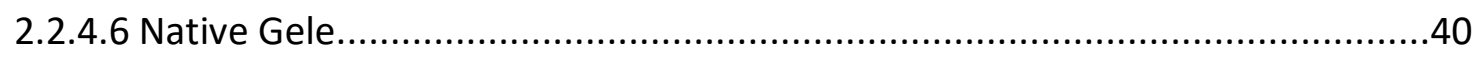

2.2.4.7 Coomassie Färbung von Acryamid-Gelen..................................................41

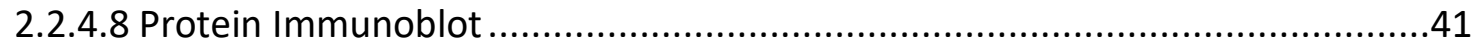

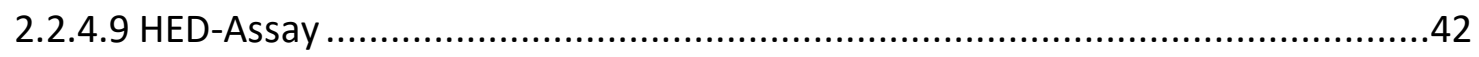

2.2.4.10 Rekonstitution von Eisen-Schwefel-Clustern.......................................42

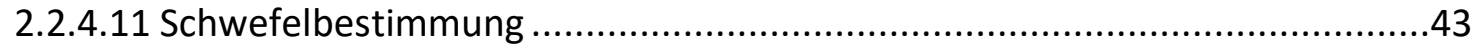

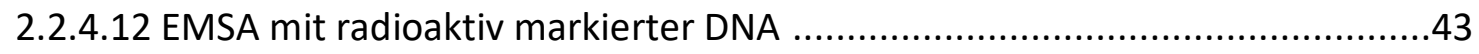

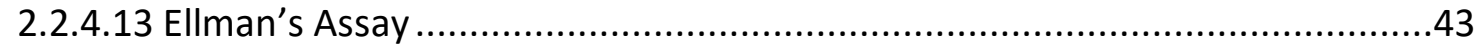

2.2.4.14 Löslichkeits- und Stabilitätstests .........................................................44

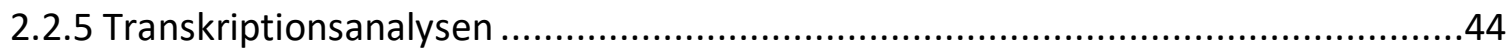


2.2.5.1 RNA Extraktion .44

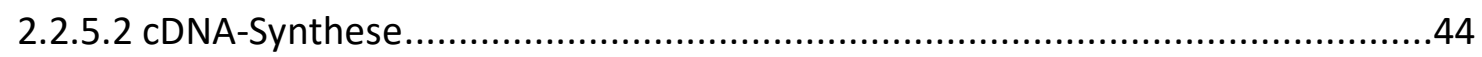

2.2.5.3 Quantitative Echtzeit-PCR (qRT-PCR) ................................................45

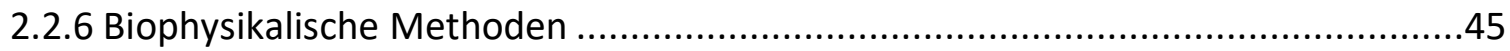

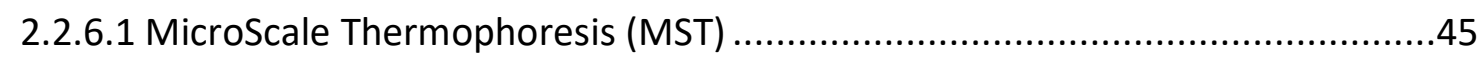

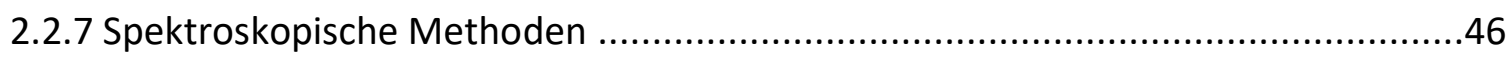

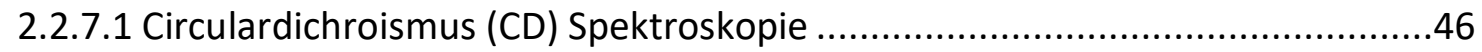

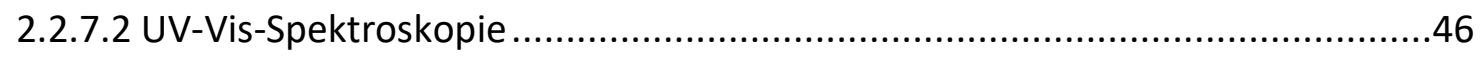

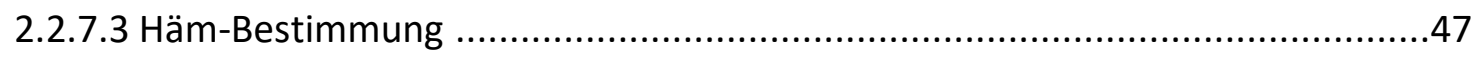

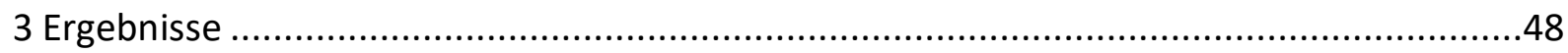

3.1 Analyse des CC-Typ Glutaredoxin ROXY19 in vitro .............................................48

3.1.1 Der Einfluss des Tags und der Co-Expression des Interaktionspartners TGA2 auf die

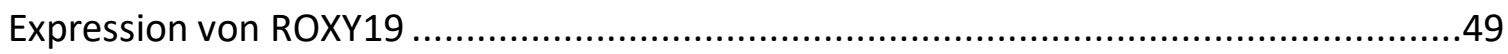

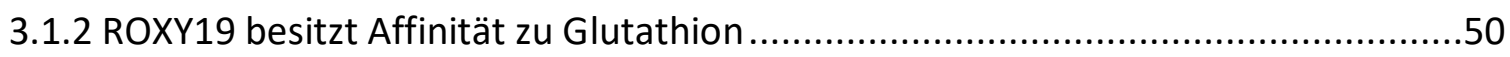

3.1.3 ROXY19 zeigt keine enzymatische Aktivität im HED-Assay.................................52

3.1.4 ROXY19 inkorporiert eine Eisen-Schwefel-Spezies ........................................53

3.1.5 Oligomerbildung von ROXY19 in Abhängigkeit des Redoxzustandes ....................56

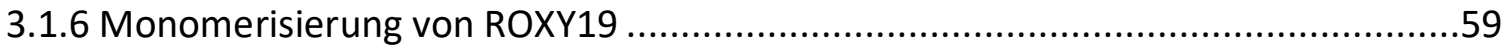

3.1.7 Einfluss von ROXY19 auf die Bindeeigenschaften von TGA2 an das as-1 Element..62

3.2 Analyse des CC-Typ Glutaredoxins ROXY19 in planta .........................................69

3.2.1 ROXY19 reprimiert Entgiftungsgene.........................................................69

3.2.2 Einfluss von Eisenmangel auf die Repression von ROXY19 auf TGA-abhängige Gene . .71

3.2.3 Komplementation der roxy18roxy19roxy20 Mutante.......................................73

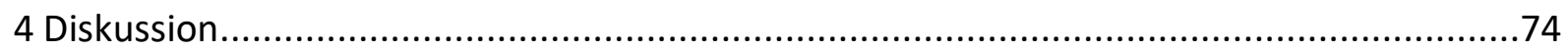

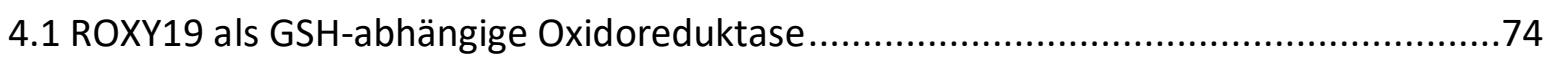

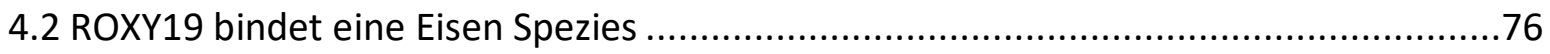

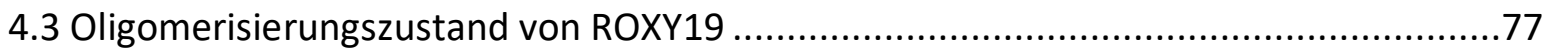

4.4 Der ROXY19-induzierte Supershift des TGA2-as-1 * Komplex ..................................78

4.5 Verstärkung der Bindung von TGA2 an das as-1 Element durch ROXY19.....................79

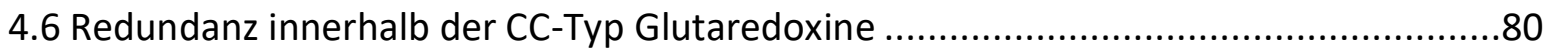

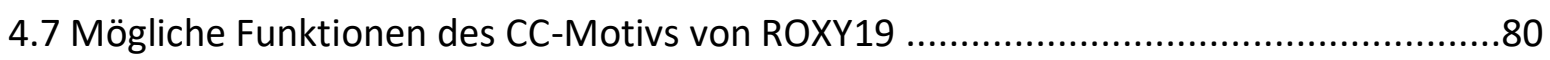

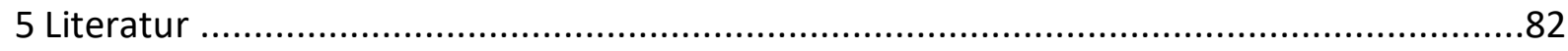


6 Anhang

.90

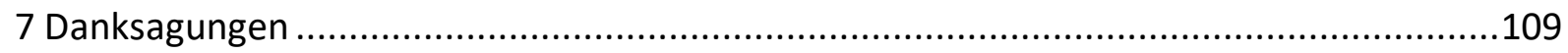

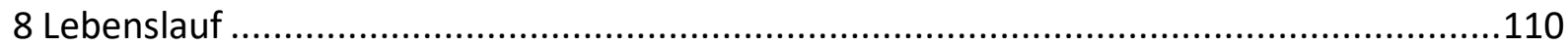




\section{Zusammenfassung}

Glutaredoxine sind kleine weit verbreitete Enzyme, die durch die sogenannte Thioredoxin Faltung charakterisiert sind und ein aktives Zentrum besitzen, welches durch Glutathion reduziert werden kann. Die Glutaredoxine werden anhand ihres aktiven Zentrums in drei Klassen eingeteilt: Klasse I CPYC-Typ, Klasse II CGFS-Typ und Klasse III CC-Typ (in Arabidopsis thaliana auch ROXYs genannt). Ihre biochemischen Eigenschaften als Oxidoreduktasen und Gerüstproteine für Eisen-Schwefel-Cluster sind für die CPYC und CGFS Klasse in der Literatur beschrieben. Ihre Funktionen liegen in der Redox-Homöostase der Zelle, der Regulation von Signalprozessen und der DNA-Synthese. Die CC-Typ Klasse ist spezifisch für Landpflanzen. Für Mitglieder dieser Klasse wurde gezeigt, dass sie an Entwicklungs- und Pathogenabwehrprozessen beteiligt sind.

ROXYs interagieren physikalisch und genetisch mit TGA Transkriptionsfaktoren. Ektopisch exprimiertes ROXY19 unterdrückt die Klasse II TGA-vermittelte (TGA2, TGA5 und TGA6) Expression von Ethylen/Jasmonsäure-induzierten Abwehrgenen und der Expression von Klasse II TGA-abhängigen Detoxifikationsgenen. Das Ziel dieser Arbeit war es den Mechanismus dieser ROXY19-vermittelten Repressionen zu untersuchen. Mögliche Mechanismen wären eine enzymatische Aktivität von ROXY19, die eine Redoxmodifikation von Cysteinresten erlauben würde oder die Inkorporation eines Eisen-Schwefel-Clusters als Regulationsmechanismus.

Um diese Glutaredoxin-spezifischen Funktionen zu untersuchen, wurde rekombinant exprimiertes ROXY19 aus Escherichia coli verwendet. Mithilfe der MicroScale Thermophorese konnte eine Glutathion-Bindung, die abhängig vom CCMC Motiv war, nachgewiesen werden. Die Affinität von ROXY19 zum Glutathion war vergleichbar mit der eines CPYC-Typ Glutaredoxin (GRX370), welches enzymatische Aktivität im 2-Hydroxyethyldisulfid-Assay besaß. ROXY19 hingegen besaß keine Aktivität im 2-Hydroxyethyldisulfid-Assay. Eine Mutation des aktiven Zentrums von ROXY19 zum CPYC Motiv war nicht ausreichend, um eine Aktivität im 2-Hydroxyethyldisulfid-Assay zu beobachten. Die Eisen-Schwefel-Cluster Analysen ergaben, dass ROXY19 eine Eisen-Spezies unbekannten Typs inkorporieren konnte. Weitere Analysen zeigten, dass rekombinant exprimiertes ROXY19 aus Escherichia coli als Oligomer vorlag. Rekonstitutionsversuche zur Bestimmung des putativen Eisen-SchwefelClusters mit dem Oligomer und Monomer waren nicht erfolgreich.

Aufgrund von "Electrophoretic Mobility Shift Assay“-Analysen konnte ein möglicher Mechanismus der Regulation von TGA2 gefunden werden. ROXY19 zeigte einen positiven Einfluss auf die Bindeeigenschaften von TGA2 an ein radioaktiv markiertes activating sequence-1 Promotor Fragment (beinhaltet die TGA Bindesequenz 5'-TGACG'-3). Diese Eigenschaft war jedoch unabhängig vom aktiven Zentrum und konnte ebenfalls bei dem CPYC-Typ Glutaredoxin GRX370 beobachtet werden. ROXY19 konnte eine zusätzliche Veränderung der Mobilität des TGA2-activating sequence-1 Komplexes in der Gelelektrophorese hervorrufen. Diese Daten sprechen für einen ROXY19-TGA2 Komplex an der DNA. Dieser Komplex könnte die Möglichkeit bieten TOPLESS an Promotor Regionen von Klasse II TGA-kontrollierten Genen zu rekrutieren. 
Huang et al. (2016) zeigten, dass Pflanzen die im Col-0 Hintergrund ROXY19 ektopisch exprimieren schlechter auf Medium mit dem Xenobiotikum 2,3,5-Triiodobenzoesäure als Col-0 Pflanzen wachsen. Dies konnte auf eine ROXY19-vermittelte Repression von Genen die an der Entgiftung beteiligt sind zurückgeführt werden. Die Repression ist abhängig vom CCMC Motiv des ROXY19, eine Mutation zum SSMS zeigte Wildtyp Wachstum. In dieser Arbeit konnte in planta gezeigt werden, dass der durch das 2,3,5-Triiodobenzoesäure verursachte Wachstumsphänotyp von Pflanzen, die ROXY19 ektopisch exprimierten (Huang et al., 2016), vom ersten Cystein des CCMC Motivs, aber nicht vom zweiten, abhängig war. Desweiteren konnte gezeigt werden, dass die Eisenverfügbarkeit keinen Einfluss auf die ROXY19-vermittelte Repression von Zielgenen der Klasse II TGA Transkriptionsfaktoren hatte. 


\section{Summary}

Glutaredoxins are small widespread enzymes that are characterized by the so-called thioredoxin fold. They have an active center which can be reduced by glutathione. The glutaredoxins are divided into three classes according to their active center: class I CPYCtype, class II CGFS-type and class III CC-type (called ROXYs in Arabidopsis thaliana). For class I and II the biochemical properties as oxidoreductases and scaffold proteins for iron-sulfur clusters are described. They contribute to the redox homeostasis of the cell, the regulation of signalling processes, and DNA synthesis. The CC-type class is specific to higher land plants. It has been found to be involved in developmental processes and pathogen defense responses.

ROXYs interact physically and genetically with TGA transcription factors. Ectopically expressed ROXY19 suppressed class II TGA-mediated (TGA2, TGA5 and TGA6) expression of ethylene/jasmonic acid-induced defense genes and detoxification genes. The aim of this work was to investigate a possible mechanism for this repression. Possibilities are an enzymatic activity of ROXY19, which allows a redox modification of cysteine residues, or the incorporation of an iron-sulfur cluster as a possible regulatory mechanism.

To investigate these glutaredoxin-specific functions, recombinantly expressed ROXY19 from Escherichia coli was used. The affinity to glutathione was detected for ROXY19 with the help of MicroScale Thermophoresis. The affinity was dependent on the CCMC motif and similar to a CPYC type glutaredoxin (GRX370) which had enzymatic activity in the 2-hydroxyethyl disulfide assay. However, ROXY19 had no activity in the 2-hydroxyethyl disulfide assay. A mutation of the active site to the CPYC motif was not sufficient to ensure activity in the 2hydroxyethyl disulfide assay. The iron-sulfur cluster analysis showed that ROXY19 was able to incorporate an iron species of an unknown type. Further analysis showed that recombinantly expressed ROXY19 from Escherichia coli formed higher molecular oligomers. Reconstitution experiments to determine the type of iron-sulfur cluster with the oligomer and monomer were unsuccessful.

Based on Electrophoretic Mobility Shift Assay analysis, a possible mechanism of ROXY19 to control TGA2 activity was discovered. ROXY19 showed a positive influence on TGA2 binding on a radioactive labeled activating sequence-1 promoter fragment (including the TGA binding sequence 5 '-TGACG'-3). This feature was independent of the active site and was also observed for the CPYC type glutaredoxin GRX370. ROXY19 induced an additional change in the mobility of the TGA2-activating sequence-1 complex in gel electrophoresis. These data support a ROXY19-TGA2 complex bound to the DNA. The complex might be a possibility to recruit TOPLESS to promoter regions of class II TGA-controlled genes.

Huang et al. (2016) observed that plants ectopically expressing ROXY19 in Col-0 background show reduced growth on the xenobiotic 2,3,5-triiodobenzoic acid compared to Col-0 plants. This was based on the ROXY19-mediated repression of detoxification genes. The repression is dependent on the CCMC motif of ROXY19, a mutation to SSMS showed wild-type-like growth. In this work it was shown in planta that the 2,3,5-triiodobenzoic acid susceptible phenotype of plants expressing ROXY19 (Huang et al., 2016) was depending on the first but not the second cysteine of the CCMC motif. Furthermore it was shown, that iron availability 
had no influence on the ROXY19-mediated repression of class II TGA transcription factor target genes. 
$35 S$

${ }^{\circ} \mathrm{C}$

$\varnothing$

$\mu$

$\mu \mathrm{F}$

$\mu \mathrm{L}$

$\alpha$

A. thaliana und At

ACC

ae

AFT

anae

AP2/ERF

APS

$a s-1$

attP

(m)AU

$\beta$

$\beta-\mathrm{Me}$

BAK1

B. cinerea

BolA

bp

BRI1

BSA

BSO

bZIP

$\mathrm{CaCl}_{2}$

CaMV

CCD
35S Promotor des CaMV

Grad Celsius

Durchmesser

Mikro

Mikrofarad

Mikroliter

Alpha

Arabidopsis thaliana

1-Aminocyclopropan-1-carbonsäure

aerob

(engl.) Activator of Ferrous Transport

anaerob

APETALA2/Ethylene Responsive Factor

Ammoniumpersulfat

(engl.) activating sequence 1

attachment sites

Absorptionseinheiten (engl. absorbance units)

Beta

$\beta$-Mercaptoethanol

(BRI1)-assoziierte Rezeptor-ähnliche Kinase 1

Botrytis cinerea

(engl.) DNA-binding transcriptional regulator BolA

Basenpaar(e)

BRASSINOSTEROID INSENSITIVE 1

Rinderalbumin (engl. Bovine Serum Albumins)

Buthionin-Sulfoximin

basic Leucine-Zipper

Calciumchlorid

Cauliflower Mosaic Virus

Charge-coupled Device 


\begin{tabular}{|c|c|}
\hline CD-Spektroskopie & Circulardichroismus-Spektroskopie \\
\hline ChiP & Chromatin-Immunopräzipitationen \\
\hline $\mathrm{ClA}$ & cytosolischen [Fe-S]-Montage \\
\hline $\mathrm{cm}^{2}$ & (Quadrat) Zentimeter \\
\hline COI1 & CORONATINE INSENSITIVE1 \\
\hline Col-0 & Columbia \\
\hline $\mathrm{cp}$ & Chloroplast \\
\hline CT & threshold cycle \\
\hline CTR1 & CONSTITUTIVE TRIPLE RESPONSE1 \\
\hline Cys & Cystein \\
\hline DMSO & Dimethylsulfoxid \\
\hline (c)DNA & $\begin{array}{l}\text { (komplementäre) Desoxyribonukleinsäure (engl. deoxyribonucleic } \\
\text { acid) }\end{array}$ \\
\hline dNTPs & Desoxyribonukleosidtriphosphate \\
\hline DTT & Dithiothreitol \\
\hline$\varepsilon$ & Extinktionskoeffizient \\
\hline E. coli & Escherichia coli \\
\hline EDTA & Ethylendiamintetraessigsäure \\
\hline EIN3 & ETHYLENE INSENSITIVE3 \\
\hline EMSA & (engl.) Electrophoretic Mobility Shift Assay \\
\hline engl. & Englisch \\
\hline EPR & (engl.) electron paramagnetic resonance \\
\hline ER & Endoplasmatischen Retikulum \\
\hline ET & Ethylen \\
\hline $\mathrm{EtBr}$ & Ethidiumbromid \\
\hline [Fe-S]-Cluster & Eisen-Schwefel-Cluster \\
\hline FPLC & Schnelle Proteinflüssigkeitschromatographie \\
\hline g & Gramm \\
\hline GeFi & Gel-Filtration \\
\hline GFP & Grün fluoreszierendes Protein \\
\hline GRAS & $\begin{array}{l}\text { GIBBERELLIC-ACID INSENSITIVE (GAI), REPRESSOR of GAI (RGA) and } \\
\text { SCARECROW (SCR) }\end{array}$ \\
\hline
\end{tabular}




\begin{tabular}{|c|c|}
\hline GSH & Glutathion (reduziert) \\
\hline GSSG & Glutathion-Dimer (oxidiert) \\
\hline GSTs & Glutathion-S-Transferasen \\
\hline GR & Glutathionreduktase \\
\hline GRX & Glutaredoxin \\
\hline HA & Hämagglutinin \\
\hline HABA & 2- [4'-Hydroxybenzolazo]benzoesäure \\
\hline $\mathrm{HCl}$ & Salzsäure \\
\hline HED & 2-Hydroxyethyldisulfid \\
\hline HPLC & Hochleistungsflüssigkeitschromatographie \\
\hline Hs & Homo sapiens \\
\hline Ile & Isoleucin \\
\hline IPTG & Isopropyl- $\beta$-D-thiogalactopyranosid \\
\hline$J A$ & Jasmonsäure \\
\hline$J A Z$ & JASMONATE ZIM DOMAIN \\
\hline $\mathrm{K}_{2} \mathrm{HPO}_{4}$ & Dikaliumhydrogenphosphat \\
\hline kbp & Kilobasenpaar \\
\hline $\mathrm{kBq}$ & Kilobecquerel \\
\hline KD & Dissoziationskonstante \\
\hline $\mathrm{kDa}$ & Kilodalton \\
\hline $\mathrm{KH}_{2} \mathrm{PO}_{4}$ & Kaliumdihydrogenphosphat \\
\hline $\mathrm{KOH}$ & Kaliumhydroxid \\
\hline $\mathrm{kV}$ & Kilovolt \\
\hline$\lambda$ & Lambda \\
\hline L & Liter \\
\hline LB-Medium & Lysogensäurebrühe (engl. lysogeny broth) \\
\hline M & Molar \\
\hline $\mathrm{mA}$ & Milliampere \\
\hline mbar & Millibar \\
\hline MBP & Maltose Bindeprotein \\
\hline MES & 2-(N-Morpholino)ethansulfonsäure \\
\hline MeV & Methylviologen \\
\hline
\end{tabular}




\begin{tabular}{|c|c|}
\hline $\mathrm{mg}$ & Milligramm \\
\hline $\mathrm{MgSO}_{4}$ & Magnesiumsulfat \\
\hline $\min$ & Minute(n) \\
\hline $\mathrm{mL}$ & Milliliter \\
\hline $\mathrm{mM}$ & Millimolar \\
\hline $\mathrm{MnCl}_{2}$ & Manganchlorid \\
\hline MS-Medium & Murashige und Skoog Medium \\
\hline MST & MicroScale Thermophorese \\
\hline MWCO & Molecular Weight Cut-Off \\
\hline $\mathrm{Na}_{2} \mathrm{HPO}_{4}$ & Dinatriumhydrogenphosphat \\
\hline $\mathrm{NaCl}$ & Natriumchlorid \\
\hline NADPH & $\beta$-Nicotinamide adenine dinucleotide phosphate, reduziert \\
\hline $\mathrm{NADP}^{+}$ & Oxidierte Form des NADPH \\
\hline $\mathrm{NaH}_{2} \mathrm{PO}_{4}$ & Natriumdihydrogenphosphat \\
\hline $\mathrm{NaOH}$ & Natriumhydroxid \\
\hline NF-YC11/NC2 $\alpha$ & (engl.) Nuclear Factor Y Subunit C11/Negative Cofactor $2 \alpha$ \\
\hline ng & Nanogramm \\
\hline $\mathrm{nm}$ & Nanometer \\
\hline $\mathrm{nM}$ & Nanomolar \\
\hline NPR1 & NONEXPRESSER OF PATHOGENESIS-RELATED GENES 1 \\
\hline NTD & N-terminale Domäne \\
\hline OD & Optische Dichte \\
\hline $\mathrm{O} / \mathrm{N}$ & Über Nacht (engl. over night) \\
\hline ORA59 & $\begin{array}{l}\text { OCTADECANOID-RESPONSIVE ARABIDOPSIS AP2/ERF-domain } \\
\text { protein } 59\end{array}$ \\
\hline$\Omega$ & Ohm \\
\hline PAGE & Polyacrylamid Gel Elektrophorese \\
\hline PAN & PERIANTHIA \\
\hline PCR & Polymerase-Ketten-Reaktion (engl. polymerase chain reaction) \\
\hline PDF1.2 & Plant Defensin 1.2 \\
\hline PDIs & Proteindisulfidisomerasen \\
\hline Pipes & Piperazin-N, N'-bis (2-ethansulfonsäure) \\
\hline
\end{tabular}




\begin{tabular}{|c|c|}
\hline Poly(dl-dC) & Poly (deoxyinosinic-deoxycytidylic) acid \\
\hline PR-1 & Pathogenesis related-1 \\
\hline$P t$ & Populus tremula \\
\hline PTL & PETAL LOSS \\
\hline PTT & DL-Phosphinothricin \\
\hline RGLG & (engl.) RING DOMAIN LIGASE \\
\hline$r m l$ & rootmeristem-less \\
\hline RNAi & Ribonukleinsäure-Interferenz \\
\hline roGFP & Redox-sensitives grün fluoreszierendes Protein \\
\hline ROS & reaktive Sauerstoffspezies \\
\hline rpm & Umdrehungen pro Minute (engl. revolutions per minute) \\
\hline RT & Raumtemperatur \\
\hline SA & Salicylsäure \\
\hline SAR & systemisch erworbene Resistenz \\
\hline SDS & Natriumlaurylsulfat (engl. Sodium Dodecyl Sulfate) \\
\hline sek & Sekunde(n) \\
\hline TBS(-T) & Tris-buffered saline (+Tween) \\
\hline TCEP & Tris(2-carboxyethyl)phosphin \\
\hline TEMED & Tetramethylethylendiamin \\
\hline TIBA & 2,3,5-Triiodobenzoesäure \\
\hline TPL & TOPLESS \\
\hline TR & Thioredoxinreduktase \\
\hline TRIS & Tris(hydroxymethyl)-aminomethan \\
\hline TRX & Thioredoxin \\
\hline$U$ & Einheiten (engl. units) \\
\hline UV(B) & Ultraviolett (im Wellenlängenbereich von 280 bis $315 \mathrm{~nm}$ ) \\
\hline$(v / v)$ & (Volumen/Volumen) \\
\hline Vis & Sichtbar (engl. visible) \\
\hline$(w / v)$ & (Gewicht/Volumen) \\
\hline$X V E$ & $\begin{array}{l}\text { Fusion der DNA-Bindungsdomäne des bakteriellen Repressors LexA } \\
(\mathrm{X}) \text {, der sauren transaktivierenden Domäne von VP16 (V) und der } \\
\text { regulatorischen Region des humanen Östrogenrezeptors (E; ER) }\end{array}$ \\
\hline
\end{tabular}




\section{Einleitung}

\subsection{Glutaredoxine}

Glutaredoxine (GRXs) sind kleine weit verbreitete Enzyme, die an der Redox-Homoöstase beteiligt sind. Sie sind in vielen Organismen vertreten und können in den verschiedensten zellulären Kompartimenten angetroffen werden (Ströher and Millar, 2012). Charakteristisch für die Glutaredoxine ist die sogenannte Thioredoxin (TRX) Faltung (Abbildung 1.1). Dieses Strukturmotiv, bestehend aus $4 \beta$-Faltblättern und $3 \alpha$-Helices ( $\beta 1-\alpha 1-\beta 2-\alpha 2-\beta 3-\beta 4-\alpha 3)$, findet man in den TRXs, Proteindisulfidisomerasen (PDIs), Glutathion-S-Transferasen (GSTs), Glutathionperoxidasen und den GRXs (Lu and Holmgren, 2014; Ströher and Millar, 2012). Die GRXs werden anhand ihres aktiven Zentrums in drei Hauptklassen unterteilt (Rouhier et al., 2004). Die erste Klasse besitzt ein aktives Zentrum bestehend aus Cys-Pro-Tyr-Cys (CPYC). Die zweite Klasse besteht aus Monothiol-GRXs, die ein Cys-Gly-Phe-Ser (CGFS) aktives Zentrum besitzen. Die dritte Klasse, auch CC-Typ genannt (in $A$. thaliana auch als ROXYs bezeichnet), ist eine für Pflanzen spezifische Klasse der GRXs, mit einem Cys-Cys-Met/LeuCys/Ser (CCM/LC/S) Motiv im aktiven Zentrum (Lillig et al., 2008).
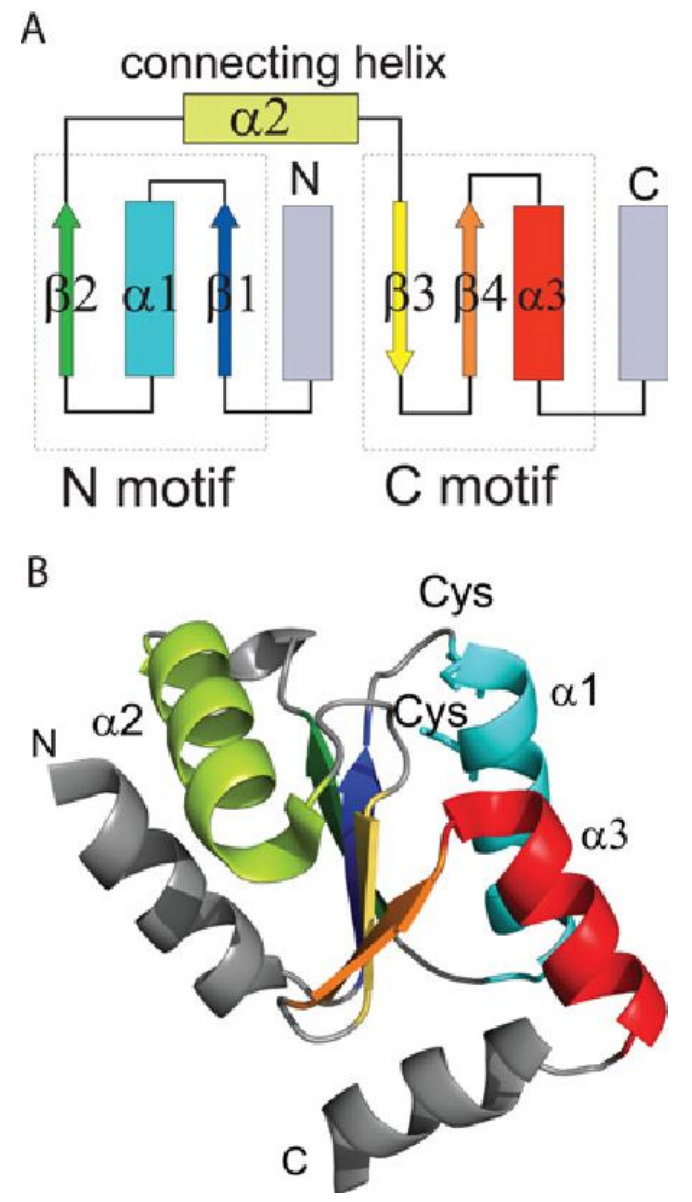

Abbildung 1.1 (A) Architektur von GRXs; $\alpha$-Helices sind als Rechtecke gezeichnet, $\beta$-Blätter als Pfeile. N- und C-terminal konservierte Regionen der TRX-Faltung sind in Farbe angegeben. (B) Struktur von $\mathrm{HsGrx2}$ (PDB-Code 2FLS). Gleiche Farbcodes wie in (A), der N- und C-Terminus sind angegeben. (Text und Abbildung aus Ströher und Millar, 2012) 
Glutathion (GSH) wird von den meisten GRXs als Co-Faktor verwendet. Die Glutathionbindung wird durch mehrere Aminosäuren stabilisiert. Dies geschieht durch die Wechselwirkung eines konservierten Lysins (Klasse I) und einem zweiten Rest in der a2Helix, vorwiegend Glutamin (Klasse I) oder Arginin (Klasse II) mit der Carboxylgruppe des Glycinrests von Glutathion. Zudem über eine Interaktion mit dem Cysteinrest des GSH durch Aminosäurereste, die dem cis-Prolin des Konsensus TVP (Klasse I) oder TFP (Klasse II) Motivs vorausgehen. Die letzte Wechselwirkung mit der Glutamyl-Gruppe des Glutathion geschieht über eine polare Aspartat-Gruppe nach einem charakteristischen GG-Motiv.

Einige GRXs verwenden GSH als Reduktionsmittel, um die Reduktion von Proteindisulfidbrücken oder Glutathionylierungen zu katalysieren. Proteinglutathionylierung ist die Bildung eines gemischten Disulfids zwischen einem Cystein des Proteins und GSH (Klatt and Lamas, 2000). Diese Modifikation des Proteins kann sowohl regulatorische Funktionen in einer Zelle haben, als auch ein Mittel zur Speicherung von GSH sein und ebenso dem Schutz eines Proteins vor oxidativem Stress (durch die Verhinderung der irreversible Oxidation von Thiolen) dienen (Dalle-Donne et al., 2008). Die Reduktion der Proteinglutathionylierung, auch Deglutathionylierung genannt, wird häufig durch GRXs katalysiert (Dalle-Donne et al., 2008). GRXs können die Deglutathionylierung durch zwei verschiedene Mechanismen katalysieren (Fernandes and Holmgren, 2004; Lillig et al., 2008). Dies ist zum einen der Monothiol-Mechanismus und zum anderen der Dithiol-Mechanismus. Der Monothiol-Mechanismus erfordert nur das N-terminale Cystein und wird daher von GRXs der CGFS-Typ Klasse verwendet (Ströher and Millar, 2012). Das N-terminale Cystein des GRX führt hierbei einen nukleophilen Angriff auf das glutathionylierte Protein aus und formt bei der Reduktion des Proteins selbst ein gemischtes Disulfid mit GSH. Die Reduktion von Proteindisulfiden erfordert die Anwendung des Dithiol-Mechanismus, bei dem zwei Cysteine im aktiven Zentrum benötigt werden (Lillig et al., 2008). Auch hier führt zunächst das Nterminale Cystein einen nukleophilen Angriff auf das Proteindisulfid aus, was zu einem gemischten Disulfid zwischen dem GRX und dem Protein führt. Im nächsten Schritt, greift das zweite Cystein im aktiven Zentrum das GRX-Protein-Intermediat an (Lillig et al., 2008). Dies führt zum reduzierten Protein und einem oxidierten GRX mit einer intramolekularen Disulfidbrücke im aktiven Zentrum. Das glutathionylierte bzw. oxidierte GRX wird durch ein (Monothiol) bzw. zwei (Dithiol) weitere(s) Molekül(e) GSH reduziert, welche zusammen ein oxidiertes Glutathion (GSSG) bilden. Das oxidierte Glutathion wird durch die NADPHabhängige Glutathionreduktase (GR) reduziert. TRXs verwenden einen dem DithiolMechanismus ähnlichen Mechanismus, werden jedoch enzymatisch durch sogenannte Thioredoxinreduktasen (TRs) wieder reduziert. 


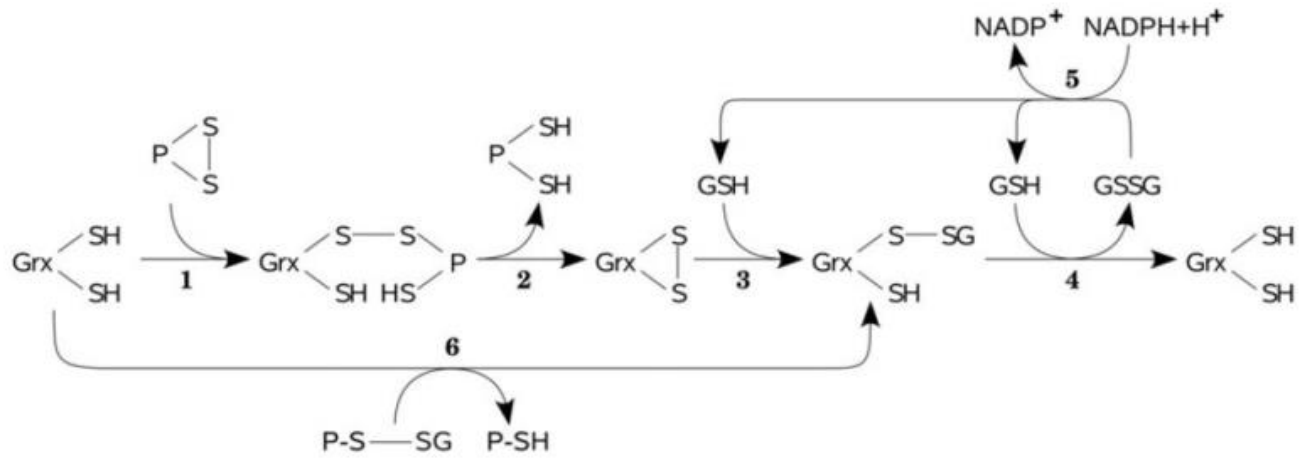

Abbildung 1.2. Reaktionsmechanismen von Glutaredoxinen. Glutaredoxine katalysieren die reversible Reduktion von Proteindisulfiden, unter Verwendung ihrer beiden aktiven Cysteinylreste (Reaktionen 1-4). Gemischte Disulfide zwischen Glutathion und Proteinen oder niedermolekularen Verbindungen werden durch den Monothiol-Mechanismus reduziert, der nur das N-terminale Cystein benötigt (Reaktionen 6 und 4). In beiden Fällen bildet sich ein Glutathiondisulfid, welches durch die Glutathionreduktase, auf Kosten von NADPH, reduziert wird (Reaktion 5) (Abbildung und Text aus (Lillig et al., 2008))

Neben dieser enzymatischen Funktion einiger GRXs, sind andere GRXs am Aufbau von [Fe-S]Clustern in der mitochondrialen Matrix oder der Übertragung von [Fe-S]-Clustern an Zielproteine beteiligt. Die Funktion solcher [Fe-S]-Cluster besteht in der Übertragung von Elektronen (z.B. in der Atmungskette). Möglicherweise dienen [Fe-S]-Cluster auch in der Pflanze als Regulatoren der Genexpression auf sich verändernde Umweltbedingungen (z.B. Eisenmangel). Ein gut beschriebenes Beispiel für eine Regulierung der Genexpression durch GRXs mit inkorporiertem [Fe-S]-Cluster ist die Regulierung von AFT1 und AFT2 in Saccharomyces cerevisiae (Pujol-Carrion et al., 2006).

[Fe-S]-Cluster sind weit verbreitete und evolutionär uralte prosthetische Gruppen. Sie sind strukturierte Anordnungen von Eisen- und Schwefelatomen, die auf Gerüstproteinen assembliert werden. Die am häufigsten auftretenden Cluster bilden die 2[Fe-S]- und 4[Fe-S]Cluster und das etwas seltenere [3Fe-4S]-Cluster (Abbildung 1.3). Das GRXC1 aus Pappel (PtGRXC1) ist ein Beispiel für ein GRX mit gebundenem 2[Fe-S]-Cluster. PtGRXC1 bildet ein Dimer und koordiniert mit jeweils dem ersten Cystein des aktiven Zentrums und der Hilfe von 2 GSH Molekülen das 2[Fe-S]-Cluster (Feng et al., 2006).

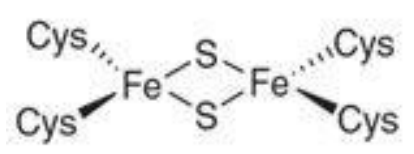

[2Fe-2S]

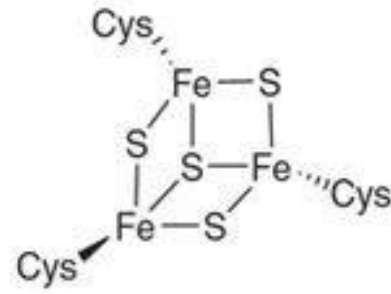

[3Fe-4S]

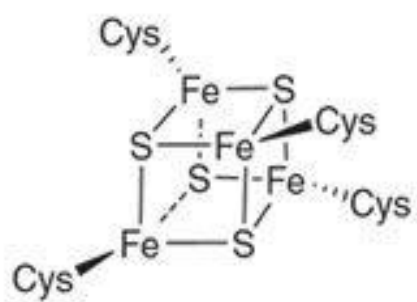

[4Fe-4S]

Abbildung 1.3. Die häufigsten [Fe-S]-Cluster in Organismen. Gezeigt sind die drei häufigsten [Fe-S]-Cluster und wie sie von ihren Gerüstproteinen koordiniert werden. (Abbildung aus (Fontecave, 2006)) 
Das Genom von Arabidopsis thaliana kodiert für sechs Mitglieder der CPYC-Klasse (GRXC1, GRXC2, GRXC3, GRXC4, GRXC5 und GRXS12), vier Mitglieder der CGFS-Klasse (GRXS14, GRXS15, GRXS16 und GRXS17) und 21 Mitglieder der CC-Klasse (ROXY1-ROXY21) (Li et al., 2009; Rouhier et al., 2004) (Abbildung 1.4).

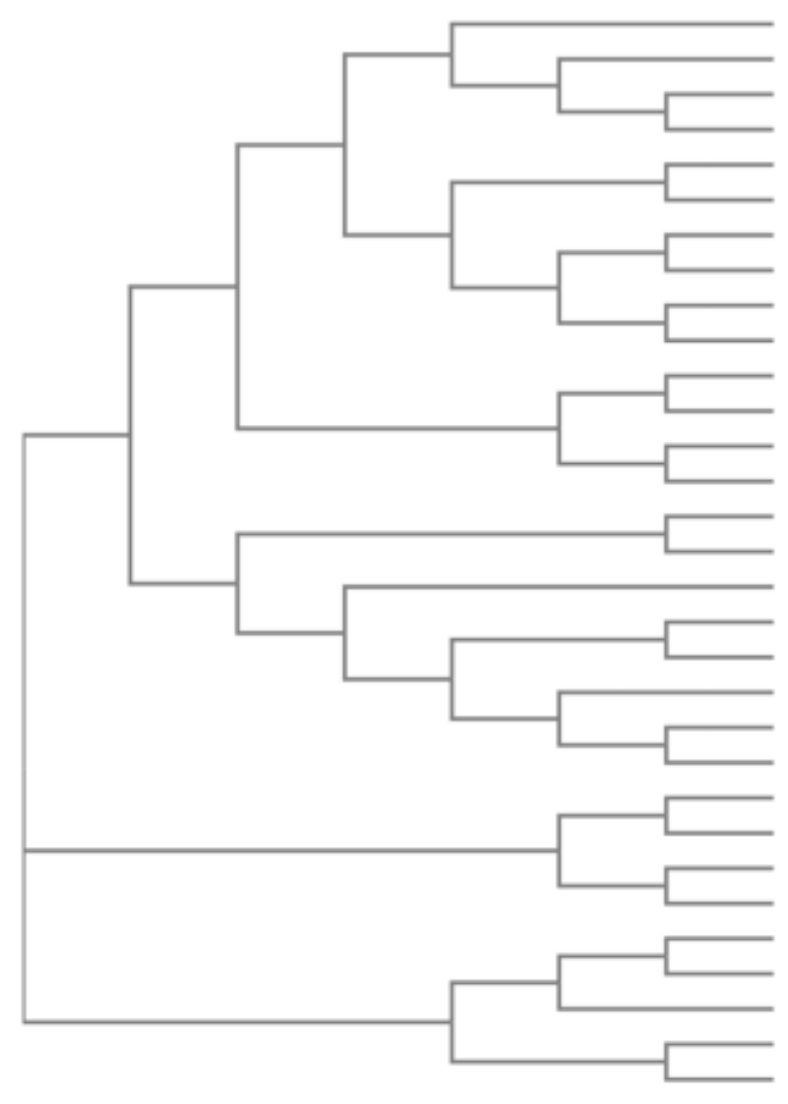

AGI Name

AT2G38270 GRXS16

AT3G15660 GRXS15/GRX4

AT3G54900 GRXS14/GRXCP

AT4G04950 GRXS17

AT1G77370 GRXC3

AT5G20500 GRXC4

AT2G20270 GRXS12

AT4G28730 GRXC5

AT5G40370 GRXC2,

ATSG63030 GRXC1

AT1G03850 ROXY18/GRXS13

AT1G28480 ROXY19/GRXC9

AT4G33040 ROXY21

AT5G11930 ROXY20

AT1G03020 ROXY16

AT3G62930 ROXY17

AT5G18600 ROXY10

AT4G15690 ROXY12

AT4G15700 ROXY11

AT4G15680 ROXY13

AT4G15660 ROXY15

AT4G15670 ROXY14

AT2G47880 ROXY9

AT3G62960 ROXY8

AT1G06830 ROXY6

AT2G30540 ROXY7

AT3G02000 ROXY1/GRXC7

AT5G14070 ROXY2/GRXC8

AT3G21460 ROXY3

AT2G47870 ROXY5

AT3G62950 ROXY4

\begin{abstract}
Abbildung $\quad 1.4 \quad$ Ein phylogenetischer Baum der ArabidopsisGlutaredoxin-Familie. Der phylogenetische Baum wurde aus Vergleichen von Proteinsequenzen, unter Verwendung der „neighbor-joining“Methode in Clustal Omega (EMBL-EBI) erstellt. Die Proteinsequenzen jedes Locus wurden aus TAIR entnommen. Die Gennamen wurden nach Rouhier et al. (2004) oder Li et al. (2009) vergeben.
\end{abstract}

\subsection{Glutaredoxine der CPYC-Klasse in Pflanzen}

Die Glutaredoxine der Klasse I (CPYC) sind in Pflanzen gut charakterisiert. Die katalytische Aktivität der CPYC-Typ GRXs in Pflanzen wurde zuerst anhand von gereinigtem Protein aus Reis im 2-Hydroxyethyldisulfid (HED)-Reduktionstest nachgewiesen (Sha et al., 1997). Später zeigten Meyer et al. (2007), dass rekombinantes GRXC1 in der Lage ist, die Disulfidbrücke von roGFP, einem künstlich hergestellten Zielprotein, zu reduzieren. roGFP ist ein redoxsensitives Protein, das durch die Substitution von zwei Aminosäuren, durch redoxaktive Cysteine aus GFP hergestellt wurde (Hanson et al., 2004). Neben der enzymatischen Oxidoreduktase Aktivität, wurde gezeigt, dass GRXs dieser Klasse als Gerüstproteine für [Fe-S]-Cluster dienen können (Rouhier et al., 2007).

AtGRXC1 ist eines von zwei bekannten CPYC-Typ GRXs in Arabidopsis thaliana, welches eine Holodimer-Struktur bilden kann, die ein [Fe-S]-Cluster inkorporiert (Riondet Christophe et al., 2012). Das nächst verwandte AtGRXC2 ist dazu nicht in der Lage. Auch für das Pappel PtGRXC1 wurde gezeigt, dass es ein [Fe-S]-Cluster inkorporieren kann (Feng et al., 2006; Rouhier et al., 2007). AtGRXC2 wurde als ein interagierendes Protein von BRASSINOSTEROID 
INSENSITIVE 1 (BRI1)-assoziierter Rezeptor-ähnlicher Kinase 1 (BAK1) isoliert. In-vitro biochemische Assays zeigten, dass AtGRXC2 die BAK1-Glutathionylierung katalysiert und die BAK1-Peptidkinaseaktivität hemmt (Bender et al., 2015). BAK1 ist das erste beschriebene Zielprotein, welches von GRXC2 glutathionyliert werden kann. Mutationen in GRXC1 und GRXC2 sind aphenotypisch, die grxc1 grxc2 Mutante jedoch letal (Tabelle 1.1).

Über AtGRXC3 und AtGRXC4 ist bisher nichts bekannt. Für AtGRXC5 wurde gezeigt, dass es in zwei Formen in Escherichia coli exprimiert wird (Couturier et al., 2011). Das monomere AtGRXC5 Apoprotein besitzt eine Deglutathionylierungsaktivität, während das dimere Holoprotein einen 2[Fe-S]-Cluster enthält (Couturier et al., 2011). Ortsspezifische Mutageneseexperimente und die Auflösung der Röntgenkristallstruktur in der Holoform von AtGRXC5 zeigten, dass, obwohl nicht an seiner Ligation beteiligt, das Vorhandensein des zweiten aktiven Cysteins (Cys ${ }^{32}$ ) für die Clusterbildung erforderlich ist (Couturier et al., 2011). Die Aktivität von AtGRXC5 beruht ausschließlich auf einem Monothiol-Mechanismus (Couturier et al., 2011).

Um neue Zielproteine von GRXs zu finden, werden neuartige Proteomics-Technologien entwickelt. Einer dieser Ansätze basiert auf der Annahme, dass ein intermediärer Komplex zwischen dem Dithiol GRX und seinem Zielprotein gebildet wird (Abbildung 1.2). Solche intermediäre Komplexe wurden für TRXs und ihre Zielproteine gezeigt. Eine Mutation des Cterminalen Cysteins des TRX aktiven Zentrums stabilisiert einen solchen intermediären Komplex (Brandes et al., 1993). Daraus ergibt sich die Möglichkeit, eine markierte Mutante dieses Cysteins von TRXs oder GRXs zu exprimieren, um Zielproteine, die kovalent an das TRX/GRX gebunden sind, zu identifizieren. Mithilfe dieses Verfahrens wurden 94 mögliche Zielproteine (darunter viele PRXs) in der Pflanze für PtGRXC4 identifiziert (Rouhier et al., 2005). Viele dieser Proteine sind auch bekannte Zielproteine von TRXs.

Tabelle 1.1. Zusammenfassung der Glutaredoxine der CPYC-Klasse. Gezeigt sind die bekannten Funktionen der CPYC Glutaredoxine in Arabidopsis thaliana und bekannte Phänotypen der dazugehörigen Mutanten.

\begin{tabular}{|c|c|c|c|c|}
\hline GRX & Funktion & Mutante & Phänotyp & Quelle \\
\hline GRXC1 & $\begin{array}{l}\text { Holodimer bindet }[\mathrm{Fe}-\mathrm{S}] \\
\text { Cluster }\end{array}$ & $\operatorname{grxc1}$ & $\begin{array}{l}\text { Aphenotypisch, } \\
\text { Abnahme der globalen } \\
\text { GRX Aktivität }\end{array}$ & $\begin{array}{l}\text { (Riondet } \\
\text { Christophe et al., } \\
\text { 2012) }\end{array}$ \\
\hline \multirow[t]{2}{*}{ GRXC2 } & $\begin{array}{l}\text { Interaktion mit und } \\
\text { Glutathionylierung von BAK1 }\end{array}$ & grxc2 & $\begin{array}{l}\text { Aphenotypisch, } \\
\text { Abnahme der globalen } \\
\text { GRX Aktivität }\end{array}$ & $\begin{array}{l}\text { (Riondet } \\
\text { Christophe et al., } \\
\text { 2012) }\end{array}$ \\
\hline & $\begin{array}{l}\text { GRXC1 und GRXC2 teilen } \\
\text { redundante und } \\
\text { lebenswichtige Funktionen }\end{array}$ & grxc1 grxc2 & letal & $\begin{array}{l}\text { (Riondet } \\
\text { Christophe et al., } \\
\text { 2012) }\end{array}$ \\
\hline GRXC3 & Nicht beschrieben & grxc3 & Nicht beschrieben & / \\
\hline GRXC4 & Nicht beschrieben & grxc4 & Nicht beschrieben & / \\
\hline GRXC5 & $\begin{array}{l}\text { Lokalisation im Chloroplasten, } \\
\text { Apoprotein besitzt } \\
\text { Deglutathionylierungsaktivitä } \\
\text { t, Holoprotein bindet 2[Fe-S]- } \\
\text { Cluster }\end{array}$ & grxc5 & Nicht beschrieben & $\begin{array}{l}\text { (Couturier et al., } \\
\text { 2011) }\end{array}$ \\
\hline
\end{tabular}




\subsection{Glutaredoxine der CGFS-Klasse in Pflanzen}

In Arabidopsis thaliana sind vier CGFS-Typ GRX vorhanden (GRXS14, GRXS15, GRXS16 und GRXS17). Cheng et al. (2006) isolierten ein Chloroplasten-lokalisiertes GRX des CGFS-Typs (AtGRXcp; GRXS14), dessen in planta Expression in jungen Keimblättern, grünen Geweben und Leitbündeln erhöht ist (Cheng et al., 2006). Die Analyse von Pflanzen die GRXS14 exprimimieren zeigte Defekte im frühen Keimlingswachstum unter oxidativen Stressbedingungen und eine erhöhte Proteincarbonylierung in Chloroplasten (Cheng et al., 2006). Pflanzen, die GRXS14 ektopisch exprimieren zeigen zudem einen reduzierten Chlorophyllgehalt unter Kontroll- und Hochlicht, sowie unter Hochsalzbedingungen (Rey Pascal et al., 2017). Für das Pappel PtGRXS14 ist die Struktur bekannt (Wang et al., 2014). Für GRXS14 wurde gezeigt, dass es ein 2[Fe-S]-Cluster (Bandyopadhyay et al., 2008) mit BolA inkorporieren kann (Roret et al., 2014). BolA-Proteine sind als stressabhängige Transkriptionsregulatoren definiert, die aber auch am Eisenstoffwechsel beteiligt sind.

Das mitochondriale Monothiol-Glutaredoxin S15 ist essentiell für die Reifung von EisenSchwefel-Proteinen in Arabidopsis thaliana. Rekombinantes GRXS15 ist in der Lage ein [FeS]-Cluster mithilfe von GSH zu koordinieren und zu übertragen (Moseler et al., 2015). Ströher et al. (2016) zeigten, dass GRXS15 am [Fe-S]-Cluster-Transfer in den Mitochondrien beteiligt ist. Dies hat Einfluss auf Liponsäure-abhängige Enzyme, Pflanzenwachstum und ArsenToleranz in Arabidopsis. Rekombinantes GRXS15 hat eine sehr geringe Deglutathylierungsund Dehydroascorbat-Reduktase-Aktivität (Ströher et al., 2016).

Auch für das mitochondriale GRXS16 wurde gezeigt, dass es ein 2[Fe-S]-Cluster inkorporieren kann (Bandyopadhyay et al., 2008). GRXS16 umfasst zwei funktionale Domainen, eine Nterminale Domäne (NTD) mit einem Gly-Ile-Tyr-Tyr-lle-Gly (GIY-YIG)-Endonuklease Motiv und eine C-terminale GRX-Domäne, um die Redox-Regulierung und DNA-Spaltung in Chloroplasten zu koordinieren. GRXS16-NTD ist in der Lage $\lambda$ DNA und Chloroplastengenomische DNA zu spalten, die Nukleaseaktivität ist in GRXS16 durch die Bildung einer Disulfidbrücke zwischen den beiden Domänen reduziert (Liu et al., 2013).

Das atypische nukleo-zytoplasmatische GRXS17 besteht aus vier Domänen, einer $\mathrm{N}$ terminalen TRX-ähnlichen Domäne, gefolgt von drei CGFS-Domänen und interagiert mit BolA (Couturier et al., 2014). GRXS17 kann glutathionyliertes BolA2 vollständig reduzieren (Couturier et al., 2014). Daher ist die Hypothese, dass GRXS17 den Redoxzustand von BolA2 regulieren und als Redoxschalter für die Aktivierung oder Inaktivierung der BolA-DNABindungsaktivität in Reaktion auf Stressbedingungen dienen könnte (Couturier et al., 2014). GRXS17 befindet sich als Reaktion auf Temperaturstressbedingungen im Zytoplasma und im Zellkern (Cheng et al., 2011). GRXS17 zeigt eine erhöhte Expression in den Sprossmeristemen und reproduktiven Geweben (Knuesting et al., 2015). Rekombinantes GRXS17 inkorporierte mehrere 2[Fe-S]-Cluster (Knuesting et al., 2015). Der Nuclear Factor Y Subunit C11/Negative Cofactor $2 \alpha$ (NF-YC11/NC2 $\alpha$ ) wurde als Interaktionspartner von GRXS17 identifiziert. GRXS17 könnte durch die Interaktion mit NF-YC11/NC2 $\alpha$ ein von der Photoperiode erzeugtes Redoxsignal weiterleiten, um die Meristemfunktion aufrechtzuerhalten (Knuesting et al., 2015). GRXS17 ist ein Zielprotein der Arabidopsis-E3-Ubiquitin-Ligasen RING DOMAIN LIGASE 
3 (RGLG3) und RGLG4 (Nagels Durand et al., 2016). GRXS17 assoziiert mit den meisten bekannten cytosolischen [Fe-S]-Montage (CIA) Komponenten (Iñigo et al., 2016).

Mutationen der CGFS-Klasse GRXS haben vor allem Auswirkung auf die Reifung von [Fe-S]Proteinen (Tabelle 1.2).

Tabelle 1.2. Zusammenfassung der Glutaredoxine der CGFS-Klasse. Gezeigt sind die bekannten Funktionen der CGFS Glutaredoxine in Arabidopsis thaliana und bekannte Phänotypen der dazugehörigen Mutanten.

\begin{tabular}{|c|c|c|c|c|}
\hline GRX & Funktion & Mutante & Phänotyp & Quelle \\
\hline \multirow{2}{*}{$\begin{array}{l}\text { GRXS14 } \\
\text { (AtGRXcp) }\end{array}$} & Lokalisation im Chloroplasten & grxs14 & Kein Wachstumsdefekt & Cheng et al. (2006) \\
\hline & & grxs14 grxs16 & $\begin{array}{l}\text { Langsameres } \\
\text { Wachstum, bei } \\
\text { längerer Dunkelheit ein } \\
\text { erhöhter } \\
\text { Chlorophyllverlust und } \\
\text { Abnahme von } \\
\text { Proteinen die an der } \\
\text { Reifung von [Fe-S]- } \\
\text { Proteinen beteiligt sind } \\
\end{array}$ & $\begin{array}{l}\text { (Rey Pascal et al., } \\
\text { 2017) }\end{array}$ \\
\hline GRXS15 & $\begin{array}{l}\text { Lokalisation in Mitochondrien, } \\
\text { Reifung von [Fe-S]-Proteinen, } \\
\text { bindet [Fe-S]-Cluster mit GSH, } \\
\text { geringe } \\
\text { Deglutathionylierungsaktivität }\end{array}$ & $\begin{array}{l}\text { Teilweise } \\
\text { Entfernung aus } \\
\text { den } \\
\text { Mitochondrien }\end{array}$ & $\begin{array}{l}\text { Verlangsamtes } \\
\text { Wachstum und Atmung }\end{array}$ & $\begin{array}{l}\text { (Moseler et al., } \\
2015) \\
\text { (Ströher et al., } \\
2016)\end{array}$ \\
\hline GRXS16 & $\begin{array}{l}\text { Lokalisation in Mitochondrien, } \\
\text { bindet } 2[\mathrm{Fe}-\mathrm{S}] \text {-Cluster }\end{array}$ & grxs16 & Nicht beschrieben & $\begin{array}{l}\text { (Bandyopadhyay } \\
\text { et al., 2008) } \\
\text { (Liu et al., 2013) }\end{array}$ \\
\hline GRXS17 & $\begin{array}{l}\text { Nukleo-zytoplasmatische } \\
\text { Lokalisation, Interaktion mit } \\
\text { BolA, Reduktion von } \\
\text { glutathionyliertem BolA2, } \\
\text { bindet mehrere } 2[\mathrm{Fe}-\mathrm{S}]-\mathrm{Cluster}, \\
\text { Interaktion mit NF-YC11/NC2 } \alpha \text {, } \\
\text { Assoziation mit cytosolischen } \\
\text { [Fe-S]-Montage Komponenten, } \\
\text { Zielprotein für RGLG3 und } 4\end{array}$ & grxs17 & $\begin{array}{l}\text { Geringe Abnahme der } \\
\text { Aktivitäten von [Fe-S]- } \\
\text { Enzymen, sensitiver } \\
\text { gegenüber hohen } \\
\text { Temperaturen und } \\
\text { langen Photoperioden } \\
\text { (längliche Blätter, } \\
\text { kompromittiertes } \\
\text { Sprossapikalmeristem } \\
\text { und verzögerte } \\
\text { Verschraubung), } \\
\text { sensitiver gegenüber } \\
\text { DNA-Schäden, erhöhte } \\
\text { Expression von DNA- } \\
\text { Schadensmarkergenen }\end{array}$ & $\begin{array}{l}\text { (Cheng et al., } \\
\text { 2011) } \\
\text { (Couturier et al., } \\
2014 \text { ) } \\
\text { (Knuesting et al., } \\
\text { 2015) } \\
\text { (Iñigo et al., 2016) } \\
\text { (Nagels Durand et } \\
\text { al., 2016) }\end{array}$ \\
\hline
\end{tabular}




\subsection{Glutaredoxine der CC-Klasse in Pflanzen}

Die CC-Typ Klasse umfasst 21 Mitgliedern in Arabidopsis. Allerdings ist über diese Mitglieder weniger bekannt als über die anderen beiden Klassen. Dies könnte daran liegen, dass CC-Typ GRXs aufgrund ihres hydrophoben C-Terminus (GALWL) schwierig in E. coli zu exprimieren sind (Couturier et al., 2010). Durch die Veränderung des C-terminalen Endes von PtGRXS7.2, einem CC-Typ GRX der Pappel, konnten einige Holoproteine gereinigt werden, die typische Merkmale eines [Fe-S]-Clusters (bräunliche Färbung der Eluate und ein spezifisches UV/Vis Absorptionsspektrum), sowie eine sehr geringe Aktivität im HED-Test zeigten (Couturier et al., 2010). Bei einem alternativen Ansatz wurde das CGYC aktive Zentrum des PtGRXC1 bzw. CPYC des PtGRXC4 durch ein CCMC bzw. CCMS Motiv ersetzt. Das mutierte GRXC1 inkorporierte ein 2[Fe-S]-Cluster als Holodimer und das mutierte GRXC4 besaß eine geringe GSH-abhängige Reduktase Aktivität in der monomeren Apo-Form (Couturier et al., 2010). Aufgrund dieser Studie kann angenommen werden, dass GRXs des CC-Typs möglicherweise ebenfalls [Fe-S]-Cluster und/oder Oxidoreduktase Aktivität besitzen könnten.

Genetische Untersuchungen an den CC-Typ GRXs führten zu der Umbenennung zur „ROXY“Klasse in $A$. thaliana. Die roxy1 Mutante zeigt während der Blütenentwicklung nur durchschnittlich 2,5 Blüttenblätter anstatt der üblichen vier und auch in späteren Stadien der Entwicklung ist die Blütenmorphogenese betroffen (Xing et al., 2005). ROXY1 (GRXC7) und ROXY2 (GRXC8) sind redundant bezüglich ihrer Funktion in der Antherenentwicklung. Die roxy1 und roxy2 Mutanten sind fruchtbar und produzieren normale Antheren, die roxy1 roxy2 Doppelmutante ist steril und produziert keine Pollen (Xing and Zachgo, 2008). Komplementationsexperimente zeigten, dass der erste, aber nicht der letzte Cysteinrest im putativen aktiven Zentrum für die ROXY1-Funktion in der Blütenblattentwicklung entscheidend ist (Xing et al., 2005). Zudem ist ein konservierter Glycinrest, der für die GSHBindung wichtig ist, für die ROXY1-Funktion kritisch (Xing and Zachgo, 2008). Das konservierte Proline ${ }^{100}$ des TVP Motivs war jedoch für die ROXY1 Funktion entbehrlich (Xing and Zachgo, 2008).

ROXY1 und ROXY2 können mit TGA-Transkriptionsfaktoren interagieren (Li et al., 2009; Murmu et al., 2010). In Betracht auf den roxy1 Phänotypen ist besonders die Interaktion mit dem TGA Transkriptionsfaktor PERIANTHIA (PAN), der an der Festlegung der Blütenorganzahl beteiligt ist (Chuang et al., 1999), interessant. Die pan Mutante bildet ein zusätzliches fünftes Blütenblatt. Eine roxy1 pan Doppelmutante zeigte ebenfalls ein fünftes Blütenblatt. Dies bedeutet, dass ROXY1 „upstream" von PAN lokalisiert ist. Für die ROXY1-Funktion sind die Kernlokalisation und die Interaktion mit PAN erforderlich. Dabei ist nur einer $\left(\mathrm{Cys}^{340}\right)$ von sechs Cystein Resten von PAN erforderlich um den pan Phänotypen zu komplementieren (Li et al., 2009). Durch den Austausch von Cysteinen zu Serinen wird ein permanenter reduzierter Zustand simuliert. Deshalb kann spekuliert werden, dass für das Cys ${ }^{340}$ ein oxidierter (Zwischen-) Zustand für die PAN Aktivität benötigt wird, wohingegen die anderen Cysteine permanent reduziert sein können. Daher könnte die Aktivität von PAN durch eine ROXY1-katalysierte post-translationale Redox-Modifikation negativ reguliert werden.

Auch die ptl (PETAL LOSS) Mutante führt zu einer reduzierten Anzahl von Blütenblättern (Griffith et al., 1999). Vor Kurzem wurde gezeigt, dass der Verlust von Blütenblättern in der 
pt/ Mutante von der ROXY1 Funktion abhängig ist (Quon et al., 2017). ROXY1 konnte in dieser Studie mit PTL interagieren und hier wurde vorgeschlagen, dass ROXY1 unter reduzierenden Bedingungen PTL bindet und es aktiviert, indem es spezifische konservierte Cysteine reduziert, was zu einer Wachstumsunterdrückung zwischen Sepalen und den Sepalenrändern führt.

Murmu et al. (2010) zeigten, dass die tga9 tga10 Doppelmutante einen ähnlichen Phänotypen wie die roxy1 roxy2 Doppelmutante hinsichtlich der Antherenentwicklung zeigt. Das TGA9 und TGA10 Expressionsmuster überschneidet sich mit dem von ROXY1 und ROXY2, wo sie vermutlich einen gemeinsamen Satz von Genen regulieren, um die Antherenentwicklung zu fördern. ROXY1 und ROXY2 könnten auch hier die TGA9 und TGA10 Transkriptionsaktivität durch Redox-Modifikationen beeinflussen.

ROXY11 (GRXS3), ROXY13 (GRXS4), ROXY12 (GRXS5), ROXY14 (GRXS7) und ROXY15 (GRXS8) gehören zu einer Gruppe von CC-Typ GRXs, deren Expression in Arabidopsis thaliana Sprossen und Wurzeln durch Nitrat, aber nicht durch Ammonium induziert werden (Patterson et al., 2016; Walters and Escobar, 2016). ROXY11/12/13/14/15 sind in einem „Tandem-Array“ auf Chromosom 4 angeordnet und zeigen eine sehr hohe Sequenzähnlichkeit. ROXY11/12/13/14/15 haben praktisch identische Sequenzen, regulatorische Muster und Funktionen (Walters and Escobar, 2016). RNAi Linien von ROXY11 zeigten ein verlängertes Wachstum der Primärwurzel (Patterson et al., 2016) im Vergleich zu Col-0. Somit ergibt sich eine vermutliche Funktion für ROXY11-15 als negative Regulatoren des primären Wurzelwachstums durch eine mögliche Reaktion auf die Verfügbarkeit von Nitrat im Boden.

Für die CC-Typ GRXs wurde ebenfalls gezeigt, dass sie bei Reaktionen der Pflanze auf Umwelteinflüsse eine Rolle spielen. Es wird spekuliert, dass das Abwehrhormon Salicylsäure (SA) den Ethylen/Jasmonat (ET/JA) Signalweg negativ durch Manipulation der Transkriptionsaktivität von Klasse II TGA Transkriptionsfaktoren (TGA2, 5 und 6) regulieren könnte. Die Expression von ROXY19 (GRX480, GRXC9), welches als Interaktionspartner von TGA2 in einem Hefe-Zwei-Hybrid-Screen gefunden wurde, wird durch SA in einer Klasse II TGA-abhängigen Weise induziert (Ndamukong et al., 2007). Transgene Arabidopsis Pflanzen, die ektopisch ROXY19 exprimieren, zeigen nahezu eine Wildtyp-ähnliche Expression von Standard-Markergenen für SA-induzierbare Antworten. Im Gegensatz dazu werden der JA/ET Signalweg und die durch Xenobiotika induzierbaren Antworten reprimiert (Huang et al., 2016; Ndamukong et al., 2007). Eine direkte Wechselwirkung zwischen ROXY19 und KlasseII-TGAs legt wiederum nahe, dass SA-induziertes ROXY19 die ET/JA-abhängige Transaktivierungskapazität von Klasse-II-TGA über Redox-Modifikation inaktivieren könnte. Die Klasse II TGA TFs-abhängige Expression des Hauptregulators des ET/JA-Signalwegs ORA59 (OCTADECANOID-RESPONSIVE ARABIDOPSIS AP2/ERF-domain protein 59), wird durch Expression von ROXY19 in A. thaliana, reprimiert. Nur ROXYs mit einem C-terminalen ALWLMotiv können die ORA59-Promotoraktivität in transient transformierten Pflanzenprotoplasten reprimieren (Zander et al., 2012). Das ALWL-Motiv ist ebenfalls wichtig, um den roxy1 Phänotyp zu komplementieren, was darauf hindeutet, dass die ROXYabhängigen Funktionen in Entwicklungs- und Verteidigungs-assoziierten Prozessen durch 
denselben Mechanismus ausübt werden könnten (Li et al., 2011; Zander et al., 2012). Ektopische Expression von ROXY1 oder ROXY19 in A. thaliana resultiert in einer erhöhten Suszeptibilität gegenüber nekrotrophen Pathogenen (wie Botrytis cinerea) (Wang et al., 2009; Zander et al., 2012). Dies kann der Repression der ORA59-vermittelten Abwehr durch die GRXs und einer Akkumulation von Wasserstoffperoxid (förderlich für Infektionen mit $B$. cinerea) zugeschrieben werden.

Herrera-Vásquez et al. (2015) zeigten, dass die ROXY19 Expression durch UVB-Exposition induziert werden kann. Desweiteren konnte gezeigt werden, dass TGA2 und TGA3, aber nicht TGA1, konstitutiv an die Promotorregion des ROXY19 gebunden sind. Außerdem konnte gezeigt werden, dass eine ektopische Expression von ROXY19 die endogene ROXY19 Expression reprimiert. ROXY19 reguliert somit seinen endogenen Promotor negativ. Nähere Untersuchungen dieser Regulation ergaben, dass ROXY19 mit dem TGA2/TGA3 Komplex am endogenen ROXY19 Promotor assoziiert. Dies legt nahe, dass ROXY19 seine eigene Genexpression durch Bindung an TGA-Faktoren reguliert, während diese an die DNA gebunden sind.

Eine Mutation in ROXY18 (GRXS13), dem nächsten Homolog von ROXY19, führt zu einer erhöhten Resistenz gegenüber $B$. cinerea. Die Expression der Markergene für die nekrotrophe Pathogenabwehr PDF1.2 und biotrophe Pathogenabwehr PR-1 sind in der roxy18 Mutante unverändert (La Camera et al., 2011). Die erhöhte Resistenz ist demnach auf keine erhöhte Expression von Genen des nekrotrophen/biotrophen Abwehrprozesses zurückzuführen. Infektionen mit diesem nekrotrophen Pilz führen zu einer erhöhten Expression von ROXY18 und Induktion der Synthese von JA und SA. Der Mechanismus, wie ROXY18 die nekrotrophe Pathogeninfektion erleichtert, ist bisher nicht geklärt. „Knockdown" Linien von ROXY18 zeigen erhöhte Basalspiegel von Superoxidradikalen und vermindertes Pflanzenwachstum, sowie eine verminderte Toleranz gegenüber Methylviologen (MeV) und Hochlichtbehandlungen (beides Zustände photooxidativer Belastung durch Superoxidionen) (Laporte et al., 2012). Linien, die ROXY18 (GRXS13.2) ektopisch exprimieren, zeigen reduzierte MeV und Hochlicht-induzierte Schäden, sowie eine Erhöhung des Superoxidspiegels und des Ascorbat/Dehydroascorbat-Verhältnisses nach Hochlicht-induziertem Stress. Somit ist ROXY18 entscheidend für die Begrenzung der basalen und photooxidativen Stress-induzierten Produktion reaktiver Sauerstoffspezies (ROS) und ein Mitglied des ROS-Auffang-/Antioxidationsnetzwerkes, das eine besonders geringe funktionelle Redundanz mit anderen ROXYs zeigt (Laporte et al., 2012).

Eine Zusammenfassung der Funktionen aller beschriebenen ROXYs und die Phänotypen der dazugehörigen Mutanten sind in Tabelle 1.3 dargestellt. 
Tabelle 1.3. Zusammenfassung der Glutaredoxine des CC-Typs. Gezeigt sind die bekannten Funktionen der CCTyp Glutaredoxine in Arabidopsis thaliana und bekannte Phänotypen der dazugehörigen Mutanten.

\begin{tabular}{|c|c|c|c|c|}
\hline GRX & Funktion & Mutante & Phänotyp & Quelle \\
\hline ROXY1 & $\begin{array}{l}\text { Normale } \\
\text { Antherenentwicklung }\end{array}$ & roxy1 & $\begin{array}{l}\text { Nur 2,5 Blüttenblätter, } \\
\text { fruchtbar, normale } \\
\text { Antheren }\end{array}$ & $\begin{array}{l}\text { (Xing et al., 2005) } \\
\text { (Xing and Zachgo, } \\
\text { 2008) }\end{array}$ \\
\hline \multirow[t]{2}{*}{ ROXY2 } & $\begin{array}{l}\text { Normale } \\
\text { Antherenentwicklung }\end{array}$ & roxy2 & $\begin{array}{l}\text { Fruchtbar, normale } \\
\text { Antheren }\end{array}$ & $\begin{array}{l}\text { (Xing and Zachgo, } \\
\text { 2008) }\end{array}$ \\
\hline & & roxy1 roxy2 & Steril, keine Pollen & $\begin{array}{l}\text { (Xing and Zachgo, } \\
\text { 2008) }\end{array}$ \\
\hline $\begin{array}{l}\text { ROXY11 } \\
\text { ROXY12 } \\
\text { ROXY13 } \\
\text { ROXY14 } \\
\text { ROXY15 }\end{array}$ & $\begin{array}{l}\text { negative Regulatoren des } \\
\text { primären Wurzelwachstums }\end{array}$ & RNAi ROXY11 & $\begin{array}{l}\text { längeres Wachstum der } \\
\text { Primärwurzel }\end{array}$ & $\begin{array}{l}\text { (Patterson et al., } \\
2016 \text { ) } \\
\text { (Walters and } \\
\text { Escobar, 2016) }\end{array}$ \\
\hline ROXY18 & $\begin{array}{l}\text { Begrenzung der basalen und } \\
\text { photooxidativen Stress- } \\
\text { induzierten Produktion von } \\
\text { ROS und ein Mitglied des } \\
\text { ROS-Auffang- } \\
\text { /Antioxidationsnetzwerkes }\end{array}$ & $\begin{array}{l}\text { roxy18 } \\
\text { knock down } \\
\text { roxy18 }\end{array}$ & $\begin{array}{l}\text { erhöhten Resistenz } \\
\text { gegenüber } B \text {. cinerea } \\
\text { erhöhter Basalspiegel } \\
\text { von Superoxidradikalen } \\
\text { und vermindertes } \\
\text { Pflanzenwachstum, } \\
\text { verminderte Toleranz } \\
\text { gegenüber (MeV) und } \\
\text { Hochlichtbehandlunge } \\
\text { n }\end{array}$ & $\begin{array}{l}\text { (La Camera et al., } \\
\text { 2011) } \\
\text { (Laporte et al., } \\
2012 \text { ) }\end{array}$ \\
\hline ROXY19 & $\begin{array}{l}\text { Repression von Zielgenen der } \\
\text { Klasse II TGA } \\
\text { Transkriptionsfaktoren }\end{array}$ & & & $\begin{array}{l}\text { (Ndamukong et } \\
\text { al., 2007) } \\
\text { (Zander et al., } \\
\text { 2012) } \\
\text { (Huang et al., } \\
\text { 2016) }\end{array}$ \\
\hline
\end{tabular}

\subsection{Die Bedeutung von Klasse II TGA Transkriptionsfaktoren in Arabidopsis thaliana}

Wie bereits angemerkt, interagieren CC-Typ GRXs mit TGA-Transkriptionsfaktoren (TGAs). TGAs sind Transkriptionsfaktoren mit einer basischen DNA-bindenden Region und einem Leucin-Zipper-Motiv (bZIP) zur Dimerisierung (Ellenberger, 1994). Sie sind notwendig für Hormonsignaltransduktionsprozesse (SA und ET/JA), für die Aktivierung des Programms zur Entgiftung von Xenobiotika und für eine normale Blütenentwicklung. Das Arabidopsis thaliana Genom kodiert für insgesamt zehn Mitglieder der TGA Familie. Diese werden in fünf Klassen unterteilt: Klasse I umfasst TGA1 und TGA4, Klasse II TGA2, TGA5 und TGA6, Klasse III TGA3 und TGA7, Klasse IV TGA9 und TGA10 und Klasse V PERIANTHIA (PAN) (Abbildung 1.5). TGAs binden an Varianten der palindromischen DNA Sequenz 5'-TGACGTCA-3', wobei die 5'TGACG-3' Sequenz ausreichend für die Bindung ist. Diese wurde zuerst im BlumenkohlMosaik-Virus („Cauliflower Mosaic Virus“, CaMV) 35 S Promotor beschrieben (Katagiri et al., 1989). 


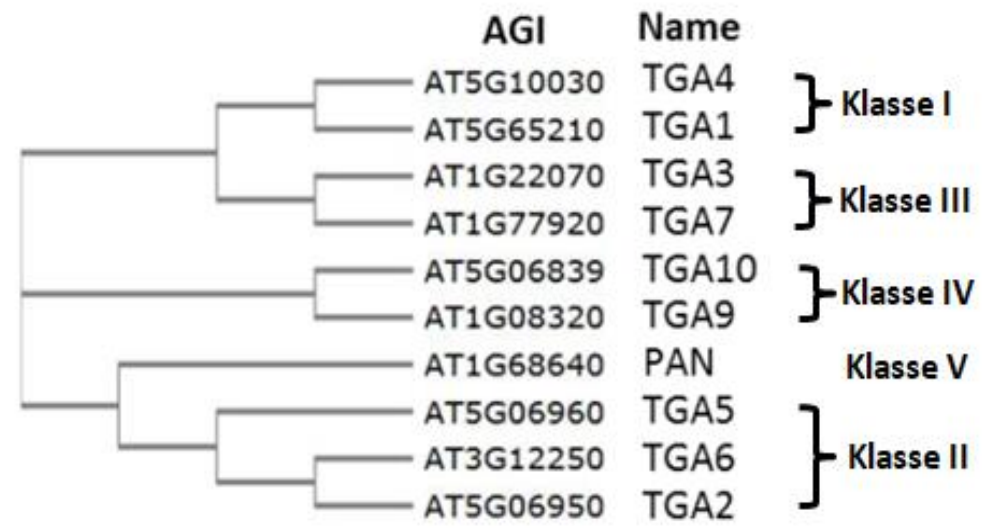

Abbildung $\quad$ 1.5. Ein phylogenetischer Baum der Arabidopsis TGA-Familie. Proteinsequenzen wurden von TAIR erhalten und unter Verwendung von Clustal Omega (EMBL-EBI) der phylogenetische Baum erstellt (von Dr. Li Jun Huang).

Diese Arbeit konzentriert sich auf die Klasse II TGA Transkriptionsfaktoren TGA2, TGA5 und TGA6, die positive Regulatoren der Pflanzenabwehrreaktion „systemisch erworbene Resistenz (SAR)" sind (Zhang et al., 2003). Diese langanhaltende und breite Immunantwort gegen biotrophe und hemi-biotrophe Pathogene wird in den distalen Pflanzenteilen nach lokaler Infektion mit einem biotrophen Pathogen ausgeprägt. Für die Etablierung der SAR benötigt die Pflanze das Phytohormon SA. Die SA-Signaltransduktion wird durch den Transkriptions-Co-Aktivator NPR1 (NONEXPRESSER OF PATHOGENESIS-RELATED GENES 1) kontrolliert. Die NPR1-Homologe NPR3 und NPR4 wurden als SA-Rezeptoren und Regulatoren der NPR1 Stabilität nachgewiesen (Fu et al., 2012). NPR1 liegt im nicht induzierten Zustand im Cytosol als Oligomer vor. Dieses wird durch intermolekulare Disulfidbindungen gebildet (Mou et al., 2003). Nach der SAR-Induktion tritt eine biphasische Veränderung des zellulären Reduktionspotentials auf. Dies führt zu einer Reduktion von NPR1 und damit zur monomeren Form. Monomeres NPR1 akkumuliert im Zellkern, wo es im Zusammenspiel mit Klasse-II TGA Faktoren die Genexpression aktiviert.

ET/JA-induzierte Abwehrreaktionen gegen nekrotrophe Pathogene sind ebenfalls von TGAs der Klasse II abhängig (Zander et al., 2010). Steigende ET-Konzentrationen inaktivieren die am Endoplasmatischen Retikulum (ER)-lokalisierten ET-Rezeptoren, dies führt zu einer Inaktivierung der CTR1 (CONSTITUTIVE TRIPLE RESPONSE1) Kinase und zur folglichen Stabilisierung von EIN3 (ETHYLENE INSENSITIVE3). EIN3 ist ein Transkriptionsfaktor, der die ORA59 (OCTADECANOID-RESPONSIVE ARABIDOPSIS AP2/ERF-domain protein 59) Expression aktiviert. EIN3 wird ebenfalls über den JA-Signaltransduktionsweg gesteuert (Zhu et al., 2011). Dies geschieht durch die Interaktion mit JASMONATE ZIM DOMAIN (JAZ) Proteinen, die als negative Regulatoren der Transkription fungieren (Chini et al., 2007; Pauwels and Goossens, 2011; Pauwels et al., 2010; Thines et al., 2007). Akkumulierendes JasmonoylIsoleucin (JA-lle) bindet an das F-Box Protein CORONATINE INSENSITIVE1 (COI1), dies erleichtert die COI1-JAZ Bindung. COI1 vermittelt durch die Poly-Ubiquitinierung den Abbau von JAZ (Chini et al., 2007; Thines et al., 2007). Die Aktivierung von ORA59 kann somit durch zwei Mechanismen vermittelt werden: (1) Durch die ET-induzierte Stabilisierung von EIN3 und (2) durch den JA-induzierten Abbau der JAZ Repressoren (Abbildung 1.6). Der Promotor von ORA59 besitzt ein TGACGT-Element, an das die Klasse II TGAs binden können, um so die 
ORA59 Transkription und weiterer ET/JA-regulierter Zielgene wie PDF1.2 zu induzieren. TGAFaktoren spielen jedoch nur bei erhöhten ET-Konzentrationen eine Rolle für die PDF1.2 Expression (Zander et al., 2010).

Die SA und ET/JA-vermittelten Abwehrreaktionen können nicht gleichzeitig aktiviert werden und je nach Zeitpunkt und Intensität der Infektionen mit biotrophen und nekrotrophen Pathogenen, wird einer der beiden Wege priorisiert (Pieterse et al., 2009). Hierdurch ergibt sich die Notwendigkeit, dass sich der SA-Signalweg und der JA/ET-Signalweg gegenseitig reprimieren müssen. Zander et. al (2014) zeigten, dass die Aktivität des ORA59 Promotor negativ durch SA über Klasse II TGA Faktoren reguliert werden kann. Zudem wird der Abbau des ORA59 Proteins durch SA eingeleitet (Van der Does et al., 2013).

Chromatin-Immunopräzipitationen (ChIP) entschlüsselten, dass Klasse II TGAs direkt an den ORA59 Promotor binden können (Zander et al., 2014). Ein möglicher Mechanismus für die Inaktivierung von TGA2 am ORA59 Promotor wurde nach der Identifizierung von ROXY19 postuliert, welches im Hefe-Zwei-Hybrid Test mit Klasse II TGAs physikalisch interagieren kann. Ektopisch exprimiertes ROXY19 reprimiert die ET/JA-induzierte ORA59 und PDF1.2 Expression auf eine Klasse II TGA-abhängige Weise (Ndamukong et al., 2007; Zander et al., 2012) (Abbildung 1.6).

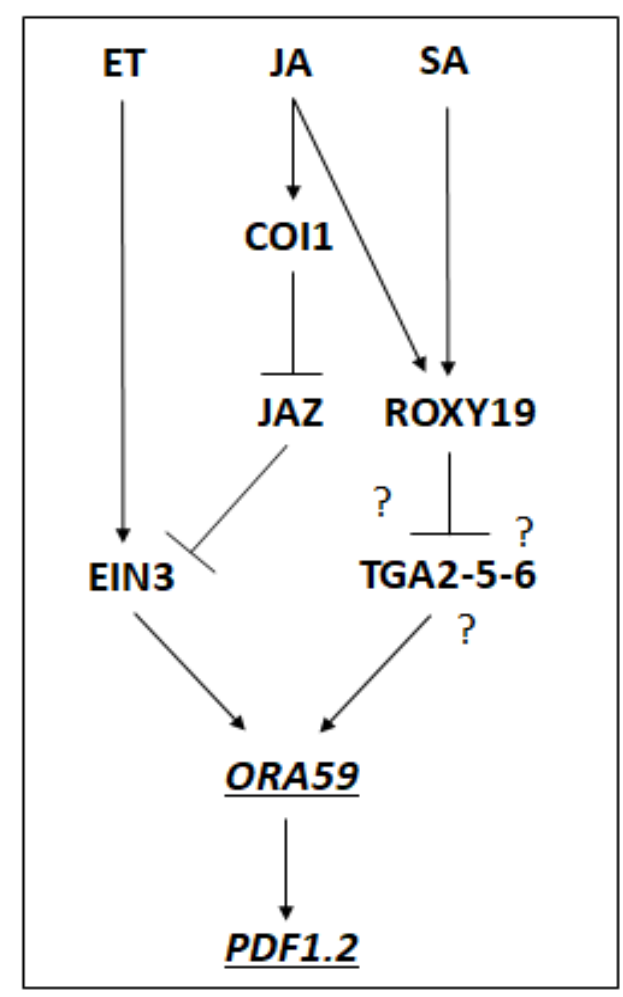

Abbildung 1.6. Vereinfachte Schemazeichnung der ROXY19abhängigen Regulierung von ORA59. ROXY19 Expression wird durch JA und SA induziert. Die negative Regulierung des Transkriptionsfaktors ORA59 durch ROXY19 ist TGA2-5-6abhängig. Der Mechanismus ist derzeit nicht bekannt. ORA59 wird durch den ET und JA stabilisierten ERF Transkriptionsfaktor EIN3 positiv reguliert. ORA59 ist ein Hauptregulator der JA/ET-induzierten Pathogenabwehr und reguliert unter anderem das Markergen PDF1.2 positiv.

TGAs der Klasse II sind zudem an der Aktivierung von Entgiftungsgenen nach Behandlungen mit Oxylipinen oder Xenobiotika beteiligt (Fode et al., 2008; Mueller et al., 2008).

Eine Microarray-Anaylse zeigte, dass 56\% (250/446) der Herbizid Safener-induzierten und 60\% (247/411) der Phytoprostan-PPA1-induzierten Gene in der tga256 Mutante (in der alle TGAs der Klasse II fehlen) niedriger exprimiert werden. Weitere Analysen zeigten, dass $60 \%$ 
bzw. 42\% dieser Gene ein TGACG-Motiv in ihren Promotoren enthielten (Behringer Carina et al., 2011; Mueller et al., 2008). Folglich können xenobiotische Stressfaktoren diese Gene durch die Aktivierung von Klasse II TGAs induzieren. Die Aktivierung einer Untergruppe der Entgiftungsgene erfordert das TGA-interagierende GRAS (GIBBERELLIC-ACID INSENSITIVE (GAI), REPRESSOR of GAI (RGA) and SCARECROW (SCR)) Protein SCL14 (einem Interaktionspartner von TGA2) (Fode et al., 2008). Kürzlich wurde gezeigt, dass ektopisch exprimiertes ROXY19 (und ROXY18) den Entgiftungsweg negativ reguliert (Huang et al., 2016). Ähnlich wie die tga256 Mutante sind 35S:ROXY19-Pflanzen anfälliger für die xenobiotische Chemikalie TIBA. Die repressive Funktion ist abhängig vom putativen aktiven Zentrum (CCMC), welches auch zum CPYC mutiert werden kann, aber nicht zum SSMS.

Eine Vielzahl von Xenobiotika zeigt eine Induktion von gemeinsamen Genen (Behringer Carina et al., 2011; Mueller et al., 2008). Dies weist auf eine geteilte Signaltransduktion der Chemikalien hin. Es ist bekannt, dass verschiedene xenobiotische Stressfaktoren eine ROSAkkumulation hervorrufen und oxidativen Stress verursachen (Ramel et al., 2012). Das as-1ähnliche Promotorelement kann durch oxidativen Stress induziert werden. Der ROS Induktor $\mathrm{MeV}$ aktiviert das as-1-ähnliche Promotorelement, während Antioxidantien (wie Dimethylthioharnstoff und butyliertes Hydroxyanisol) SA-induzierte oxidative Schäden verhindern und SA-aktivierte as-1-ähnliche Elemente inhibieren (Garretón et al., 2002). Ein möglicher Signaltransduktionsweg des xenobiotischen Entgiftungswegs könnte sein, dass Xenobiotika die Akkumulation von ROS induzieren, dies kann durch TGA Transkriptionsfaktoren wahrgenommen werden. Dies führt zur Bindung der TGAs an as-1ähnliche Elemente von Xenobiotika-induzierbaren Genpromotoren, deren Expression hierdurch aktiviert wird.

\subsection{ROXY19 interagiert mit TOPLESS}

Uhrig et al. (2017) zeigten, dass ROXYs mit Transkriptions-Co-Repressoren der TOPLESS (TPL) Familie, die mit TUP1 in Pilzen und GROUCHO/TLE in Tieren verwandt sind interagieren können. Diese Interaktion wird durch das am Ende des C-Terminus konservierte Ala(Leu/Ile)-Trp-(Leu/Val) Motiv vermittelt. Es konnte zudem ein ternärer Komplex zwischen TGA2, ROXY19 und TPL in Hefe nachgewiesen werden. Somit könnten CC-Typ GRXs als Adapterproteine für den Zusammenbau von Transkriptionsrepressor-Komplexen an TGAregulierten Promotoren fungieren. Die repressive Funktion des ROXY19 könnte demnach durch „Chromatin Remodelling“ verursacht werden.

\subsection{CC-Typ Glutaredoxine könnten die Bindungseigenschaften von TGA Faktoren beeinflussen}

Eine weitere Möglichkeit für eine Funktion der CC-Typ GRXs könnte ein Einfluss auf die Bindeaktivität der TGA TFs sein. Für PAN wurde gezeigt, dass die Bindung an einen Promotor eines Zielgenes unter oxidierenden Bedingungen stark reduziert ist (Gutsche and Zachgo, 2016). Die redox-sensitive DNA-Bindung wird über einen nur in PAN vorkommenden $\mathrm{N}$ Terminus vermittelt, der in anderen Arabidopsis TGA TFs nicht vorhanden ist und fünf Cysteine umfasst. Zwei N-terminale PAN-Cysteine, $\mathrm{Cys}^{68}$ und $\mathrm{Cys}^{87}$, bilden eine 
Disulfidbrücke und $\mathrm{Cys}^{340}$, lokalisiert in einer C-terminalen putativen Transaktivierungsdomäne, kann möglicherweise S-glutathionyliert sein (Gutsche and Zachgo, 2016). Mutationen der einzelnen Cysteine im N-Terminus von PAN waren jedoch in der Lage die pan Mutante zu komplementieren, womit die Disulfidbrücke keinen Einfluss auf das Bindeverhalten von PAN hat (Li et al., 2009). Nur die $\mathrm{Cys}^{340}$ Ser Mutante war nicht in der Lage pan zu komplementieren. $\mathrm{Cys}^{340}$ ist daher der einzige Cysteinrest, welcher wichtig für die Funktion von PAN ist. Dieses Cystein könnte ein spezifisches Ziel für Redoxmodifikationen durch ROXY1 und/oder ROXY2 sein.

\subsection{Ziel der Arbeit}

Das Ziel dieser Arbeit war es, die Eigenschaften von ROXY19 in vitro zu untersuchen. Insbesondere wurden Glutaredoxin-spezifische Eigenschaften, wie die Glutathionbindung, enzymatische Aktivität als Oxidoreduktase und die Eisen-Schwefel-Cluster Inkorporation adressiert. Es sollte geklärt werden, ob das Pflanzen-spezifische hoch konservierte CCMC/S Motiv der CC-Typ Klasse GRXs dieselben biochemischen Eigenschaften wie die CPYC-Typ oder CGFS-Typ GRXs hat. Dies könnte einen Hinweis auf einen möglichen Mechanismus der Repression von TGA Klasse II kontrollierten Genen ergeben.

In planta sollte der TIBA anfällige Phänotyp von Pflanzen, die ROXY19 exprimieren (Huang et al., 2016), einem der Cysteine im putativen aktiven Zentrum zugeordnet werden. Desweiteren sollte der Einfluss der Eisenverfügbarkeit in planta auf die ROXY19-vermittelte Repression von TGA Klasse II kontrollierten Genen getestet werden. 


\subsection{Material}

\subsubsection{Organismen}

2.1.1.1 Bakterien

\begin{tabular}{|c|c|c|c|}
\hline $\begin{array}{l}\text { Bakterien } \\
\text { Stamm }\end{array}$ & Beschreibung (Genotyp) & Verwendung & Referenz \\
\hline $\begin{array}{l}\text { Escherichia coli } \\
\mathrm{DH} 5 \alpha\end{array}$ & $\begin{array}{l}\text { F- Ф80lacZ } \triangle M 15 \\
\Delta(\text { lacZYA-argF) U169 } \\
\text { recA1 endA1 hsdR17(rk-, } \\
m k+) \text { phoA } \\
\text { supE44 thi-1 gyrA96 relA1 } \\
\lambda\end{array}$ & $\begin{array}{l}\text { Vermehrung von } \\
\text { Plasmiden ohne } \\
\text { „Gateway" Kassette }\end{array}$ & $\begin{array}{l}\text { Thermo Fisher } \\
\text { Scientific }\end{array}$ \\
\hline $\begin{array}{l}\text { Escherichia coli } \\
\text { DB3.1 }\end{array}$ & $\begin{array}{l}\text { F- gyrA462 end } A 1 \Delta(s r 1- \\
\text { recA) } m c r B \\
\text { mrr hsdS20(rB-, } m B-) \\
\text { supE44 ara-14 } \\
\text { galK2 lacY1 proA2 } \\
\text { rpsL20(SmR) xyl-5 } \\
\lambda-\text { leu } m t / 1\end{array}$ & $\begin{array}{l}\text { Vermehrung von } \\
\text { Plasmiden mit } \\
\text { „Gateway“ Kassette }\end{array}$ & $\begin{array}{l}\text { Thermo Fisher } \\
\text { Scientific }\end{array}$ \\
\hline $\begin{array}{l}\text { Escherichia coli } \\
\text { BL-21(DE3) }\end{array}$ & $\begin{array}{l}\text { F-ompT gal dcm lon } \\
\text { hsd } S_{B}\left(r_{B}-m_{B}-\right) \lambda(D E 3 \text { [lacl } \\
\text { lacUV5-T7p07 ind1 sam7 } \\
\text { nin5]) }\left[m^{2} \text { lB }+\right]_{K-12}(\lambda S)\end{array}$ & Proteinexpression & NEB, USA \\
\hline $\begin{array}{l}\text { Escherichia coli } \\
\text { BL-21 star (DE3) }\end{array}$ & $\begin{array}{l}\text { fhuA2 [lon] ompT gal ( } \lambda \\
\text { DE3) [dcm] } \triangle \text { hsdS } \lambda \text { DE3 = } \\
\lambda \text { sBamHlo } \triangle E c o R I-B \\
\text { int::(lacl::PlacUV5::T7 } \\
\text { gene1) i21 } \triangle \text { nin5 }\end{array}$ & Proteinexpression & NEB, USA \\
\hline $\begin{array}{l}\text { Agrobacterium } \\
\text { tumefaciens } \\
\text { GV3101 }\end{array}$ & PMP90RK rifr, gmr & $\begin{array}{l}\text { Transformation von } \\
\text { Pflanzen }\end{array}$ & $\begin{array}{l}\text { Koncz und Schell, } \\
1986\end{array}$ \\
\hline
\end{tabular}

\subsubsection{Pflanzen}

\begin{tabular}{lll}
\hline \hline Pflanze & Beschreibung & Referenz \\
\hline Col-0 & Arabidopsis thaliana Columbia-0 & TAIR \\
\hline 35S:HA-ROXY19 & Col-0 Überexpressionslinie, exprimiert & AG Gatz und diese Arbeit \\
& ROXY19 unter der Kontrolle des CaMV & \\
& 35S-Promotor, N-terminal 3x HA-tag & \\
\hline 35S:HA-ROXY19 & Col-0 Überexpressionslinie, exprimiert & Diese Arbeit \\
SCMC & ROXY19 SCMC unter der Kontrolle des & \\
& CaMV 35S-Promotor, N-terminal 3x & \\
& HA-tag & \\
\hline 35S:HA-ROXY19 & Col-0 Überexpressionslinie, exprimiert & Diese Arbeit \\
\hline
\end{tabular}




\begin{tabular}{|c|c|c|}
\hline CSMC & $\begin{array}{l}\text { ROXY19 CSMC unter der Kontrolle des } \\
\text { CaMV 35S-Promotor, N-terminal 3x } \\
\text { HA-tag }\end{array}$ & \\
\hline $\begin{array}{l}\text { 35S:HA-ROXY19 } \\
\text { CCMS }\end{array}$ & $\begin{array}{l}\text { Col-0 Überexpressionslinie, exprimiert } \\
\text { ROXY19 CCMS unter der Kontrolle des } \\
\text { CaMV 35S-Promotor, N-terminal 3x } \\
\text { HA-tag }\end{array}$ & Diese Arbeit \\
\hline $\begin{array}{l}\text { 35S:HA-ROXY19 } \\
\text { SSMS }\end{array}$ & $\begin{array}{l}\text { Col-0 Überexpressionslinie, exprimiert } \\
\text { ROXY19 SSMS unter der Kontrolle des } \\
\text { CaMV 35S-Promotor, N-terminal 3x } \\
\text { HA-tag }\end{array}$ & AG Gatz \\
\hline Nössen & Arabidopsis thaliana Nössen & TAIR \\
\hline $\begin{array}{l}\text { roxy18roxy19roxy20 } \\
\text { Ökotypen Mix }\end{array}$ & $\begin{array}{l}\text { roxy18roxy19roxy20 Ökotypen } \\
\text { (Nössen/Ler/Col-0) Mix }\end{array}$ & $\begin{array}{l}\text { RATM16-0018-1/ } \\
\text { CSHL_ET8739/SALK_017723 }\end{array}$ \\
\hline $\begin{array}{l}\text { roxy18roxy19roxy20 } \\
\text { pUBIGATOR }\end{array}$ & $\begin{array}{l}\text { roxy18roxy19roxy20 Ökotypen } \\
\text { (Nössen/Ler/Col-0) Mix } \\
\text { Komplementation mit pUBIGATOR }\end{array}$ & Diese Arbeit \\
\hline $\begin{array}{l}\text { roxy18roxy19roxy20 } \\
\text { pUBIGATOR-ROXY19 }\end{array}$ & $\begin{array}{l}\text { roxy18roxy19roxy20 Ökotypen } \\
\text { (Nössen/Ler/Col-0) Mix } \\
\text { Komplementation mit pUBIGATOR- } \\
\text { ROXY19 }\end{array}$ & Diese Arbeit \\
\hline
\end{tabular}

\subsubsection{Plasmide}

\begin{tabular}{|c|c|c|}
\hline Plasmid & Beschreibung & Referenz \\
\hline pAC28- $\Delta$ His-GW & $\begin{array}{l}\text { Expressionsvektor für E. coli, beinhaltet } \\
\text { den T7 Promotor, das 6xHis-tag ( } \mathrm{N} \text { - } \\
\text { terminal) wurde deletiert. Mit einem } \\
\text { p15A Replikationsursprung, welcher } \\
\text { mit dem des pGP172 (ROP) kompatibel } \\
\text { ist }\end{array}$ & $\begin{array}{l}\text { AG Gatz } \\
\text { (Anhang 6.13) }\end{array}$ \\
\hline pAC28- $\triangle$ His-TGA2 & $\begin{array}{l}\text { pAC28 Derivat, beinhaltet die cDNA } \\
\text { Sequenz von TGA2 }\end{array}$ & AG Gatz \\
\hline pAC28- $\triangle$ His-TGA2 Cys & $\begin{array}{l}\text { pAC28 Derivat (deletiertes 6xHis-tag), } \\
\text { beinhaltet die cDNA Sequenz des } \\
\text { mutierten TGA2 Cys }\end{array}$ & Diese Arbeit \\
\hline pB2GW7-HA-GW & $\begin{array}{l}\text { Gateway }{ }^{\mathrm{TM}} \text { Expressionsvektor für } \\
\text { Pflanzentransformation, beinhaltet den } \\
\text { CaMV 35S-Promotor, ein } \\
\text { 3× HA-tag (N-terminal), und ein BASTA- } \\
\text { Resistenzgen als Selektionsmarker }\end{array}$ & $\begin{array}{l}\text { AG Gatz } \\
\text { (Anhang 6.14) }\end{array}$ \\
\hline pB2GW7-HA-ROXY19 & $\begin{array}{l}\text { pB2GW7-HA-GW Derivat, beinhaltet } \\
\text { die genomische DNA Sequenz von } \\
\text { ROXY19 }\end{array}$ & $\begin{array}{l}\text { AG Gatz und diese } \\
\text { Arbeit }\end{array}$ \\
\hline pB2GW7-HA-ROXY19 SCMC & $\begin{array}{l}\text { pB2GW7-HA-GWDerivat, beinhaltet die } \\
\text { DNA Sequenz des mutierten ROXY19 } \\
\text { SCMC }\end{array}$ & Diese Arbeit \\
\hline
\end{tabular}

pB2GW7-HA-ROXY19 CSMC pB2GW7-HA-GWDerivat, beinhaltet die Diese Arbeit 
DNA Sequenz des mutierten ROXY19

CSMC

\begin{tabular}{|c|c|c|}
\hline pB2GW7-HA-ROXY19 CCMS & $\begin{array}{l}\text { pB2GW7-HA-GWDerivat, beinhaltet die } \\
\text { DNA Sequenz des mutierten ROXY19 } \\
\text { CCMS }\end{array}$ & Diese Arbeit \\
\hline pB2GW7-HA-ROXY19 SSMS & $\begin{array}{l}\text { pB2GW7-HA-GWDerivat, beinhaltet die } \\
\text { DNA Sequenz des mutierten ROXY19 } \\
\text { SSMS }\end{array}$ & AG Gatz \\
\hline pDONR207 & $\begin{array}{l}\text { Gateway }{ }^{\mathrm{TM}} \text { Entry-Vektor zur Klonierung } \\
\text { von PCR Fragmenten (mit Gateway } \\
\text { Sequenz) }\end{array}$ & Invitrogen \\
\hline pDONR207-GRX370 & $\begin{array}{l}\text { Entry-Vektor Derivat, beinhaltet die } \\
\text { genomische DNA Sequenz von GRX370 } \\
\text { (Glutaredoxin C3) (AT1G77370.1) }\end{array}$ & AG Gatz \\
\hline pDONR207-GRX480 & $\begin{array}{l}\text { Entry-Vektor Derivat, beinhaltet die } \\
\text { genomische DNA Sequenz von GRX480 } \\
\text { (ROXY19) (AT1G28480) }\end{array}$ & AG Gatz \\
\hline pDONR207-ROXY19 CCMCA & $\begin{array}{l}\text { Entry-Vektor Derivat, beinhaltet die } \\
\text { DNA Sequenz des mutierten ROXY19 } \\
\text { CCMCA }\end{array}$ & Diese Arbeit \\
\hline pDONR207-ROXY19 CCMS & $\begin{array}{l}\text { Entry-Vektor Derivat, beinhaltet die } \\
\text { DNA Sequenz des mutierten ROXY19 } \\
\text { CCMS }\end{array}$ & Diese Arbeit \\
\hline pDONR207-ROXY19 CSMC & $\begin{array}{l}\text { Entry-Vektor Derivat, beinhaltet die } \\
\text { DNA Sequenz des mutierten ROXY19 } \\
\text { CSMC }\end{array}$ & Diese Arbeit \\
\hline pDONR207-ROXY19 SCMC & $\begin{array}{l}\text { Entry-Vektor Derivat, beinhaltet die } \\
\text { DNA Sequenz des mutierten ROXY19 } \\
\text { SCMC }\end{array}$ & Diese Arbeit \\
\hline pDONR207-ROXY19 SSMS & $\begin{array}{l}\text { Entry-Vektor Derivat, beinhaltet die } \\
\text { DNA Sequenz des mutierten ROXY19 } \\
\text { SSMS }\end{array}$ & Diese Arbeit \\
\hline pGP172-GFP-GW & $\begin{array}{l}\text { Gateway }^{\mathrm{TM}} \text { Expressionsvektor für E. coli, } \\
\text { beinhaltet den T7 Promotor und ein } \\
\text { Strep-GFP-tag (N-terminal) }\end{array}$ & Diese Arbeit \\
\hline pGP172-GFP-ROXY19 & $\begin{array}{l}\text { pGP172-GFP-GW Derivat, beinhaltet } \\
\text { die genomische DNA Sequenz von } \\
\text { ROXY19 }\end{array}$ & Diese Arbeit \\
\hline pGP172-GW & $\begin{array}{l}\text { Gateway }{ }^{\mathrm{TM}} \text { Expressionsvektor für E. coli, } \\
\text { beinhaltet den T7 Promotor und ein } \\
\text { Strep-tag (N-terminal), mit dem } \\
\text { Replikationsursprung ROP }\end{array}$ & AG Gatz \\
\hline pGP172-MBP-GFP & $\begin{array}{l}\text { pGP172-MBP-GW Derivat, beinhaltet } \\
\text { die DNA Sequenz von GFP }\end{array}$ & Diese Arbeit \\
\hline pGP172-MBP-GRX370 & $\begin{array}{l}\text { pGP172-MBP-GW Derivat, beinhaltet } \\
\text { die genomische DNA Sequenz von } \\
\text { GRX370 }\end{array}$ & $\begin{array}{l}\text { Björn Richts } \\
\text { (Bachelorarbeit) }\end{array}$ \\
\hline
\end{tabular}




\begin{tabular}{|c|c|c|}
\hline pGP172-MBP-GW & $\begin{array}{l}\text { Gateway }{ }^{\mathrm{TM}} \text { Expressionsvektor für E. coli, } \\
\text { beinhaltet den T7 Promotor und ein } \\
\text { Strep-MBP-tag (N-terminal) }\end{array}$ & Diese Arbeit \\
\hline pGP172-MBP-ROXY19 & $\begin{array}{l}\text { pGP172-MBP-GW Derivat, beinhaltet } \\
\text { die genomische DNA Sequenz von } \\
\text { ROXY19 }\end{array}$ & Diese Arbeit \\
\hline $\begin{array}{l}\text { pGP172-MBP-ROXY19 } \\
\text { CCMCA }\end{array}$ & $\begin{array}{l}\text { pGP172-MBP-GW Derivat, beinhaltet } \\
\text { die DNA Sequenz des mutierten } \\
\text { ROXY19 CCMCA }\end{array}$ & Diese Arbeit \\
\hline $\begin{array}{l}\text { pGP172-MBP-ROXY19 } \\
\text { CCMS }\end{array}$ & $\begin{array}{l}\text { pGP172-MBP-GW Derivat, beinhaltet } \\
\text { die DNA Sequenz des mutierten } \\
\text { ROXY19 CCMS }\end{array}$ & Diese Arbeit \\
\hline pGP172-MBP-ROXY19 CPYC & $\begin{array}{l}\text { pGP172-MBP-GW Derivat, beinhaltet } \\
\text { die DNA Sequenz des mutierten } \\
\text { ROXY19 CPYC }\end{array}$ & $\begin{array}{l}\text { Björn Richts } \\
\text { (Bachelorarbeit) }\end{array}$ \\
\hline $\begin{array}{l}\text { pGP172-MBP-ROXY19 } \\
\text { CSMC }\end{array}$ & $\begin{array}{l}\text { pGP172-MBP-GW Derivat, beinhaltet } \\
\text { die DNA Sequenz des mutierten } \\
\text { ROXY19 CSMC }\end{array}$ & Diese Arbeit \\
\hline $\begin{array}{l}\text { pGP172-MBP-ROXY19 } \\
\text { SCMC }\end{array}$ & $\begin{array}{l}\text { pGP172-MBP-GW Derivat, beinhaltet } \\
\text { die DNA Sequenz des mutierten } \\
\text { ROXY19 SCMC }\end{array}$ & Diese Arbeit \\
\hline pGP172-ROXY19 & $\begin{array}{l}\text { pGP172-GW Derivat, beinhaltet die } \\
\text { genomische DNA Sequenz von ROXY19 }\end{array}$ & Diese Arbeit \\
\hline pTTL GUS as-1 & Plasmid für das kalte as-1 Fragment & C. Thurow \\
\hline pUBIGATOR & $\begin{array}{l}\text { Derivat des pALLIGATOR2: Besitzt den } \\
\text { UBQ10 Promoter und ein } 3 \mathrm{X}-\mathrm{HA} \text { tag }\end{array}$ & $\begin{array}{l}\text { C. Thurow } \\
\text { (unveröffentlicht) } \\
\text { (Anhang 6.15) } \\
\end{array}$ \\
\hline pUBIGATOR-ROXY19 & $\begin{array}{l}\text { pUBIGATOR Derivat, beinhaltet die } \\
\text { genomische DNA Sequenz von ROXY19 }\end{array}$ & AG Gatz \\
\hline pUC57/T-as-1-Bpil & $\begin{array}{l}\text { Plasmid für das as-1 Fragment zur } \\
\text { radioaktiven Markierung für den EMSA }\end{array}$ & AG Gatz \\
\hline
\end{tabular}

2.1.3 Primer

\begin{tabular}{lr}
\hline \hline Primer & Sequenz \\
\hline \#27 GUS ocg42 & \\
\hline Acc65I-GFP-for & GTTAAGGTACCAATGGTGAGCAAGGGCGAG \\
\hline Acc65I-MBP-rev & GTTAAGGTACCATAGTCTGCGCGTCTTTCAGG \\
\hline $\begin{array}{lr}\text { CmR418-fwd } \\
\text { Seq Primer }\end{array}$ & AGAATATGTTTTCGTCTCAGCCAATCC \\
\hline GFP-for & GGGGACAAGTTTGTACAAAAAAGCAGGCTCCATGGTGAGCAAGGGCGAGG \\
\hline GFP-rev & GGGGACCACTTTGTACAAGAAAGCTGGGTCCTACTTGTACAGCTCGTCCATGCC \\
\hline $\begin{array}{l}\text { GRX480-CCMS- } \\
\text { d 1 }\end{array}$ & CGGAGAGGATGTTGCATGTCTCATGTGG \\
\hline $\begin{array}{l}\text { GRX480-CCMS- } \\
\text { 1 }\end{array}$ & CCACATGAGACATGCAACATCCTCTCCG \\
\hline HA forw & GCGGCCGCATCTTTTACCCA \\
\hline
\end{tabular}




\begin{tabular}{|c|c|}
\hline MBP-752-for & CAAGGGTCAACCATCCAAAC \\
\hline Ndel-GFP-for & GAAGCATATGATGGTGAGCAAGGGCGAG \\
\hline pB2GW7-fwd & CACAATCCCACTATCCTTCGCA \\
\hline pB2GW7-rev & CATGAGCGAAACCCTATAAGAACC \\
\hline rev23 & TTCACACAGGAAACAGCTATGAC \\
\hline $\begin{array}{l}\text { ROXY19- } \\
\text { CCMCA-for }\end{array}$ & CGGAGAGGATGTTGCATGTGTGCGGTGGTGAGGAGGCTGCTTCTT \\
\hline $\begin{array}{l}\text { ROXY19- } \\
\text { CCMCA-rev-2 }\end{array}$ & AAGAAGCAGCCTCCTCACCACCGCACACATGCAACATCCTCTCCG \\
\hline $\begin{array}{l}\text { ROXY19- } \\
\text { CCMCR-for-2 }\end{array}$ & CGGAGAGGATGTTGCATGTGTCGTGTGGTGAGGAGGCTGCTTCTT \\
\hline $\begin{array}{l}\text { ROXY19- } \\
\text { CCMCR-rev-2 }\end{array}$ & AAGAAGCAGCCTCCTCACCACACGACACATGCAACATCCTCTCCG \\
\hline $\begin{array}{l}\text { ROXY19-CSMC- } \\
\text { for }\end{array}$ & GTGATTGGACGGAGAGGATGTTCCATGTGTCATGTGGTGAGGAGG \\
\hline $\begin{array}{l}\text { ROXY19-CSMC- } \\
\text { rev }\end{array}$ & ССТССТСАССАСАTGACACATGGAACATCCTCTCCGTCCAATCAC \\
\hline Sacl-MBP-for & GGTAAGAGCTCAATGAAAATCGAAGAAGGTAAACTG \\
\hline Sacl-SUMO-for & GGTAAGAGCTCAATGTCGGACTCAGAAGTCAATCAAG \\
\hline SEQ-L1 pDONR & TCGCGTTAACGCTAGCATGGATCTC \\
\hline SEQ-L2 pDONR & GTAACATCAGAGATTTTGAGACAC \\
\hline T7 SEQ Primer & TAATACGACTCACTATAGGG \\
\hline T7 term rev & CCTTTCGGGCTTTGTTAGCAG \\
\hline uni24 & ACGACGTTGTAAAACGACGGCCAG \\
\hline & Oligonukleotide für qRT-PCR \\
\hline UBQ5 for & GACGCTTCATCTCGTCC \\
\hline UBQ5 rev & GTAAACGTAGGTGAGTCCA \\
\hline CYP81D11 for & TTATGATACTTGCCGGGACTG \\
\hline CYP81D11 rev & TCGATTTCGGTCTTTGCC \\
\hline PDF1.2 for & CTTGTTCTCTTTGCTGCTTTC \\
\hline PDF1.2 rev & CATGTTTGGCTCCTTCAAG \\
\hline ROXY18 & QuantiTect: QT00867314 \\
\hline bHLH039 & QuantiTect: QT00793534 \\
\hline
\end{tabular}

\subsubsection{Chemikalien, Enzyme, Kits und Antikörper}

\subsubsection{Chemikalien}

\begin{tabular}{ll}
\hline \hline Chemical & Source \\
\hline 2-Hydroxyethyl Disulfid (HED) & Sigma \\
\hline $\begin{array}{l}\text { 3-(2-Pyridyl)-5,6-diphenyl-1,2,4-triazine-4',4"-disulfonic } \\
\text { acid sodium salt }\end{array}$ & Sigma \\
\hline$\alpha$-32P-dATP & Hartmann Analytic \\
\hline Agar (Bakterien) & ROTH \\
\hline Agar-Agar plant & ROTH \\
\hline Agarose & Sigma \\
\hline
\end{tabular}




\begin{tabular}{|c|c|}
\hline Ammonium Eisen (II) Sulfat Hexahydrat & Sigma \\
\hline Ammonium Eisen(III) Citrat & Sigma \\
\hline Ammoniumthiocyanat & ROTH \\
\hline APS & Biometra \\
\hline $\mathrm{B}(\mathrm{OH})_{3}$ & ROTH \\
\hline Bromphenolblau & ROTH \\
\hline $\mathrm{CaCl}_{2}$ & ROTH \\
\hline Coomassie & MERCK \\
\hline Cystein Hydrochlorid Monohydrat & Sigman \\
\hline D-desthiobiotin & iba \\
\hline DMSO & ROTH \\
\hline DTT & ROTH \\
\hline EDTA & AppliChem \\
\hline Ellmans Reagent & Thermo Scientific \\
\hline Essigsäure & ROTH \\
\hline EtBr & ROTH \\
\hline Fleischextrakt & ROTH \\
\hline Glycerin (86\%) & $\mathrm{ROTH}$ \\
\hline Glycin & ROTH \\
\hline Guanidinthiocyanat & ROTH \\
\hline HABA & Sigma \\
\hline Harnstoff & ROTH \\
\hline $\mathrm{HCl}$ & ROTH \\
\hline Hefeextrakt & ROTH \\
\hline IPTG & ROTH \\
\hline Isopropanol & ROTH \\
\hline Kaliumferricyanid (III) & Sigma \\
\hline $\mathrm{KCl}$ & ROTH \\
\hline $\mathrm{K}_{2} \mathrm{HPO}_{4}$ & ROTH \\
\hline $\mathrm{KH}_{2} \mathrm{PO}_{4}$ & ROTH \\
\hline $\mathrm{KOH}$ & ROTH \\
\hline$L(+)$-Ascorbinsäure & ROTH \\
\hline L-Cystein Hydrochlorid Monohydrat & Sigma \\
\hline Lysozym & AGS Gmbh \\
\hline MES & ROTH \\
\hline Methanol & ROTH \\
\hline $\mathrm{MgSO}_{4}$ & ROTH \\
\hline $\mathrm{MnCl}_{2}$ & ROTH \\
\hline MS-Medium & Duchefa \\
\hline $\mathrm{N}, \mathrm{N}$-Dimethyl-p-phenylenediamine sulfate salt & Sigma \\
\hline Na-Acetat & ROTH \\
\hline $\mathrm{Na}_{2} \mathrm{HPO}_{4}$ & ROTH \\
\hline $\mathrm{NaCl}$ & ROTH \\
\hline $\mathrm{NaH}_{2} \mathrm{PO}_{4}$ & ROTH \\
\hline $\mathrm{NaOH}$ & ROTH \\
\hline Natriumdithionit & Sigma \\
\hline
\end{tabular}




\begin{tabular}{|c|c|}
\hline Natriumhypochlorid Lösung & ROTH \\
\hline OrangeG & Sigma \\
\hline Pepton & ROTH \\
\hline Phenol gesättigt mit 0,1 M Citratpuffer & Sigma \\
\hline Pipes & ROTH \\
\hline Poly(deoxyinosinic-deoxycytidylic)acid sodium salt & Sigma \\
\hline Protease Inhibitor Cocktail (EDTA-free, mini-tablet) & biotool \\
\hline Pyridin & Sigma \\
\hline Rotiphorese $^{\circledR}$ Gel 30 (37.5:1) acrylamide:bisacrylamide & ROTH \\
\hline Saccharose & ROTH \\
\hline SDS & ROTH \\
\hline Strep-Tactin ${ }^{\circledR}$ Sepharose $^{\circledR}$ (50\% suspension) & Iba \\
\hline SYBR Green I & Cambrex \\
\hline TEMED (99\%, p.а.) & ROTH \\
\hline TIBA & Sigma \\
\hline tri-Na-Citrat & ROTH \\
\hline TRIS & ROTH \\
\hline Trypton & ROTH \\
\hline Tween 20 & ROTH \\
\hline Xylencyanol & Sigma \\
\hline$\beta$-Mercaptoethanol & ROTH \\
\hline $\begin{array}{l}\beta \text {-Nicotinamide adenine dinucleotide phosphate, } \\
\text { reduced tetra(cyclohexylammonium) salt (NADPH) }\end{array}$ & Sigma \\
\hline
\end{tabular}

\subsubsection{Enzyme}

\begin{tabular}{ll}
\hline \hline Enzyme & Source \\
\hline DNase I & Thermo Scientific \\
\hline SUMO-Protease & tebu-bio \\
\hline TEV Protease & Sigma \\
\hline Glutathion-Reduktase (aus Hefe) & Sigma \\
\hline T4 DNA Ligase (5 Weiss $U / \mu \mathrm{L})$ & Thermo Scientific \\
\hline Klonase Mix (BP,LR) & Invitrogen \\
\hline Restriktionsenzyme & MBI Fermentas, New England \\
& Biolabs \\
\hline Reverse Transkriptase H- & MBI Fermentas \\
\hline RNase A & Qiagen \\
\hline \hline
\end{tabular}

\subsubsection{Kits}

\begin{tabular}{ll}
\hline \hline Kit & Source \\
\hline Additive Screen & Hampton Research \\
\hline Nucleo Spin ${ }^{\circledast}$ Gel and PCR Clean-up & Macherey-Nagel \\
\hline Nucleo Spin ${ }^{\circledR}$ Plasmid & Macherey-Nagel \\
\hline Nucleo Spin ${ }^{\circledR}$ Plasmid PC100 Prep Kit (Midi,Maxi) & Macherey-Nagel \\
\hline Phusion High-Fidelity DNA Polymerase & Thermo Scientific \\
\hline RevertAid Reverse Transcriptase & Thermo Scientific \\
\hline
\end{tabular}




\begin{tabular}{ll}
\hline Gateway $^{\circledR}$ Technology kit & Invitrogen \\
\hline Pierce 660nm Protein Assay Reagent & Thermo Scientific \\
\hline Solubility \& Stability Screen I & Hampton Research \\
\hline Solubility \& Stability Screen II & Hampton Research \\
\hline SuperSignal ${ }^{\circledR}$ West Femto Maximum Sensitivity Substrate & Thermo Scientific \\
\hline \hline
\end{tabular}

\subsubsection{Antikörper}

\begin{tabular}{lll}
\hline \hline Antikörper & Eigenschaft & Hersteller \\
\hline$\alpha$-HA-Tag & Polyklonal aus Kaninchen & abcam \\
\hline$\alpha$-tga2,5 & Polyklonal aus Kaninchen & (Ndamukong et al., \\
& & $2007)$ \\
\hline$\alpha$-Kaninchen & Aus Esel & GE Healthcare \\
\hline \hline
\end{tabular}

\subsubsection{Antibiotika}

\begin{tabular}{lll}
\hline \hline Antibiotikum & Konzentration & Hersteller \\
\hline Ampicillin & $100 \mathrm{mg} / \mathrm{L}$ & AGS \\
\hline Gentamycin & $25 \mathrm{mg} / \mathrm{L}$ & Duchefa \\
\hline Kanamycin & $50 \mathrm{mg} / \mathrm{L}$ & Sigma \\
\hline PTT & $6 \mathrm{mg} / \mathrm{L}$ & Sigma \\
\hline Spectinomycin & $100 \mathrm{mg} / \mathrm{L}$ & Duchefa \\
\hline \hline
\end{tabular}

\subsubsection{Medien und Puffer}

\subsubsection{Medien}

\begin{tabular}{ll}
\hline \hline LB & $10 \mathrm{~g} / \mathrm{L}$ Trypton \\
& $5 \mathrm{~g} / \mathrm{L}$ Hefeextrakt \\
& $10 \mathrm{~g} / \mathrm{L} \mathrm{NaCl}$ \\
& $\mathrm{pH} 7,0$ einstellen \\
& $20 \mathrm{~g} / \mathrm{L}$ Trypton \\
& $10 \mathrm{~g} / \mathrm{L}$ Hefeextrakt \\
& $10 \mathrm{~g} / \mathrm{L} \mathrm{NaCl}$ \\
$\mathrm{pH} 7,0$ einstellen \\
\hline YEB & $10 \mathrm{~g} / \mathrm{L}$ Fleischextrakt \\
& $2 \mathrm{~g} / \mathrm{L}$ Hefeextrakt \\
& $5 \mathrm{~g} / \mathrm{L}$ Pepton \\
& $5 \mathrm{~g} / \mathrm{L} \mathrm{Saccharose}$ \\
& $\mathrm{pH} 7,0$ mit NaOH einstellen \\
& nach dem Autoklavieren $+2 \mathrm{mM} \mathrm{MgSO}_{4}$ \\
& $4,4 \mathrm{~g} / \mathrm{L}$ MS-Medium \\
& $0,5 \mathrm{~g} / \mathrm{L}$ MES \\
& $10 \mathrm{~g} / \mathrm{L}$ Saccharose \\
& $\mathrm{pH} 5,7$ mit KOH einstellen \\
\hline MS-Medium &
\end{tabular}




\subsubsection{Puffer}

\begin{tabular}{|c|c|}
\hline SDS-Laufpuffer (10X) & $\begin{array}{l}250 \mathrm{mM} \text { TRIS } \\
1,9 \mathrm{M} \text { Glycin } \\
1 \%(\mathrm{w} / \mathrm{v}) \text { SDS }\end{array}$ \\
\hline TBS (10X) & $\begin{array}{l}20 \mathrm{mM} \text { TRIS } \\
130 \mathrm{mM} \mathrm{NaCl} \\
\mathrm{pH} 7,6 \mathrm{mit} \mathrm{HCl} \text { einstellen } \\
\text { für TBS-T: }+0,1 \%(\mathrm{v} / \mathrm{v}) \text { Tween } 20\end{array}$ \\
\hline TBE (10X) & $\begin{array}{l}1 \mathrm{M} \mathrm{TRIS} \\
1 \mathrm{M} \mathrm{B}(\mathrm{OH})_{3} \\
0,02 \mathrm{M} \mathrm{EDTA} \\
\end{array}$ \\
\hline Transferpuffer & $\begin{array}{l}48 \mathrm{mM} \text { TRIS } \\
39 \mathrm{mM} \text { Glycin } \\
0,04 \%(\mathrm{w} / \mathrm{v}) \mathrm{SDS} \\
20 \%(\mathrm{v} / \mathrm{v}) \text { Methanol }\end{array}$ \\
\hline $\begin{array}{l}\text { Nativer Laufpuffer } \\
\text { (10X) }\end{array}$ & $\begin{array}{l}250 \mathrm{mM} \text { TRIS } \\
1,9 \mathrm{M} \text { Glycin }\end{array}$ \\
\hline TAE (20X) & $\begin{array}{l}0,8 \mathrm{M} \text { Tris } \\
0,83 \mathrm{M} \mathrm{B}(\mathrm{OH})_{3} \\
0,1 \mathrm{mM} \mathrm{EDTA}\end{array}$ \\
\hline Wasch-Puffer & $\begin{array}{l}50 \mathrm{mM} \text { Natriumphosphatpuffer } \mathrm{pH} \mathrm{8,0} \\
200 \mathrm{mM} \mathrm{NaCl}\end{array}$ \\
\hline Elutions-Puffer & $\begin{array}{l}50 \mathrm{mM} \text { Natriumphosphatpuffer } \mathrm{pH} 8,0 \\
200 \mathrm{mM} \mathrm{NaCl} \\
2,5 \mathrm{mM} \text { Desthiobiotin }\end{array}$ \\
\hline $\begin{array}{l}\text { 5X Bindepuffer } \\
\text { (EMSA) }\end{array}$ & $\begin{array}{l}125 \mathrm{mM} \mathrm{HEPES} \mathrm{pH} \mathrm{7,6} \\
50 \mathrm{mM} \mathrm{MgCl}_{2} \\
1 \mathrm{mM} \mathrm{CaCl}_{2} \\
50 \% \text { (v/v) Glycerin } \\
5 \mathrm{mM} \mathrm{DTT} \mathrm{(vor} \mathrm{Gebrauch)}\end{array}$ \\
\hline $\begin{array}{l}\text { Auftragspuffer } \\
\text { (EMSA) }\end{array}$ & $\begin{array}{l}210 \mu \mathrm{L} 5 X \text { Bindepuffer (EMSA) } \\
290 \mu \mathrm{L} \text { Glycerin (86\%) }\end{array}$ \\
\hline $4 \mathrm{M}$ Harnstoffpuffer & $\begin{array}{l}4 \text { M Harnstoff } \\
16,6 \%(v / v) \text { Glycerin } \\
5 \%(w / v) \text { SDS } \\
0,02 \%(w / v) \text { Bromphenolblau } \\
+5 \%(v / v) \beta \text {-Mercaptoethanol frisch vor Benutzung }\end{array}$ \\
\hline EtBr & $\begin{array}{l}50 \mu l \text { (einer 1\%-igen wässrigen Lösung }(10 \mathrm{mg} / \mathrm{mL}) ; \mathrm{ROTH}) \text { in } 0,5 \mathrm{~L} \\
\mathrm{H}_{2} \mathrm{O}\end{array}$ \\
\hline $\begin{array}{l}\text { 1\%-ige Agarose } \\
\text { Lösung }\end{array}$ & $\begin{array}{l}10 \mathrm{~g} / \mathrm{L} \text { Agarose UltraPure in } 1 \mathrm{~L} 1 \mathrm{x} \text { TAE Puffer } \\
\text { in der Mikrowelle bei } 800 \mathrm{~W} \text { erhitzen } \\
\text { Lagerung bei } 65^{\circ} \mathrm{C}\end{array}$ \\
\hline $\begin{array}{l}\text { RPB-Puffer } \\
\text { (SDS-Ladepuffer) }\end{array}$ & $\begin{array}{l}200 \mathrm{mM} \text { DTT } \\
100 \mathrm{mM} \text { TRIS pH 6,8 } \\
4 \%(\mathrm{w} / \mathrm{v}) \text { SDS } \\
20 \%(\mathrm{v} / \mathrm{v}) \text { Glycerin } \\
0,02 \%(\mathrm{w} / \mathrm{v}) \text { Bromphenolblau }\end{array}$ \\
\hline
\end{tabular}




\begin{tabular}{ll}
\hline Nativer Ladepuffer & $100 \mathrm{mM}$ TRIS pH 6,8 \\
& $20 \%(\mathrm{v} / \mathrm{v})$ Glycerol \\
& $0,02 \%$ (w/v) Bromphenolblau \\
\hline Ellman's Puffer & $100 \mathrm{mM}$ Natriumphosphat pH 8,0 \\
& $1 \mathrm{mM}$ EDTA \\
\hline Trizol-Puffer & $380 \mathrm{~mL} / \mathrm{L}$ Phenol gesättigt mit 0,1 M Citratpuffer $\mathrm{pH} 4,3$ \\
& $0,8 \mathrm{M}$ Guanidinthiocyanat \\
& $0,4 \mathrm{M} \mathrm{Ammoniumthiocyanat}$ \\
& $33,4 \mathrm{~mL} / \mathrm{L} \mathrm{3} \mathrm{M} \mathrm{Na-Acetatlösung} \mathrm{pH} \mathrm{5,2}$ \\
& $5 \%$ Glycerin \\
\hline Hochsalzpuffer & $1,2 \mathrm{M} \mathrm{NaCl}$ \\
& $0,8 \mathrm{tri}-\mathrm{Na}-\mathrm{Citrat}$ \\
\hline Transformations- & $10 \mathrm{mM} \mathrm{Pipes}$ \\
Puffer (E. coli) & $15 \mathrm{mM} \mathrm{CaCl} 2$ \\
& $250 \mathrm{mM} \mathrm{KCl}$ \\
& $\mathrm{pH} \mathrm{6,7} \mathrm{(mit} \mathrm{KOH)}$ \\
& $55 \mathrm{mM} \mathrm{MnCl}$ \\
\hline \hline
\end{tabular}

\subsubsection{Laborzubehör}

3D Schüttler: Vibrax VXR basic, Magnetrührer: RH basic 2 (IKA), Agarose Gelsystem, PAGelsystem, Western-Blot Halbtrockenkammer (Universität Göttingen), Analysewaage: Extend, Wasserentsalzer: Arium pro ID (Sartorius), Autoklav: VX-95 bzw. VX-150 (Systec), CCD Kamera: ChemoCam, Geldokumentationssystem: Gel Imager (PA-Gele) (Intas), Eismaschine (Ziegra), Elektroporator: Gene Pulser ${ }^{\circledR} \mathrm{II}$, Elektroporationsküvetten, PCR-Gerät: MyCycler, qRT-PCR-Gerät: iCyclert (BioRad), Elektrophoresestromgeber: EV243 bzw. EV231 (Consort), Feinwaage: 572 (Kern), Geldokumentationssystem (Agarosegele): Transilluminator (Biostep), Heizblock: MHR 11 bzw. TH 26 (HLC Biotech), Inkubator (Memmert), Kühlzentrifuge: Heraeus Fresco 17, Mikrozentrifuge: Pico17, RNA-/DNA-Messgerät: NanoDrop2000, Sterilbank: Heraguard bzw. SAFE 2020, Tischzentrifuge: Heraeus Pico 117 (ThermoScientific), Kühlzentrifuge: Rotina 38R (Hettich), Kühlzentrifuge: RC6+ (Sorvall), Mikrotiterplattenleser: SynergyHT (BioTek), Planzenanzuchtskammer (JohnssonControls), pH-Meter: pH211 (Hanna Instruments), Photometer: Libera S11 (Biochrom), Vakuumpumpe: MD 1C (Vacuubrand), Vortexer: Vortex Genie 2 (Scientific Industries), Wasserbad: 1092 (GFL), Laufkammern (PAA-Gele): GIBCOBRL Model V15-17 (Life Technonolgies), Geltrockner (PAA-Gele): Phero-Temp (Biotec Fischer), Entwicklung von PAA-Gelen: Speicherfolie (Imaging Plate, BAS-MP 2040S 20x40cm, FUJIFILM), Eraser (ERASER, raytest) und SpeicherfolienEinleser (BAS-1000, FUJIFILM), Ultraschallgerät: SONOPLUS HD 3400 (Bandelin), Gelfiltrationssäulen: PD-10 (GE Healthcare) 


\subsection{Methoden}

\subsubsection{Molekularbiologische Techniken}

\subsubsection{Polymerase Kettenreaktion}

Die Polymerase Kettenreaktion (englisch: „polymerase chain reaction“ (PCR)) (Saiki et al., 1985) ermöglicht die in vitro Amplifikation von DNA Fragmenten. In dieser Arbeit wurde ausschließlich die Phusion High-Fidelity DNA Polymerase verwendet. Die Reaktionen wurden in einem MyCycler ${ }^{\mathrm{TM}}$ Bio-Rad Thermocycler ausgeführt. Abhängig von den benutzten Primern wurde die Hybridisierungstemperatur angepasst. Ein Ansatz beinhaltete 0,2 mM dNTPs, 1-10 ng Template DNA und je 5 pmol des Vorwärts- und Rückwärts Primers in $1 \mathrm{X}$ HF Phusion Puffer. Für eine kbp DNA-Sequenz wurden 30 Sekunden Zeit zur Amplifizierung gegeben.

\begin{tabular}{|llll|}
\hline Initiale Denaturierung & $98^{\circ} \mathrm{C}$ & 30 sek & \\
Denaturierung & $98^{\circ} \mathrm{C}$ & 15 sek & \\
Hybridisierung & $50-68^{\circ} \mathrm{C}$ & 30 sek & X35 \\
Amplifizierung & $72^{\circ} \mathrm{C}$ & $30 \mathrm{sek} / 1 \mathrm{kbp}$ & \\
Finale Extension & $72^{\circ} \mathrm{C}$ & $10 \mathrm{~min}$ & \\
\hline
\end{tabular}

\subsubsection{Agarose Gelelektrophorese}

Die Agarose Gelelektrophorese dient der Identifizierung und horizontalen Auftrennung von DNA Fragmenten nach ihrer Größe (Länge in Basenpaaren). Die DNA-Proben wurden vor der Beladung des 1\%-igen Agarosegels mit 6X „Orange Dye“ (10X: 67\% Saccharose (w/v), 50 mM EDTA (pH 8,0), 0,42\% OrangeG (w/v)) zur Dichteerhöhung gemischt (5:1). Ein Agarosegellauf wurden in 1X TAE Puffer für 45 Minuten bei 130 Volt durchgeführt (Saiki et al., 1985) (Müllhardt, 2009) und anschließend in einer 0,1\%-igen EtBr-Lösung angefärbt. EtBr ist ein in die DNA-Basen interkalierender Farbstoff, welcher im UV-Licht $(260 \mathrm{~nm})$ detektiert werden kann (Sharp et al., 1973). Zur Größenbestimmung wurde eine Spur mit dem „DNA ladder mix" (MBI Fermentas, Deutschland) auf jedes Gel aufgetragen.

\subsubsection{Konzentrationsbestimmung von Nukleinsäuren}

Konzentrationsbestimmungen wurden mithilfe des NanoDrop 2000c nach Anweisungen des Herstellers durchgeführt.

\subsubsection{Gel und PCR Reinigung}

Die Reinigung von DNA Fragmenten wurde entweder direkt nach der PCR mithilfe des "Nucleo Spin ${ }^{\circledR}$ Gel and PCR Clean-up kit" nach Anweisungen des Herstellers durchgeführt oder über einen Agarosegellauf. Aus dem Agarosegel wurden die DNA-Fragmente unter UVLicht $\left(320 \mathrm{~nm}\right.$ ) ausgeschnitten und dann ebenfalls mit dem "Nucleo Spin ${ }^{\circledR}$ Gel and PCR Cleanup kit" nach Anweisungen des Herstellers gereinigt. 


\subsubsection{Fragmentierung von DNA mit Restriktionsenzymen}

Restriktionsenzyme schneiden DNA Sequenzen an definierten palindromischen Motiven, dies kann dazu genutzt werden, um Plasmide anhand von "Schnittmustern“ zu analysieren und um Plasmide für eine Ligation (2.2.1.6) zu linearisieren. Die Restriktionen wurden, abhängig von den verwendeten Enzymen, in definierten Puffer Systemen (vom Hersteller zur Verfügung gestellt) durchgeführt. Die verwendete Menge von Enzymen wurde nach der folgenden Formel berechnet:

$\mathrm{U}=\frac{\text { bp lambda }(\lambda) \text { Bakteriophage } * \text { Restriktionsstellen im Plasmid } * \mu \mathrm{g} \text { verdauter DNA } * \text { Aktivität }(100 \%)}{\text { bp Plasmid } * \text { Restriktionsstellen } \lambda * \text { Stunden Inkubation } * \text { Aktivität im verwendeten Puffer }}$

Die Auswertung des Fragmentierungsmusters erfolgte nach einem Agarosegellauf (2.2.1.2).

\subsubsection{Ligation}

Die Ligation ist eine Methode, um zueinander komplementäre DNA Fragmente (wie zum Beispiel nach einem Restriktionsverdau) miteinander zu verknüpfen und wurde daher im Rahmen dieser Arbeit zur Klonierung von Plasmiden verwendet. Die Verknüpfung erfolgte durch die T4 DNA Ligase. Eine Ligasereaktion umfasste 50-100 ng Plasmid Rückgrat, einen sechs-fachen Überschuss des einzufügenden DNA-Fragments und 5 U T4 DNA Ligase in 1X T4 Ligase Puffer. Die Reaktion wurde vor der Transformation in E. coli für zwei bis vier Stunden bei RT inkubiert.

\subsubsection{Gateway ${ }^{\mathrm{TM}}$ Klonierung}

Neben der Ligation bietet die Gateway Technologie von Invitrogen eine weitere Möglichkeit zur Klonierung von Plasmiden. Diese Methode beruht auf dem Rekombinationssystem des Bakteriophagen $\lambda$, um Gene in einen sogenannten "Entry Vektor" über definierte „attachment sites" (attP) zu inserieren. Die attP Sequenzen müssen das zu inserierende Gen flankieren und werden über Primer in einer PCR eingefügt. Das attP flankierte Gen wird mithilfe des BP-Klonase Mix mit der „Gateway Kassette“ des „Entry Vektors" ausgetauscht. Aus dem Entry Vektor kann das Gen, mithilfe des LR-Klonase Mix, in diverse "Destination Vektoren“ übertragen werden (Hartley et al., 2000). Die Klonierungen wurden nach Angaben des Herstellers durchgeführt.

\subsubsection{Plasmid Reinigung}

Rekombinant amplifizierte Plasmide aus Escherichia coli (E. coli) und Agrobacterium tumefaciens wurden mithilfe des „Nucleo Spin ${ }^{\circledR}$ Plasmid kit“ (3 mL Kultur) oder „Nucleo Spin ${ }^{\circledR}$ Plasmid PC100 Prep kit“ (300 mL Kultur) nach Angaben des Herstellers isoliert.

\subsubsection{Sequenzierungen}

Sequenzierungen von DNA Sequenzen wurden durch externe Firmen (SeqLab Microsynth AG (Deutschland, Göttingen) und GATC (Deutschland, Konstanz)) durchgeführt. 


\subsubsection{Transformationstechniken}

\subsubsection{Herstellung von chemisch kompetenten Escherichia coli}

E. coli Zellen aus einem Glycerin-Vorrat wurden auf einer LB-Platte (ohne Antibiotikum) ausplattiert und $\mathrm{O} / \mathrm{N}$ bei $37^{\circ} \mathrm{C}$ inkubiert. Am nächsten Tag wurde eine Kolonie gepickt und in einem $100 \mathrm{~mL}$ Kolben in $10 \mathrm{~mL}$ LB-Medium bei $37^{\circ} \mathrm{C}$ (220 rpm) für 8 Stunden inkubiert, um eine Vorkultur zu erhalten. Von dieser Vorkultur wurden $200 \mu \mathrm{L}$ benutzt, um die $300 \mathrm{~mL} \mathrm{LB}$ Medium Hauptkultur in einem $2 \mathrm{~L}$ Kolben anzuimpfen. Die Hauptkultur wurde $\mathrm{O} / \mathrm{N}$ bei $18^{\circ} \mathrm{C}$ (220 rpm) bis zu einer OD von 0,8 - 1,2 angezogen. Anschließend wurde die Kultur in sechs $50 \mathrm{~mL}$ Falcon Gefäße aufgeteilt und zentrifugiert (4.000 rpm, $\left.10 \mathrm{~min}, 4^{\circ} \mathrm{C}\right)$. Der Überstand wurde verworfen und das Zellpellet wurde in $15 \mathrm{~mL}$ Transformations-Puffer resuspendiert. Nach einer Inkubation von 15 min auf Eis wurden je drei der Falcon Gefäße miteinander vereinigt. Die verbliebenden zwei Falcons wurden erneut zentrifugiert $(4.000 \mathrm{rpm}, 10 \mathrm{~min}$, $4^{\circ} \mathrm{C}$ ) und der Überstand verworfen. Das Pellet wurde in $15 \mathrm{~mL}$ Transformations-Puffer resuspendiert, anschließend wurden $525 \mu \mathrm{L}$ DMSO unter leichtem Vortexen hinzugegeben. Nach 5 min Inkubation auf Eis wurden erneut $525 \mu \mathrm{L}$ DMSO unter leichtem Vortexen hinzugegeben und 5 min auf Eis inkubiert. Abschließend wurden $200 \mu \mathrm{L}$ Aliquots direkt in flüssigen Stickstoff schockgefroren. Die Aliquots wurden bei $-70^{\circ} \mathrm{C}$ für bis zu 6 Monate gelagert.

\subsubsection{Transformation von Escherichia coli}

Chemisch kompetente E. coli Zellen wurden vor Plasmidzugabe auf Eis für 20-30 min aufgetaut. Für Expressions-Transformationen (BL21-DE3 star) wurden $100 \mathrm{ng}$ von jedem Plasmid verwendet, bei Re-Transformationen von Plasmiden 1-10 ng und bei BP/LRReaktionen, sowie Ligationen wurden je die kompletten Reaktionsansätze eingesetzt und für 30 min auf Eis inkubiert. Danach wurde ein Hitzeschock $\left(42^{\circ} \mathrm{C}\right)$ für 90 Sekunden durchgeführt und die Zellen auf Eis für 3 min abgekühlt. Nachdem $800 \mu \mathrm{L}$ dyT-Medium hinzugegeben wurden, wurden die Zellen für 45 min bei $37^{\circ} \mathrm{C}$ auf einem Dreher inkubiert. Nach der Inkubation wurden die Zellen zentrifugiert ( $6.000 \mathrm{rpm}, 2 \mathrm{~min}$ ) und $800 \mu \mathrm{L}$ des Überstands abgekippt. Das Zellpellet wurde im verbliebenden Medium resuspendiert und auf LB-Platten mit den entsprechenden Antibiotika ausplattiert. Die Platten wurden umgedreht bei $37^{\circ} \mathrm{C}$ $\mathrm{O} / \mathrm{N}$ inkubiert.

\subsubsection{Transformation von Agrobacterium tumefaciens}

Elektrokompetente Agrobacterium tumefaciens Zellen wurden vor Plasmidzugabe auf Eis für 20-30 min aufgetaut. Für jede Transformation wurden $100 \mathrm{ng}$ Plasmid verwendet und gemeinsam für $30 \mathrm{~min}$ auf Eis inkubiert. Anschließend wurde die Elektroporation mit dem GenePulser II $(2,5 \mathrm{kV}, 25 \mu \mathrm{F}, 400 \Omega)$ durchgeführt. Nach der Elektroporation wurden die Zellen mit $1 \mathrm{~mL}$ YEB-Medium durchmischt und auf dem Dreher für 2 Stunden bei $29^{\circ} \mathrm{C}$ inkubiert. Nach der Inkubation wurden die Zellen abzentrifugiert (6.000 rpm, $2 \mathrm{~min}$ ) und 800 $\mu \mathrm{L}$ des Überstands abgekippt. Das Zellpellet wurde im verbliebenden Medium resuspendiert und auf YEB-Platten mit den entsprechenden Antibiotika ausplattiert. Die Platten wurden umgedreht bei $29^{\circ} \mathrm{C}$ für 2-3 Tage inkubiert. 


\subsubsection{Transformation von Arabidopsis thaliana}

Für eine stabile Transformation von Arabidopsis thaliana wurde die "floral dip" Methode verwendet (Clough and Bent, 1998). A. thaliana Pflanzen wurden für 4-5 Wochen (bis zur Ausbildung der ersten Blüten) im Langtag (16 Stunden Licht und 8 Stunden Dunkelheit) angezogen. Vor der eigentlichen Transformation der Pflanzen, wurde Agrobacterium tumefaciens transformiert (2.2.2.3) und Einzelkolonien nach dem richtigen Plasmid durch Restriktionsverdau-Analyse (2.2.1.5) und Sequenzierung (2.2.1.9) überprüft. Einzelkolonien, die das richtige Plasmid beherbergten wurden zunächst in einer $10 \mathrm{~mL}$ YEB-Medium Kultur (mit den entsprechenden Antibiotika) in einem $100 \mathrm{~mL}$ Kolben bei $29^{\circ} \mathrm{C}$ (220 rpm) für 2 Tage angezogen. Mit dieser $10 \mathrm{~mL}$ Vorkultur wurde die $300 \mathrm{~mL}$ YEB-Medium Hauptkultur (mit den entsprechenden Antibiotika) in einem $2 \mathrm{~L}$ Kolben bei $29^{\circ} \mathrm{C}(220 \mathrm{rpm}) \mathrm{O} / \mathrm{N}$ angeimpft. Am nächsten Tag wurde die Kultur zentrifugiert (5.000 rpm, $20 \mathrm{~min}$ ) und der Überstand verworfen. Das Pellet wurde in $15 \mathrm{~mL}$ einer 5\%-igen Saccharose-Lösung (mit 0,02\% SilwetL77) resuspendiert. Mit dieser Zell-Suspension wurden $500 \mathrm{~mL}$ der $5 \%$-igen SaccharoseLösung (mit 0,02\% Silwet-L77) auf eine OD von 0,8 eingestellt. In diese Lösung wurden die Blütenstände der zu transformierenden Pflanzen für mindestens 30 Sekunden pro Pflanze mehrere Male eingetaucht. Die Pflanzen wurden anschließend bis zur Ernte im Langtag angezogen.

\subsubsection{Kultivierungsmethoden}

\subsubsection{Oberflächensterilisation von Arabidopsis thaliana Samen}

A. thaliana Samen wurden in einem Exikator mithilfe von Chlorgas unter leichtem Vakuum sterilisiert. Dafür wurden $50 \mathrm{~mL}$ einer Natriumhypochlorid Lösung mit 2,5 mL Salzsäure (32\%) gemischt und dann ein Unterdruck von 800 mbar angelegt. Nach 2 Stunden wurde der Unterdruck wieder abgelassen und die Samen unter einer Sterilbank abgedampft, bevor die Samen auf Erde ausgelegt wurden. Für die Aussaat auf Platten wurden $100 \mathrm{~mL}$ einer Natriumhypochlorid Lösung mit $5 \mathrm{~mL}$ Salzsäure (32\%) gemischt und dann ein Unterdruck von 800 mbar angelegt und für 4 Stunden inkubiert, bevor die Samen unter der Sterilbank abdampften.

\subsubsection{Wachstum von Arabidopsis thaliana Samen auf MS-Platten}

Für die sterile Anzucht von Pflanzen auf Platten, wurden oberflächensterilisierte Samen (2.2.3.1) auf MS-Platten ausgelegt. Die Wachstumsbedingungen waren 12 Stunden Licht und 12 Stunden Dunkelheit. Zur Selektion homozygoter Linien aus dem heterozygoten Samenpool wurden MS-Platten mit PTT verwendet. Für Phänotypenexperimente mit TIBA wurden MS-Platten mit $50 \mu \mathrm{M}$ TIBA oder $50 \mu \mathrm{M}$ DMSO verwendet. Experimente für die Eisenverfügbarkeit wurden auf $1 / 2 \mathrm{MS}$-Platten mit den angegebenen Zusätzen durchgeführt.

\subsubsection{Biochemische Methoden}

\subsubsection{Proteinextrakte aus $A$. thaliana}

Für Proteinextrakte aus $A$. thailana wurden zwei bis drei Blätter in einem $2 \mathrm{~mL}$ Reaktionsgefäß mit einer Stahlkugel (Mirostahl, $\varnothing 5 \mathrm{~mm}$ ) geerntet und sofort in flüssigem Stickstoff schockgefroren. Die Proben wurden dann in einer Retsch (Retsch MM301) zermahlen (4 Sekunden 30 1/sek, 10 Sekunden 20 1/sek, 30 Sekunden 18 1/sek). Das Pulver 
wurde mit demselben Volumen an 4M Harnstoff Puffer versetzt und für 10 min gevortext. Das Gemisch wurde für 10 min bei $65^{\circ} \mathrm{C}$ erhitzt und danach für 15 min zentrifugiert (13.000 rpm). Der Überstand wurde in ein neues Reaktionsgefäß überführt und bei $-20^{\circ} \mathrm{C}$ gelagert.

\subsubsection{Proteinexpression aus $E$. coli}

Für jede Proteinexpression wurden E. coli Transformationen, die nicht älter als zwei Wochen waren, verwendet. Am Vortag wurden $10 \mathrm{~mL}$ LB-Medium (mit entsprechenden Antibiotika) in einem $100 \mathrm{~mL}$ Kolben mit einer Einzelkolonie angeimpft. Die Kulturen wurden bei $37^{\circ} \mathrm{C}$ in einem Schüttler $(220 \mathrm{rpm})$ angezogen. Am nächsten Morgen wurde die OD der Vorkultur gemessen und eine Expressionskultur mit einer OD von 0,03 eingestellt (aerob $500 \mathrm{~mL} \mathrm{LB}$ Medium und anaerob $800 \mathrm{~mL}$ LB-Medium jeweils in $2 \mathrm{~L}$ Kolben mit den entsprechenden Antibiotika). Die Expressionskultur wurde bis zu einer OD von 0,8 bis 1,5 bei $37^{\circ} \mathrm{C}$ in einem Schüttler (aerob: $220 \mathrm{rpm}$, anaerob: $170 \mathrm{rpm}$ ) angezogen. Nach Erreichen der OD wurde eine uninduzierte Probe genommen $(\mathrm{mL}=2 / \mathrm{OD})$ und dem Rest der Expressionskultur 0,5\% Ethanol hinzugeben. Nach dem Durchmischen der Kultur wurde der Kolben in einem Eisbad gekühlt und dann für 2 Stunden bei $4^{\circ} \mathrm{C}$ inkubiert. Sowohl die Ethanolbehandlung als auch die Kälteinkubation sollen die Zellen dazu anregen Faltungshelfer-Proteine zu exprimieren, die bei der Faltung des zu überexprimierenden Proteins helfen sollen. Zur Induktion wurden 0,5 mM IPTG verwendet und zusätzlich wurde ein Gemisch aus $30 \mu \mathrm{M}$ Eisen (III) Citrat und $30 \mu \mathrm{M}$ Ascorbinsäure hinzugegeben (in alle ROXY19 oder GRX370 Ansätze). Die Expression fand bei $20{ }^{\circ} \mathrm{C} \mathrm{O} / \mathrm{N}$ in einem Schüttler statt (aerob: $220 \mathrm{rpm}$, anaerob: $170 \mathrm{rpm}$ ). Am nächsten Tag wurden die Expressionskulturen in Zentrifugengefäßen mit $6.000 \mathrm{rpm}$ für 15 min bei $4^{\circ} \mathrm{C}$ zentrifugiert und die Pellets in $20 \mathrm{~mL}$ Medium resuspendiert und in ein $50 \mathrm{~mL}$ Falcon überführt, welches ebenfalls mit $4.000 \mathrm{rpm}$ für $30 \mathrm{~min}$ bei $4^{\circ} \mathrm{C}$ zentrifugiert wurde. Der Überstand wurde verworfen und die Pellets bei $-70^{\circ} \mathrm{C}$ eingefroren.

\subsubsection{Proteinreinigung aus E. coli}

Nach der Proteinexpression in E. coli wurden die geernteten Zellen zunächst in $20 \mathrm{~mL}$ Wasch-Puffer (mit einer Tablette Protease Inhibitor Cocktail) resuspendiert und eine Stunde mit $10 \mathrm{mg} / \mathrm{mL}$ Lysozym inkubiert. Der Zellaufschluss erfolgte durch ein Ultraschallgerät (SONOPLUS HD 3400 (Bandelin)) (Programm: 50\% Amplitude, 1 sek Puls, 2 sek Pause für 15 min). Das Ultraschallgerät wurde vor jeder Nutzung neu kalibriert (nach Angaben des Herstellers). Für anaerobe Zellkulturen wurde der Aufschluss in einem Atmosbag (Sigma) mit Stickstoffatmosphäre durchgeführt. Vor der eigentlichen Reinigung wurde eine $100 \mu \mathrm{L}$ Probe abgenommen, um die Löslichkeit (Pellet oder Überstand) des Proteins zu klären (zentrifugiert bei $13.300 \mathrm{rpm}, 80 \mathrm{~min}, 4^{\circ} \mathrm{C}$ ). Nach dem Aufschluss wurden die Extrakte zentrifugiert $\left(20.000 \mathrm{rpm}, 45 \mathrm{~min}, 4^{\circ} \mathrm{C}\right)$ und der Überstand mit Strep-Tactin Beads $(1 \mathrm{~mL} 50 \%$ Suspension für $20 \mathrm{~mL}$ Extrakt) auf einem Dreher (3 rpm) für 2-3 Stunden bei $4^{\circ} \mathrm{C}$ inkubiert. Die Beads wurden vor ihrer Benutzung dreimal mit Waschpuffer gewaschen. Nach der Inkubation wurden die Beads zentrifugiert (500 rpm, $5 \mathrm{~min}, 4^{\circ} \mathrm{C}$ ). Vom Überstand wurden $100 \mu \mathrm{L}$ für spätere Analysen abgenommen (Ungebundene Fraktion) und der Rest verworfen. Alle anschließenden Arbeiten wurden auf Eis durchgeführt. Die Beads wurden anschließend sieben Mal mit $1 \mathrm{~mL}$ Waschpuffer gewaschen von jeder Waschfraktion (W1-W7) wurden 100 $\mu \mathrm{L}$ für spätere Analysen aufbewahrt. Nachdem die Beads gewaschen wurden, wurden sie für je $5 \mathrm{~min}$ mit $500 \mu \mathrm{L}$ Elutionspuffer inkubiert und insgesamt fünf Mal eluiert (E1-E5). Die Beads wurden bis zu dreimal regeneriert (mit 1 mM HABA in Waschpuffer). Die Regeneration 
umfasste drei Waschschritte mit $1 \mathrm{~mL}$ HABA-Puffer und abschließendem Waschen mit $1 \mathrm{~mL}$ Waschpuffer bis die Beads wieder farblos waren.

\subsubsection{Konzentrationsbestimmung von Proteinen}

Konzentrationsbestimmungen wurde mit dem „Pierce $660 \mathrm{~nm}$ Protein assay" (Thermo Scientific) anhand der Anweisungen des Herstellers durchgeführt. Zur Berechnung der Konzentrationen wurde eine BSA Standard-Reihe verwendet (0 $\mu \mathrm{g}, 1 \mu \mathrm{g}, 3 \mu \mathrm{g}, 6 \mu \mathrm{g}$ und $9 \mu \mathrm{g})$.

\subsubsection{SDS-Polyacrylamid Gel Elektrophorese (SDS-PAGE)}

Die SDS-PAGE ist eine Methode zur Auftrennung von Proteinen nach ihrer Größe in einem elektrischen Feld. Für E. coli Proteine und Extrakte wurde die nachfolgende ExtraktionsMethode benutzt (für $A$. thaliana siehe 2.2.4.1). Die Proteine wurden zunächst vollständig denaturiert, dies geschah durch SDS, DTT (bzw. $\beta$-Mercaptoethanol) und aufkochen bei $100^{\circ} \mathrm{C}$ für $5 \mathrm{~min}$ in RPB-Puffer. Die Disulfidbrücken der Proteine wurden durch das Reduktionsmittel aufgelöst und SDS interferiert mit hydrophoben Wechselwirkungen, neben dieser Funktion werden negative Ladungen durch die Anlagerung von SDS, in Abhängigkeit zur Proteingröße eingebracht, was die Wanderungsgeschwindigkeit linear vom Logarithmus der Masse abhängig macht. Für eine saubere Auftrennung der Proteine liegt dem eigentlichen Trenngel ein Sammelgel auf, dieses diente der groben Auftrennung von kleinen und großen Proteinen in einem weitmaschigen Acryamidnetz (4\%). Das Trenngel trennte die Proteine dann in einem engermaschigen Acryamidnetz (10-15\%) feiner auf.

In dieser Arbeit wurde eine modifizierte Methode nach Laemmli (Laemmli, 1970) verwendet. Abweichungen sind in der untenstehenden Tabelle angegeben. Leere Spuren in Gelen wurden mit RPB-Puffer aufgefüllt. Zur Einschätzung der Größe wurde in eine Spur ein Größenstandard (Prestained Protein Ladder Plus, MBI Fermentas) geladen. Der Gellauf wurde in 1X SDS-Laufpuffer durchgeführt. In Abhängigkeit zur Gelgröße (kleine von BioRad (10 oder 15 Spuren): 60-70 min bei 180V oder große: selbstgebaute AG Gatz (22 oder 33 Spuren): $130-150$ min bei 160V) und der Größe der zu untersuchenden Proteine, wurde die Laufzeit und Spannung angepasst.

\begin{tabular}{|l|l|}
\hline Sammelgel & Trenngel \\
\hline $125 \mathrm{mM}$ TRIS-HCl pH 6,8 & $375 \mathrm{mM}$ TRIS-HCl pH 8,8 \\
\hline $4 \%(\mathrm{w} / \mathrm{v})$ Acrylamid & $10-15 \%$ Acrylamide \\
\hline $0,1 \%(\mathrm{w} / \mathrm{v})$ SDS & $0,1 \%(\mathrm{w} / \mathrm{v})$ SDS \\
\hline $0,1 \%(\mathrm{w} / \mathrm{v})$ APS & $0,1 \%(\mathrm{w} / \mathrm{v})$ APS \\
\hline $0,01(\mathrm{v} / \mathrm{v})$ TEMED & $0,01(\mathrm{v} / \mathrm{v})$ TEMED \\
\hline
\end{tabular}

\subsubsection{Native Gele}

Da bei der SDS-PAGE die Proteine komplett denaturiert werden, eignet sie sich nicht für Untersuchungen von Proteinkomplexen. Um Proteinkomplexe auf Gelen sehen zu können muss auf alle reduzierenden und denaturierenden Komponenten verzichtet werden. Daher wurden Proben für native Gele mit nativem Ladepuffer gemischt und ohne Erhitzung direkt auf ein natives Gel (Zusammensetzung siehe Tabelle unten) geladen. Die Besonderheit bei den hier verwendeten nativen Gelen war, dass es aufgrund der geringen Prozentigkeit des Trenngels (6\%) kein Sammelgel gab. Leere Spuren in Gelen wurden mit nativem Ladepuffer aufgefüllt. Zur Einschätzung der Größe wurde in eine Spur ein nativer Größenstandard 
(NativMark ${ }^{\mathrm{TM}}$ Unstained Protein Standard, Invitrogen) geladen. Für den Gellauf wurde $1 \mathrm{X}$ nativer Laufpuffer verwendet. Da Proteinkomplexe instabil sein können, wurden die Läufe stets auf Eis bei 60 Volt für 3 Stunden durchgeführt.

\begin{tabular}{|l|}
\hline Natives Gel \\
\hline $375 \mathrm{mM}$ TRIS-HCl pH 8,8 \\
\hline $6 \%(\mathrm{w} / \mathrm{v})$ Acrylamid \\
\hline $0,1 \%(\mathrm{w} / \mathrm{v})$ APS \\
\hline $0,01(\mathrm{v} / \mathrm{v})$ TEMED \\
\hline
\end{tabular}

\subsubsection{Coomassie Färbung von Acryamid-Gelen}

Um Proteine in SDS-PAGE oder nativen Gelen sichtbar zu machen wurde in dieser Arbeit eine Coomassie-Lösung (10\% Essigsäure mit 0,01\% Coomassie Brilliant Blue) verwendet (Bennett and Scott, 1971). Vor der eigentlichen Färbung wurden die Poren der Gele durch eine 15minütige Fixierung (10\% Essigsäure, 20\% Isopropanol) geweitet, hiernach wurden die Gele in Plastikbehältern für 1-2 Stunden in der Coomassie-Lösung angefärbt und anschließend $\mathrm{O} / \mathrm{N}$ in einer Entfärberlösung (10\% Essigsäure) entfärbt. Nach dem Entfärben wurden die Proteinbanden (welche sich nicht entfärben) sichtbar. Dies hilft bei der Identifizierung von Proteinen anhand ihrer Größe. Desweiteren ist es möglich anhand der Bandenintensität eine ungefähre Konzentration (mithilfe eines Standards, BSA $5 \mu \mathrm{g}$ ) abzuschätzen.

\subsubsection{Protein Immunoblot}

Der Protein Immunoblot (Western Blot) bezeichnet den Transfer von Proteinen auf eine PVDF-Membran im elektrischen Feld (Kyhse-Andersen, 1984), die zuvor über eine SDS-PAGE aufgetrennt wurden. Die Proteine wandern dabei, durch die SDS gegebenen negativen Ladungen, in Richtung Anode und werden hierbei von der PVDF-Membran aufgehalten. Aufgrund hydrophober Wechselwirkungen können die Proteine an die PVDF-Membran Oberfläche binden. Hier erfolgt die immunologische Untersuchung der immobilisierten Proteine.

Für die Durchführung musste die PVDF-Membran zunächst in Methanol aktiviert werden. Das Gel wurde auf der PVDF-Membran zwischen jeweils drei Lagen in Transferpuffer angefeuchteten Whatman-Papier ${ }^{\circledR}$ positioniert und zwischen zwei Graphitelektroden der Blottingapparatur platziert. Der Proteintransfer erfolgte für 90 min mit einer Stromstärke von $1 \mathrm{~mA} / \mathrm{cm}^{2}$ PVDF-Membran. Anschließend wurden alle unspezifischen Bindestellen durch eine zweistündige Inkubation der PVDF-Membran mit TBS-T (+5\% Milchpulver) unter konstantem Schwenken bei RT geblockt. Der Primärantikörper in TBS-T (+5\% Milchpulver) wurde $\mathrm{O} / \mathrm{N}$ bei $4^{\circ} \mathrm{C}$ unter konstantem Schwenken inkubiert. Am nächsten Tag wurde die Membran fünf Mal für jeweils $5 \mathrm{~min}$ in TBS-T gewaschen. Die Inkubation des Sekundärantikörper in TBS-T (+5\% Milchpulver) erfolgte bei RT für zwei Stunden unter konstantem Schwenken und erneutem Waschen der Membran für fünf Mal 5 min in TBS-T. Zur Entwicklung der PVDF-Membran, wurde diese zunächst vollständig mit einer Substratlösung (SuperSignal ${ }^{\circledR}$ West Femto Maximum Sensitivity Substrate) bedeckt und für 5 min inkubiert. Dieses Substrat wurde von der an den Sekundärantikörper gekoppelten Meerrettichperoxidase in ein von einer CCD-Kamera (Intas) detektierbares Signal umgesetzt. 


\subsubsection{HED-Assay}

Der HED-Assay ist eine Methode um die enzymatische Aktivität von Glutaredoxinen nachzuweisen. Hierbei wird die Reduktionsfähigkeit der potentiellen Enzyme getestet. Im HED-Assay wird während der Vor-Inkubation (15 min) das HED spontan vom Glutathion (GSH) reduziert, dabei entstehen $\beta$-Mercaptoethanol ( $\beta-\mathrm{Me}$ ) und ein gemischtes Disulfid zwischen $\beta$-Mercaptoehtanol und Glutathion ( $\beta$-Me-SG) (Lillig et al., 2008). Die gemischten Disulfide können wiederum von Glutaredoxinen (GRXs) reduziert werden, wobei $\beta$-Me und GRX-SG entstehen. GRX-SG kann mithilfe eines zweiten GSH Moleküls reduziert werden, dabei entstehen GRX und GSSG. GSSG kann wiederum von der Glutathion-Reduktase reduziert werden. Die Glutathion-Reduktase benötigt für diese Funktion NADPH welches zu $\mathrm{NADP}^{+}$oxidiert wird. Die Umwandlung von NADPH zu NADP ${ }^{+}$kann spektrophotometrisch bei $340 \mathrm{~nm}$ beobachtet werden (nur NADPH absorbiert bei dieser Wellenlänge). Ein Ansatz bestand aus $0,1 \mathrm{mg} / \mathrm{mL}$ BSA, 0,2 mM NADPH, $2 \mathrm{mM}$ EDTA, $6 \mu \mathrm{g} / \mathrm{mL}$ Glutathion-Reduktase, $0,7 \mathrm{mM}$ HED, und $1 \mathrm{mM} \mathrm{GSH}$ in $100 \mathrm{mM}$ TRIS-HCl (pH 7,9). Die getestete Proteinkonzentration variierte zwischen $50 \mathrm{nM}$ bis zu $500 \mathrm{nM}$.

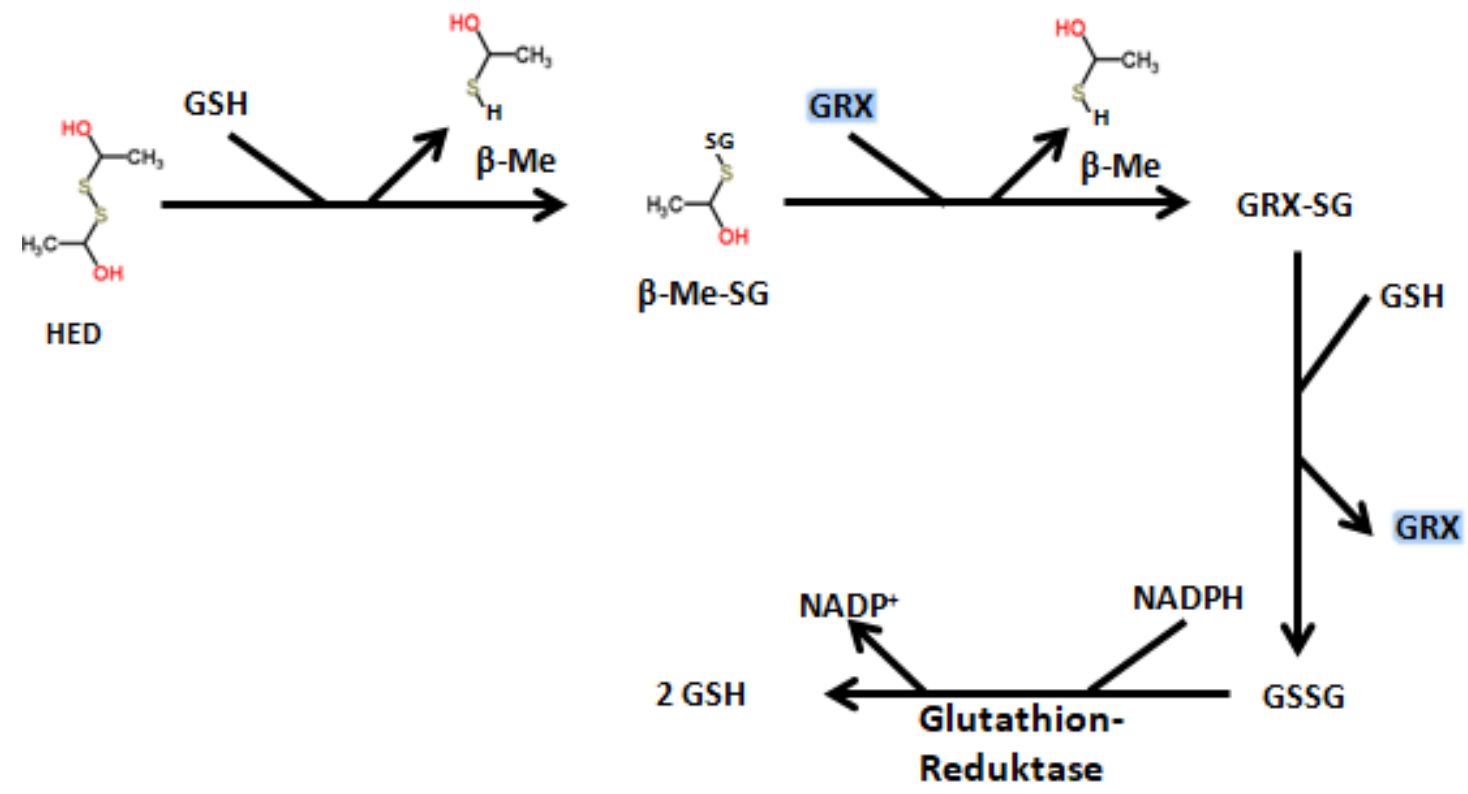

Abbildung 2.1. Schematische Darstellung des HED-Assay. HED reagiert spontan mit GSH zu $\beta$-Me und $\beta$-MeSG. GRX reduziert $\beta$-Me-SG zu einem zweiten Molekül $\beta$-Me und wird dabei selbst glutathionyliert (GRX-SG). Ein zweites Molekül GSH reduziert GRX-SG zu GRX und wird dabei selbst oxidiert (GSSG). GSSG wird unter NADPH-Verbrauch durch die Glutathion-Reduktase wieder zu 2 Molekülen GSH und oxidiertem NADP ${ }^{+}$ umgewandelt. Die Oxidation des NADPH zu NADP ${ }^{+}$kann spektrophotometisch bei $340 \mathrm{~nm}$ beobachtet werden.

\subsubsection{Rekonstitution von Eisen-Schwefel-Clustern}

Die Rekonstitution ist eine Methode die in vitro Eisen-Schwefel Cluster aufgrund der Eigenschaften des getesteten Proteins inkorporiert. Die Rekonstitutionen von EisenSchwefel-Clustern des ROXY19 wurden unter anaeroben Bedingungen durchgeführt. Zuerst wurden 50-100 $\mu \mathrm{M}$ ROXY19 (in Kaliumphophat Puffer pH 8,0) für eine Stunde mit 5 mM DTT inkubiert (in $100 \mu \mathrm{L}$ ), um ROXY19 zu reduzieren und die vorhandenen Cluster zu verdrängen. Anschließend wurde im fünffachen Überschuss Ammonium Eisen (III) Citrat hinzugegeben und für 10 min inkubiert. Danach wurden äquimolare Mengen (zum Eisen) an Lithiumsulfit und GSH langsam hinzugegeben und für weitere 45 min inkubiert. Überschüssiger Schwefel, Eisen und GSH wurden mithilfe Gelfiltrationschromatographie über eine PD-10 Säule (GE 
Healthcare) entfernt. Eingebaute Cluster wurden mittels UV-VIS-Spektroskopie und CDSpektroskopie nachgewiesen (AG Lill, nicht publiziert).

\subsubsection{Schwefelbestimmung}

Die Anwesenheit von Schwefel wurde mithilfe der Methylenblau-Methode nach Kirsten und Patel (1972) überprüft. Hierfür wurden $20 \mu \mathrm{L}$ ROXY19 $(530 \mu \mathrm{M})$ mit $90 \mu \mathrm{L} 20 \mathrm{mM} \mathrm{N}, \mathrm{N}$ Dimethyl-p-phenylendianinsulfat (in $7,2 \mathrm{M} \mathrm{HCl}$ ) und $90 \mu \mathrm{L} 30 \mathrm{mM} \mathrm{FeCl}_{3}$ (in $1,2 \mathrm{M} \mathrm{HCl}$ ) gemischt. Nach $10 \mathrm{~min}$ Inkubation wurde die Absorption bei $667 \mathrm{~nm}$ gemessen. Die Konzentration des enthaltenen Schwefel konnte über eine Standardkurve verschiedener Konzentrationen von $\mathrm{Na}_{2} \mathrm{~S}$ berechnet werden $\left(y=0,00603 x-0,00211 ; R^{2}=0,99896 ; y=\right.$ Absorption bei $667 \mathrm{~nm}, \mathrm{x}=$ Konzentration).

\subsubsection{EMSA mit radioaktiv markierter DNA}

Zur Identifizierung und Charakterisierung von Protein-DNA-Komplexen in vitro wurde im Rahmen dieser Arbeit der radioaktive EMSA verwendet. Zunächst wurde das as-1 Promoter DNA-Fragment aus dem Plasmid pUC57/T-as-1-Bpi (durch Verdau von $15 \mu \mathrm{g}$ mit $2 \mu \mathrm{L}$ Bpil in $20 \mu \mathrm{L}$ ) hergestellt. Für die radioaktive Markierung wurden $4 \mu \mathrm{L}$ des Restriktionsansatzes (ohne Gelelution) mit $2 \mu \mathrm{L}$ Puffer Grün (MBI Fermentas), 8,2 $\mu \mathrm{L} \mathrm{H}_{2} \mathrm{O}, 0,8 \mu \mathrm{L}$ Klenow exo minus $(5 \mathrm{U} / \mu \mathrm{L})$ und $4 \mu \mathrm{L} \alpha-32 \mathrm{P}-\mathrm{dATP}(2000 \mathrm{kBq})$ gemischt und für 2 Stunden bei $37^{\circ} \mathrm{C}$ inkubiert. Überschüssiges $\alpha-32 P-d A T P$ wurde durch eine anschließende Säulenreinigung (G25 Spin Column, GE Healthcare) abgetrennt. Das Fragment wurde zusätzlich über ein natives PAA-Gel (5\% Acryamid, 1X TBE, 10\% Glycerin, 0,06\% APS und 0,006\% TEMED) in 1X $\mathrm{TBE}$, durch Ausschneiden, gereinigt. Das radioaktiv markierte Fragment wurde $\mathrm{O} / \mathrm{N}$ aus dem Gel bei $37^{\circ} \mathrm{C}$ mit Wasser eluiert.

Das markierte Fragment wurde später mit 100-300 Counts pro Probe eingesetzt $(4 \mu \mathrm{L}$ des Eluats). Als Größenstandard diente Box (67\% (w/v) Saccharose, 50 mM EDTA, 0,42\% Farbstoff (Bromphenolblau, OrangeG, Xylencyanol (1:1:1)) welches zusammen mit $4 \mu \mathrm{L}$ des Fragments in der jeweils ersten Spur jeden Gels geladen war. Alle anderen Ansätze waren in 1X Bindepuffer und beinhalteten $3 \mu \mathrm{g}$ Poly dl-dC als Kompetitor für nicht-spezifische DNABindeproteine. Additive (z.B. GSH oder Eisen) und eingesetzte Proteinmengen sind in den jeweiligen Experimenten angegeben.

An die PAA-Gele wurde eine Spannung von $62-65 \mathrm{~V}$ in $1 \mathrm{X}$ TBE bei $4^{\circ} \mathrm{C}$ für $15-17$ Stunden angelegt. Nach dem Lauf wurden die Gele für 15 min fixiert (10\% Essigsäure, 30\% Methanol). Die Gele wurden anschließend auf einem Geltrockner für 3 Stunden bei $80^{\circ} \mathrm{C}$ unter konstantem Vakuum getrocknet. Das Signal wurde nach der Trocknung für 3 Stunden auf eine Speicherfolie übertragen. Das Signal konnte hiernach mithilfe des SpeicherfolienEinlesers (BAS-1000, FUJIFILM) von der Speicherfolie auf den Computer übertragen werden. Die Auswertung erfolgte über die vom Hersteller bereitgestellte Software "BAS-READ" und „BAS-PC" (FUJIFILM).

\subsubsection{Ellman's Assay}

Der Ellman's Assay ist eine Methode zur Bestimmung von Thiolgruppen (-SH) und kann daher zur quantitativen Bestimmung des Redoxzustandes von Proteinen (dessen Anzahl von Cysteinen bekannt ist) genutzt werden. Für den Assay wurde in einer Mikrotiter-Platte eine

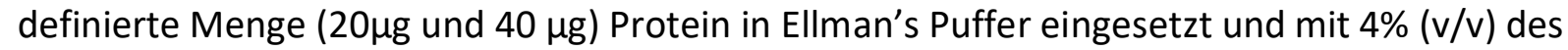
Ellman's Reagent (gelöst in Ellman's Puffer, $4 \mathrm{mg} / \mathrm{mL}$ ) gemischt. Der Ansatz wurde vor der Messung bei $320 \mathrm{~nm}$ für $15 \mathrm{~min}$ bei RT inkubiert. Über eine Eichgerade mit definierten 
Mengen an Cystein Hydrochlorid Monohydrat konnte die Menge an reduzierten Thiolgruppen berechnet werden.

\subsubsection{Löslichkeits- und Stabilitätstests}

Zur Bestimmung der Löslichkeit und Stabilität unter verschiedenen Bedingungen wurden die von Hampton Research entwickelten Tests unter Angaben des Herstellers verwendet (Howe, 2004; McPherson, 1982).

\subsubsection{Transkriptionsanalysen}

\subsubsection{RNA Extraktion}

Die Isolierung pflanzlicher RNA wurde basierend auf der TRIZOL-Extraktionsmethode (Chomczynski, 1993) durchgeführt. Schockgefrorenes Pflanzenmaterial wurde zu feinem Pulver gemörsert und $200 \mathrm{mg}$ mit $1,3 \mathrm{~mL}$ Trizolpuffer gemischt. Das Gemisch wurde anschließend für $10 \mathrm{~min}$ bei RT gevortext. Nach der Zugabe von $260 \mu \mathrm{L}$ Chloroform wurden die Proben für 10 weitere Minuten gevortext. Die Trennung der wässrigen Phase mit den Nukleinsäuren und der organischen Phase mit Proteinen und Zelltrümmern erfolgte durch Zentrifugation ( $45 \mathrm{~min}, 13.000 \mathrm{rpm}, 4^{\circ} \mathrm{C}$ ). $800 \mu \mathrm{L}$ der wässrigen Phase wurden in ein neues Reaktionsgefäß übertragen und mit $300 \mu \mathrm{L}$ Isopropanol und $300 \mu \mathrm{L}$ Hochsalzpuffer durch invertieren gemischt. Die Fällung der RNA erfolgte durch erneute Zentrifugation (60 min, $13.000 \mathrm{rpm}, 4^{\circ} \mathrm{C}$ ). Das RNA-Pellet wurde in ein neues Reaktionsgefäß überführt und zweimal mit 70\% Ethanol gewaschen (10 min, $\left.13.000 \mathrm{rpm}, 4^{\circ} \mathrm{C}\right)$. Anschließend wurde das Pellet bei $37^{\circ} \mathrm{C}$ für $10 \mathrm{~min}$ getrocknet und in $25-50 \mu \mathrm{L}$ Wasser bei $65^{\circ} \mathrm{C}$ für $10 \mathrm{~min}$ gelöst. Die Konzentrationen wurden mithilfe des NanoDrop 2000c (2.2.1.3) bestimmt.

\subsubsection{2 cDNA-Synthese}

Für die Synthese der cDNA wurde $1 \mu \mathrm{g}$ RNA verwendet, diese wurde mit DNase I und $1 \mu \mathrm{L}$ 10X DNase I Puffer für 30 min bei $37^{\circ} \mathrm{C}$ inkubiert. Dieser Schritt verhindert die Kontamination der cDNA mit genomischer DNA. Die DNase I wurde durch Zugabe von $1 \mu \mathrm{L} 25 \mathrm{mM}$ EDTA für $10 \mathrm{~min}$ bei $65^{\circ} \mathrm{C}$ inaktiviert. Zufallsnonamere und Oligo-dT Oligonukleotide dienten als Startoligonukleotide der cDNA Synthese. Die Hybridisierung an die RNA erfolgte bei $70^{\circ} \mathrm{C}$ für 10 min. Für die Amplifizierung wurden 20 nmol dNTPs, $4 \mu \mathrm{IRT} 5 \mathrm{x}$-Reaktionspuffer und $60 \mathrm{U}$ Reverse Transkriptase $\mathrm{H}$ - bei $42^{\circ} \mathrm{C}$ für $70 \mathrm{~min}$ hinzugegeben. Die Inaktivierung der Transkriptase erfolgte bei $70^{\circ} \mathrm{C}$ für $10 \mathrm{~min}$. CDNA wurde bei $-20^{\circ} \mathrm{C}$ gelagert. 


\subsubsection{Quantitative Echtzeit-PCR (qRT-PCR)}

Die Quantifizierung der Genexpression wurde mithilfe der qRT-PCR durchgeführt. Das Maß der zunehmenden DNA wurde durch den Farbstoff SYBR Green, welcher nur in DNAgebundener Form fluoresziert, bestimmt. Der Reaktionsmix bestand aus $1 \mu$ ler 1:10 verdünnten cDNA als Matrize sowie $1 \mu \mathrm{N} \mathrm{NH}_{4}$-Reaktionspuffer, 0,25 U BIOTaq DNAPolymerase (Bioline), $2 \mathrm{mM} \mathrm{MgCl}$, $100 \mu \mathrm{M}$ dNTPs, 0,4 $\mu \mathrm{M}$ der Oligonukleotide, $10 \mathrm{nM}$ Fluorescein (BioRad) und 100.000 fach verdünnter SYBR Green I Lösung (Cambrex). Der Reaktionsmix wurde mit $\mathrm{ddH}_{2} \mathrm{O}$ auf ein Volumen von $25 \mu \mathrm{l}$ aufgefüllt. Das verwendete PCRProgramm wird in der unten stehenden Tabelle beschrieben. Die Auswertung der relativen

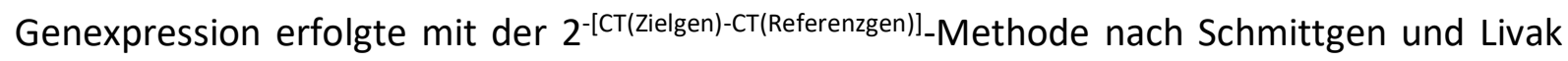
(2008).

\begin{tabular}{l|c|c|c} 
& Dauer & Temperatur & Wiederholung \\
\hline Primäre Denaturierung & 2 min & $95^{\circ} \mathrm{C}$ & $1 \mathrm{x}$ \\
\hline Denaturierung & 20 sek & $95^{\circ} \mathrm{C}$ & \multirow{2}{*}{$40 \mathrm{x}$} \\
\hline Hybridisierung & 20 sek & $55^{\circ} \mathrm{C}$ & \\
\hline Amplifizierung & 40 sek & $72^{\circ} \mathrm{C}$ & \\
\hline \multirow{2}{*}{ Finale Amplifizierung } & 4 min & $72^{\circ} \mathrm{C}$ & \\
\cline { 2 - 3 } & $1 \mathrm{~min}$ & $95^{\circ} \mathrm{C}$ & \\
\cline { 2 - 3 } & $1 \mathrm{~min}$ & $55^{\circ} \mathrm{C}$ & $81 \mathrm{x}$ \\
\hline Schmelzkurve & $10 \mathrm{sek}$ & $55^{\circ} \mathrm{C}-95^{\circ} \mathrm{C}$ & \\
& & &
\end{tabular}

\subsubsection{Biophysikalische Methoden}

\subsubsection{MicroScale Thermophoresis (MST)}

Die MicroScale Thermophorese wurde von der Firma NanoTemper Technologies entwickelt und basiert auf dem Phänomen der Diffusion von Teilchen innerhalb eines Temperaturgradienten (Ludwig-Soret-Effekt). Da dieser Effekt bei allen Stoffen auftritt, ist er universell anwendbar und kann daher auch für biologische Makromoleküle angewendet werden (Duhr and Braun, 2006).

Alle Messungen wurden nach der vom Hersteller angegebenen Vorgehensweise durchgeführt (Wienken et al., 2010). Die getesteten Glutaredoxine wurden mit NT-495 (Monolith Protein Labeling Kit BLUE-NHS (Amine Reactive); NanoTemper Technologies) den Angaben des Herstellers entsprechend markiert, anschließend aliquotiert und nach dem Schockgefrieren im flüssigen Stickstoff bei $-70^{\circ} \mathrm{C}$ gelagert. Die Initialmessungen wurden mit einer Startkonzentration von $200 \mu \mathrm{M}$ des markierten Glutaredoxins bis zu einer Endkonzentration von $200 \mathrm{nM}$ (durch eine 1:1 Titrationsreihe) durchgeführt. Auf Basis der erhaltenen Daten des Standardansatzes, wurde die Software "Concentration Finder" 
(NanoTemper Technologies) zur Verfeinerung, der im Experiment zu verwendenden Konzentration, verwendet. Dabei variierten die Floreszenzen der einzelnen Proben nicht um mehr als 10\%. Alle Messreihen wurden dreimal, zu je Triplikaten durchgeführt. Mithilfe der Origin 8 Datenanalyse- und Grafiksoftware (OriginLab) unter Verwendung einer sigmoidalen Anpassung mit folgender, von Dr. rer. nat Sven Freibert implementierten Funktion, erfolgte die Auswertung:

$$
T=P_{u}+\frac{A_{b}\left(\varphi+\tau+K_{d}-\sqrt{\left(\varphi+\tau+K_{d}\right)^{2}-4 \varphi \tau}\right)}{2 \varphi}
$$

T: Thermophorese; Pu: Plateau (ungebundene Fraktion); $A_{b}$ : Bindungsamplitude; $\varphi$ : Konzentration des gelabelten Proteins; $r$ : Konzentration des titrierten Moleküls; $K d$ : Dissoziationskonstante

Für alle Messungen wurden der Monolith NT.115 (Blue/Red) (NanoTemper Technologies) verwendet.

Alle MST Experimente wurden von Dr. rer. nat. Sven Freibert (Philipps Universität Marburg) durchgeführt, dies beinhaltete das Markieren der Proteine, sowie die MST Messungen und die Auswertung der Daten.

\subsubsection{Spektroskopische Methoden}

\subsubsection{Circulardichroismus (CD) Spektroskopie}

Das Prinzip der CD-Spektroskopie basiert auf optisch aktiven Molekülen, welche zirkular polarisiertes Licht bei unterschiedlichen Wellenlängen unterschiedlich stark absorbieren können. Dies wird in der Biologie hauptsächlich dazu verwendet, um sekundäre Strukturelemente von Proteinen aufzuklären (UV-CD-Spektroskopie). Zusätzlich lassen sich im UV-Vis Bereich Übergänge von Charge-Transfer-Komplexen nachweisen (zum Beispiel Metall-Komplexe). Desweiteren lassen sich im nahen Infrarotbereich geometrische und elektronische Strukturen durch $d \rightarrow d$ Orbital Übergänge von Metallen bestimmen. In dieser Arbeit wurde die UV-CD-Spektroskopie verwendet um potentielle Eisen-Schwefel-Cluster und sekundäre Strukturelemente nachzuweisen. Die Messungen wurden auf der Basis der publizierten Parameter und Vorgehensweise durchgeführt (Bonomi et al., 2008; Webert et al., 2014). Die Endkonzentration der gemessenen Proteine war $10 \mu \mathrm{M}$ im Elutionspuffer. Die Messungen erfolgten durch das CD-Spektrometer J-815 (Jasco).

\subsubsection{UV-Vis-Spektroskopie}

Die UV-Vis-Spektroskopie ist eine Methode, welche die elektromagnetischen Wellen des UVund sichtbaren Lichts nutzt um Elektronen (der äußeren Orbitale) anzuregen und auf ein höheres Energieniveau zu heben. Dies kann genutzt werden um, die Anwesenheit von EisenSchwefel-Clustern, freiem Eisen, Hämgruppen und ähnlichem nachzuweisen. Die UV-VisSpektroskopie liefert somit zusätzliche Daten zur CD-Spektroskopie. Im Rahmen dieser Arbeit wurden $200 \mu \mathrm{L}$ Eluat $(50-100 \mu \mathrm{M})$ gemessen (da die Methode nicht-invasiv ist, wurde das Protein für spätere Analysen weiter verwendet). Die Messungen erfolgten durch das UV/Vis-Sprktralphotometer U-550 (Jasco). 


\subsubsection{Häm-Bestimmung}

Hämgruppen sind weit verbreitete Co-Faktoren von Proteinen (zum Beispiel in Hämoglobin und Cytochrome P450) und lassen sich spektroskopisch relativ einfach nachweisen. Im Rahmen dieser Arbeit wurde ein Protokoll von lan Barr und Feng Guo (Barr and Guo, 2015) verwendet. Hierbei wird das Protein (im Elutionspuffer, $50 \mu \mathrm{M}$ ) mit einer Lösung $(0,2 \mathrm{M}$ $\mathrm{NaOH}, 40 \%$ (v/v) Pyridin, $500 \mu \mathrm{M}$ Kaliumferricyanid) 1:1 gemischt. Diese Probe wird zunächst gemessen und entspricht dem oxidierten Zustand. Anschließend werden $1 \%$ (v/v) 0,5 M Natriumdithionit in 0,5 M NaOH hinzugegeben und gut durchmischt. Die Probe wird sofort alle 60 sek gemessen und der Scan mit dem höchsten Peak entspricht dem Spektrum des reduzierten Zustandes. Mithilfe des Extinktions-Coeffizienten (Barr and Guo, 2015) und des Lambert-Beer'sche Gesetz $A=\varepsilon * c * I$ (Absorption = Extinktions-Coeffizient * Konzentration

* Weglänge) und der Spektren der oxidierten und reduzierten Probe, kann der Typ der Hämgruppe bestimmt werden. 


\section{Ergebnisse}

Ektopisch exprimiertes ROXY19 reprimiert den Promotor des ORA59 Gens, das für den globalen Transkriptionsaktivator der JA/ET-vermittelten Pathogenabwehr kodiert (Zander et al., 2012). Die ROXY19-vermittelte Repression hängt vom C-terminalen ALWL Motiv und einem konservierten Glycin Rest $\left(\mathrm{G}^{111}\right)$, der an der GSH-Bindung beteiligt ist (diese Arbeit), ab (Zander et al., 2012). Die Mutation des Glycin ${ }^{111}$ zum Alanin hatte keinen Effekt auf die TGA2 Bindung im Hefe-Zweihybrid Test (Zander et al., 2012), wodurch eine globale strukturelle Veränderung des ROXY19 ausgeschlossen werden konnte. Der molekulare Mechanismus der ROXY19-vermittelten Repression ist derzeit nicht bekannt, könnte aber mit der Rekrutierung von TOPLESS zusammenhängen (Uhrig et al., 2017).

Zander et al. (2014) zeigten, dass die Expression von ORA59 abhängig von Klasse II TGA Transkriptionsfaktoren ist. Klasse II TGA Transkriptionsfaktoren regulieren zusammen mit ORA59 Zielgene der JA/ET- vermittelten Pathogenabwehr, wie PDF1.2 (Zander et al., 2014). Huang et al. (2016) zeigten, dass durch Klasse II TGA Transkriptionsfaktoren regulierte Gene des Detoxifikationswegs ebenfalls negativ durch die ektopische Expression von ROXY19 reguliert werden können.

Die oben genannten, publizierten Daten weisen auf eine mögliche Regulation von Klasse II TGA Transkriptionsfaktoren durch ROXY19 hin. Ziel dieser Arbeit war es die mögliche mechanistische Funktionsweise der Repression durch ROXY19 von Klasse II TGA Transkriptionsfaktoren regulierten Genen nachzuweisen.

Im ersten Teil (3.1) wurden die biochemischen Eigenschaften von ROXY19 in vitro mit rekombinant exprimiertem und gereinigtem Protein aus $E$. coli charakterisiert.

Der zweite Teil (3.2) beschäftigt sich mit der Funktion des ROXY19 in planta und beschreibt die Phänotypen der ROXY19 Überexpression und die Auswirkungen auf die Pflanze.

In beiden Teilen wurden Verknüpfungen zwischen den Eigenschaften und dem putativen aktiven Zentrum (CCMC) erstellt, um die Konservierung des CC-Motivs in Teilen erklären zu können und möglicherweise eine prinzipielle Funktionsweise der ROXYs zu beschreiben.

\subsection{Analyse des CC-Typ Glutaredoxin ROXY19 in vitro}

In diesem Teil wurde rekombinant exprimiertes und gereinigtes ROXY19 auf seine biochemischen Eigenschaften hin untersucht. Dabei wurden zunächst klassische Eigenschaften von Glutaredoxinen, wie die GSH-Bindung, enzymatische Aktivität und EisenSchwefel-Cluster Inkorporation überprüft. Desweiteren wurde mit Hilfe von EMSAs der Einfluss von ROXY19 auf das Bindeverhalten von TGA2 an das as-1 Element untersucht. Neben dem Wildtyp Protein wurden verschiedene Mutanten mit Austauschen im putativen aktiven Zentrum auf ihre Funktion untersucht, um die Bedeutung des CC-Motivs näher zu charakterisieren. 


\subsubsection{Der Einfluss des Tags und der Co-Expression des Interaktionspartners TGA2 auf die Expression von ROXY19}

ROXY19 besitzt einen, in fast allen ROXYs, konservierten hydrophoben C-Terminus (LXXLL und ALWL Motiv (Abbildung 3.1A)). Dieser ist für die Interaktion zwischen ROXYs und TGA Transkriptionsfaktoren und die hiermit beschriebenen Funktionen unabdingbar (Li et al., 2009, 2011; Zander et al., 2012). Uhrig et al. (2017) zeigten, dass ein C-terminales GFP-Tag die reprimierende Funktion des ROXY19 beeinträchtigt. Daher wurden alle ROXY19 Varianten mit einem $\mathrm{N}$-terminalen Tag versehen.

Die Expression einer Strep-ROXY19 (pGP172-ROXY19) Variante zeigte eine niedrige Ausbeute an Protein (Abbildung 3.1B). Durch die zusätzliche Fusion eines GFP-Tags (pGP172-GFPROXY19), zwischen Strep-Tag und ROXY19, konnte die Ausbeute pro Liter Kultur gesteigert werden (Abbildung 3.1B). Diese Steigerung belief sich von ca. 0,1 mg/L (Strep-ROXY19) auf ca. $2 \mathrm{mg} / \mathrm{L}$ (Strep-GFP-ROXY19). Da GFP jedoch Cysteine besitzt, die in späteren Experimenten interferieren könnten, wurde ein weiterer Expressionsvektor konstruiert, in dem das GFP durch das MBP ersetzt wurde (pGP172-MBP-ROXY19). Auch die Strep-MBPROXY19 Fusion wurde stark exprimiert (Ausbeuten zwischen $1 \mathrm{mg} / \mathrm{L}$ bis $3 \mathrm{mg} / \mathrm{L}$ ) und konnte durch eine Co-Expression mit dem Interaktionspartner TGA2 (pAC28-TGA2, ohne zusätzliches Tag) zusätzlich gesteigert werden (Ausbeuten zwischen $1 \mathrm{mg} / \mathrm{L}$ bis $6 \mathrm{mg} / \mathrm{L}$ ) (Abbildung 3.1C). Für alle weiteren Experimente wurde eine Co-Expression von Strep-MBPROXY19 mit PAC28-TGA2 verwendet.

A MQGTISCARNYNMTTTVGESLRPLSLKT QGNGERVRMVVEENAVIVIGRRGCCMC HVVRRLLLGLGVNPAVLEIDEEREDEVLSE LENIGVQGGGGTVKLPAVYVGGRLFGGL DRVMATHISGELVPILKEVGALWL
B

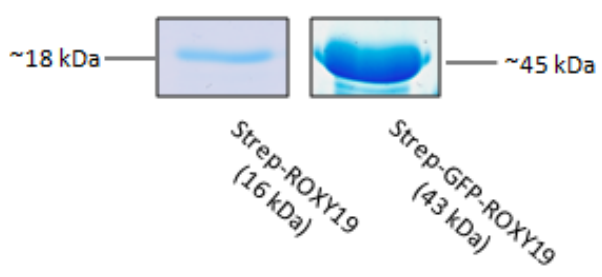

C

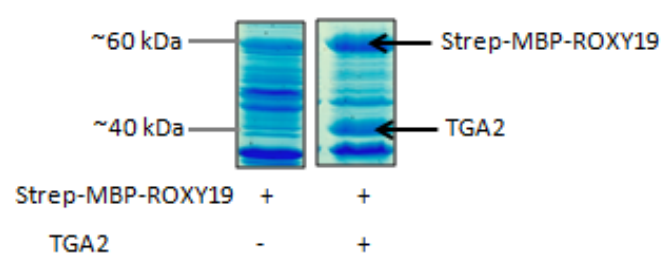

Abbildung 3.1. ROXY19 Expression wird durch ein großes $\mathbf{N}$-terminales Tag und den Interaktionspartner TGA2 positiv beeinflusst. (A) Gezeigt ist die Aminosäure-Sequenz (137 Aminosäuren, $15 \mathrm{kDa}$ ) von ROXY19 (AT1G28480.1) mit dem putativen aktiven Zentrum $\left({ }^{52} \mathrm{CCMC}^{55}\right)$ (grün), konserviertes Glycin in der putativen Glutathion-Bindestelle $\left(\mathrm{G}^{111}\right)$ (blau), dem LxxLL-Motiv $\left({ }^{125} \mathrm{LVPIL}^{129}\right.$ ) (orange) und dem ALWL-Motiv $\left({ }^{134} \mathrm{ALWL}{ }^{137}\right)$ (rot). (B) Coomassie gefärbtes 12\%-iges SDS-PAGE Gel von jeweils 1/50 der Elutionen von Strep-ROXY19 (16 kDa) und Strep-GFP-ROXY19 (43 kDa) aus ungefähr gleicher Zellanzahl. (C) Coomassie gefärbtes 12\%-iges SDSPAGE Gel, zum Vergleich induzierter Zellkulturen (jeweils $\mathrm{mL}=2 / \mathrm{OD}$ der Hauptkultur wurden für die Analyse benutzt) von Strep-MBP-ROXY19 mit und ohne TGA2 Co-Expression. 


\subsubsection{ROXY19 besitzt Affinität zu Glutathion}

Für die meisten beschriebenen Funktionen von Glutaredoxinen, wird Glutathion (GSH) als Substrat (enzymatische Funktionen) oder Ligand (einige Eisen-Schwefel-Cluster) benötigt. Für das nachfolgende Experiment wurden aerob gereinigte Proteine verwendet (Anhang 6.12). Der Redoxzustand des ROXY19 wurde mithilfe des Ellman's Test bestimmt und ergab, dass $2 \%$ des Proteins reduziert vorlagen (Abbildung 3.2A) und das Protein ausschließlich als Oligomer vorlag (Abbildung 3.5A)). Analysen des Redoxzustandes von ROXY19 Protein aus anaerob aufgeschlossenen $E$. coli Zellen ergaben, dass ca. 50\% des Proteins im reduzierten Zustand vorlagen (Abbildung 3.2A). In den Ellman's Reaktionen wurden 6,72 $\mu \mathrm{M}$ ROXY19 eingesetzt. Daraus ergaben sich 26,9 $\mu \mathrm{M}$ Cysteine. Mithilfe einer Eichgeraden verschiedener Konzentrationen von Cystein Hydrochlorid Monohydrat $\left(y=0,0043 x+0,0051 ; R^{2}=0,9994 ; y\right.$ = Absorption bei $412 \mathrm{~nm}, \mathrm{x}=$ Konzentration) und der Absorption der Proteine bei $412 \mathrm{~nm}$ konnte für das aerob behandelte ROXY19 (Absorption: 0,003) eine Konzentration von 0,7 $\mu \mathrm{M}$ reduzierten Cysteinen und für das aus anaerob aufgeschlossenen $E$. coli Zellen gereinigte ROXY19 (Absorption: 0,061) eine Konzentration von 14,2 $\mu \mathrm{M}$ reduzierten Cysteinen berechnet werden. Dies entspricht 2\% reduziertem ROXY19 der aerob behandelten Fraktion und 53\% reduziertem ROXY19 aus anaerob aufgeschlossenen E. coli Zellen. Auch das GRX370 lag als Oligomer vor (Abbildung 3.2B). Der Redoxzustand des GRX370 wurde nicht bestimmt. Ein Vergleich der CD-Spektren von ROXY19 und GRX370 (Anhang 6.10) zeigte eine sehr ähnliche Faltung beider Proteine.

Mit diesen aerob aufgeschlossenen und gereinigten Proteinen wurde zunächst die Affinität von ROXY19 zu GSH bestimmt. Dies geschah mithilfe der MicroScale Thermophorese (MST). Diese relativ neu entwickelte Methode nutzt die Diffusion von Teilchen innerhalb eines Temperaturgradienten (Ludwig-Soret-Effekt) zur Bestimmung der Affinitätsstärke. Das nachfolgende Experiment wurde freundlicherweise von Herrn Dr. Sven Freibert (Philipps Universität Marburg) durchgeführt und ausgewertet. Abbildung 3.2C zeigt die Graphen der Dissoziationskonstanten (KD) für ROXY19 und GRX370 (AT1G77370.1, GrXC3), ein pflanzliches CPYC-Typ Glutaredoxin. Die Dissoziationskonstante ist ein Maß für die Bindungsaffinität eines Komplexes ( $K_{D}$ und Affinität sind umgekehrt verwandt), in diesem Fall, des Glutaredoxin-GSH Komplexes. Der $K_{D}$-Wert bezieht sich auf die Konzentration des GSH die benötigt wird, damit der Komplex stabil gebildet wird. Je niedriger der $\mathrm{K}_{\mathrm{D}}$-Wert und somit auch die Konzentration, desto stärker die Bindung der Komponenten im Komplex. ROXY19 und GRX370 zeigten eine sehr ähnliche Bindungsaffinität zu GSH ( $K_{D}$ Werte von 4,6 $\pm 1,0 \mu \mathrm{M}$ für ROXY19 und 12,6 $\pm 3,6 \mu \mathrm{M}$ für GRX370). Über die Affinität zwischen anderen GRXs und GSH konnten keine publizierten Daten zum Vergleich gefunden werden. MST-Messungen des Strep-MBP Tags, der ROXY19 SSMS Mutante (putatives aktives Zentrum wurde vom CCMC zum SSMS mutiert) und der ROXY19 $\mathrm{G}^{111} \mathrm{~A}$ Mutante (mit einer Mutation in der putativen GSH-Bindestelle), ergaben keine auswertbaren Dissoziationskonstanten für die Affinität (Anhang 6.1). Dies unterstützt die Spezifität der Affinität von ROXY19 zu GSH. 
A

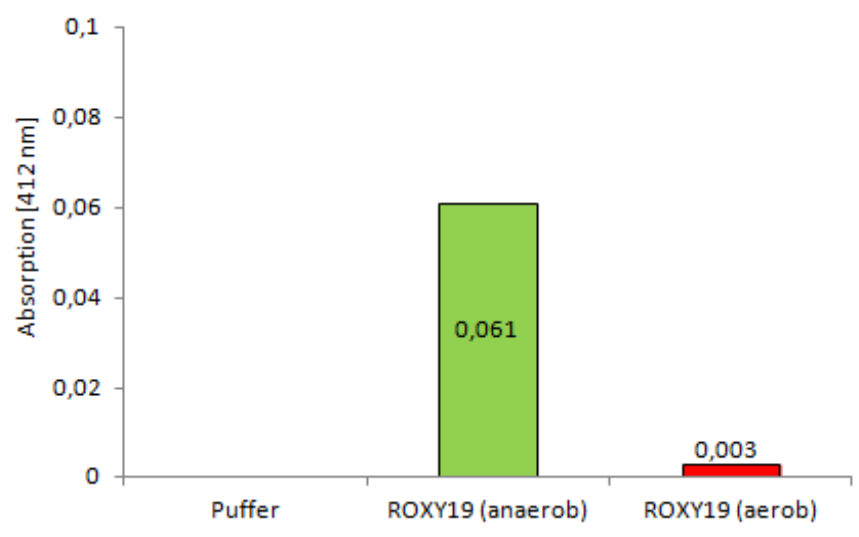

B

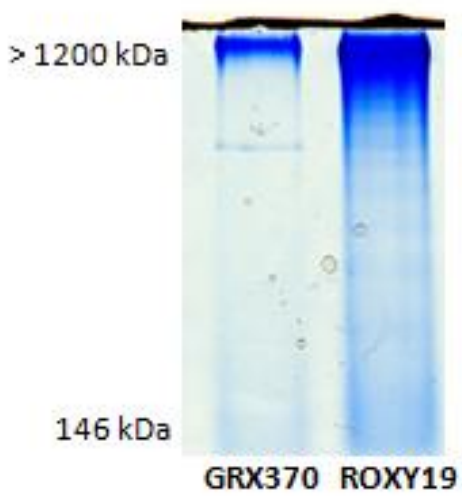

C
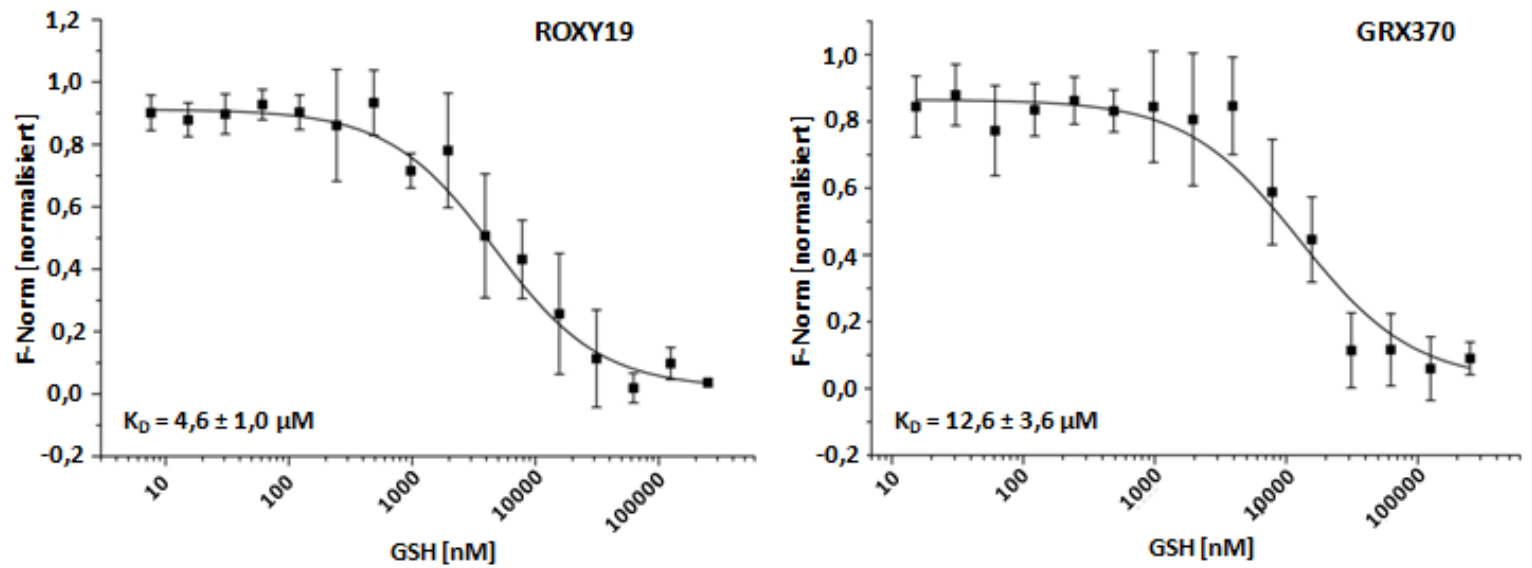

Abbildung 3.2. Affinität von ROXY19 und GRX370 zu GSH. (A) Ellman's Test von ROXY19 aerob behandelt und aus anaerob aufgeschlossenen E. coli Zellen (Peak 2 aus Abbildung 3.4A und B) behandelt. 6,72 $\mu \mathrm{M}$ ROXY19 wurden eingesetzt. Mithilfe einer Standardkurve verschiedener Konzentrationen von Cystein Hydrochlorid Monohydrat wurde die Konzentration reduzierter Cysteine von ROXY19 bei einer Absorption bei $412 \mathrm{~nm}$ bestimmt. ( $\left.y=0,0043 x+0,0051 ; R^{2}=0,9994\right)$ (B) Ausschnitte eines nativen Gels von GRX370 und anaerob behandelten ROXY19 (Peak 2) (je $20 \mu \mathrm{g}$ geladen) nach Coomassie-Färbung. (C) MST-Messungen von Strep-MBPROXY19 und Strep-MBP-GRX370 mit GSH. Gezeigt sind die Graphen der Dissoziationskonstanten ( $\left.K_{D}\right)$ für StrepMBP-ROXY19 $(4,6 \pm 1,0 \mu \mathrm{M})$ und Strep-MBP-GRX370 $(12,6 \pm 3,6 \mu \mathrm{M})$ für die normalisierte Fluoreszenz ( $F_{\text {norm }}=$ $F_{\text {heis }} / F_{\text {kalt }}$ ) gegen die GSH Konzentration. Beide Messreihen wurden dreimal, zu je Triplikaten durchgeführt. Die Messungen und Auswertungen erfolgten durch Herrn Dr. Sven Freibert (Philipps Universität Marburg). 


\subsubsection{ROXY19 zeigt keine enzymatische Aktivität im HED-Assay}

Um die mögliche enzymatische Aktivität eines Glutaredoxins zu prüfen, steht der HED-Assay zur Verfügung. Hierbei wird geprüft, ob das verwendete Glutaredoxin Deglutathionylierung nach dem Monothiol-Mechanismus mithilfe des $\mathrm{N}$-terminalen Cysteins katalysieren kann (Lillig et al., 2008). Für einige CPYC-Typ Glutaredoxine wurde eine enzymatische Aktivität nachgewiesen, z.B. für das PtGRX370 (Couturier et al., 2013). Das Glutaredoxin AtGRX370 (AT1G77370.1, GrxC3) diente im nachfolgenden HED-Assay als positive Kontrolle.

Wie erwartet zeigte AtGRX370 einen Abfall der Absorption bei $340 \mathrm{~nm}$ (Abbildung 3.3, schwarze Kurve), der mit der Reduktion (Deglutathionylierung) des HED und der folglichen Oxidation des NADPH zusammenhängt. ROXY19 hingegen zeigte keinen Abfall der Absorption bei $340 \mathrm{~nm}$ (Abbildung 3.3, blaue Kurve) und besaß somit keine enzymatische Aktivität im HED-Assay. Auch ein Austausch des aktiven Zentrums zum CPYC-Motiv (wie im GRX370 vorhanden) war nicht ausreichend, um ROXY19 eine enzymatische Aktivität im HEDAssay zu verleihen (Abbildung 3.3, grüne Kurve).

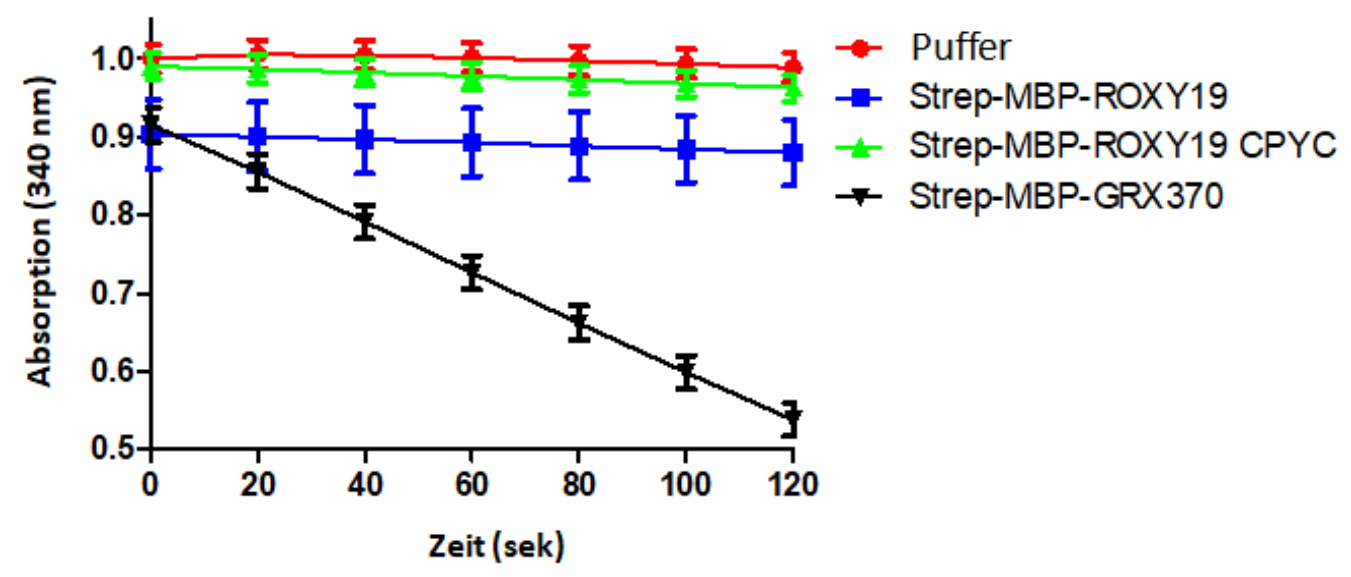

Abbildung 3.3. Aktivitäten von ROXY19, ROXY19 CPYC und GRX370 im HED-Assay. Gezeigt ist die Absorption bei $340 \mathrm{~nm}$ von Strep-MBP-ROXY19, Strep-MBP-ROXY19 CPYC und Strep-MBP-GRX370 im HED-Assay. Die eingesetzte Proteinkonzentration der Glutaredoxine betrug $100 \mathrm{nM}$. Die Aktivität wird angegeben im Abfall der Absorption bei $340 \mathrm{~nm}$ gegen die Zeit (in sek). Die Puffer Kurve (rot) zeigt die spontane Oxidation des NADPH. Bei jeder Messung wurden für jedes Glutaredoxin und den Puffer 5 technische Replikate verwendet. Die Messung wurde dreimal mit ähnlichen Ergebnissen, mit unabhängig voneinander exprimierten Proteinen durchgeführt. Die Ergebnisse waren mit verschiedenen Konzentrationen der Glutaredoxine reproduzierbar. 


\subsubsection{ROXY19 inkorporiert eine Eisen-Schwefel-Spezies}

Aufgrund der fehlenden enzymatischen Aktivität im HED-Assay und braun gefärbter Elutate von ROXY19 (Abbildung 3.4A) wurde eine mögliche Inkorporation von Eisen-SchwefelClustern in ROXY19 untersucht.

Für die nachfolgenden Experimente wurde anaerob gereinigtes ROXY19 (Co-Expression mit TGA2) (mit der Ausrüstung in der Abteilung von Herrn Prof. Dr. Roland Lill, Philipps Universität Marburg) verwendet. Daher variierten die Anzuchtbedingungen der E. coli Zellen (vom Methoden Teil 2.2.4.2). Die Anzucht erfolgte in $5 \mathrm{~L}$ Kolben mit $2 \mathrm{~L}$ LB-Medium und Schüttlern die für $5 \mathrm{~L}$ Kolben ausgelegt sind. Insgesamt wurden $12 \mathrm{~L}$ Kultur für den anaeroben Aufschluss der Zellen und die anaerobe Reinigung über das Strep-Tag mit einen ÄKTA ${ }^{\text {TM }}$ purifier 10/UV-900/Frac-950 verwendet. Die Gesamtausbeute an ROXY19 betrug ca. $100 \mathrm{mg}$. Um eine möglichst hohe Reinheit sicher zu stellen, wurde das gereinigte ROXY19 zusätzlich über eine Gelfiltrationssäule separiert (Abbildung 3.4A und B). Die vier gesammelten Fraktionen wurden getrennt voneinander weiter analysiert.

Peak 1 und 2 beinhalteten Proteine mit höher molekularen Oligomeren mit einer dunkel braunen Farbe und co-gereinigtem TGA2. Dies machte ca. $90 \%$ des Gesamt-Eluates aus (Abbildung 3.4A und B). Der schwach bräunliche Peak 3 hingegen beinhaltete das mögliche ROXY19 Monomer oder Dimer (Bande im nativen Gel bei $146 \mathrm{kDa}$, von hier an als Monomer bezeichnet), wobei co-gereinigtes TGA2 nicht im Western Blot nachweisbar war (Abbildung 3.4A und B). Das Protein des farblosen Peaks 4 zeigte eine Bande im nativen Gel bei $60 \mathrm{kDa}$ und beinhaltete keinen TGA2 und könnte daher abgetrenntes Strep-MBP sein (ca. 43 kDa) (Abbildung 3.4A und B). Im Allgemeinen wurde(n) nur ein bis fünf TGA2 pro 100 ROXY19 cogereinigt (Abbildung 3.4B und Anhang 6.12). Die weiteren Experimente wurden mit ROXY19 aus Peak 2 fortgeführt. Im Vergleich zu dem Monomer war das Oligomer aufgrund der höheren Konzentrationen und der stärker bräunlichen Farbe vielversprechender für EisenSchwefel-Cluster Analysen (Untersuchungen am Monomer erfolgen in einem späteren Abschnitt).

Zunächst wurde zum Nachweis von inkorporiertem Eisen ein UV-VIS-Spektrum gemessen (Abbildung 3.4C). Dieses zeigte, dass gebundenes Eisen in der Probe vorhanden war (Schulter bei $420 \mathrm{~nm}$ ). Eine Schulter bei $420 \mathrm{~nm}$ ist charakteristisch für die Anwesenheit eines 2[Fe-S]-Clusters oder eine Mischung von 2[Fe-S] und linearen [3Fe-4S]-Clustern (Zhang et al., 2013). Jedoch, im Vergleich zur eingesetzten Proteinmenge (1:75 Verdünnung) machte es eine geringe Menge aus, sodass nicht jedes ROXY19 Eisen gebunden haben konnte. Das Verhältnis $(280 \mathrm{~nm} / 420 \mathrm{~nm})$ betrug 20,1. Mithilfe der Extinktionskoeffizienten $(\varepsilon)$ von ROXY19 $\left(\varepsilon_{\text {ROXY } 19}=81000 \mathrm{M}^{-1} \mathrm{~cm}^{-1}\right), 4[\mathrm{Fe}-\mathrm{S}]$-Cluster $\left(\varepsilon_{4[\mathrm{Fe}-\mathrm{S}]}=15000 \mathrm{M}^{-1} \mathrm{~cm}^{-1}\right)$ und 2[Fe-S]-Cluster $\left(\varepsilon_{2[\mathrm{Fe}-}\right.$ $\left.\mathrm{s}]=8000 \mathrm{M}^{-1} \mathrm{~cm}^{-1}\right)$, kann eine mögliche Besetzung von ROXY19 mit dem jeweiligen Cluster berechnet werden. Das Verhältnis $\left(\varepsilon_{\text {Roxy } 19} / \varepsilon_{4[\mathrm{Fe}-\mathrm{S}]}\right)$ beträgt 5,45 und das Verhältnis $\left(\varepsilon_{\text {ROXY19 }} / \varepsilon_{2[\mathrm{Fe}-\mathrm{S}]}\right)$ beträgt 10,23 . Bringt man nun das Verhältnis $(280 \mathrm{~nm} / 420 \mathrm{~nm})(20,1) \mathrm{mit}$ dem Verhältnis $\left(\varepsilon_{\text {ROXY19}} / \varepsilon_{4[\mathrm{Fe}-\mathrm{S}]}\right)(5,45)$ in Verbindung ergibt sich ein Verhältnis ROXY19/Fe/s $_{\text {von }}$ 3,69:1:1 und mit dem Verhältnis $\left(\varepsilon_{\text {ROXY19}} / \varepsilon_{2[\mathrm{Fe}-\mathrm{S}]}\right)(10,23)$ ein Verhältnis ${ }_{\mathrm{ROXY19} / \mathrm{Fe} / \mathrm{s}}$ von 1,96:1:1. Dies bedeutet, bei einem 4[Fe-S]-Cluster wären 16 ROXY19 Moleküle pro Cluster vorhanden. 
Bei einem Dimer das ein 4[Fe-S]-Cluster inkorporiert wären 14 Moleküle unbesetzt (88\%), bzw. bei einem Tetramer 12 Moleküle unbesetzt (75\%). Für das 2[Fe-S]-Cluster wären 4 ROXY19 Moleküle vorhanden, daraus ergibt sich bei einem Dimer, dass 50\% unbesetzt wären und für ein Tetramer 0\% unbesetzte ROXY19 Moleküle.

Um mögliche Hinweise auf die Art des inkorporierten putativen Clusters zu erhalten, wurden CD-Spektren und EPR-Spektren gemessen (Abbildung 3.4D und E). Die CD-Spektren (Abbildung 3.4D) wurden von ROXY19 vor der Gelfiltration (grüne Kurve, Peak 1-4) und nach der Gelfiltration von ROXY19 aus Peak 2 (blaue Kurve) aufgenommen. Allerdings wiesen beide Spektren weder auf ein 2[Fe-S]- noch auf ein 4[Fe-S]-Cluster hin. Dies wird ferner durch das EPR-Spektrum (Abbildung 3.4E) unterstützt. Der geringe g Faktor <2 spricht für kein klassisches [Fe-S]-Signal und lässt zunächst auf ein halbbesetztes d-Orbital schließen. Dies kann bei degradierten [3Fe-4S]-Clustern oder ähnlichem vorkommen. Zudem ergab das EPR-Spektrum ein potentielles Häm Signal bei einem g-Faktor von 2,3-2,4 und ein Signal von freiem Fe (III) (g-Faktor von 4-5) (Messungen und Auswertungen der EPR Spektren erfolgten durch Herrn Dr. Sven Freibert (Philipps Universität Marburg)).

Da wahrscheinlich nicht alle ROXY19 Glutaredoxine mit einem potentiellen Cluster beladen waren (Abbildung 3.4C) und in E. coli Eisen unspezifisch eingebaut werden könnte, wurde versucht eine Rekonstitution durchzuführen. Dabei wird zunächst das potentielle Cluster durch DTT verdrängt. Anschließend wird versucht ein Cluster mithilfe einer Eisen- und Schwefelquelle wieder einzubauen. Bei der hier verwendeten Methode wurde auf den enzymatischen Einbau eines Clusters durch IscS oder ähnliche Enzyme verzichtet, da bei Eisen- und Schwefelüberschuss IscS und andere Enzyme unspezifisch Cluster einbauen können. Dies bedeutet für die hier angewendete Methode, dass der Einbau eines Clusters von den Eigenschaften des ROXY19 [Fe-S]-Cluster zu binden abhängt. Wie das CD-Spektrum zeigte (Abbildung 3.4D, schwarze Kurve), konnte kein [Fe-S]-Cluster für ROXY19 rekonstituiert werden und auch die inkorporierte Eisen-Spezies vor und nach der Gelfiltration wurde nicht wieder eingebaut. Welche Eisen-Spezies vom ROXY19 gebunden wird bleibt somit zum jetzigen Zeitpunkt unklar. Jedoch ließ sich durch MS-Analysen zeigen, dass kein GSH (oder GSSG) in den analysierten Proben vorhanden war (Anhang 6.2). Die Bindung der Eisen-Spezies erfolgte daher GSH-unabhängig. Die Anwesenheit von Schwefel wurde mithilfe der Methylenblau-Methode nach Kirsten und Patel (1972) überprüft. Es konnten 0,38 Schwefelatome pro ROXY19 nachgewiesen werden (Abbildung 3.4F). Diese ergaben sich aus einer Absorption von 0,121 (bei $667 \mathrm{~nm}$ ). Über die Standardkurve des $\mathrm{Na}_{2} \mathrm{~S}$ ( $y=0,00603 x-0,00211 ; R^{2}=0,99896 ; y=$ Absorption bei $667 n m, x=$ Konzentration) ergaben sich 20,1 $\mu \mathrm{M}$ Schwefelatome in $200 \mu \mathrm{L}$. In den $20 \mu \mathrm{L}$ der Probe waren dementsprechend 201 $\mu \mathrm{M}$ Schwefelatome. Auf die $530 \mu \mathrm{M}$ ROXY19 bezogen ergab sich das Verhältnis 1:0,38. Da die Besetzung von ROXY19 mit Clustern unbekannt ist, kann aus dieser Information kein Clustertyp berechnet werden. 
A
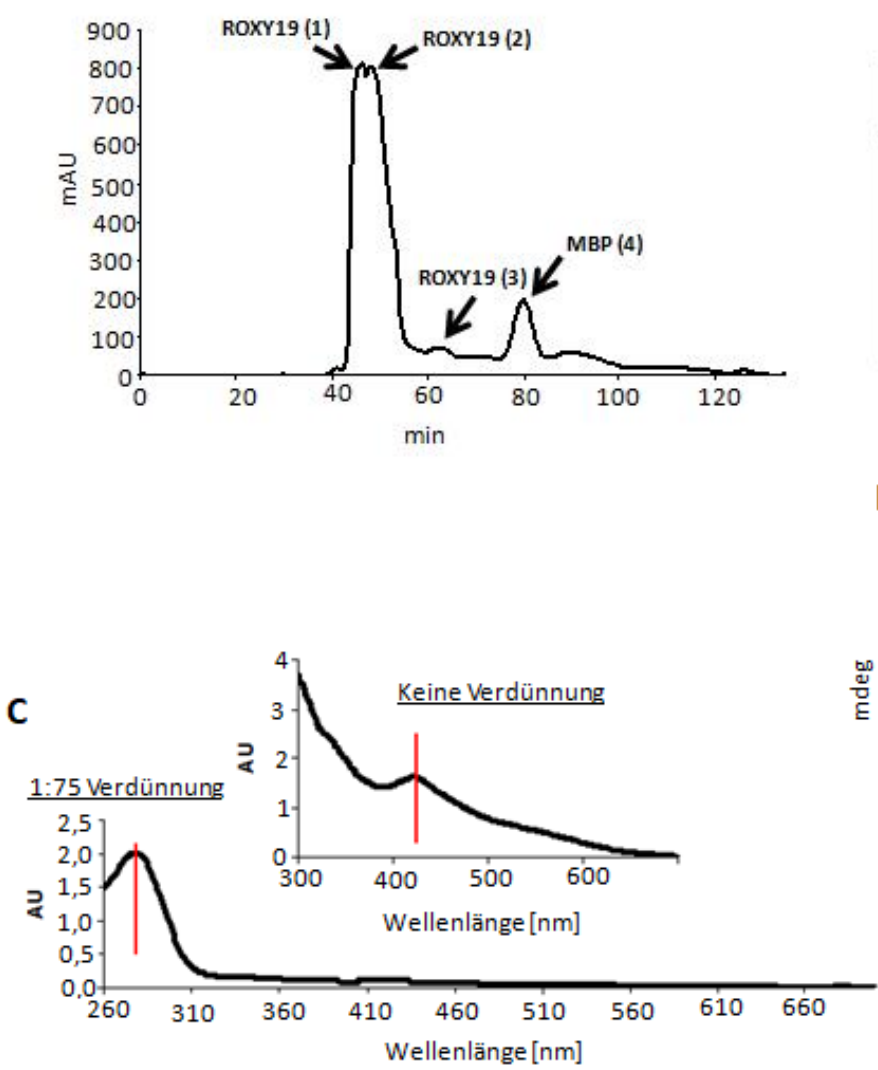

E

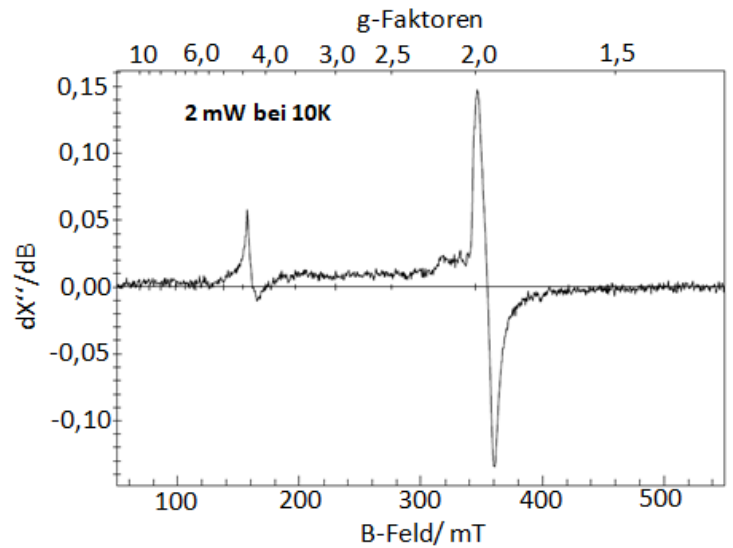

F

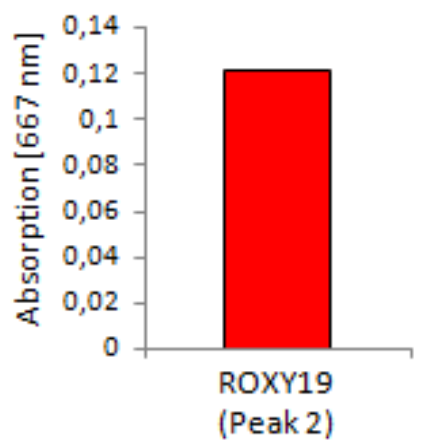

B

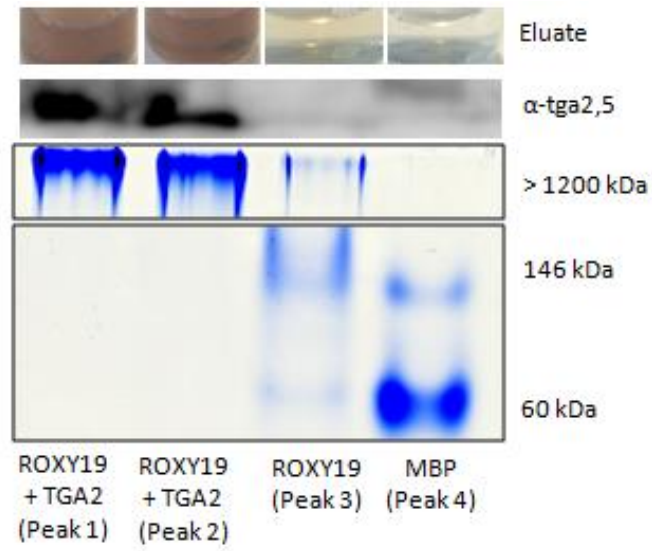

D
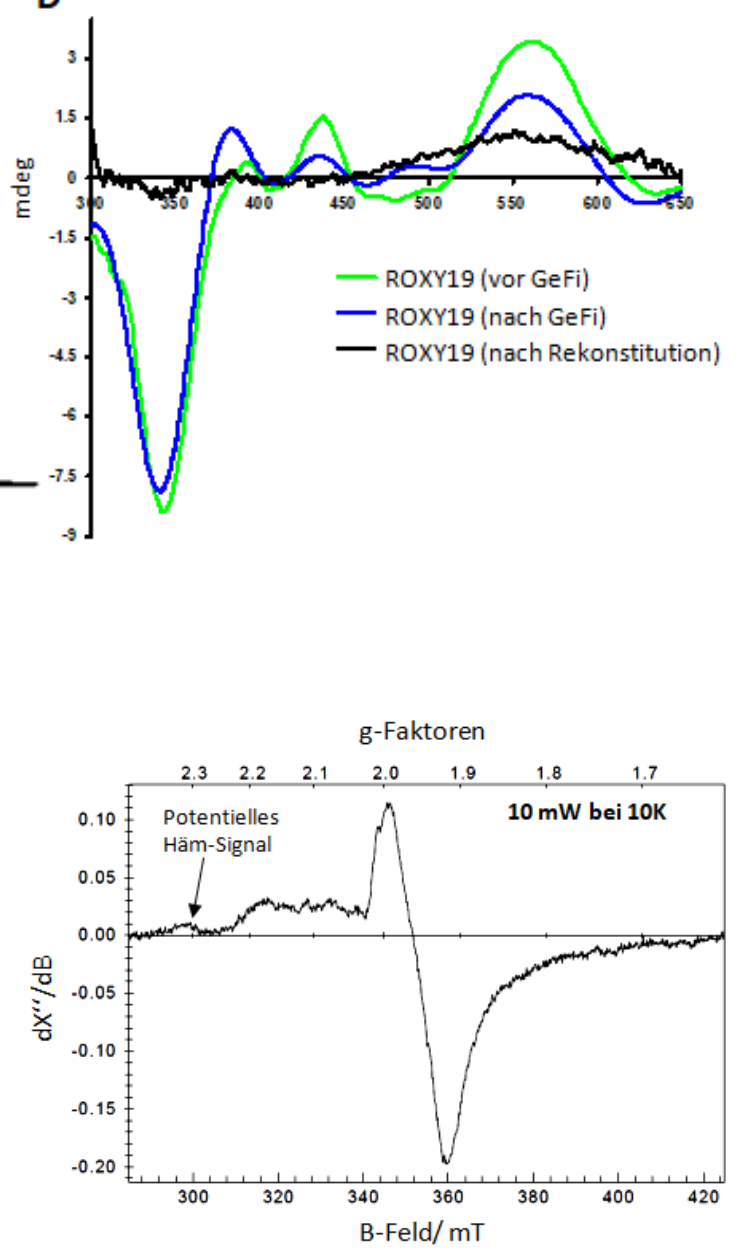
Abbildung 3.4. Eisen-Schwefel-Cluster Analysen für ROXY19. (A) Gelfiltration einer anaeroben Reinigung von ROXY19 (Co-Expression mit TGA2) die die vier verwendeten Peaks zeigt. (B) Oben: Fotos der Elutate einer anaeroben Reinigung von ROXY19 (Co-Expression mit TGA2) nach einer Gelfiltration (Peaks 1-4 aus (A)); Mitte: Western Blot Analyse der Peaks 1-4 auf die Anwesenheit von TGA2. Der Nachweis erfolgte durch einen spezifisch gegen TGA2 und TGA5 gerichteten Antikörper ( $\alpha$-tga2,5). Es wurden 500 ng Protein aus jedem Peak geladen; Unten: Ausschnitte eines nativen Gels der Peaks 1-4 (je $20 \mu \mathrm{g}$ geladen) nach Coomassie-Färbung. (C) UV-VIS-Spektrum des ROXY19 aus Peaks 2 (aus (B)); Oben: Spektrum der unverdünnten Fraktion zur Bestimmung der Eisenkonzentration; Unten: Spektrum einer 1:75 Verdünnung zur Bestimmung der Proteinkonzentration. (D) CD-Spektren von ROXY19 vor der Gelfiltration (Peak 1-4), ROXY19 nach der Gelfiltration (Peak 2) und ROXY19 nach der Rekonstitution (Peak 2). (E) EPR Spektren von ROXY19 (Peak 2) mit $2 \mathrm{~mW}$ bei $10 \mathrm{~K}$ (links) und mit $10 \mathrm{~mW}$ bei $10 \mathrm{~K}$ (rechts). Die Messungen und Auswertung der EPR-Spektren erfolgten durch Herrn Dr. Sven Freibert (Philipps Universität Marburg). AU = relative Absorptionseinheiten. (F) Schwefelbestimmung nach Kirsten und Patel (1972). Es wurden $20 \mu \mathrm{L}$ ROXY19 (530 $\mu \mathrm{M})$ mit $90 \mu \mathrm{L} 20 \mathrm{mM} \mathrm{N}, \mathrm{N}-$ Dimethyl-p-phenylendianinsulfat (in 7,2 M HCl) und $90 \mu \mathrm{L} 30 \mathrm{mM} \mathrm{FeCl}_{3}$ (in 1,2 M HCl) gemischt. Nach 10 min Inkubation wurde die Absorption bei $667 \mathrm{~nm}$ gemessen. Die Konzentration des enthaltenen Schwefel konnte über eine Standardkurve verschiedener Konzentrationen von $\mathrm{Na}_{2} \mathrm{~S}$ berechnet werden. $(y=0,00603 x-0,00211$; $\left.\mathrm{R}^{2}=0,99896\right)$

\subsubsection{Oligomerbildung von ROXY19 in Abhängigkeit des Redoxzustandes}

Wie Abbildungen 3.4A und B zeigten, bildete ROXY19 hochmolekulare Oligomere und nur ein kleiner Anteil lag als mögliches Monomer vor. Die Frage stellt sich, ob das Oligomer oder das Monomer die biologisch aktive Form ist. Sollte das Oligomer die aktive Form sein, könnten Redoxeigenschaften des ROXY19 ein möglicher Mechanismus für die Oligomerisierung sein. Dieser könnte abhängig von den Cysteinen des ROXY19 oder der Zielproteine (z.B. TGA2) sein.

ROXY19 besitzt vier Cysteine (drei davon im putativen aktiven Zentrum), wodurch die Ausbildung von intermolekularen Disulfidbrücken zwischen mehreren ROXY19 Monomeren eine Möglichkeit zur Oligomerisierung bietet. Um diese Hypothese zu überprüfen, wurde ROXY19 (Peak 2) mit verschiedenen reduzierenden Reagenzien behandelt und der Oligomerisierungszustand mittels einer Gelelektrophorese unter nicht-denaturierenden Bedingungen überprüft. Eine einstündige Behandlung mit $100 \mathrm{mM}$ DTT zeigte eine teilweise Monomerisierung des Oligomers (Abbildung 3.5A). Andere reduzierende Reagenzien, wie 1 M $\beta$-Mercaptoethanol (Abbildung 3.5A) oder $100 \mathrm{mM}$ TCEP (nicht gezeigt, da präzipitiert) zeigten keinen Effekt auf das ROXY19 Oligomer. So scheint der Oligomerisierungszustand nur teilweise vom Redoxzustand des ROXY19 abhängig zu sein. Auffällig war die Bande bei 146 kDa für ein mögliches Monomer. Um sicher zu stellen, dass es sich bei dieser Bande um das Monomer handelt wurde ROXY19 vollständig denaturiert (6 M Harnstoff) (Abbildung 3.5B). Über eine Dialyse (Slide-A-Lyzer MINI Dialysis Devices, 3.5K MWCO, Sigma) wurde ROXY19 schrittweise renaturiert, dabei waren verschiedene Stufen der Oligomerisierung sichtbar (Dimer, Tetramer, etc) (in Abbildung 3.5B gekennzeichnet). Um die spontane Oligomerisierung zu verhindern, wurden 100 mM DTT dem Dialysepuffer beigemischt. Diese Präventionsmaßnahme erzielte jedoch nur einen Teilerfolg (Abbildung 3.5B) und der Anteil an Monomer war nur geringfügig höher als die DTT-Behandlung in Abbildung 3.5A. Nach der Anreicherung von ROXY19 durch eine Ankonzentrierung (Vivaspin ${ }^{\circledR} 2$, 3K MWCO, GE Healthcare) veränderte sich das Verhältnis zwischen Monomer und Oligomer nicht. 
A

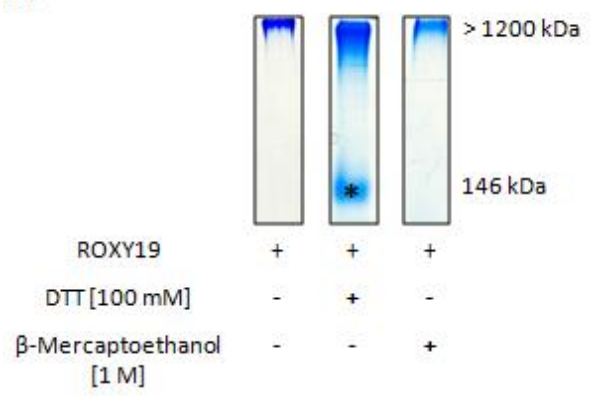

B

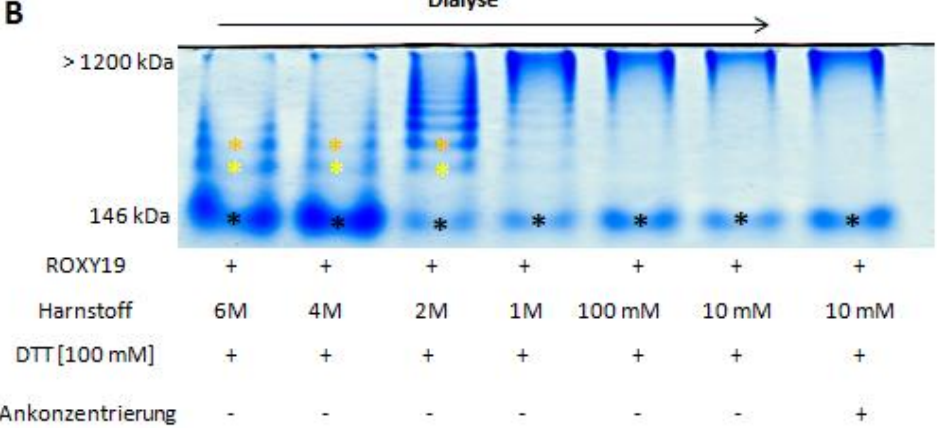

Abbildung 3.5. Das ROXY19 Monomer zeigt eine Bande bei $146 \mathrm{kDa}$ in nativen Gelen. (A) Ausschnitte eines nativen Gels von ROXY19 (co-exprimiert mit TGA2) behandelt mit DTT oder $\beta$-Mercaptoethanol (je $20 \mu \mathrm{g}$ geladen) nach Coomassie-Färbung. (B) Natives Gel von ROXY19 behandelt mit 6 M Harnstoff (je $20 \mu \mathrm{g}$ geladen) und den einzelnen Dialyse Schritten nach Coomassie-Färbung. Das Monomer ist mit einem schwarzen Stern, das Dimer mit einem gelben Stern und das Tetramer mit einem orangenen Stern gekennzeichnet.

Um zu überprüfen, ob die Oligomerisierung durch das ungewöhnliche CCMC Motiv im aktiven Zentrum hervorgerufen wird, wurden die einzelnen Cysteine (SCMC, CSMC, CCMS und SSMS), sowie das direkt darauf folgende konservierte Histidin (CCMCA) und das putative aktive Zentrum zum Klasse I GRX (CPYC) Motiv mutiert und in E. coli exprimiert. Zusätzlich wurde der Einfluss des einzigen Cysteins von TGA2 (welcher nur in der Oligomerfraktion nachweisbar war (Abbildung 3.4B)) in Abhängigkeit zum putativen aktiven Zentrum des ROXY19 geprüft. In der TGA2 Cys Mutante (TGA2 Cys) wurde das Cystein durch ein Serin ausgetauscht. Abbildungen 3.6A und $\mathrm{B}$ zeigen die ROXY19 Mutanten jeweils co-exprimiert mit TGA2 bzw. der TGA2 Cystein Mutante. Hier fällt auf, dass eine Mutation des putativen aktiven Zentrums, vom CCMC zum CPYC in einer Anreicherung des möglichen Monomers resultiert, unabhängig davon, welche Variante des TGA2 co-exprimiert wurde. Die SCMC Mutante liegt co-exprimiert mit TGA2 exklusiv als Oligomer vor, wohingegen co-exprimiert mit TGA2 Cys das Monomer und eine weitere Bande bei 60 kDa vorhanden waren. Die CSMC und CCMS Mutanten zeigten unabhängig vom TGA2 mehr Monomer als der Wildtyp, der Großteil lag aber weiterhin als Oligomer vor. Das mutierte CCMCA Motiv zeigte nur eine sehr geringe Anreicherung des Monomers (unabhängig vom TGA2). Die SSMS Mutante wies eine starke Anreicherung des Monomers, co-exprimiert mit TGA2 auf und eine wesentlich schwächere mit TGA2 Cys auf. Allerdings wurde die Co-Expression mit TGA2 Cys nur einmal durchgeführt. Zur Bestätigung der vorliegenden Ergebnisse sind weitere Wiederholungen erforderlich.

Analytische Gelfiltrationsläufe (die Messungen der Gelfiltrationsläufe erfolgten durch Herrn Dr. Sven Freibert (Philipps Universität Marburg) mit einer Shodex PROTEIN KW-802.5 (E206015) Säule der einzelnen Mutanten (10 $\mu \mathrm{g}$ in einem Volumen von $20 \mu \mathrm{L}$, in $50 \mathrm{mM}$ Tris pH 8, $200 \mathrm{mM} \mathrm{NaCl}, 10 \mathrm{mM}$ DTT) (co-exprimiert mit TGA2) bestätigten die Anwesenheit des Monomers (Abbildung 3.6C). Zudem wies die CSMC Mutante ein mögliches Hexamer und die CPYC Mutante ein mögliches Oktamer auf, die im nativen Gel nicht zu sehen waren. Die Daten für die CCMCA Mutante widersprachen sich mit denen des nativen Gels, in dem fast ausschließlich das Oligomer zu sehen war, zeigte der Gelfiltrationslauf, dass fast 
ausschließlich Monomer vorhanden war. Nimmt man alle Ergebnisse bezüglich der Mutanten des putativen Zentrums zusammen, lässt sich sagen, dass der Oligomerisierungszustand stark von der Sequenz im putativen aktiven Zentrum abhing. Jedoch konnten in keinem Fall einheitliche Fraktionen gewonnen werden.
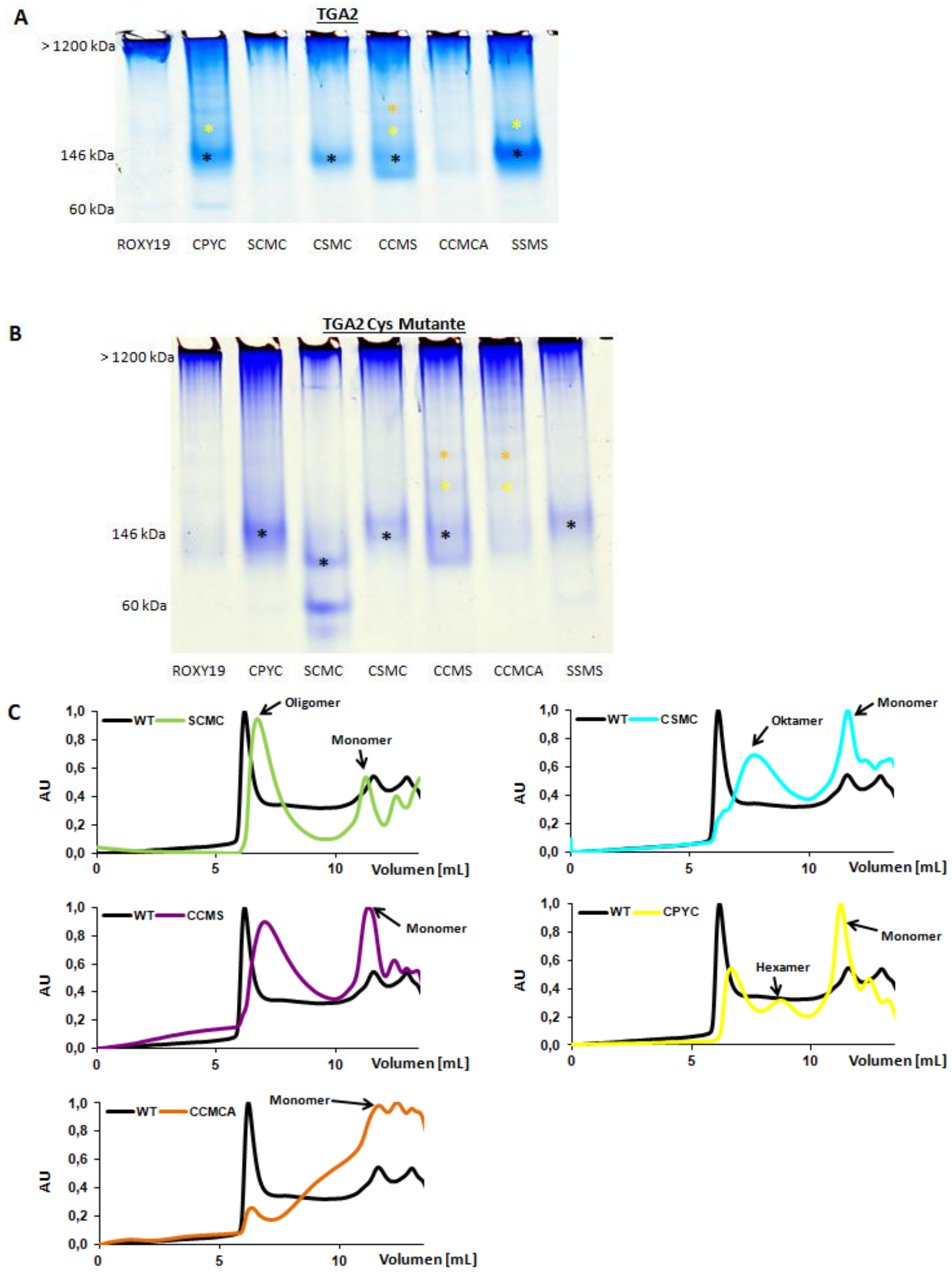
Abbildung 3.6. Abhängigkeit der Oligomerisierung vom putativen aktiven Zentrum des ROXY19 (A) Natives Gel von ROXY19 Mutanten co-exprimiert mit TGA2 (je $20 \mu \mathrm{g}$ geladen) nach Coomassie-Färbung. (B) Natives Gel von ROXY19 Mutanten co-exprimiert mit TGA2 Cys (je $20 \mu \mathrm{g}$ geladen) nach Coomassie-Färbung. (C) Gelfiltrationsläufe von ROXY19 Mutanten verglichen mit dem Wildtyp Protein (die Gelfiltrationsläufe erfolgten durch Herrn Dr. Sven Freibert (Philipps Universität Marburg) mit einer Shodex PROTEIN KW-802.5 (E206015) Säule, MWCO: 150000 Da). Das Monomer ist mit einem schwarzen Stern, das Dimer mit einem gelben Stern und das Tetramer mit einem orangenen Stern gekennzeichnet.

\subsubsection{Monomerisierung von ROXY19}

Da die Oligomerisierung nur partiell vom Redoxzustand der Cysteine abhing, wurden im nachfolgenden Experiment mögliche optimale Pufferbedingungen und Additive getestet, die ebenfalls eine essentielle Rolle bei der Oligomerisierung spielen könnten. Hierfür wurden die von Hampton Research zur Verfügung gestellten Screens verwendet (Solubility \& Stability Screen I und II, sowie der Additive Screen). Die vorgefertigten Bedingungen wurden nach Herstellerangaben mit ROXY19 gemischt und in Kapillaren überführt, um die Löslichkeit (Oligomerisierung) und Stabilität mithilfe des Monolith NT.115 (NanoTemper Technologies) anhand des Verhältnis der Fluoreszenz Absorptionen (350 nm / $330 \mathrm{~nm}$ ) bei steigenden Temperaturen $\left(20^{\circ} \mathrm{C}-95^{\circ} \mathrm{C}\right) \mathrm{zu}$ bestimmen.

Die gemessene interne Fluoreszenz des Strep-MBP-ROXY19 wird vor allem durch die Stabilität beeinflusst. Ein denaturiertes Protein hat eine andere interne Fluoreszenz als ein gefaltetes. Auch die Löslichkeit spielt eine Rolle, da ein Präzipitat andere Eigenschaften besitzt als ein vollständig gelöstes Protein. Daher zeigen sich gute Bedingungen in einer Kurve mit größerer Steigung oder größerem Abfall mit einem Wendepunkt bei höheren Temperaturen.

Diese Tests ergaben, dass vor allem verschiedene Arten von Zuckern fördernd für die Löslichkeit und Stabilität von ROXY19 waren (Abbildung 3.7A, Anhang 6.3). Die Proteinstabilität ist das Netto-Gleichgewicht der Kräfte, die bestimmen, ob ein Protein seine native gefaltete Konformation oder ein denaturierter (entfalteter oder ausgedehnter) Zustand sein wird. Glukose zeigte einen positiven Effekt auf die Löslichkeit und Stabilität von ROXY19, da die Kurve einen größeren Abfall bei einer hohen Temperatur aufzeigte $\left(65^{\circ} \mathrm{C}\right)$, wohingegen D-Sorbitol nur einen schwachen Abfall zeigte und daher keinen Effekt auf die Löslichkeit und Stabilität hatte (Abbildung 3.7A).

Eine gute Löslichkeit und Stabilität von ROXY19 zeigten folgende Zucker: $750 \mathrm{mM}$ D-(+)Trehalose-Dihydrat $\left(62^{\circ} \mathrm{C}\right), 2 \mathrm{M}$ Saccharose $\left(69^{\circ} \mathrm{C}\right), 2 \mathrm{M}$ Methyl $\alpha$-D-Glucopyranosid $\left(63^{\circ} \mathrm{C}\right)$, $30 \%(\mathrm{w} / \mathrm{v})$ D- $(+)$-Glukose-Monohydrat $\left(65^{\circ} \mathrm{C}\right), 30 \%(\mathrm{w} / \mathrm{v})$ Saccharose $\left(60^{\circ} \mathrm{C}\right), 30 \%(\mathrm{w} / \mathrm{v})$ Trehalose-Dihydrat $\left(62^{\circ} \mathrm{C}\right), 100 \mathrm{mM}$ 6-O- $\alpha$-D-Maltosyl- $\beta$-Cyclodextrin $\left(64^{\circ} \mathrm{C}\right), 10 \mathrm{mM}(2-$ Hydroxylpropyl)- $\beta$-Cyclodextrin $\left(56^{\circ} \mathrm{C}\right), 80 \mathrm{mM} \alpha$-Cyclodextrin $\left(64^{\circ} \mathrm{C}\right), 10 \mathrm{mM} \beta$-Cyclodextrin $\left(64^{\circ} \mathrm{C}\right)$ und $50 \mathrm{mM}$ Methyl- $\beta$-Cyclodextrin $\left(53^{\circ} \mathrm{C}\right)$.

Neben diesen Zuckern waren folgende Bedingungen ebenfalls für die Löslichkeit und Stabilität von ROXY19 fördernd: $500 \mathrm{mM}$ L-Argininamid-Dihydrochlorid $\left(45^{\circ} \mathrm{C}\right), 200 \mathrm{mM} \mathrm{MES}$ Monohydrat mit $2 \mathrm{M} \mathrm{NaCl} \mathrm{pH} \mathrm{6,0}\left(58^{\circ} \mathrm{C}\right), 200 \mathrm{mM}$ MES-Monohydrat mit $4 \mathrm{M} \mathrm{NaCl} \mathrm{pH} \mathrm{6,0}$ $\left(45^{\circ} \mathrm{C}\right)$, BIS-TRIS Propan mit $4 \mathrm{M} \mathrm{NaCl} \mathrm{pH} \mathrm{8,5}\left(49^{\circ} \mathrm{C}\right), 3 \mathrm{M} \mathrm{NDSB}-195\left(58^{\circ} \mathrm{C}\right), 5 \%(\mathrm{w} / \mathrm{v}) \mathrm{n}$ - 
Dodecyl- $\beta$-D-Maltosid $\left(43^{\circ} \mathrm{C}\right), 30 \%(\mathrm{w} / \mathrm{v})$ Trimethylamin N-Oxid Dihydrat $\left(61^{\circ} \mathrm{C}\right)$ und $30 \%$ (w/v) 1,5-Diaminopentan Dihydrochlorid $\left(47^{\circ} \mathrm{C}\right)$ (Anhang 6.3).

Die in den Screens gefundenen Bedingungen ergaben bei einer nachträglichen Behandlung von $20 \mu \mathrm{g}$ ROXY19 nur eine Mischung aus Monomer und Oligomer (Abbildung 3.7B).

Daher wurde auf eine erneute Harnstoffbehandlung (Abbildung 3.5B) zurückgegriffen. Eine Trennung der beiden Fraktionen (Monomer und Oligomer) über eine Säule (Vivaspin ${ }^{\circledR} 2$, 100K MWCO, GE Healthcare) verblieb erfolglos (nicht gezeigt). Deswegen wurden die beiden Fraktionen über ein FPLC System (ÄKTA ${ }^{\mathrm{TM}}$ purifier 10/UV-900/Frac-950 (GE Healthcare)) mit einer Superdex 200 10/300 GL (GE Healthcare) voneinander getrennt. Dabei fiel auf, dass die Proteine sowohl nach der Dialyse als auch ohne Dialyse an der Säule zu einem Großteil oligomerisierten. Das verbliebene Protein konnte in eine Monomer- und Oligomer- Fraktion separiert werden (Abbildung 3.7C). Mit der Monomer-Fraktion wurde erneut eine [Fe-S]-Cluster Rekonstitution durchgeführt. Aber auch in das Monomer konnte kein Eisen-Schwefel-Cluster während der Rekonstitution eingebaut werden (Abbildung 3.7D).

A

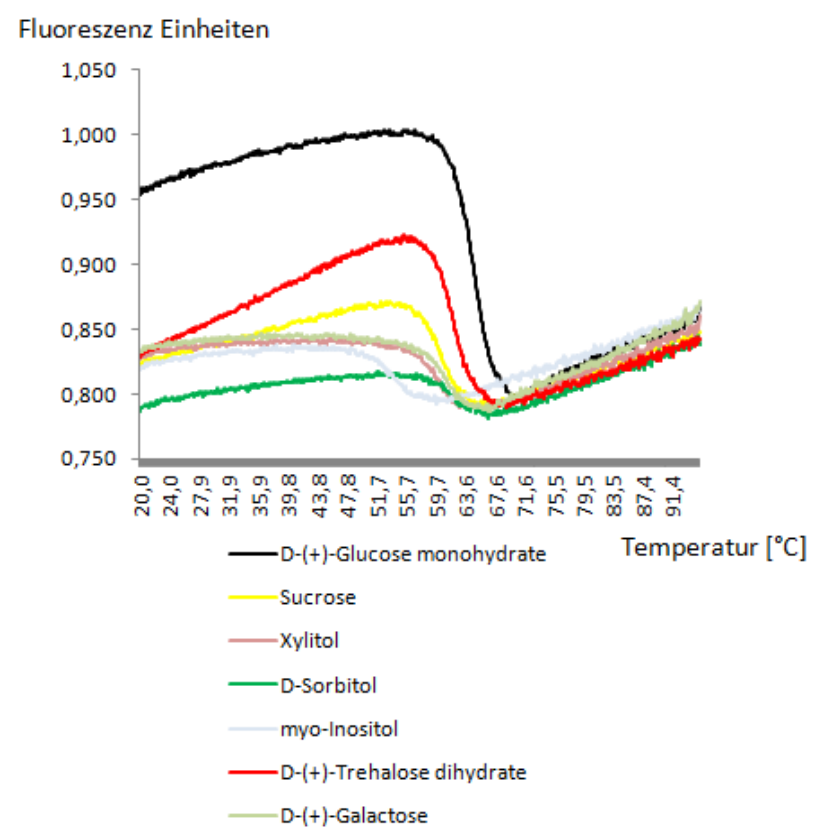

Fluoreszenz Einheiten

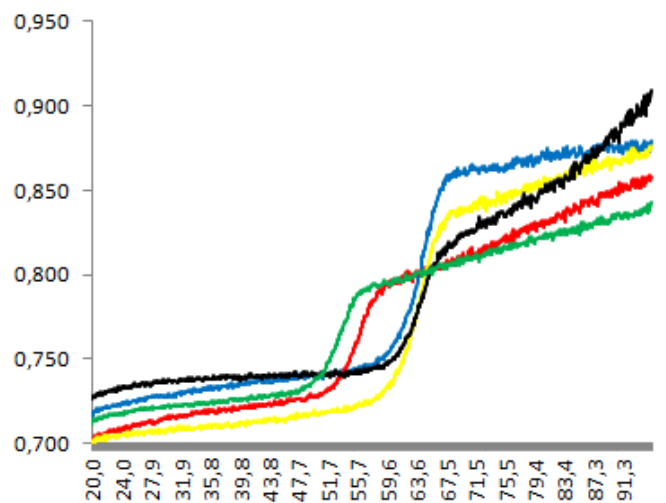

(1)

6-O- $\alpha$-D-Maltosyl- $\beta$-cyclodextrin

- (2-Hydroxypropyl)-B-cyclodextrin

$\alpha$-Cyclodextrin

B-Cyclodextrin

Methyl- $\beta$-cyclodextrin

B

$>1200 \mathrm{kDa}$

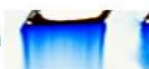

mant
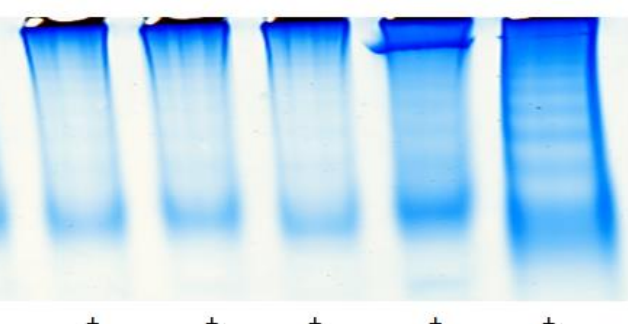

ROXY19

Additiv

В-Сус $\quad \beta$-Сус

Glu

Sac

Man Mani Arg 


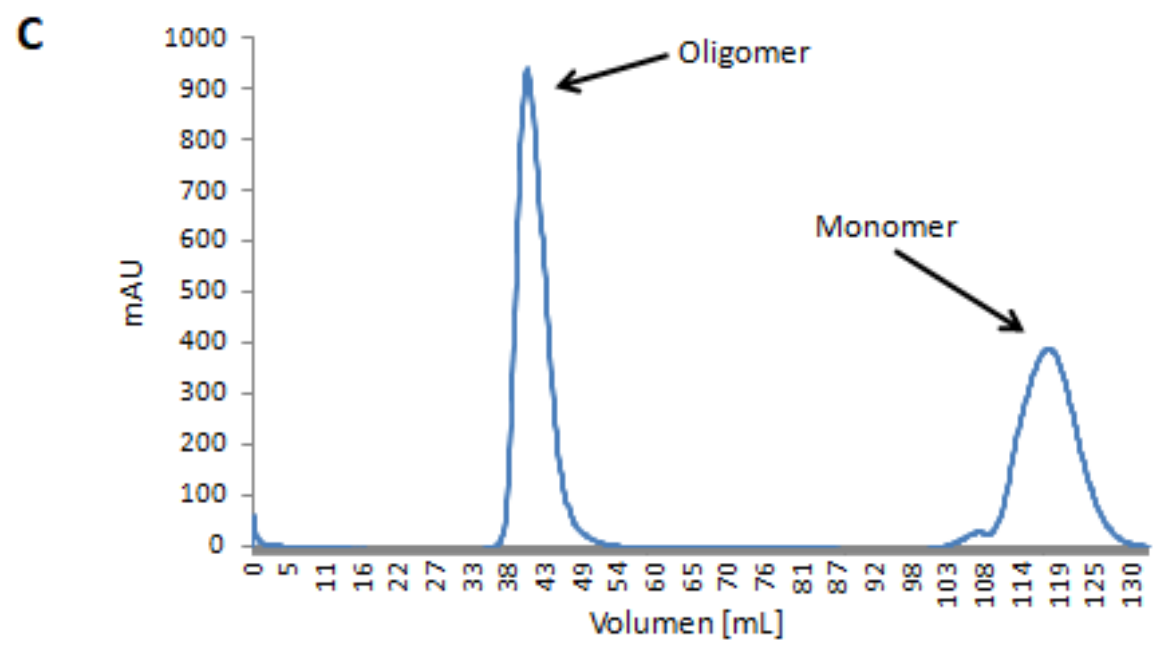

D

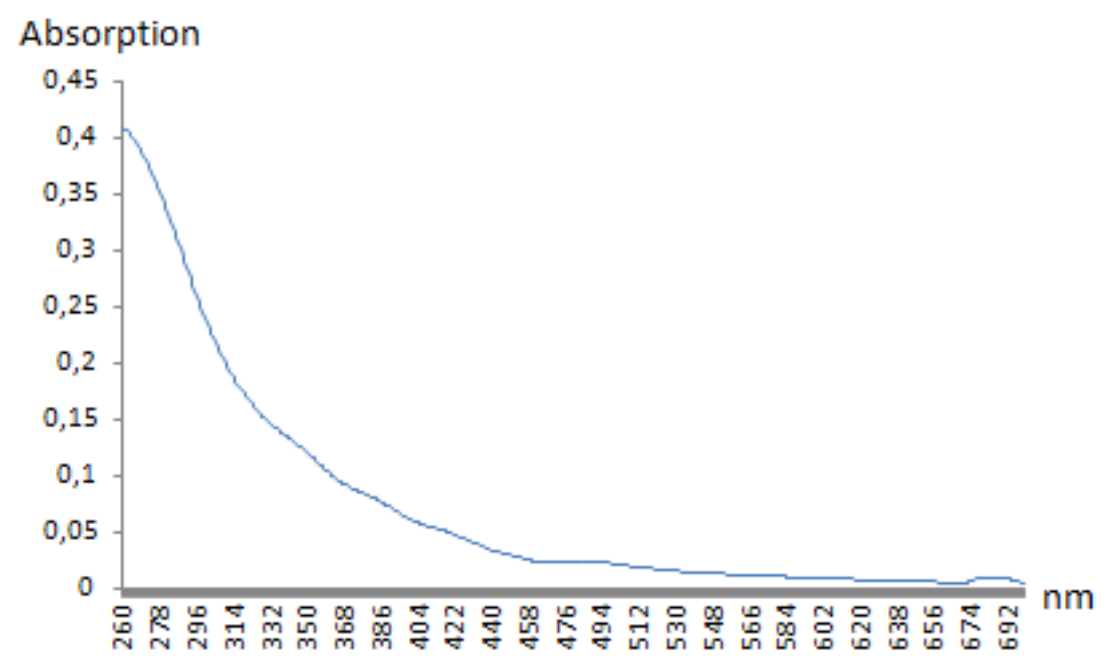

Abbildung 3.7. Monomerisierung von ROXY19. (A) Ausgewählte Bedingungen des Solubility \& Stability Screen (Hampton Research) der Fluoreszenz Einheiten von ROXY19 (Absorption bei $350 \mathrm{~nm} / 330 \mathrm{~nm}$ ) gegen die Temperatur aufgetragen. (B) Natives Gel von anaerob aufgeschlossenem ROXY19, behandelt mit verschiedenen Zuckern und Arginin (je $20 \mu \mathrm{g}$ geladen) nach Coomassie-Färbung. ROXY19 in Spur 2 wurde im Aufschluss-, Wasch- und Elutionspuffer mit $10 \mathrm{mM} \quad \beta$-Cyclodextrin ( $\beta$-Cyc) behandelt, wohingegen alle weiteren Behandlungen nachträglich für 1 Stunde bei RT erfolgten mit $10 \mathrm{mM} \beta$-Cyclodextrin ( $\beta$-Cyc), 30\% Glukose (Glu), 30\% Saccharose (Sac), 0,5 M Mannose (Man), 10\% Mannitol (Mani) und 0,5 M Arginin (Arg). (C) Gelfiltration von $6 \mathrm{M}$ Harnstoff behandeltem ROXY19 über ein FPLC System (ÄKTA ${ }^{\mathrm{TM}}$ purifier 10/UV-900/Frac-950) mit einer Superdex 200 10/300 GL. (D) UV-Vis Spektrum der Monomerfraktion aus (C) nach der Rekonstitution. 


\subsubsection{Einfluss von ROXY19 auf die Bindeeigenschaften von TGA2 an das as-1 Element}

Ob ROXY19 einen Einfluss auf das DNA-Bindeverhalten von TGA2 hat, wurde mit den nachfolgenden Experimenten untersucht. Um das Bindeverhalten von Transkriptionsfaktoren an der DNA zu untersuchen, wurde im Rahmen dieser Arbeit der EMSA mit einem radioaktiv markierten as-1 Element verwendet. Die Methode basiert auf einer Veränderung der Mobilität des radioaktiv markierten DNA Fragmentes in der Gelelektrophorese. In den folgenden Experimenten wurde ein radioaktiv markiertes as-1 Promoter Fragment $\left(a s-1^{*}\right)$ von 88 bp Länge, welches zwei TGA2 Bindemotive (TGACG) beinhaltet, verwendet. TGA2 bindet sein Bindemotiv als Dimer, dementsprechend können vier TGA2 pro $a s-1 *$ binden. Je nachdem ob eine (einfache Besetzung, gelber Pfeil in Abbildung 3.8, Spur 3) oder beide (doppelte Besetzung, roter Pfeil in Abbildung 3.8, Spur 3) Bindestellen von TGA2 besetzt wurden, ergibt sich eine niedrigere (eine) oder höhere (beide) Veränderung der Mobilität in der Gelelektrophorese des as-1* im EMSA.

Für TGA2 wurde ein Gesamtzellextrakt aus E. coli Zellen, die TGA2 (ohne Tag) exprimieren verwendet. Abbildung 3.8 zeigt, dass der $E$. coli TGA2 Extrakt eine Veränderung der Mobilität in der Gelelektrophorese des as-1* bewirkte (Spuren 2-6) (TGA2-as-1* Komplex). Ein Extrakt aus $E$. coli Zellen, die mit dem Vektor $\mathrm{pET3B}$ transformiert worden waren verursachte keine Veränderung der Mobilität in der Gelelektrophorese des as-1* (Abbildung 3.8, Spuren 7 und 8). Die Spuren des PET3B Extraktes zeigten zudem die Wirkung von DNasen. In der 1:2 Verdünnung (Spur7) wurde das as-1* durch die DNasen abgebaut. Eine 1:10 Verdünnung (Spur 8) war ausreichend die Menge an DNasen soweit herabzusetzen, dass dieser Abbau nicht mehr geschah.

Die Verdünnungen der TGA2 Extrakte zeigten, dass in der 1:10 (Spur 2) und 1:30 (Spur 3) Verdünnung as-1* fast ausschließlich in der doppelten Besetzung von TGA2 gebunden wurde und kein freies as-1* mehr detektierbar war. Dies bedeutet, dass ein Überschuss an TGA2 vorhanden war. Dieser Überschuss geht mit weiteren Verdünnungen verloren (1:100 (Spur 4) und 1:300 (Spur 5)), da freies $a s-1^{*}$ wieder detektierbar wurde und die einfache Besetzung favorisiert wurde. In der 1:1000 (Spur 6) Verdünnung war TGA2 fast nicht mehr nachweisbar. Für weitere Experimente mit TGA2 wurde eine 1:20 Verdünnung gewählt. 


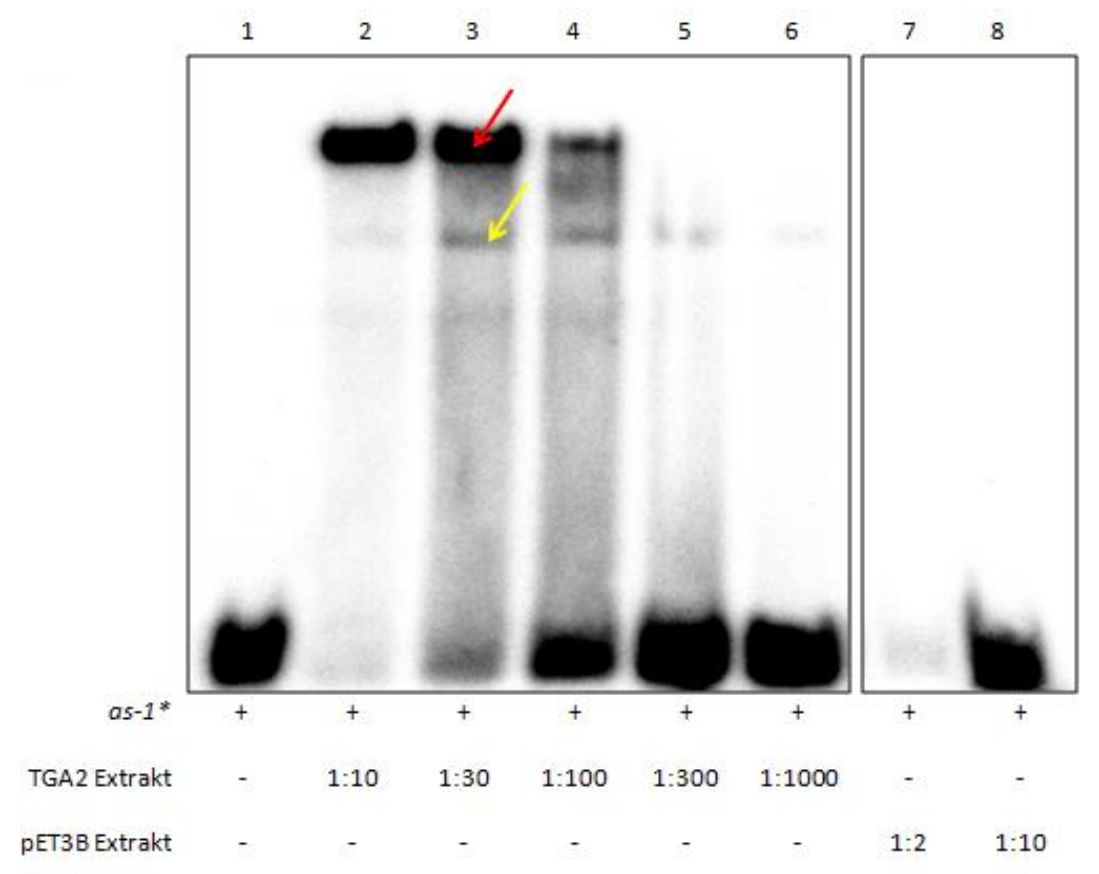

\begin{abstract}
Abbildung 3.8. Einfluss von TGA2 auf as-1*. EMSA mit radioaktiv markiertem as-1 Element von Gesamtzellextrakten von E. coli Expressionen von TGA2 (pAC28-TGA2) oder einem Leervektor (pET3B), in verschiedenen Verdünnungen, inkubiert mit dem radioaktiv markiertem 88 bp as-1 element (as-1*) Der rote Pfeil gibt die Position der doppelten Besetzung und der gelbe Pfeil der einfachen Besetzung des as-1* mit TGA2 Dimeren an.
\end{abstract}

Durch die Zugabe von ROXY19, welches mit TGA2 interagieren kann (Ndamukong et al., 2007), sollte eine weitere Veränderung der Mobilität des TGA2-as-1* Komplexes in der Gelelektrophorese stattfinden (Supershift). In Abhängigkeit, ob das Monomer oder Oligomer bindet, sollte diese Veränderung der Mobilität des TGA2-as-1* Komplexes in der Gelelektrophorese bei einer Interaktion mit TGA2 unterschiedlich ausfallen. Hierfür wurden das ROXY19 Oligomer (Peak 2) und Monomer (Peak 3) (aus Abbildung 3.4A und B) untersucht. Da in der ROXY19 Monomer-Fraktion (Peak 3) kein TGA2 vorhanden war, wurde zusätzlich TGA2 Extrakt zur Probe gegeben. Zum ROXY19 Oligomer (Peak 2) mit vorhandenem TGA2 (Abbildung 3.4B) wurde auf die Zugabe von weiterem TGA2 verzichtet. Abbildung 3.9 zeigt, dass das Monomer und Oligomer dieselbe Veränderung der Mobilität des TGA2-as-1* Komplex in der Gelelektrophorese verursachten (Spuren 4 und 6). Dieser Effekt ist somit unabhängig vom Oligomerisierungszustand des ROXY19. Allerdings kann aufgrund der hohen Sensitivität des EMSA nicht ausgeschlossen werden, dass geringe Mengen des Monomers in der Oligomer-Fraktion vorhanden waren oder entstanden sind, die die Veränderung der Mobilität des TGA2-as-1*-Komplexes in der Gelelektrophorese hervorgerufen haben. Die Abbildung zeigt zudem, dass GSH keinen Einfluss auf die Veränderung der Mobilität des ROXY19-TGA2-as-1* Komplexes in der Gelelektrophorese hatte. 


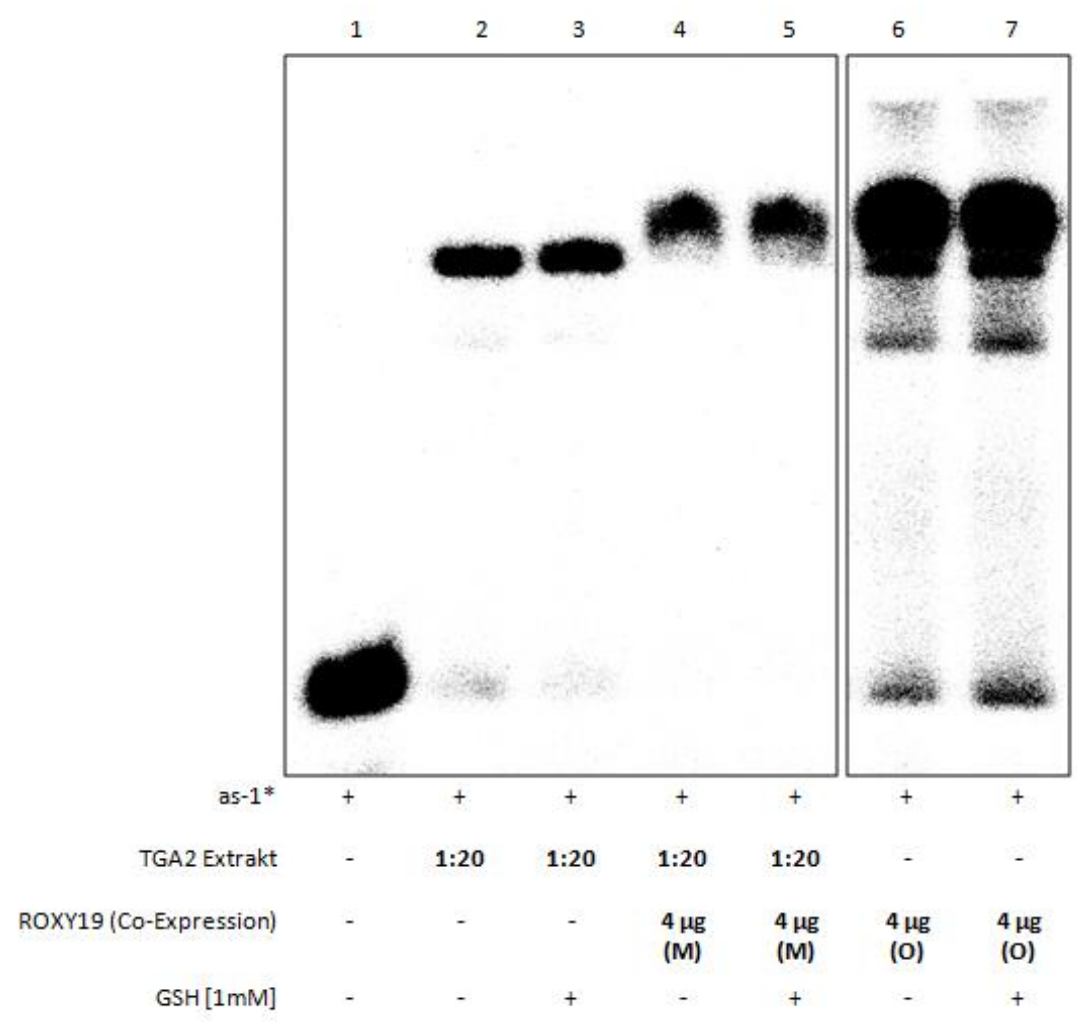

Abbildung 3.9. Einfluss des ROXY19 Oligomer und Monomer auf den TGA2-as-1* Komplex. EMSA mit radioaktiv markiertem as-1 Element von Gesamtzellextrakten von E. coli Expressionen von TGA2 (pAC28-TGA2) (1:20 Verdünnung) mit aus $E$. coli anaerob gereinigtem ROXY19 (co-exprimiert mit TGA2), inkubiert mit dem radioaktiv markiertem 88 bp as-1 element (as-1*). Es wurden je $4 \mu \mathrm{g}$ des Monomers (M, Peak 3 aus Abbildung 3.4) oder des Oligomers (O, Peak 2 aus Abbildung 3.4) eingesetzt jeweils mit und ohne $1 \mathrm{mM} \mathrm{GSH.}$

Um die Aktivität des ROXY19 zu bestimmen, muss das Verhältnis zwischen ROXY19 und dem TGA2-as-1* Komplex berechnet werden. Für die Menge an as-1* lässt sich grob berechnen, dass $15 \mu \mathrm{g}$ Plasmid (ca. 5000 bp) verdaut wurden, wovon das 88 bp Fragment 270 ng (1,8\%) ausmacht. Für die Markierung wurden 1/5 (54 ng) eingesetzt. Geht man davon aus, dass durch die Gelelution 50\% verloren wurden, sind $27 \mathrm{ng}$ vorhanden. 88 bp haben eine molekulare Masse von 57.200 Da. Daraus ergibt sich eine Konzentration von 62 pMol as-1*, bei $4 \mu \mathrm{L}$ in jeder Probe aus einer Gelelution von $500 \mu \mathrm{L}$, wären dies 500 femtoMol die in jeder Spur eingesetzt wurden. Aufgrund der eingesetzten Mengen von ROXY19 (4 $\mu \mathrm{g}, 224$ nMol) und des TGA2-as-1* Komplexes (500 femtoMol), lässt sich sagen, dass ein 450.000facher Überschuss an ROXY19 vorhanden war.

Das gereinigte ROXY19 war jedoch nicht verdünnbar (Anhang 6.5). Daher wurden Experimente mit nicht radioaktiv markiertem as-1 Element (kaltes Fragment) durchgeführt um zu klären wie aktiv das gereinigte ROXY19 tatsächlich war. Dieses kalte Fragment war ca. 200 bp lang und besaß zehn TGA2 Bindemotive (TGACG). Dieses wurde durch eine PCR (Template: pTTL GUS as-1; Primer: uni24 und \#27GUS ocg42) mit anschließender Reinigung gewonnen.

Verdünnungsexperimente mit dem kalten Fragment (Abbildung 3.10, Anhang 6.4) zeigten, dass bei einer Zugabe von einem 3750x Überschuss des kalten Fragmentes, genug TGA2 im 
ROXY19 Eluat vorhanden war, um an das radioaktiv markierte as-1* zu binden (Abbildung 3.10). Zudem war die Veränderung der Mobilität des TGA2-as-1* Komplexes durch ROXY19 noch bei einem 3750x Überschuss zu sehen, hier wäre der ROXY19 Überschuss im Vergleich zum TGA2-as-1* Komplex nur noch 120:1. Dies entspricht fast dem Verhältnis an Überschuss von ROXY19 zum co-gereinigten TGA2 (1-5 pro 100 ROXY19, Anhang 6.12). Allerdings zeigten nicht alle TGA2-as-1* Komplexe die Veränderung der Mobilität in der Gelelektrophorese. Hieraus lässt sich über den Anteil der TGA2-as-1* Komplexe die eine Veränderung der Mobilität in der Gelelektrophorese zeigten schließen, dass ca. $50 \%$ der $4 \mu \mathrm{g}$ ROXY19 inaktiv waren. Dies bedeutet bei einem 3750x Überschuss, dass nur jedes 240. ROXY19 aktiv ist $(0,4 \%)$.

Auffällig war, dass in höheren Überschüssen als der 1500x Überschuss an kaltem as-1 Fragment das gereinigte ROXY19 und der TGA2 Extrakt begrenzend wurden (sichtbar in der abnehmenden Bandenintensität). Somit wäre bei einem 1500x Überschuss nur jedes 600 . ROXY19 aktiv (0,2\%).
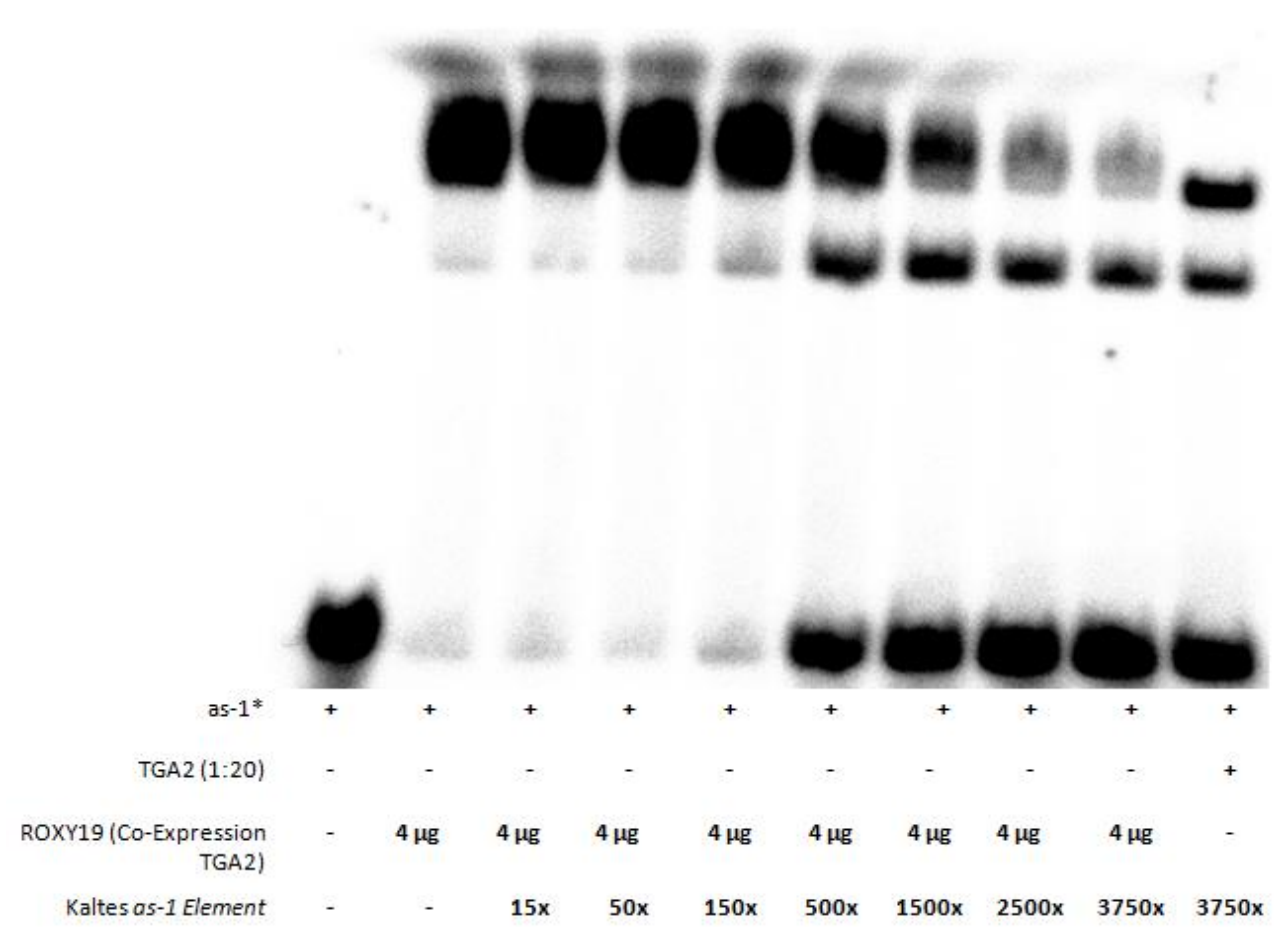

nhang 6.10. Einfluss von nicht radioaktiv markiertem as-1 Element auf die durch ROXY19 verursachte Veränderung der Mobilität des TGA2-as-1* Komplex. EMSA mit radioaktiv markiertem as-1 Element von einem anaerob aufgeschlossenem ROXY19 Eluat co-exprimiert mit TGA2 (pAC28-TGA2) (4 $\mu$ g) gemischt mit nicht radioaktiv markiertem (kaltes) as-1 Element in verschiedenen Konzentrationen. Anschließend wurden die Proben mit dem radioaktiv markiertem 88 bp as-1 element (as-1*) inkubiert.

Desweiteren ist die Veränderung der Mobilität des TGA2-as-1* Komplexes in der Gelelektrophorese durch ROXY19 abhängig von der Art des Zellaufschlusses des ROXY19. Nur ROXY19, welches aus Zellen die unter Stickstoffatmosphäre aufgeschlossen wurden gereinigt wurde, verursachte die Veränderung der Mobilität des TGA2-as-1* Komplexes in der Gelelektrophorese, wohingegen gereinigter ROXY19 aus Zellen die an der Luft 
aufgeschlossenen wurden keinen Effekt auf den TGA2-as-1* Komplex zeigte (Abbildung 3.11A, Spuren 5 und 4). Es gab keinen Unterschied der Veränderung der Mobilität des TGA2as-1* Komplexes in der Gelelektrophorese zwischen ROXY19, welches anaerob aufgeschlossen, gereinigt und gelagert wurde (Peak 2 und 3) (Abbildung 3.9) und ROXY19, welches aus anaerob aufgeschlossenen $E$. coli Zellen aerob gereinigt und anschließend gelagert wurde (Abbildung 3.11A).

Eine Western-Blot Analyse der Menge an TGA2, der mit ROXY19 co-gereinigt wurde und der eingesetzten Menge an TGA2 in der 1:20 Verdünnung (Abbildung 3.11B) ergab, dass in der 1:20 TGA2 Verdünnung mehr TGA2 vorhanden war als in den ROXY19 Fraktionen. Daraus ergab sich, dass die 1:20 TGA2 Kontrollspuren nicht vergleichbar waren mit Spuren zu denen kein zusätzlicher TGA2 gegeben wurde. Durch eine Verdünnungsreihe des TGA2 Extraktes konnte eine 1:160 Verdünnung als vergleichbare Menge für den TGA2 der mit ROXY19 cogereinigt wurde bestimmt werden (Abbildung 3.11B).

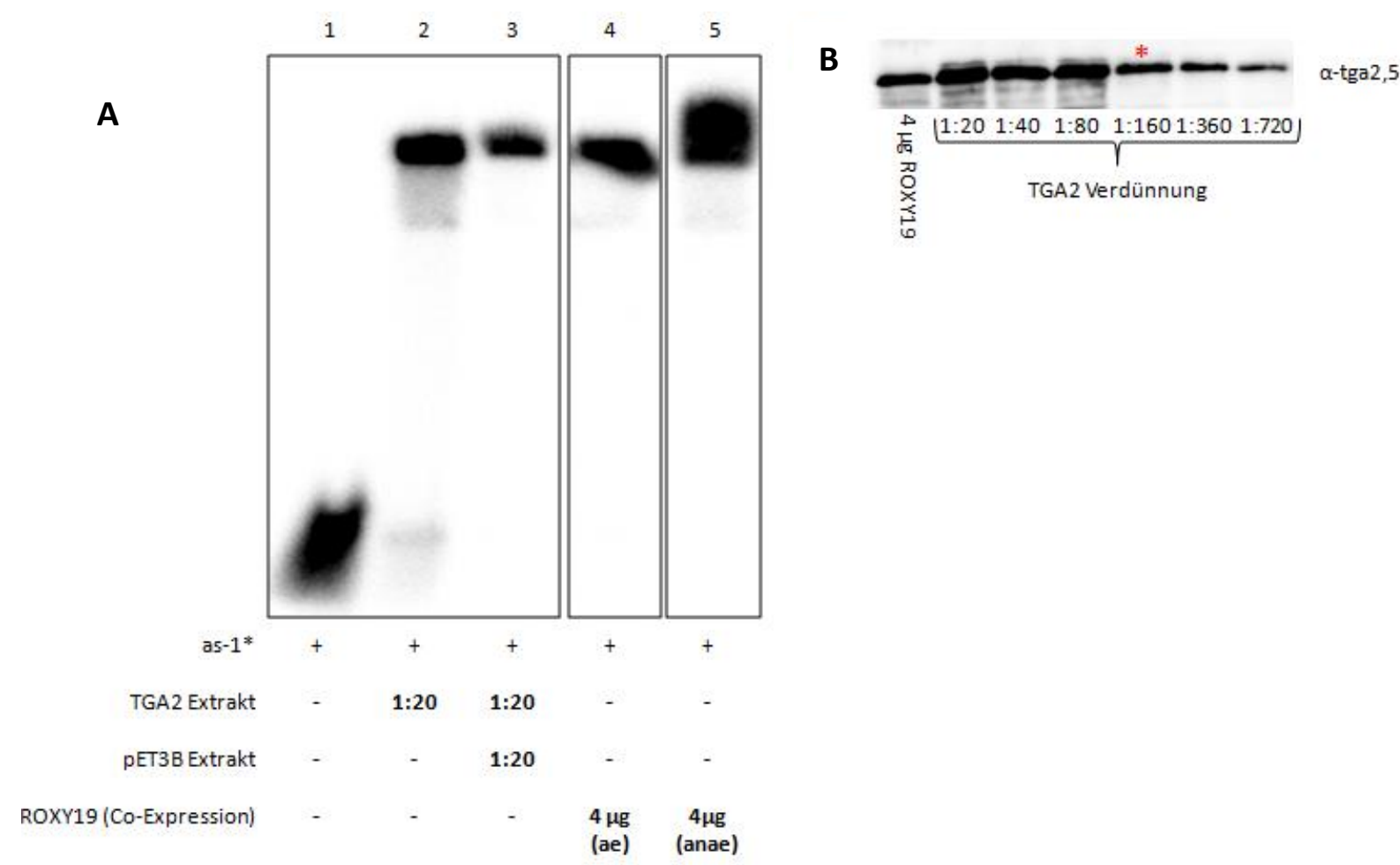

Abbildung 3.11. Einfluss von aerob und anaerob gereinigtem ROXY19 auf den TGA2-as-1* Komplex. (A) EMSA mit radioaktiv markiertem as-1 Element von Gesamtzellextrakten von E. coli Expressionen von TGA2 (pAC28TGA2) (1:20 Verdünnung) mit aus E. coli anaerob oder aerob aufgeschlossenem, gereinigtem ROXY19 (coexprimiert mit TGA2) oder dem 1:20 verdünntem Gesamtzellextrakt des Leervektors (pET3B), inkubiert mit dem radioaktiv markiertem 88 bp as-1 element (as-1*). Es wurden je $4 \mu \mathrm{g}$ von aerob (ae) oder anaerob (anae) aufgeschlossenem ROXY19 eingesetzt. (B) Western Blot Analyse auf die Anwesenheit von TGA2 in der CoExpression mit ROXY19 und verschiedenen Verdünnungen der Gesamtzellextrakte von E. coli von TGA2 (pAC28TGA2). Der Nachweis erfolgte durch einen spezifisch gegen TGA2 und TGA5 gerichteten Antikörper ( $\alpha$-tga2,5). Der * markiert die für spätere Experimente gewählte Verdünnung die der Menge an TGA2 in der Co-Expression entspricht. 
Um definierte Bedingungen zu schaffen, wurde nachfolgend gereinigtes ROXY19 mit TGA2 Extrakt (1:160) gemischt. Das nachfolgende Experiment mit der 1:160 Verdünnung des TGA2, zeigte keine Veränderung der Mobilität des as-1* in der Gelelektrophorese (Abbildung 3.12, Spur 2). Die Kombination von ROXY19 gemischt mit TGA2 (Abbildung 3.12, Spur 2) bildete den TGA2-as-1* Komplex und zeigte eine geringe weitere Veränderung der Mobilität des TGA2-as-1* Komplexes (Supershift) in der Gelelektrophorese durch ROXY19 wie in Abbildung 3.9 und 3.11A.

Dieses Ergebnis spricht für eine Verstärkung der Bindung des TGA2 an das as-1* durch ROXY19, da der TGA2-as-1* Komplex nur durch Zugabe von ROXY19 sichtbar wird. Um diese Eigenschaft des ROXY19 näher zu charakterisieren, wurden die Mutanten des putativen aktiven Zentrums (SCMC, CSMC, CCMS, CCMCA, CPYC und SSMS) ebenfalls auf den beobachteten Effekt untersucht. Abbildung 3.12 zeigt die Ergebnisse dieses Experimentes. Das Wildtyp Protein ROXY19 verstärkte die Bindung von TGA2 an das as-1* (Spur 3). Die CPYC Mutante (Spur 4) hingegen zeigte eine eindeutige Veränderung der Mobilität des TGA2-as-1* Komplex in der Gelelektrophorese in eine distinkte obere Bande (Supershift). Alle weiteren Mutanten (Spuren 5-9) zeigten die Verstärkung der Bindung von TGA2 an das as-1* (Variation in den einzelnen Experimenten von schwacher bis starker Bindung für die einzelnen Mutanten, wie z.B. CSMC). Auch ein anderes getestetes ROXY, das ROXY9 (Spur 10), zeigte die Verstärkung der Bindung von TGA2 an das as-1*. Anhang 6.4 zeigt, dass die Verstärkung der Bindung von TGA2 an das as-1* durch ROXY19 auch bei einem 1500x Überschuss des kalten Fragmentes möglich war. Da die Verstärkung ohne kaltes Fragment nur etwa $5 x$ höher als mit kaltem Fragment ausfiel, lässt sich hieraus schließen, dass mehr aktives ROXY19 vorhanden war, als die Experimente ohne kaltes Fragment vermuten ließen. Der beobachtete Effekt der Verstärkung der Bindung von TGA2 an das as-1* wurde ebenfalls für das GRX370 beobachtet (Anhang 6.6), jedoch nicht für BSA und Strep-MBP-GFP (Anhang 6.7).

Abschließend wurde gezeigt, dass Eisen $\left(\mathrm{Fe}^{2+}\right.$ und $\mathrm{Fe}^{3+}$ ) keinen Einfluss auf die Verstärkung der Bindung von TGA2 an das as-1* hat (Anhang 6.8). 


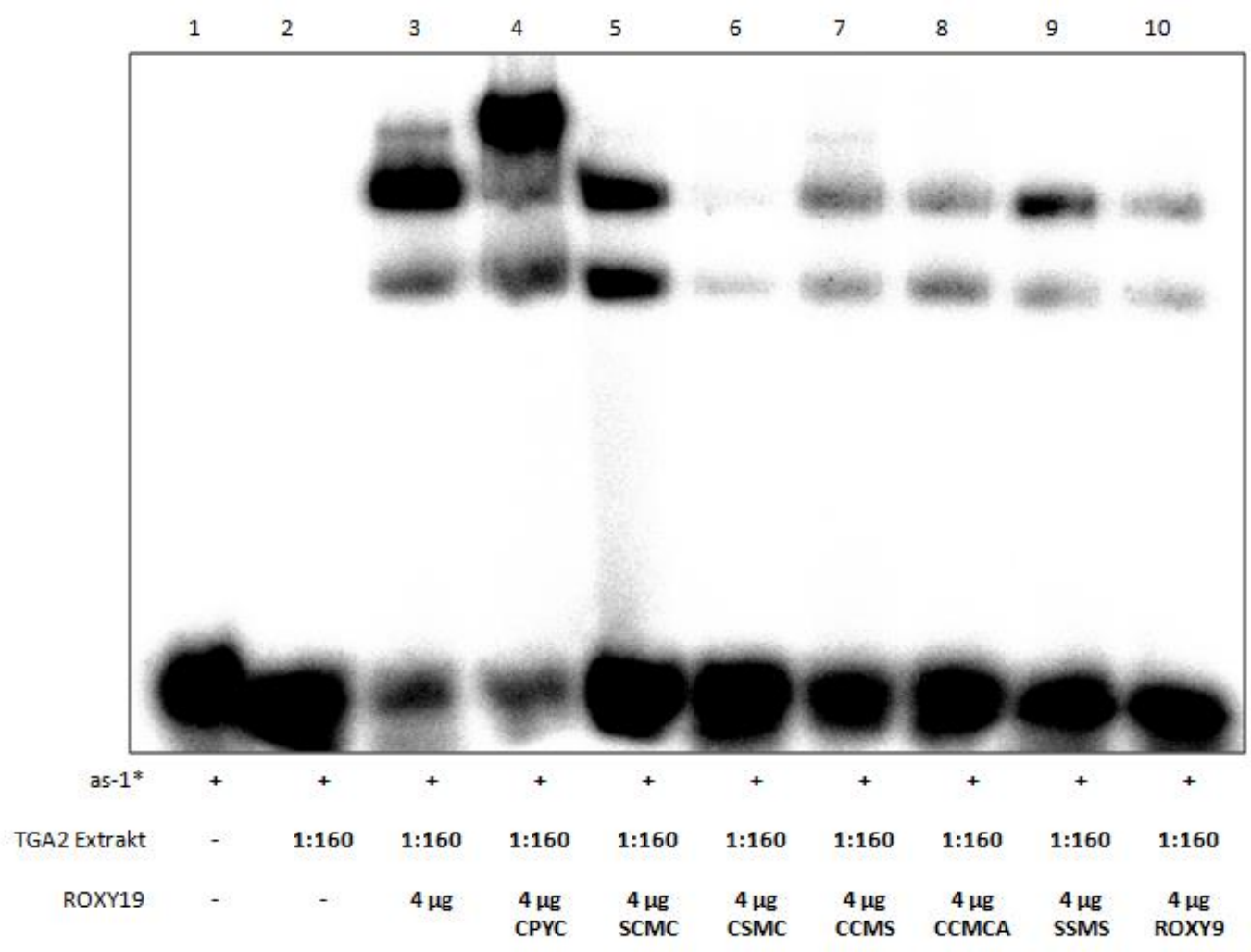

Abbildung 3.12. Einfluss des aktiven Zentrums von ROXY19 auf die Verstärkung der Bindung von TGA2 an das as-1*. (E) EMSA mit radioaktiv markiertem as-1 Element von Gesamtzellextrakten von E. coli Expressionen von TGA2 (pAC28-TGA2) (1:160 Verdünnung) mit aus E. coli anaerob gereinigtem ROXY19 (und ROXY19 Mutanten des putativen aktiven Zentrums), inkubiert mit dem radioaktiv markiertem 88 bp as-1 element (as-1*). Es wurden je $4 \mu \mathrm{g}$ von ROXY19 und den ROXY19 Mutanten eingesetzt. Der Expressionsvektor pGP172-MBP-ROXY9 wurde freundlicherweise von Katrin Treffon zur Verfügung gestellt. 


\subsection{Analyse des CC-Typ Glutaredoxins ROXY19 in planta}

Der zweite Teil dieser Arbeit behandelt die für ROXY19 in planta beschriebenen Funktionen und Phänotypen in Abhängigkeit zum putativen aktiven Zentrum.

\subsubsection{ROXY19 reprimiert Entgiftungsgene}

Die konstitutive Expression von ROXY19 unter dem starken CaMV 35 S Promotor in $A$. thaliana führte zu einem im Vergleich zum Wildtyp schlechteren Wachstum auf MS Platten, die das Xenobiotikum TIBA enthielten (Huang et al., 2016). Dies konnte auf die Repression von TIBA-induzierten Genen, die am Entgiftungsweg beteiligt sind, zurückgeführt werden (z.B. CYP81D11, OPR2) (Huang et al., 2016). Dabei wurde gezeigt, dass die Repression dieser Gene vom putativen aktiven Zentrum des ROXY19 abhängig ist (eine Mutante, bei der die drei Cysteine des putativen aktiven Zentrums zu Serinen ausgetauscht wurden (CCMC zu SSMS) zeigte die Repression und den sensitiven Wachstumsphänotypen nicht mehr) (Huang et al., 2016). Um den zugrunde liegenden Mechanismus aufzuklären, ist es zunächst wichtig das oder die beteiligte(n) Cystein(e) zu kartieren. Hierfür wurden stabil transformierte homozygote $A$. thaliana Linien (in Col-0) von ROXY19 und ROXY19 Mutanten unter dem CaMV 355 Promotor mit N-terminalen 3xHA-Tag hergestellt. Bei den Mutanten handelte es sich um Einzelaustausche der Cysteine des putativen aktiven Zentrums von ROXY19 (CCMC zu SCMC, CSMC und CCMS).

Wie bereits publiziert wurde, wuchsen Pflanzen die ROXY19 (CCMC) konstitutiv in A. thaliana exprimierten schlechter auf MS-Platten mit TIBA verglichen zum Col-0 Wildtyp. Dieser Phänotyp konnte durch den Austausch aller Cysteine des putativ aktiven Zentrums von ROXY19 zu Serinen (SSMS) gerettet werden (Huang et al., 2016) (Abbildung 3.13A). Die konstitutive Expression des ersten Austauschs (SCMC) wuchs wie die ROXY19 SSMS Mutante und Col-0 auf MS-Platten mit TIBA (Abbildung 3.13A). Konstitutive Expressionen des zweiten (CSMC) und dritten (CCMS) Austausches wuchsen wie ROXY19 (CCMC) auf MS-Platten mit TIBA (Abbildung 3.13A). Das Vorhandensein der Proteine in den einzelnen Linien, wurde in einem Western Blot gezeigt (Abbildung 3.13B). Somit ist das erste Cystein des CCMC Motivs verantwortlich für das schlechtere Wachstum auf MS-Platten mit TIBA und daher wahrscheinlich auch für die Repression der Entgiftungsgene. Das konservierte zweite Cystein der CC-Typ Glutaredoxine spielte keine Rolle bei dem beobachteten Wachstumsphänotyp auf MS-Platten mit TIBA. Warum das zweite Cystein so konserviert ist bleibt unklar. 
A
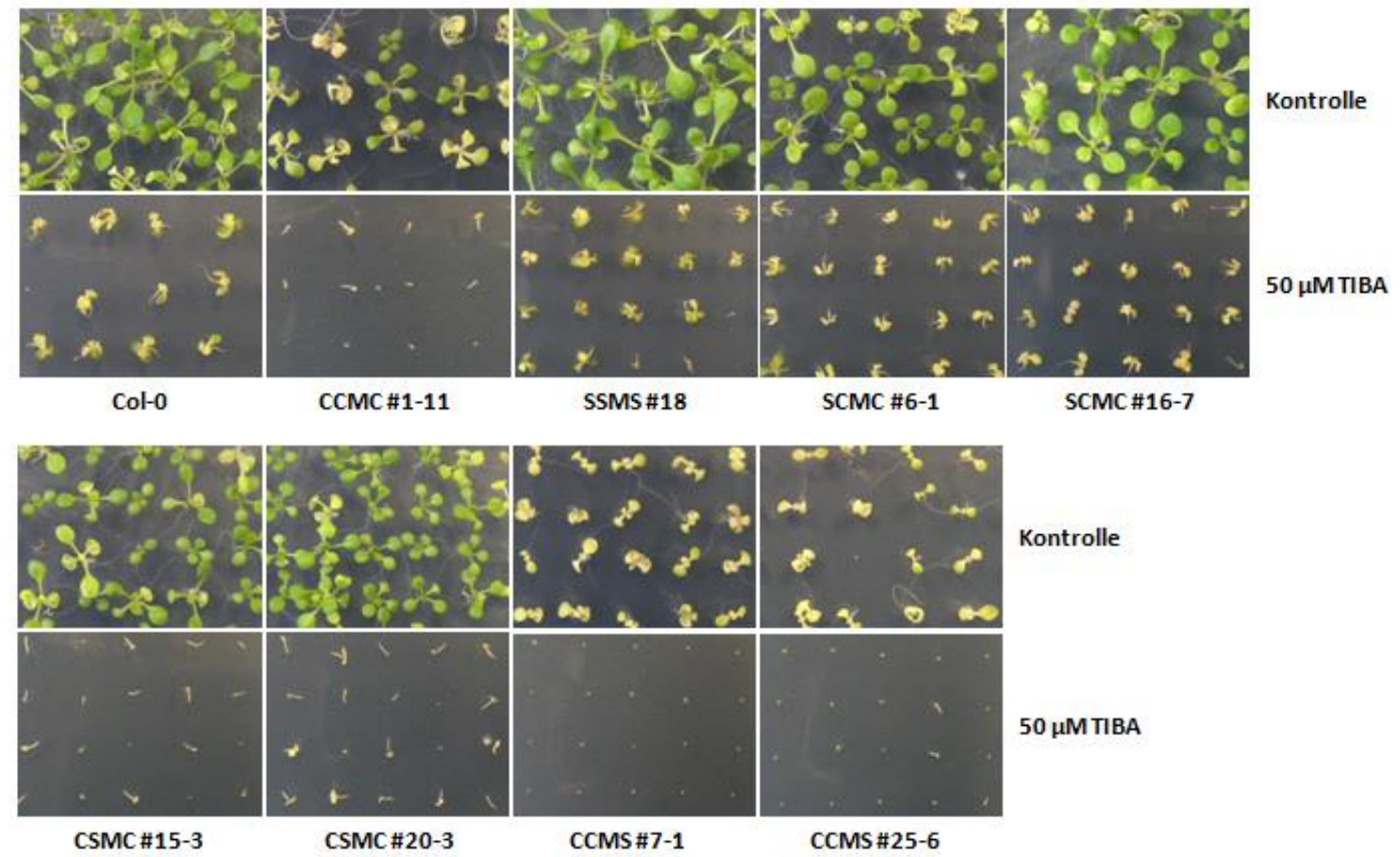

B

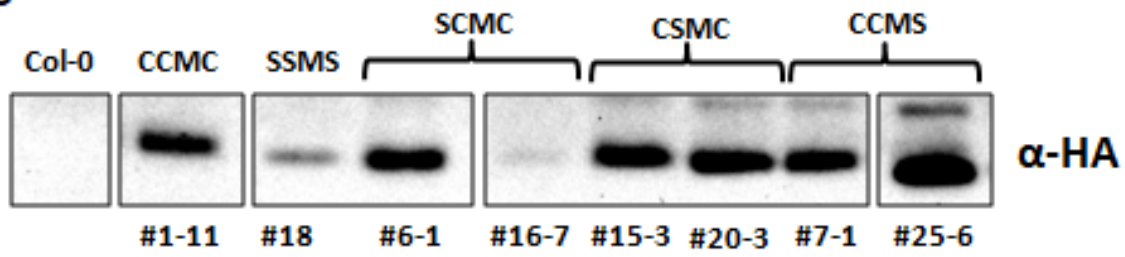

Abbildung 3.13. Einfluss von xenobiotischem TIBA auf Pflanzen die ROXY19 überexprimieren. (A)Wachstumsphänotypen von Col-0 und Pflanzen die ROXY19 (CCMC) oder ROXY19 Mutanten überexprimieren auf MS-Platten mit TIBA. Arabidopsis Samen keimten und wuchsen auf MS-Platten mit $50 \mu \mathrm{M}$ TIBA oder DMSO (Kontrolle) für 2 Wochen (12 Stunden Licht / 12 Stunden Dunkelheit) bevor sie fotografiert wurden. Es handelte sich bei den Pflanzen um stabil transformierte homozygote Linien unter dem $35 \mathrm{~S}$ Promoter mit einem N-terminalen HA-tag in Col-0. (B) Western Blot Analyse der Pflanzen Linien aus (A) der Kontrollbehandlungen. In jede Spur wurden 7,5 $\mu \mathrm{g}$ Extrakt geladen. HA-ROXY19 Protein wurde mit dem $\alpha-\mathrm{HA}$ Antikörper nachgewiesen. Alle Proben befanden sich auf einem Western Blot, nicht gezeigte Linien wurden dort entfernt wo sich die Lücken befinden. Die ROXY19 SSMS \#18 Samen wurden von Dr. Li-Jun Huang zur Verfügung gestellt. 


\subsubsection{Einfluss von Eisenmangel auf die Repression von ROXY19 auf TGA-abhängige Gene}

Wie im vorangegangenen Experiment gezeigt wurde, spielte das erste Cystein des CCMC Motivs die entscheidende Rolle bei der Sensibilität gegenüber TIBA (Abbildung 3.13A). Doch wie wird die Repression mechanistisch vermittelt? Eine Möglichkeit ist die Abhängigkeit von Eisen-Schwefel-Clustern. Wie im vorausgegangenen Teil gezeigt wurde, besitzt ROXY19 die Möglichkeit eine Eisen Spezies zu inkorporieren (Abbildung 3.4). Diese könnte auch in planta inkorporiert werden und eine Rolle bei der Funktion von ROXY19 spielen. Um einen möglichen Einfluss von Eisen auf die ROXY19-vermittelte Repression beobachten zu können, wurde im nachfolgenden Experiment eine JA/ACC-Behandlung gewählt. Eine Änderung der Behandlung von TIBA zu JA/ACC wurde vorgenommen, da Pflanzen die konstitutiv ROXY19 exprimieren schlecht auf MS-Platten mit TIBA wachsen und daher kein Material für die weitere Auswertung liefern (Huang et al., 2016), Abbildung 3.13). Eine JA/ACC-Behandlung aktiviert Zielgene, die bei einer konstitutiven Expression von ROXY19 reprimiert werden (Ndamukong et al., 2007). Ziel des Experimentes war es die Repression dieser Gene durch die Abwesenheit oder den Überschuss von Eisen möglicherweise aufzuheben.

Daher wurden im folgenden Experiment Linien die konstitutiv ROXY19 exprimieren (ROXY19 $\mathrm{OE})$ im Vergleich zu Col-0 Wildtyp Pflanzen auf ihre Repression unter Eisenüberschuss und Eisenmangel untersucht. Die Samen keimten und wuchsen zunächst für 10 Tage auf $1 / 2$ MSPlatten. Danach wurde die Hälfte der ausgelegten Pflanzen beider Genotypen jeweils für 3 Tage auf $1 / 2$ MS-Platten mit zusätzlichem Eisen oder $1 / 2$ MS-Platten mit dem Eisenchelator Ferrozin umgesetzt. Die ausgelegten Pflanzen beider Genotypen wurden danach erneut halbiert und für zwei weitere Tage auf zusätzlichem Eisen mit und ohne JA/ACC, sowie Eisenmangel mit und ohne JA/ACC umgesetzt (Abbildung 3.14A). Nach insgesamt 15 Tagen wurden alle Proben geerntet und mithilfe qRT-PCR eine Transkriptionsanalyse einiger Zielgene durchgeführt (Abbildung 3.14B).

Die Repression des Genes CYP81D11 in der ROXY19 OE Linie (Huang et al., 2016) konnte weder durch zusätzliches Eisen noch durch Eisenmangel aufgehoben werden (Abbildung 3.14B). Wie die Col-0 Kontrolle zeigte spielte die Verfügbarkeit von Eisen nur eine geringfügige Rolle für die Menge an CYP81D11 Transkripten (Abbildung 3.14B). CYP81D11 war nur geringfügig durch JA/ACC-Behandlung induzierbar (Abbildung 3.14B). Auch das JA/ACC-induzierbare Markergen PDF1.2 der nekrotrophen Pathogenabwehr wurde nicht durch Eisen in Col-0 beeinflusst und wurde in der ROXY19 OE Linie weiterhin unabhängig von der Eisenverfügbarkeit reprimiert (Abbildung 3.14B). Die Verfügbarkeit von Eisen hatte keinen Einfluss auf ROXY18, ein negativ durch ROXY19 reguliertes Gen (Abbildung 3.14B). Der Eisenmangel wurde anhand der Induktion der Expression des Markergens bHLHO39 gezeigt (Abbildung 3.14B). 
A

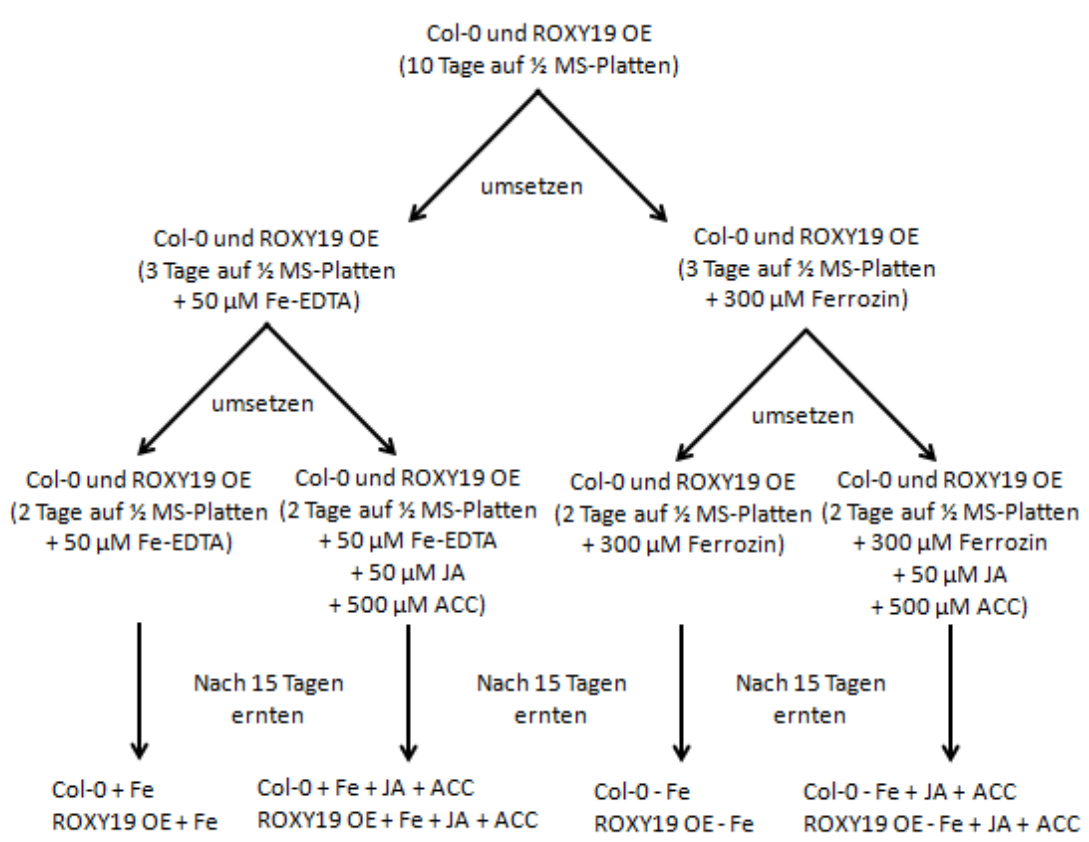

B
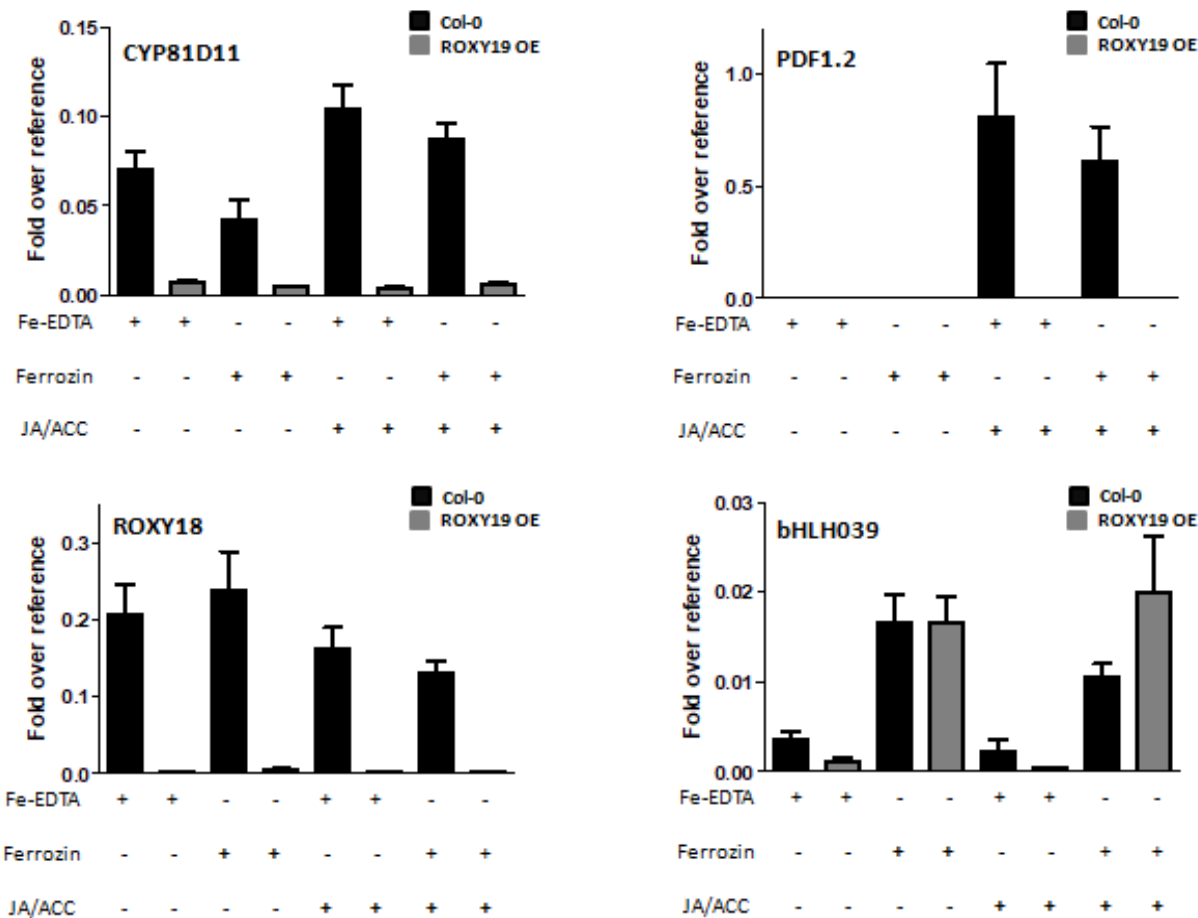

Abbildung 3.14. Einfluss von Eisenmangel auf die ROXY19 vermittelte Repression in Arabidopsis thaliana. (A) Schematischer Versuchsablauf des Experimentes. Col-0 und ROXY19 OE Samen wurden für 10 Tage auf 1/2 MSPlatten angezogen. Die Hälfte der Platten beider Genotypen wurden jeweils für 3 Tage auf $1 / 2$ MS-Platten mit zusätzlichem Eisen (50 $\mathrm{MM}$ Fe-EDTA) oder $1 / 2$ MS-Platten unter Eisenmangel (300 $\mu \mathrm{M}$ des Eisenchelators Ferrozin) umgesetzt. Die Platten beider Genotypen wurden erneut halbiert und für 2 Tage auf zusätzlichem Eisen (50 $\mu \mathrm{M}$ Fe-EDTA) mit und ohne JA/ACC (50 $\mu \mathrm{M}$ JA und $500 \mu \mathrm{M}$ ACC), sowie Eisenmangel (300 $\mu \mathrm{M}$ Ferrozin) mit und ohne JA/ACC (50 $\mu \mathrm{M}$ JA und $500 \mu \mathrm{M}$ ACC) umgesetzt. Nach insgesamt 15 Tagen (12 Stunden Licht und 12 Stunden Dunkelheit) wurden alle Platten geerntet. (B) qRT-PCR Analyse der Proben aus (A). Nachdem die Proben geerntet wurden, wurde die RNA isoliert und nach der cDNA-Synthese CYP81D11 (Entgiftungsgen), PDF1.2 (Abwehrgen), ROXY18 (ROXY19-abhängig) und bHLHO39 (Eisenmangelmarker) auf ihre relative Expression hin untersucht. 


\subsubsection{Komplementation der roxy18roxy19roxy20 Mutante}

Bisher wurde ausschließlich mit Pflanzen, die konstitutiv ROXY19 exprimieren, gearbeitet, da kein im Col-0 Hintergrund vorhandener Gen „knock out“ von ROXY19 zur Verfügung steht und daher auch keine möglichen Phänotypen für Komplementationsexperimente.

Im A. thaliana Genom sind 20 weitere ROXYs kodiert, daher lässt sich spekulieren, dass einige ROXYs redundant sind. Der nächste Verwandte des ROXY19 ist ROXY18. Eine roxy18roxy19 Mutante im Col-0/Nössen/Ler Hintergrund zeigt keinen Phänotypen. Der zusätzliche „knock out“ des ROXY20 (nächster Verwandter zu ROXY18 und ROXY19) zur roxy18roxy19roxy20 Mutante resultierte in einer Aufhebung der Repression der Anthocyanbiosynthese. Dies zeigte sich in einer starken Rotfärbung der Blätter (Zander (unpubliziert), Abbildung 3.15). Die roxy18roxy19roxy20 Mutante zeigte zudem einen verspäteten Blühzeitpunkt im Vergleich zu Col-0 oder Nössen.

Eine Komplementation der roxy18roxy19roxy20 Mutante im Col-0/Nössen/Ler Hintergrund mit ROXY19 war nicht erfolgreich. Beide Phänotypen konnten nicht durch ein UBQ10:ROXY19 Konstrukt komplementiert werden (Abbildung 3.15). Die Komplementation zeigte eine schwächere Rotfärbung der Blätter, diese war allerdings auch in der VektorKontrolle zu sehen (Abbildung 3.15 und Anhang 6.9). In Bezug auf die Aufhebung der Repression der Anthocyanbiosynthese konnte keine Redundanz beobachtet werden.

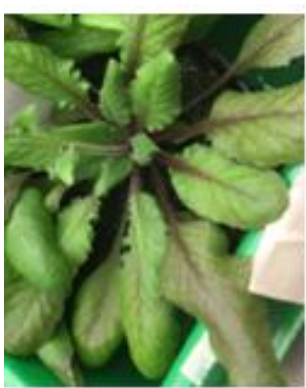

Col-0

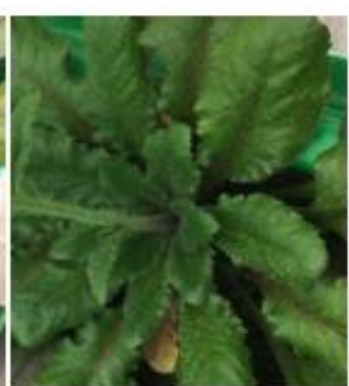

Nössen

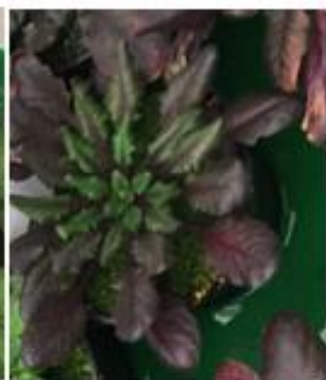

roxy18roxy19roxy20

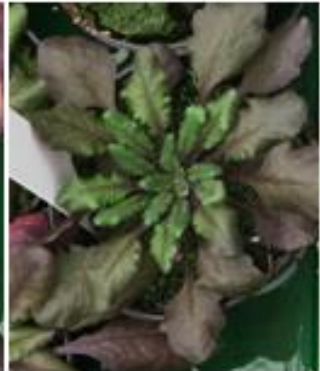

roxy18roxy19roxy20 pUBIGATOR

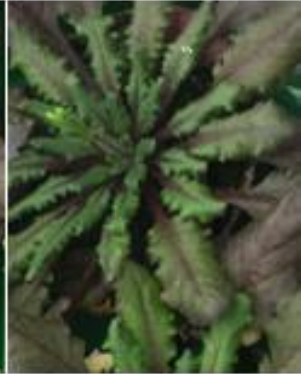

roxy18roxy19roxy20 pUBIGATOR-ROXY19

Abbildung 3.15. Komplementation der roxy18roxy19roxy20 Mutante. Die roxy18roxy19roxy20 Mutante zeigte im Starklicht (160-190 $\left.\mathrm{mol} / \mathrm{m}^{2} / \mathrm{sek}\right)$ einen Anthocyanin Phänotypen. Die Dreifachmutante wurde mit dem Vektor (pUBIGATOR) und ROXY19 (pUBIGATOR-ROXY19) komplementiert. Die Pflanzen wuchsen zunächst im Langtag (16 Stunden Licht / 8 Stunden Dunkelheit) unter normalen Lichtbedingungen $\left(80-100 \mu \mathrm{mol} / \mathrm{m}^{2} / \mathrm{sek}\right)$ für 4 Wochen und wurden dann für 2 weitere Wochen Starklicht (160-190 $\left.\mu \mathrm{mol} / \mathrm{m}^{2} / \mathrm{sek}\right)$ ausgesetzt. 


\section{Diskussion}

\subsection{ROXY19 als GSH-abhängige Oxidoreduktase}

Die vorliegende Arbeit hatte das Ziel, einen Mechanismus der ROXY19-vermittelten Repression in Abhängigkeit zum konservierten CCMC Motiv zu charakterisieren. Die Ergebnisse bezogen sich auf aus E. coli gewonnenem ROXY19. Dies sollte stets beim Reflektieren der Ergebnisse beachtet werden. ROXY19 wurde unter aeroben Bedingungen zu $100 \%$ und nach anaeroben Aufschluss zu 40-60\% als oxidiertes Oligomer aus E. coli gereinigt. Das rekombinante ROXY19 konnte mit ähnlicher Affinität wie das CPYC-Typ Glutaredoxin GRX370 GSH binden (Abbildung 3.2C). Bei diesem Ergebnis sollte beachtet werden, dass es sich um aerob aufgeschlossenes und gereinigtes ROXY19 (und GRX370) gehandelt hat. Dies bedeutet, dass ROXY19 als oxidiertes Oligomer und GRX370 als Oligomer vorlag. Da die CDSpektren beider Proteine (Anhang 6.10) auf eine richtige Faltung hindeuteten und GRX370 zusätzlich im HED-Assay aktiv war, kann davon ausgegangen werden, dass die GSH-Bindung von ROXY19 spezifisch war. Dafür sprachen auch die SSMS Mutante und Glycin ${ }^{111}$ Alanin Mutante von ROXY19, die keine Affinität zu GSH zeigten. Es kann nicht ausgeschlossen werden, dass sich der Redoxzustand oder der Oligomerisierungszustand während der Markierung mit dem "Monolith NT Protein Labeling kit BLUE-NHS" verändert hat. Der Farbstoff bindet kovalent an primäre Amine (z.B. Lysin) durch eine reaktive NHS-Estergruppe und modifiziert so Proteine sehr effizient. Nach der Markierung wurde der nicht gebundene Farbstoff über die mitgelieferte Gelfiltrationssäule abgetrennt und das markierte Protein im Ausgangspuffer zurückgewonnen.

Wie spätere Experimente mit dem nicht markierten ROXY19 zeigten, hat diese GSH-Bindung unter diesen Bedingungen keine Funktion. Es kann jedoch zum jetzigen Zeitpunkt nicht ausgeschlossen werden, dass markiertes ROXY19 („Monolith NT Protein Labeling kit BLUE$N H S^{\prime \prime}$ ) in einer aktiven Form vorliegt und nicht markiertes ROXY19 inaktiv im Bezug auf GSHabhängige Funktionen ist.

Auch eine Mutation des putativen aktiven Zentrums des ROXY19 vom CCMC Motiv zum CPYC war nicht ausreichend, um ROXY19 die enzymatische Funktion im HED-Assay zu verleihen. Couturier et al. (2010) zeigten, für ein mutiertes GRXC1 (mit einem CCMS Motiv) eine 2[FeS]-Cluster Inkorporation und für ein mutiertes GRXC4 (mit einem CCMC Motiv) eine abgeschwächte GSH-abhängige Reduktase Aktivität. Daher könnten im ROXY19 weitere strukturelle Veränderungen vorhanden sein, die eine solche Funktion nicht mehr ermöglichen. Eine solche mögliche strukturelle Veränderung könnte mit Hilfe der Röntgenstrukturanalyse von ROXY19 nachgewiesen werden. Im Rahmen dieser Arbeit wurde versucht Protein für eine Röntgenstrukturanalyse des ROXY19 bereitzustellen. Allerdings wäre hierfür eine große Menge an reinem Monomer (10-100 mg) vonnöten gewesen, die mit den angewendeten Techniken nicht gewonnen werden konnte. Hoffnung besteht für weitere Experimente durch Katrin Treffon (AG Gatz), die die Expression von ROXY19 in Insektenzellen durchführt und hier möglicherweise genug Monomer für eine Röntgenstrukturanalyse reinigen könnte. Sollte es Veränderungen geben, würden diese klein ausfallen, da beide, ROXY19 und GRX370, die Glutaredoxin-spezifische Thioredoxin-Faltung 
aufweisen. Wie bereits oben erwähnt, wurde dies durch CD-Spektroskopie gezeigt (Anhang 6.10). In der CD-Spektroskopie wurden die Faltungen von GRX370 und ROXY19 miteinander verglichen. Da beide Spektren sehr ähnlich ausfielen, kann spekuliert werden, dass beide Proteine auch eine sehr ähnliche Faltung aufweisen. Durch den Vergleich konnte ausgeschlossen werden, dass ROXY19 ungefaltet aus E. coli isoliert wurde. Der Oligomerisierungszustand von ROXY19 könnte dennoch ein Artefakt aus E. coli sein und negativen Einfluss auf putative Funktionen nehmen.

In der Pflanze könnte ROXY19 dennoch enzymatisch aktiv sein, da im HED-Assay nur ein künstliches Substrat zur Verfügung steht, könnte ROXY19 spezifische Proteinmodifikationen katalysieren (z.B. am TGA2). Experimente mit TGA2 als spezifisches Substrat (für (De-) Glutathionylierungen durch ROXY19), unter Anwendung des Ellman's Test, verliefen wenig vielversprechend. Da die Abtrennung von GSH und DTT (durch ZEBA Spin Desalting Columns 7K MWCO, Thermo Fisher Scientific) nicht sichergestellt werden konnte (Puffer war nach dreimaligen Durchlauf immer noch mit GSH und DTT kontaminiert und mit jedem weiteren Durchlauf nahm die Proteinkonzentration von TGA2 zu stark ab), wurden die Experimente eingestellt. Eine andere Möglichkeit (neben dem Ellman's Test) zum Nachweis von Modifikationen bietet die Massenspektrometrie (in Kombination mit Verfahren zur Stabilisierung von Redoxmodifikationen), die bei Wiederaufnahme dieses Gedanken Anwendung finden sollte. In diesem Zusammenhang sollten die ROXY19 Mutanten ebenfalls untersucht werden, ob sie spezifische Substrate (wie TGA2) (de-) glutathionylieren können, um eine mögliche enzymatische Aktivität einem Cystein zuzuordnen.

Ob die GSH-Bindung in planta eine Rolle spielt, wurde im Rahmen dieser Arbeit nicht verfolgt. Eine Möglichkeit, dies zu überprüfen, wäre die Repression der TGA2-abhängigen Zielgene (z.B. PDF1.2) durch die ektopische Expression von ROXY19 in einer GSH „knock-out" oder "knock-down“ Mutante (z.B. der Glutathion Synthase (GSH2)) zu untersuchen. Da der Phänotyp für einige „knock-out" Linien der Glutathion Synthase letal für Keimlinge (SAIL_301_C06 und CS68140) ist (Pasternak et al., 2008; Sessions et al., 2002) und für andere (z.B. SAIL_505_C02 und SALK_086162) nicht in der Datenbank TAIR beschrieben, ist es fragwürdig ob eine ektopische Expression von ROXY19 in der gsh2 Mutante möglich wäre. Unter Verwendung von Vorwärtsgenetikansätzen wurden mehrere Mutanten identifiziert, in denen verminderte GSH-Gehalte durch weniger schwere Mutationen im GSH1-Gen verursacht werden. Von diesen zeigt die rm/1-Mutante (rootmeristem-less1), die weniger als $5 \%$ des Wildtyp-Glutathiongehalts aufweist, den auffälligsten Phänotypen, da sie kein Wurzelapikalmeristem entwickelt (Vernoux et al. 2000). Diese beschriebene Mutante könnte für eine ektopische Expression von ROXY19 und somit der Analyse der GSH-Abhängigkeit der Repression von TGA2-kontrollierten Zielgenen durch ROXY19 dienen. Eine weitere Möglichkeit ist der Einsatz des hochspezifischen, nicht toxischen GSH-Synthese Inhibitors 1Buthionin-Sulfoximin (BSO). Koornneef et al. (2008) zeigten, dass BSO die antagonistische Wirkung von SA auf die JA-induzierte PDF1.2 Expression reduzierte und die Signalwechselwirkung zwischen SA und JA redoxmoduliert sein könnte. Der Einsatz von BSO in Pflanzen die ROXY19 ektopisch exprimieren könnte vielleicht zur Aufhebung der 
Repression mancher Zielgene durch ROXY19 führen, sofern für die Repression GSH benötigt wird.

Eine weitere Möglichkeit ist, dass GSH nur für die Etablierung der Repression benötigt wird, für die Aufrechterhaltung der Repression aber entbehrlich ist. Um dies zu untersuchen, muss der Zeitpunkt der ROXY19 Expression kontrolliert werden. Dies kann durch die Regulation eines Promotors, der dem ROXY19 Gen vorgestellt ist (z. B. XVE, ein Östrogenrezeptor basierter Transaktivator) bewerkstelligt werden. Col-0 Pflanzen die ROXY19 ektopisch exprimieren könnten nach 10 Tagen Wachstum für 3 Tage auf $1 / 2$-MS Platten mit BSO und anschließend für 2 weitere Tage auf $1 / 2-M S$ Platten mit BSO und Östrogen umgesetzt werden. Durch Transkriptionsanalysen Klasse II TGA-kontrollierter Gene (z.B. PDF1.2, ORA59, CYP81D11) kann überprüft werden, ob die Repression durch ROXY19 nicht etabliert werden konnte.

\subsection{ROXY19 bindet eine Eisen Spezies}

Gereinigtes ROXY19 enthielt eine Eisenspezies, jedoch kein GSH (Anhang 6.2). Die Frage ist, ob diese Bindung des Eisens spezifisch oder ein Artefakt ist, der der Expression in E. coli zuschulden ist. Da die Rekonstitution eines [Fe-S]-Clusters in das Monomers (Abbildung 3.7D) nicht möglich war, bleibt das putative Cluster im Oligomer höchst spekulativ. Auch ein Zusammenhang zwischen Eisen und ROXY19 konnte in planta nicht gefunden werden (Abbildung 3.14), da die ROXY19-vermittelte Repression der TGA2-abhängigen Gene (PDF1.2, CYP81D11, ROXY18) unter Eisenmangelbedingungen nicht aufgehoben werden konnte. Allerdings könnte der Eisenmangel in diesem Experiment nicht groß genug gewesen sein, um einen Effekt auf die Repression zu zeigen. Da der einzige Anhaltspunkt die Induktion des Eisenmangel Markergens bHLHO39 war, gab es keine weiteren Hinweise wie viel Eisen den Pflanzen noch zur Verfügung stand. Außerdem ist Ferrozin ein Chelator für $\mathrm{Fe}^{2+}$ und die Pflanze könnte weiterhin $\mathrm{Fe}^{3+}$ (wie es im zugegebenen Fe-EDTA vorliegt) an der Zellmembran zu $\mathrm{Fe}^{2+}$ reduzieren und aufnehmen. Da die Eisenkonzentration in der Zelle nicht gemessen wurde, kann über das Ausmaß des Eisenmangels keine Aussage getroffen werden. Ebenso könnte Eisen für die Etablierung (wie für GSH in 4.1 beschrieben) der Repression benötigt werden, aber für die Aufrechterhaltung der Repression entbehrlich sein.

Mithilfe des radioaktiven ${ }^{55} \mathrm{Fe}$ Eisenisotops könnte die Anwesenheit von Eisen in ROXY19 in vivo bestimmt werden. Hierfür müssten Pflanzen die ektopisch ROXY19 exprimieren auf MSPlatten unter niedrigen Eisenkonzentrationen keimen und für ca. 10 Tage wachsen und anschließend auf Platten mit ${ }^{55} \mathrm{Fe}$ für 2-3 Tage umgesetzt werden. Radioaktiv markierte ROXY19 Proteine könnten über das HA-Tag gereinigt werden und das Eisen in einem möglichen [Fe-S]-Cluster könnte im Szintillationszähler nachgewiesen werden.

Ebenfalls schwierig erwies sich eine Verknüpfung zwischen der Eisen-Bindung und dem aktiven Zentrum. In vitro wurden Versuche unternommen, die Eisen-Bindung einem Cystein des putativen aktiven Zentrum zu zuordnen. Allerdings ließen sich die Mutanten nicht für UV-Vis-Spektren und CD-Spektren ankonzentrieren, sondern präzipitierten bei dem Versuch. Den einzigen Hinweis ergab die Farbe der Eluate: die SCMC Mutante (schwach braun), CSMC 
(wie CCMC), CCMS (wie CCMC), CPYC (wie CCMC), CCMCA (wie CCMC) und SSMS (farblos) (nicht gezeigt). Daher lässt sich spekulieren, dass zur Bindung der Eisen Spezies das erste Cystein beitragen könnte. Wird zusätzlich die Funktion des ersten Cysteins in planta betrachtet, lässt sich spekulieren, dass für die Repression von Genen des Entgiftungswegs (Huang et al., 2016) die Eisen-Bindung benötigt werden könnte.

Eine weitere Eigenschaft von ROXY19, war eine potentielle Häm-Bindung im EPR-Spektrum (Abbildung 3.4E). Weitere Untersuchungen ergaben, dass maximal 1\% der ROXY19 Proteine im Oligomer eine Häm-Gruppe des Typ b gebunden hatten (Anhang 6.11), dies spricht für eine unspezifische Bindung des Häm $b$ an ROXY19. Allerdings ergaben Pull down Experimente von TGA2 mit ROXY19 ebenfalls, dass auf 100 ROXY19 Proteine nur 1-5 TGA2 Proteine kamen (Anhang 6.12). Daher könnte der Häm-Anteil auch durch eine Bindung eines ROXY19-TGA2-Häm-b Komplexes erklärt werden. Ob das Häm b durch ROXY19, TGA2 oder beide gebunden wird ist unklar.

\subsection{Oligomerisierungszustand von ROXY19}

Da unbekannt ist, ob ROXY19 als Monomer oder Oligomer in planta agiert, sollten die jeweiligen Ergebnisse stets ausschließlich auf das Monomer oder Oligomer bezogen werden. In vitro konnte das ROXY19 Oligomer nicht vollständig in das Monomer umgewandelt werden. Reduktion (Abbildung 3.5A) und Mutation der Cysteine im putativen aktiven Zentrum (Abbildung 3.6A und B) erzielten nur Teilerfolge. Auch die Suche nach optimalen Pufferbedingungen und Additiven (Abbildung 3.7A und B) zeigte zwar mehr Monomer als in der Kontrolle, das Oligomer überwog aber weiterhin.

ROXY19 besitzt vier Cysteine. Mutiert man drei wie in der SSMS Mutante, verbleibt nur ein einziges, welches maximal ein Dimer mit einem weiteren ROXY19 bilden könnte. Die Mutation der Cysteine zeigte einen positiven Effekt auf die Anreicherung des Monomers. Die Cysteine waren aber nicht ausschließlich für die Oligomerisierung verantwortlich. Außerdem zeigte die ROXY19 CPYC Mutante einen stärkeren positiven Effekt auf die Anreicherung des Monomers (drei vorhandene Cysteine). Dies schließt zumindest die reine Anwesenheit von Cysteinen als Oligomerisierungskern aus. Die Oligomerisierung könnte auch durch eine Interaktion ohne Disulfidbrücken zwischen mehreren ROXY19 Untereinheiten zustande kommen, diese könnte zumindest partiell vom Redoxzustand und dem putativen aktiven Zentrum abhängig sein. Eine Möglichkeit wäre hier das C-terminale ALWL Motiv zu untersuchen. Durch die Mutation des ALWL Motivs zum Pappel GRXC4 C-Terminus (SEQKDL) (Couturier et al., 2010) könnte die Oligomerisierung des ROXY19 (teilweise) aufgehoben werden.

Der Redoxzustand des ROXY19 wurde mithilfe des Ellman's Test bestimmt und ergab ROXY19, das unter aeroben Bedingungen gewonnen wurde, dass $100 \%$ oxidiert vorlagen (nur Oligomer vorhanden), wohingegen das aus anaerob aufgeschlossenen Zellen gereinigte ROXY19 zu 40-60\% reduziert vorlag (eine Mischung von Oligomer und Monomer (80:20)) (Abbildung 3.2A, Abbildung 3.5A). 
Warum Zucker als gute Bedingungen in den Löslichkeits- und Stabilitätstests von Hampton Research gefunden wurden (Abbildung 3.7A), könnte zumindest teilweise am MBP-Tag liegen. Das MBP-Tag hat eine große Affinität zum Zucker Maltose und könnte geringe, aber ausreichende Affinität zu anderen Zuckern besitzen, um die Strep-MBP-ROXY19 Untereinheiten teilweise von einander zu verdrängen. Da diese Tests nur Hinweise auf mögliche Pufferbedingungen liefern, könnte der beobachtete Effekt dennoch nicht spezifisch sein. Für das MBP konnte gezeigt werden, dass keine Oligomere gebildet werden (Caine et al., 2011). Verfolgt man die Idee der Zucker weiter, könnte spekuliert werden, dass ROXY19 in der Zelle als Oligomer vorliegt und zum Transport (eventuell durch das für den Zuckertransport verantwortliche Phloem) monomerisiert wird. Das Signal zur Umwandlung vom Oligomer zum Monomer könnte eine steigende Zuckerkonzentration sein. Eine Frage, die sich aus dieser Überlegung ergibt ist, ob ROXY19 von Zelle zu Zelle bzw. von einem Teil der Pflanze zu einem anderen transportiert werden kann oder nach der Expression in dieser einen Zelle verbleibt. Um dies zu überprüfen könnte man ROXY19 (z.B. mit GFP-Tag) unter einem gewebespezifischen Promoter in Arabidopsis thaliana exprimieren und andere Gewebe auf die Anwesenheit des Proteins überprüfen (z.B. im Fluoreszenzmikroskop oder durch Western Blot Analyse). So könnte ein Hinweis gewonnen werden, ob ROXY19 Gewebeübergreifend transportiert wird. Dieser Transport könnte über die Plasmodesmata erfolgen.

\subsection{Der ROXY19-induzierte Supershift des TGA2-as-1* Komplex}

Um einen Effekt auf die elektrophoretische Mobilität des TGA2-as-1* Komplex (Abbildung 3.12 und Anhang 6.5-8) zu beobachten wurden 4 ug ROXY19 benötigt. Auffällig war, dass es nicht möglich war das ROXY19 Eluat zu verdünnen oder weniger als $4 \mu \mathrm{g}$ einzusetzen (Anhang 6.5).

Es könnten daher viele ROXY19 Moleküle für eine direkte Interaktion benötigt werden. Gegen diese Überlegung spricht vor allem, dass die Veränderung der Mobilität des TGA2-as1 * Komplexes in der Gelelektrophorese durch ROXY19 sehr viel kleiner ausfiel als erwartet und es keinen Unterschied zwischen Monomer (59,5 kDa) und Oligomer (> $1200 \mathrm{kDa}$ ) gab (Abbildung 3.9). Dies scheint eine direkte Interaktion für das Oligomer unwahrscheinlich zu machen. Obwohl das Monomer den ROXY19-TGA2-as-1* Komplex durch Interaktion bilden könnte, bleibt die Frage, wie das Oligomer dieselbe Veränderung der Mobilität in der Gelelektrophorese induzieren kann? Eine Möglichkeit wäre eine durch ROXY19-induzierte Konformationsänderung des TGA2, die zu einem weiteren TGA2-as-1* Komplex führt, der andere Eigenschaften in der Gelelektrophorese aufweist. Es könnte aber auch sein, dass eine kleine Menge des Monomers, die in der Oligomerfraktion entstehen könnte, verantwortlich für die Veränderung der Mobilität in der Gelelektrophorese ist.

Um zu testen, ob die Veränderung der Mobilität des TGA2-as-1* Komplex in der Gelelektrophorese in die höhere Bande (Supershift) ROXY19 Protein enthält, wurde versucht diese höhere Bande durch einen $\alpha$-Strep-Antikörper (StrepMAB-Classic, iba) gegen das StrepTag des ROXY19 weiter nach oben zu verschieben. Dieses Experiment verlief ohne 
detektierbare Veränderung der Mobilität für den ROXY19-TGA2-as-1* Komplex in der Gelelektrophorese. Da keine positive Kontrolle vorhanden war, kann allerdings nicht ausgeschlossen werden, dass das Experiment technisch nicht funktionierte. Der $\alpha$-StrepAntikörper könnte, durch einen zu großen Überschuss an ROXYY19, der nicht an den TGA2$a s-1 *$ Komplex gebunden wurde, nicht im EMSA nachweisbar gebunden worden sein. Sollte dies der Fall gewesen sein, wäre es nicht möglich, ROXY19, gebunden an den TGA2-as-1* Komplex nachzuweisen, da die großen Mengen an ROXY19 die in diesem Experiment nicht gebunden war, hinderlich sind. Die Expression von ROXY19 in Insektenzellen (Katrin Treffon) könnte eine Möglichkeit zur Minderung der Proteinmenge sein, wodurch ein Nachweis mithilfe des $\alpha$-Strep-Antikörpers möglich werden könnte.

Auffällig ist auch die, durch die ROXY19 CPYC-induzierte Veränderung der Mobilität des TGA2-as-1* Komplexes in der Gelelektrophorese, die höher als die Veränderung der Mobilität in der Gelelektrophoreseen des Wildtyp Proteins ausfällt. Das CPYC-Typ GRX370 zeigte keine solche Veränderung der Mobilität des TGA2-as-1* Komplexes in der Gelelektrophorese in eine höhere Bande. Dieser Supershift des TGA2-as-1* Komplexes ist somit spezifisch für ROXY19. Warum die Veränderung der Mobilität in der Gelelektrophorese durch ROXY19 CPYC anders ausfällt als für alle anderen ROXY19 Varianten bleibt unklar. Auffällig ist nur, dass die CPYC Mutante mehr Monomer bildet (Abbildung 3.7A-C) im Vergleich zum ROXY19, aber dennoch nicht aktiv im HED-Assay war (Abbildung 3.3).

Der ROXY19-TGA2-DNA Komplex bietet die Möglichkeit TOPLESS an Promotor Regionen TGA2-kontrollierter Gene zu rekrutieren und diese zu reprimieren. Für den ROXY19 Promotor wurde gezeigt, dass ROXY19 mit TGA-Faktoren an der DNA assoziiert ist (HerreraVásquez et al., 2015).

\subsection{Verstärkung der Bindung von TGA2 an das as-1 Element durch ROXY19}

Das erste Cystein des CCMC Motivs, welches für den Wachstumsphänotypen unter TIBAStress unerlässlich war (Abbildung 3.13A), war für die Verstärkung der Bindung von TGA2 an das as-1*-Element nicht wichtig (Abbildung 3.12). Die SCMC Mutante war, wie das Wildtyp Protein, in der Lage die Bindung von TGA2 an das as-1*-Element zu verstärken. Dies könnte einen Widerspruch der in vitro und in planta Daten bedeuten, sofern der beobachtete Phänotyp von der Bindungsverstärkung der TGA Transkriptionsfaktoren an die as-1 Elemente in Promoter Regionen abhängig ist und nicht nach einem anderen Mechanismus abläuft. Da TGA Transkriptionsfaktoren Aktivatoren der Genexpression sind, könnte die Repression durch ROXY19 von einem anderen Mechanismus abhängig sein. Allerdings könnte ROXY19 die Bindung von TGA2 an das as-1 Element verstärken, um TOPLESS effektiver an die Promotor Regionen zu rekrutieren.

Unabhängig vom Mechanismus muss gesagt werden, dass die beobachtete Verstärkung der Bindung nicht für ROXY19 spezifisch war, da ein nicht verwandtes CPYC-Typ GRX, das GRX370 (Anhang 6.6), ebenfalls diese Funktion erfüllen konnte. Es konnte kein nachweisbarer GRX370-TGA2-as-1* Komplex beobachtet werden. Dies schließt eine direkte 
Interaktion aus und stellt keinen Widerspruch zu den publizierten Daten von Ndamukong (2007) dar.

Auch die Mutanten des putativen aktiven Zentrums von ROXY19 (SCMC, CSMC, CCMS, CCMCA, SSMS und CPYC) konnten die Verstärkung der Bindung von TGA2 an das as-1*Element induzieren (Abbildung 3.12). Dies bedeutet, dass der Effekt unabhängig vom aktiven Zentrum ist, da selbst die ROXY19 SSMS Mutante noch einen Effekt zeigte. Wie die Verstärkung der Bindung funktioniert, ist nicht klar, insbesondere da eine direkte Interaktion zwischen TGA2 und GRX370 zu mindestens im Hefe-Zweihybrid System nicht nachgewiesen wurde (Ndamukong et al., 2007). Eine Möglichkeit wäre daher eine über die ThioredoxinFaltung induzierte transiente Interaktion oder Modifikation zur Steigerung der TGA2 Bindung an das as-1*-Element.

Gegen ein inaktives ROXY19 sprechen die Experimente mit einem Überschuss von nicht radioaktiv markiertem as-1 Element (Abbildung 3.10, Anhang 6.4), die zeigten, dass ROXY19 die Bindung von TGA2 an das as-1* Element bei einem 1500x Überschuss des nicht radioaktiv markiertem as-1 Element immer noch verstärken konnte. Geht man vom TGA2 aus steigt das Verhältnis von 120:1 (vom im Ergebnisteil 3.7 berechneten Verhältnis 450.000:1 von ROXY19 zum TGA2-as-1* Komplex, ohne nicht-markiertem as-1 Element, aus) auf 480:1 (da vier TGA2 an das as-1* Element gebunden sind).

\subsection{Redundanz innerhalb der CC-Typ Glutaredoxine}

Eine weitere Frage, die sich angesichts der 20 weiteren Vertreter der ROXY Genfamilie stellt, ist deren Redundanz, vor allem mit dem nächsten Verwandten des ROXY19, dem ROXY18. Zumindest bei der Komplementation der roxy18 roxy19 roxy20 Mutante (Abbildung 3.15) spielte Redundanz keine Rolle, da die Expression von ROXY19 alleine nicht ausreichend war, um den Anthocyan-Phänotypen zu komplementieren. Da die roxy18 roxy19 Mutante keinen Phänotypen hat und für die roxy18 roxy20 Mutante nicht bekannt ist ob sie bereits den Anthocyan-Phänotypen zeigt, könnte ROXY19 keine Rolle bei der Repression der Anthocyangene spielen.

\subsection{Mögliche Funktionen des CC-Motivs von ROXY19}

Abschließend lässt sich über die funktionale Analyse des CC-Typ Glutaredoxin ROXY19 sagen, dass im Rahmen dieser Arbeit kein Mechanismus für die Repression von Klasse II TGAabhängigen Zielgenen beschrieben werden konnte. Es konnten keine Glutaredoxinspezifischen Funktionen für ROXY19 (enzymatische Funktion oder definiertes EisenSchwefel-Cluster) experimentell nachgewiesen werden. ROXY19 inkorporiert eine unbekannte Eisen-Spezies, die jedoch artifiziell sein könnte. Ein möglicher Mechanismus zur Regulation des TGA2, die Bindungsverstärkung, war nicht für ROXY19 spezifisch und kann auch von dem entfernt verwandten ROXY9 sowie dem CPYC-Typ GRX370 ermöglicht werden. Wohingegen der Supershift eine spezifische Eigenschaft des ROXY19 sein könnte. Dieser spricht für einen ROXY19-TGA2-Komplex. An diesen Komplex könnte z.B. TOPLESS zur 
weiteren Regulation von Klasse II TGA-regulierten Genen rekrutiert werden. Wie die Regulation auf molekularer Ebene abläuft konnte in dieser Arbeit nicht beschrieben werden. In planta keine Verbindung zwischen der Eisenverfügbarkeit und der Repression durch ROXY19 gefunden werden. Für den Wachstumsphänotypen durch die ektopische Expression von ROXY19 unter TIBA-Stress (Huang et al., 2016) konnte gezeigt werden, dass das erste Cystein des CCMC Motivs wichtig war. Die Frage, warum das zweite Cystein des CCMC Motivs so konserviert ist, konnte im Rahmen dieser Arbeit nicht beantwortet werden, da diesem Cystein keine Funktion zugewiesen werden konnte. 


\section{Literatur}

Bandyopadhyay, S., Gama, F., Molina-Navarro, M.M., Gualberto, J.M., Claxton, R., Naik, S.G., Huynh, B.H., Herrero, E., Jacquot, J.P., Johnson, M.K., et al. (2008). Chloroplast monothiol glutaredoxins as scaffold proteins for the assembly and delivery of [2Fe-2S] clusters. EMBO J. 27, 1122-1133.

Barr, I., and Guo, F. (2015). Pyridine Hemochromagen Assay for Determining the Concentration of Heme in Purified Protein Solutions. Bio-Protoc. 5.

Behringer Carina, Bartsch Klaus, and Schaller Andreas (2011). Safeners recruit multiple signalling pathways for the orchestrated induction of the cellular xenobiotic detoxification machinery in Arabidopsis. Plant Cell Environ. 34, 1970-1985.

Bender, K.W., Wang, X., Cheng, G.B., Kim, H.S., Zielinski, R.E., and Huber, S.C. (2015). Glutaredoxin AtGRXC2 catalyses inhibitory glutathionylation of Arabidopsis BRI1-associated receptor-like kinase 1 (BAK1) in vitro. Biochem. J. 467, 399-413.

Bennett, J., and Scott, K.J. (1971). Quantitative staining of Fraction I protein in polyacrylamide gels using coomassie brilliant blue. Anal. Biochem. 43, 173-182.

Brandes, H.K., Larimer, F.W., Geck, M.K., Stringer, C.D., Schürmann, P., and Hartman, F.C. (1993). Direct identification of the primary nucleophile of thioredoxin f. J. Biol. Chem. 268, 18411-18414.

Caine, J.M., Bharadwaj, P.R., Sankovich, S.E., Ciccotosto, G.D., Streltsov, V.A., and Varghese, J. (2011). Oligomerization and toxicity of $A \beta$ fusion proteins. Biochem. Biophys. Res. Commun. 409, 477-482.

Cheng, N.-H., Liu, J.-Z., Brock, A., Nelson, R.S., and Hirschi, K.D. (2006). AtGRXcp, an Arabidopsis Chloroplastic Glutaredoxin, Is Critical for Protection against Protein Oxidative Damage. J. Biol. Chem. 281, 26280-26288.

Cheng, N.-H., Liu, J.-Z., Liu, X., Wu, Q., Thompson, S.M., Lin, J., Chang, J., Whitham, S.A., Park, S., Cohen, J.D., et al. (2011). Arabidopsis Monothiol Glutaredoxin, AtGRXS17, Is Critical for Temperature-dependent Postembryonic Growth and Development via Modulating Auxin Response. J. Biol. Chem. 286, 20398-20406.

Chini, A., Fonseca, S., Fernández, G., Adie, B., Chico, J.M., Lorenzo, O., García-Casado, G., López-Vidriero, I., Lozano, F.M., Ponce, M.R., et al. (2007). The JAZ family of repressors is the missing link in jasmonate signalling. Nature 448, 666-671.

Chomczynski, P. (1993). A reagent for the single-step simultaneous isolation of RNA, DNA and proteins from cell and tissue samples. BioTechniques 15, 532-534, 536-537.

Chuang, C.-F., Running, M.P., Williams, R.W., and Meyerowitz, E.M. (1999). The PERIANTHIA gene encodes a bZIP protein involved in the determination of floral organ number in Arabidopsis thaliana. Genes Dev. 13, 334-344. 
Clough, S.J., and Bent, A.F. (1998). Floral dip: a simplified method for Agrobacteriummediated transformation of Arabidopsis thaliana. Plant J. 16, 735-743.

Couturier, J., Didierjean, C., Jacquot, J.-P., and Rouhier, N. (2010). Engineered mutated glutaredoxins mimicking peculiar plant class III glutaredoxins bind iron-sulfur centers and possess reductase activity. Biochem. Biophys. Res. Commun. 403, 435-441.

Couturier, J., Ströher, E., Albetel, A.-N., Roret, T., Muthuramalingam, M., Tarrago, L., Seidel, T., Tsan, P., Jacquot, J.-P., Johnson, M.K., et al. (2011). Arabidopsis Chloroplastic Glutaredoxin C5 as a Model to Explore Molecular Determinants for Iron-Sulfur Cluster Binding into Glutaredoxins. J. Biol. Chem. 286, 27515-27527.

Couturier, J., Jacquot, J.-P., and Rouhier, N. (2013). Toward a refined classification of class I dithiol glutaredoxins from poplar: biochemical basis for the definition of two subclasses. Front. Plant Sci. 4.

Couturier, J., Wu, H.-C., Dhalleine, T., Pégeot, H., Sudre, D., Gualberto, J.M., Jacquot, J.-P., Gaymard, F., Vignols, F., and Rouhier, N. (2014). Monothiol Glutaredoxin-BolA Interactions: Redox Control of Arabidopsis thaliana BolA2 and SufE1. Mol. Plant 7, 187-205.

Dalle-Donne, I., Milzani, A., Gagliano, N., Colombo, R., Giustarini, D., and Rossi, R. (2008). Molecular Mechanisms and Potential Clinical Significance of S-Glutathionylation. Antioxid. Redox Signal. 10, 445-474.

Duhr, S., and Braun, D. (2006). Why molecules move along a temperature gradient. Proc. Natl. Acad. Sci. U. S. A. 103, 19678-19682.

Ellenberger, T. (1994). Getting a grip on DNA recognition: structures of the basic region leucine zipper, and the basic region helix-loop-helix DNA-binding domains. Curr. Opin. Struct. Biol. 4, 12-21.

Feng, Y., Zhong, N., Rouhier, N., Hase, T., Kusunoki, M., Jacquot, J.-P., Jin, C., and Xia, B. (2006). Structural Insight into Poplar Glutaredoxin C1 with a Bridging Iron-Sulfur Cluster at the Active Site,. Biochemistry (Mosc.) 45, 7998-8008.

Fernandes, A.P., and Holmgren, A. (2004). Glutaredoxins: Glutathione-Dependent Redox Enzymes with Functions Far Beyond a Simple Thioredoxin Backup System. Antioxid. Redox Signal. 6, 63-74.

Fode, B., Siemsen, T., Thurow, C., Weigel, R., and Gatz, C. (2008). The Arabidopsis GRAS Protein SCL14 Interacts with Class II TGA Transcription Factors and Is Essential for the Activation of Stress-Inducible Promoters. Plant Cell 20, 3122-3135.

Fontecave, M. (2006). Iron-sulfur clusters: ever-expanding roles. Nat Chem Biol. 4, 171-4.

Fu, Z.Q., Yan, S., Saleh, A., Wang, W., Ruble, J., Oka, N., Mohan, R., Spoel, S.H., Tada, Y., Zheng, N., et al. (2012). NPR3 and NPR4 are receptors for the immune signal salicylic acid in plants. Nature 486, 228-232. 
Garretón, V., Carpinelli, J., Jordana, X., and Holuigue, L. (2002). The as-1 Promoter Element Is an Oxidative Stress-Responsive Element and Salicylic Acid Activates It via Oxidative Species. Plant Physiol. 130, 1516-1526.

Griffith, M.E., Conceicao, A. da S., and Smyth, D.R. (1999). PETAL LOSS gene regulates initiation and orientation of second whorl organs in the Arabidopsis flower. Development 126, 5635-5644.

Gutsche, N., and Zachgo, S. (2016). The N-Terminus of the Floral Arabidopsis TGA Transcription Factor PERIANTHIA Mediates Redox-Sensitive DNA-Binding. PLoS ONE 11.

Hanson, G.T., Aggeler, R., Oglesbee, D., Cannon, M., Capaldi, R.A., Tsien, R.Y., and Remington, S.J. (2004). Investigating Mitochondrial Redox Potential with Redox-sensitive Green Fluorescent Protein Indicators. J. Biol. Chem. 279, 13044-13053.

Hartley, J.L., Temple, G.F., and Brasch, M.A. (2000). DNA Cloning Using In Vitro Site-Specific Recombination. Genome Res. 10, 1788-1795.

Herrera-Vásquez, A., Salinas, P., and Holuigue, L. (2015). Transcriptional Control of Glutaredoxin GRXC9 Expression by a Salicylic Acid-Dependent and NPR1-Independent Pathway in Arabidopsis. Plant Mol Biol Report 33, 624-637.

Howe, P.W.A. (2004). A straight-forward method of optimising protein solubility for NMR. J. Biomol. NMR 30, 283-286.

Huang, L.-J., Li, N., Thurow, C., Wirtz, M., Hell, R., and Gatz, C. (2016). Ectopically expressed glutaredoxin ROXY19 negatively regulates the detoxification pathway in Arabidopsis thaliana. BMC Plant Biol. 16 (1):200.

Iñigo, S., Durand, A.N., Ritter, A., Le Gall, S., Termathe, M., Klassen, R., Tohge, T., De Coninck, B., Van Leene, J., De Clercq, R., et al. (2016). Glutaredoxin GRXS17 Associates with the Cytosolic Iron-Sulfur Cluster Assembly Pathway1. Plant Physiol. 172, 858-873.

Katagiri, F., Lam, E., and Chua, N.-H. (1989). Two tobacco DNA-binding proteins with homology to the nuclear factor CREB. Nature 340, 727-730.

Klatt, P., and Lamas, S. (2000). Regulation of protein function by S-glutathiolation in response to oxidative and nitrosative stress. Eur. J. Biochem. 267, 4928-4944.

Knuesting, J., Riondet, C., Maria, C., Kruse, I., Bécuwe, N., König, N., Berndt, C., Tourrette, S., Guilleminot-Montoya, J., Herrero, E., et al. (2015). Arabidopsis Glutaredoxin S17 and Its Partner, the Nuclear Factor $Y$ Subunit C11/Negative Cofactor $2 \alpha$, Contribute to Maintenance of the Shoot Apical Meristem under Long-Day Photoperiod. Plant Physiol. 167, 1643-1658.

Koornneef, A., Leon-Reyes, A., Ritsema, T., Verhage, A., Den Otter, F.C., Van Loon, L.C., and Pieterse, C.M.J. (2008). Kinetics of salicylate-mediated suppression of jasmonate signaling reveal a role for redox modulation. Plant Physiol. 147, 1358-1368. 
Kyhse-Andersen, J. (1984). Electroblotting of multiple gels: a simple apparatus without buffer tank for rapid transfer of proteins from polyacrylamide to nitrocellulose. J. Biochem. Biophys. Methods 10, 203-209.

La Camera, S., L'Haridon, F., Astier, J., Zander, M., Abou-Mansour, E., Page, G., Thurow, C., Wendehenne, D., Gatz, C., Métraux, J.-P., et al. (2011). The glutaredoxin ATGRXS13 is required to facilitate Botrytis cinerea infection of Arabidopsis thaliana plants. Plant J. 68, 507-519.

Laemmli, U.K. (1970). Cleavage of Structural Proteins during the Assembly of the Head of Bacteriophage T4. Nature 227, 680-685.

Laporte, D., Olate, E., Salinas, P., Salazar, M., Jordana, X., and Holuigue, L. (2012). Glutaredoxin GRXS13 plays a key role in protection against photooxidative stress in Arabidopsis. J. Exp. Bot. 63, 503-515.

Li, S., Lauri, A., Ziemann, M., Busch, A., Bhave, M., and Zachgo, S. (2009). Nuclear Activity of ROXY1, a Glutaredoxin Interacting with TGA Factors, Is Required for Petal Development in Arabidopsis thaliana. Plant Cell 21, 429-441.

Li, S., Gutsche, N., and Zachgo, S. (2011). The ROXY1 C-Terminal L**LL Motif Is Essential for the Interaction with TGA Transcription Factors. Plant Physiol. 157, 2056-2068.

Lillig, C.H., Berndt, C., and Holmgren, A. (2008). Glutaredoxin systems. Biochim. Biophys. Acta BBA - Gen. Subj. 1780, 1304-1317.

Liu, X., Liu, S., Feng, Y., Liu, J.-Z., Chen, Y., Pham, K., Deng, H., Hirschi, K.D., Wang, X., and Cheng, N. (2013). Structural insights into the N-terminal GIY-YIG endonuclease activity of Arabidopsis glutaredoxin AtGRXS16 in chloroplasts. Proc. Natl. Acad. Sci. U. S. A. 110, 95659570.

Lu, J., and Holmgren, A. (2014). The Thioredoxin Superfamily in Oxidative Protein Folding. Antioxid. Redox Signal. 21, 457-470.

McPherson, A. (1982). Preparation and Analysis of Protein Crystals (John Wiley \& Sons Inc).

Moseler, A., Aller, I., Wagner, S., Nietzel, T., Przybyla-Toscano, J., Mühlenhoff, U., Lill, R., Berndt, C., Rouhier, N., Schwarzländer, M., et al. (2015). The mitochondrial monothiol glutaredoxin S15 is essential for iron-sulfur protein maturation in Arabidopsis thaliana. Proc. Natl. Acad. Sci. U. S. A. 112, 13735-13740.

Mou, Z., Fan, W., and Dong, X. (2003). Inducers of Plant Systemic Acquired Resistance Regulate NPR1 Function through Redox Changes. Cell 113, 935-944.

Mueller, S., Hilbert, B., Dueckershoff, K., Roitsch, T., Krischke, M., Mueller, M.J., and Berger, S. (2008). General Detoxification and Stress Responses Are Mediated by Oxidized Lipids through TGA Transcription Factors in Arabidopsis. Plant Cell 20, 768-785. 
Murmu, J., Bush, M.J., DeLong, C., Li, S., Xu, M., Khan, M., Malcolmson, C., Fobert, P.R., Zachgo, S., and Hepworth, S.R. (2010). Arabidopsis Basic Leucine-Zipper Transcription Factors TGA9 and TGA10 Interact with Floral Glutaredoxins ROXY1 and ROXY2 and Are Redundantly Required for Anther Development. Plant Physiol. 154, 1492-1504.

Mülhardt, C. (2009). Der Experimentator: Molekularbiologie/ Genomics (Heidelberg: Spektrum Akademischer Verlag).

Nagels Durand, A., Iñigo, S., Ritter, A., Iniesto, E., De Clercq, R., Staes, A., Van Leene, J., Rubio, V., Gevaert, K., De Jaeger, G., et al. (2016). The Arabidopsis Iron-Sulfur Protein GRXS17 is a Target of the Ubiquitin E3 Ligases RGLG3 and RGLG4. Plant Cell Physiol. 57, 1801-1813.

Ndamukong, I., Abdallat, A.A., Thurow, C., Fode, B., Zander, M., Weigel, R., and Gatz, C. (2007). SA-inducible Arabidopsis glutaredoxin interacts with TGA factors and suppresses JAresponsive PDF1.2 transcription. Plant J. 50, 128-139.

Pasternak, M., Lim, B., Wirtz, M., Hell, R., Cobbett, C.S., and Meyer, A.J. (2008). Restricting glutathione biosynthesis to the cytosol is sufficient for normal plant development. Plant J. 53, 999-1012.

Patterson, K., Walters, L.A., Cooper, A.M., Olvera, J.G., Rosas, M.A., Rasmusson, A.G., and Escobar, M.A. (2016). Nitrate-Regulated Glutaredoxins Control Arabidopsis Primary Root Growth1[OPEN]. Plant Physiol. 170, 989-999.

Pauwels, L., and Goossens, A. (2011). The JAZ Proteins: A Crucial Interface in the Jasmonate Signaling Cascade. Plant Cell 23, 3089-3100.

Pauwels, L., Barbero, G.F., Geerinck, J., Tilleman, S., Grunewald, W., Pérez, A.C., Chico, J.M., Bossche, R.V., Sewell, J., Gil, E., et al. (2010). NINJA connects the co-repressor TOPLESS to jasmonate signalling. Nature $464,788-791$.

Pieterse, C.M.J., Leon-Reyes, A., Van der Ent, S., and Van Wees, S.C.M. (2009). Networking by small-molecule hormones in plant immunity. Nat. Chem. Biol. 5, 308-316.

Pujol-Carrion, N., Belli, G., Herrero, E., Nogues, A., and Torre-Ruiz, M.A. de la (2006). Glutaredoxins Grx3 and Grx4 regulate nuclear localisation of Aft1 and the oxidative stress response in Saccharomyces cerevisiae. J. Cell Sci. 119, 4554-4564.

Quon, T., Lampugnani, E.R., and Smyth, D.R. (2017). PETAL LOSS and ROXY1 Interact to Limit Growth Within and between Sepals But to Promote Petal Initiation in Arabidopsis thaliana. Front. Plant Sci. 8.

Ramel, F., Sulmon, C., Serra, A.-A., Gouesbet, G., and Couée, I. (2012). Xenobiotic sensing and signalling in higher plants. J. Exp. Bot. 63, 3999-4014.

Rey Pascal, Becuwe Noëlle, Tourrette Sébastien, and Rouhier Nicolas (2017). Involvement of Arabidopsis glutaredoxin S14 in the maintenance of chlorophyll content. Plant Cell Environ. 40, 2319-2332. 
Riondet Christophe, Desouris Jean Paul, Montoya Jocelyne Guilleminot, Chartier Yvette, Meyer Yves, and Reichheld Jean-Philippe (2011). A dicotyledon-specific glutaredoxin GRXC1 family with dimer-dependent redox regulation is functionally redundant with GRXC2. Plant Cell Environ. 35, 360-373.

Rodríguez-Manzaneque, M.T., Tamarit, J., Bellí, G., Ros, J., and Herrero, E. (2002). Grx5 Is a Mitochondrial Glutaredoxin Required for the Activity of Iron/Sulfur Enzymes. Mol. Biol. Cell $13,1109-1121$.

Roret, T., Tsan, P., Couturier, J., Zhang, B., Johnson, M.K., Rouhier, N., and Didierjean, C. (2014). Structural and Spectroscopic Insights into BolA-Glutaredoxin Complexes. J. Biol. Chem. 289, 24588-24598.

Rouhier, N., Gelhaye, E., and Jacquot, J.-P. (2004). Plant glutaredoxins: still mysterious reducing systems. Cell. Mol. Life Sci. CMLS 61, 1266-1277.

Rouhier, N., Villarejo, A., Srivastava, M., Gelhaye, E., Keech, O., Droux, M., Finkemeier, I., Samuelsson, G., Dietz, K.J., Jacquot, J.-P., et al. (2005). Identification of Plant Glutaredoxin Targets. Antioxid. Redox Signal. 7, 919-929.

Rouhier, N., Unno, H., Bandyopadhyay, S., Masip, L., Kim, S.-K., Hirasawa, M., Gualberto, J.M., Lattard, V., Kusunoki, M., Knaff, D.B., et al. (2007). Functional, structural, and spectroscopic characterization of a glutathione-ligated [2Fe-2S] cluster in poplar glutaredoxin C1. Proc. Natl. Acad. Sci. U. S. A. 104, 7379-7384.

Saiki, R.K., Scharf, S., Faloona, F., Mullis, K.B., Horn, G.T., Erlich, H.A., and Arnheim, N. (1985). Enzymatic amplification of beta-globin genomic sequences and restriction site analysis for diagnosis of sickle cell anemia. Science 230, 1350-1354.

Sessions, A., Burke, E., Presting, G., Aux, G., McElver, J., Patton, D., Dietrich, B., Ho, P., Bacwaden, J., Ko, C., et al. (2002). A high-throughput Arabidopsis reverse genetics system. Plant Cell 14, 2985-2994.

Sha, S., Minakuchi, K., Higaki, N., Sato, K., Ohtsuki, K., Kurata, A., Yoshikawa, H., Kotaru, M., Masumura, T., Ichihara, K., et al. (1997). Purification and Characterization of Glutaredoxin (Thioltransferase) from Rice (Oryza sativa L.). J. Biochem. (Tokyo) 121, 842848.

Ströher, E., and Millar, A.H. (2012). The biological roles of glutaredoxins. Biochem. J. 446, 333-348.

Ströher, E., Grassl, J., Carrie, C., Fenske, R., Whelan, J., and Millar, A.H. (2016). Glutaredoxin S15 Is Involved in Fe-S Cluster Transfer in Mitochondria Influencing Lipoic Acid-Dependent Enzymes, Plant Growth, and Arsenic Tolerance in Arabidopsis. Plant Physiol. 170, 1284-1299.

Thines, B., Katsir, L., Melotto, M., Niu, Y., Mandaokar, A., Liu, G., Nomura, K., He, S.Y., Howe, G.A., and Browse, J. (2007). JAZ repressor proteins are targets of the SCF ${ }^{\mathrm{CO} 1}$ complex during jasmonate signalling. Nature 448, 661-665. 
Uhrig, J.F., Huang, L.-J., Barghahn, S., Willmer, M., Thurow, C., and Gatz, C. (2017). CC-type glutaredoxins recruit the transcriptional co-repressor TOPLESS to TGA-dependent target promoters in Arabidopsis thaliana. Biochim. Biophys. Acta BBA - Gene Regul. Mech. 1860, 218-226.

Van der Does, D., Leon-Reyes, A., Koornneef, A., Van Verk, M.C., Rodenburg, N., Pauwels, L., Goossens, A., Körbes, A.P., Memelink, J., Ritsema, T., et al. (2013). Salicylic Acid Suppresses Jasmonic Acid Signaling Downstream of SCFCOI1-JAZ by Targeting GCC Promoter Motifs via Transcription Factor ORA59. Plant Cell 25, 744-761.

Vernoux, T., Wilson, R.C., Seeley, K.A., Reichheld, J.-P., Muroy, S., Brown, S., Maughan, S.C., Cobbett, C.S., Montagu, M.V., Inzé, D., et al. (2000). The ROOT MERISTEMLESS1/CADMIUM SENSITIVE2 Gene Defines a Glutathione-Dependent Pathway Involved in Initiation and Maintenance of Cell Division during Postembryonic Root Development. The Plant Cell 12, 97.

Walters, L.A., and Escobar, M.A. (2016). The AtGRXS3/4/5/7/8 glutaredoxin gene cluster on Arabidopsis thaliana chromosome 4 is coordinately regulated by nitrate and appears to control primary root growth. Plant Signal. Behav. 11.

Wang, L., Li, Y., Jacquot, J.-P., Rouhier, N., and Xia, B. (2014). Characterization of poplar GrxS14 in different structural forms. Protein Cell 5, 329-333.

Wang, Z., Xing, S., Birkenbihl, R.P., and Zachgo, S. (2009). Conserved Functions of Arabidopsis and Rice CC-Type Glutaredoxins in Flower Development and Pathogen Response. Mol. Plant 2, 323-335.

Wienken, C.J., Baaske, P., Rothbauer, U., Braun, D., and Duhr, S. (2010). Protein-binding assays in biological liquids using microscale thermophoresis. Nat. Commun. 1, ncomms1093.

Xing, S., and Zachgo, S. (2008). ROXY1 and ROXY2, two Arabidopsis glutaredoxin genes, are required for anther development. Plant J. 53, 790-801.

Xing, S., Rosso, M.G., and Zachgo, S. (2005). ROXY1, a member of the plant glutaredoxin family, is required for petal development in Arabidopsis thaliana. Development 132, 15551565.

Zander, M., La Camera, S., Lamotte, O., Métraux, J.-P., and Gatz, C. (2010). Arabidopsis thaliana class-II TGA transcription factors are essential activators of jasmonic acid/ethyleneinduced defense responses. Plant J. 61, 200-210.

Zander, M. (2011). Arabidopsis thaliana class II TGA transcription factors provide a molecular link between salicylic acid and ethylene defense signalling. Dissertation.

Zander, M., Chen, S., Imkampe, J., Thurow, C., and Gatz, C. (2012). Repression of the Arabidopsis thaliana Jasmonic Acid/Ethylene-Induced Defense Pathway by TGA-Interacting Glutaredoxins Depends on Their C-Terminal ALWL Motif. Mol. Plant 5, 831-840. 
Zander, M., Thurow, C., and Gatz, C. (2014). TGA Transcription Factors Activate the Salicylic Acid-Suppressible Branch of the Ethylene-Induced Defense Program by Regulating ORA59 Expression. Plant Physiol. 165, 1671-1683.

Zhang, B., Bandyopadhyay, S., Shakamuri, P., Naik, S.G., Huynh, B.H., Couturier, J., Rouhier, N., and Johnson, M.K. (2013). Monothiol Glutaredoxins Can Bind Linear [Fe3S4]+ and [Fe4S4]2+ Clusters in Addition to [Fe2S2]2+ Clusters: Spectroscopic Characterization and Functional Implications. J. Am. Chem. Soc. 135.

Zhang, Y., Tessaro, M.J., Lassner, M., and Li, X. (2003). Knockout Analysis of Arabidopsis Transcription Factors TGA2, TGA5, and TGA6 Reveals Their Redundant and Essential Roles in Systemic Acquired Resistance. Plant Cell 15, 2647-2653.

Zhu, Z., An, F., Feng, Y., Li, P., Xue, L., A, M., Jiang, Z., Kim, J.-M., To, T.K., Li, W., et al. (2011). Derepression of ethylene-stabilized transcription factors (EIN3/EIL1) mediates jasmonate and ethylene signaling synergy in Arabidopsis. Proc Natl Acad Sci USA 108 (30):12539-44. 


\section{Anhang}
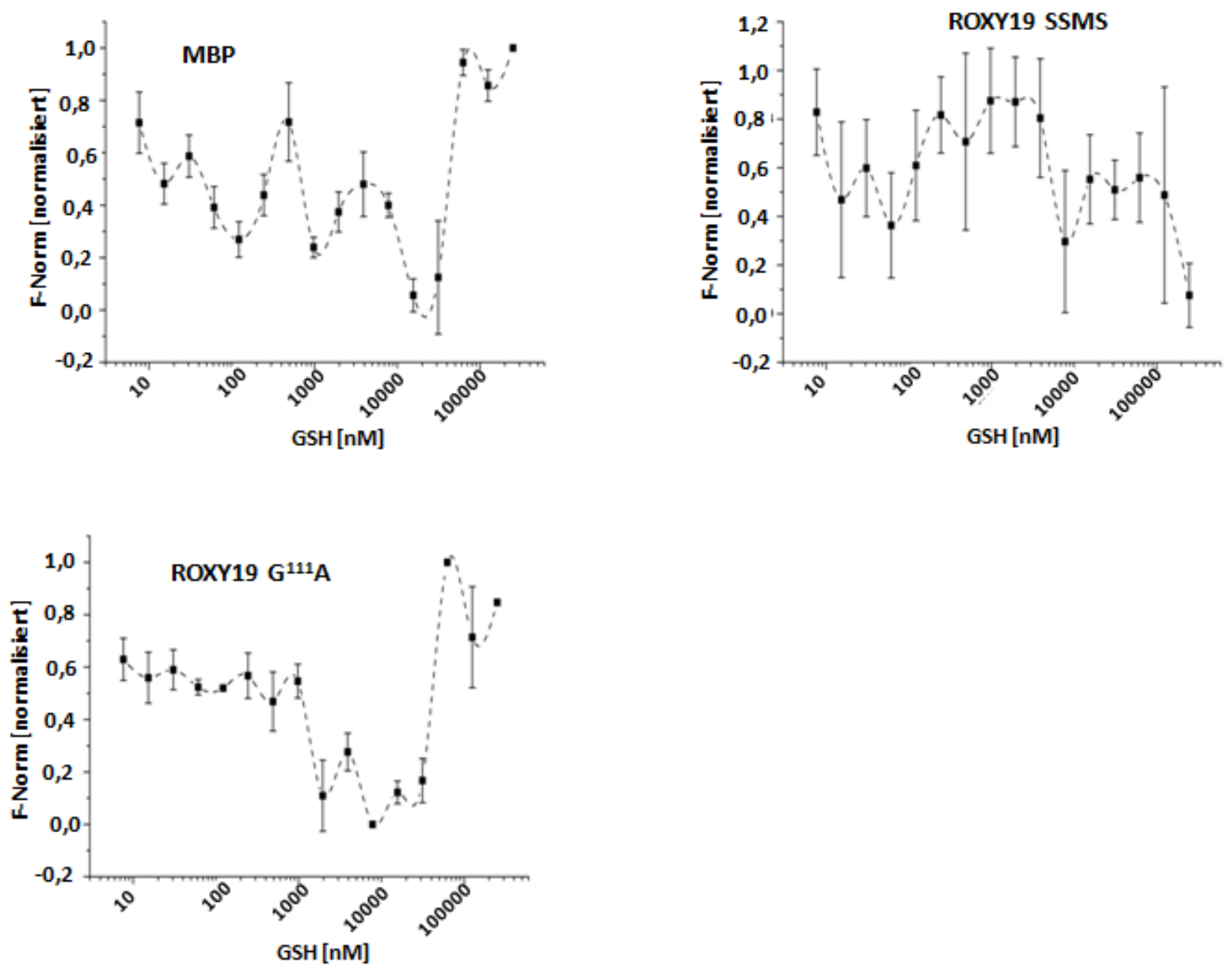

Anhang 6.1. Affinität von Strep-MBP, ROXY19 SSMS und ROXY19 G ${ }^{111}$ A zu GSH. MST-Messungen von StrepMBP, Strep-MBP-ROXY19 SSMS und Strep-MBP-ROXY19 $\mathrm{G}^{111} \mathrm{~A}$ mit GSH. Gezeigt ist die normalisierte Fluoreszenz $\left(F_{\text {norm }}=F_{\text {heis }} / F_{\text {kalt }}\right)$ gegen die GSH Konzentration. Alle drei Proteine ergaben keine messbare Dissoziationskonstante und zeigten somit keine Affinität zu GSH. Die Messreihen wurden dreimal, zu je Triplikaten durchgeführt. Die Messungen und Auswertungen erfolgten durch Herrn Dr. Sven Freibert (Philipps Universität Marburg). 

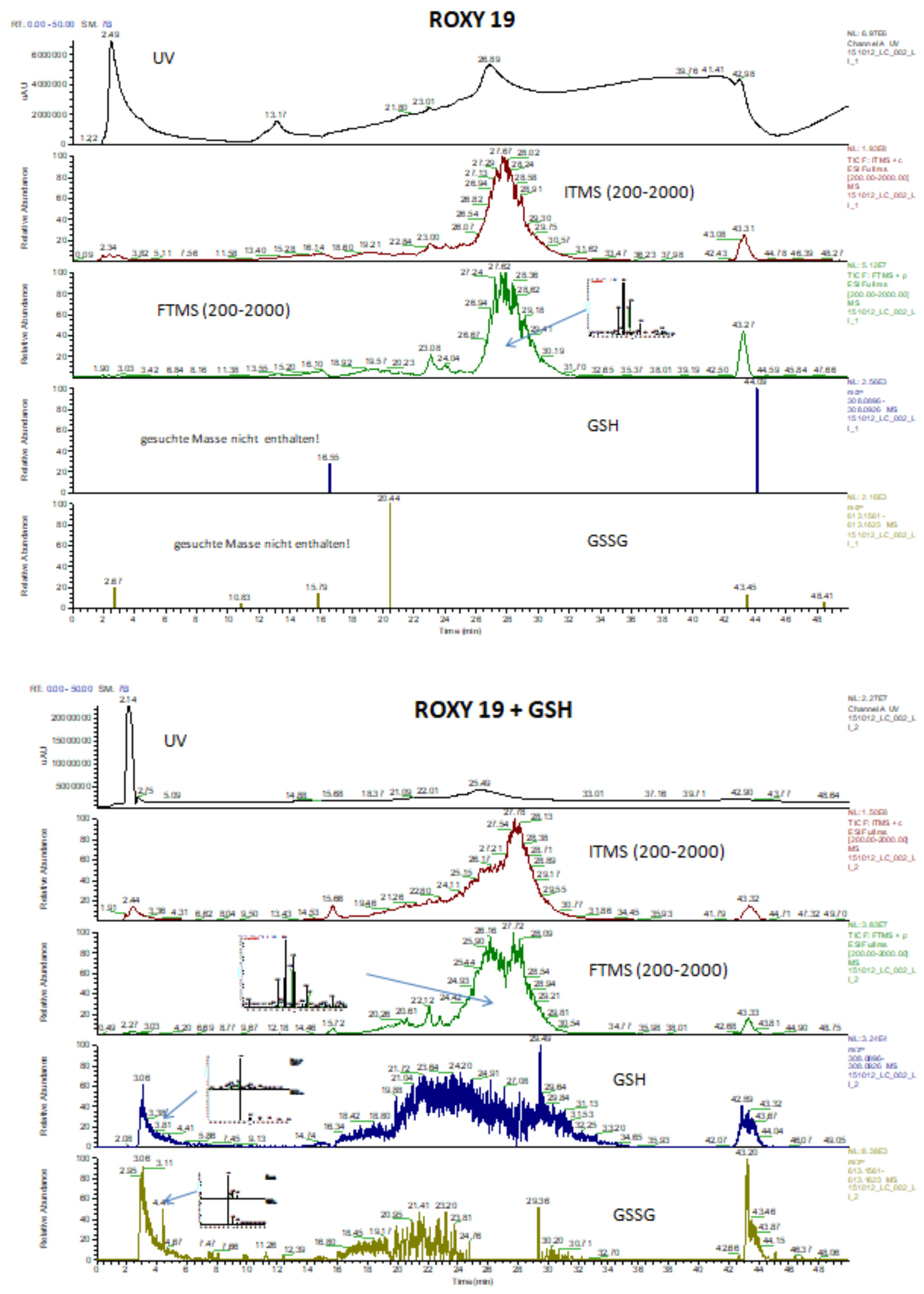
GRX370
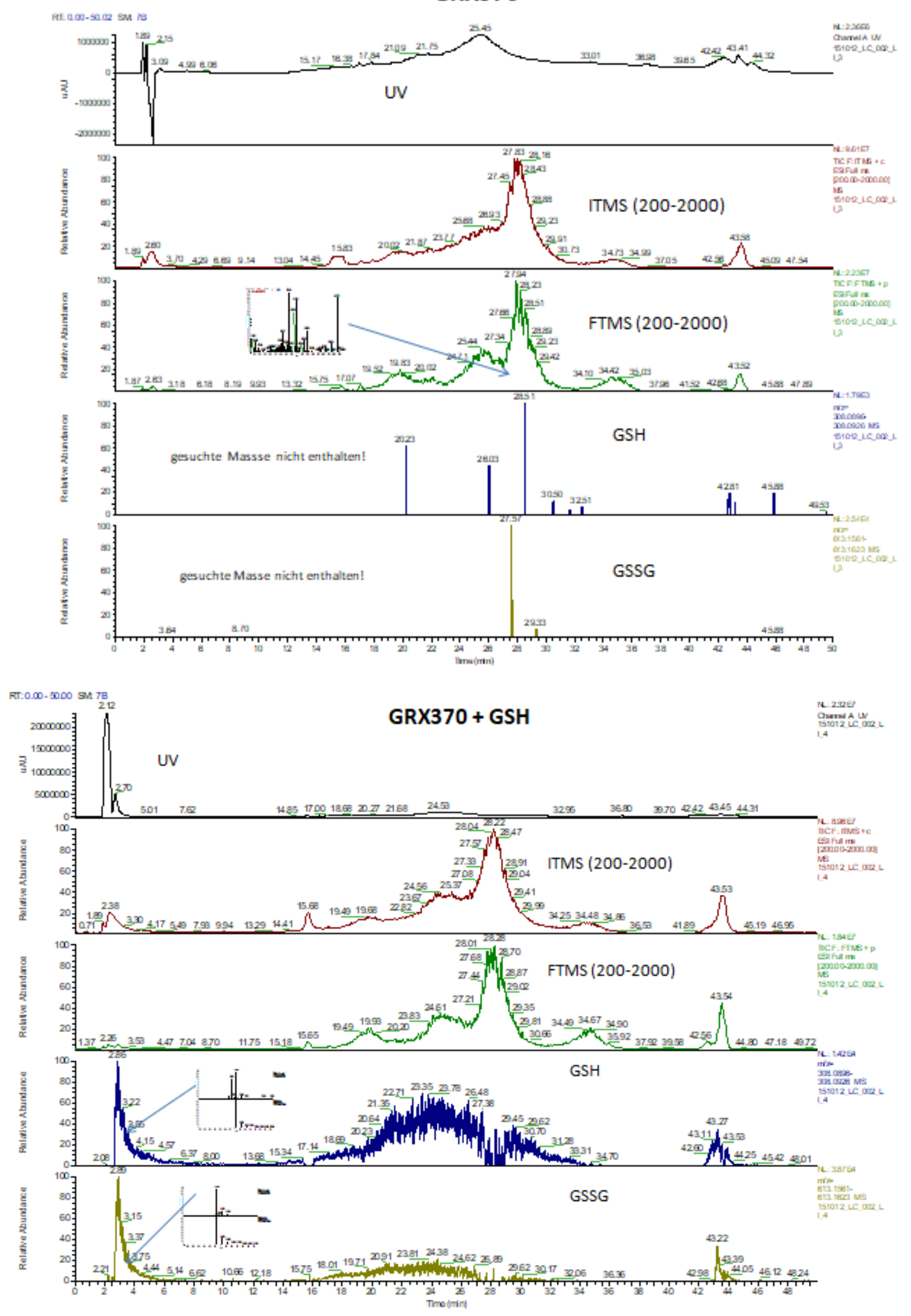

92 
Anhang 6.2. MS-Daten von ROXY19 und GRX370. Gezeigt wurde für ROXY19 und GRX370, dass nach der Expression in E. coli und Reinigung kein GSH oder GSSG gebunden ist. Dies bedeutet in Bezug auf die inkorporierte Eisen-Spezies, dass diese nicht durch GSH komplexiert wird. Diese Messungen wurden freundlicherweise an der Philipps Universität Marburg im Auftrag von Dr. Sven Freibert durchgeführt und ausgewertet. 


\begin{tabular}{|c|c|}
\hline 01 & 100 \\
\hline 02 & 75 \\
\hline 03 & 250 \\
\hline 04 & 250 \\
\hline 05 & 500 \\
\hline 06 & 500 \\
\hline 07 & 120 \\
\hline 08 & 500 \\
\hline 09 & 500 \\
\hline 10 & 500 \\
\hline 11 & 500 \\
\hline 12 & 500 \\
\hline 13 & 500 \\
\hline 14 & 200 \\
\hline 15 & 5 \\
\hline 16 & 2500 \\
\hline 17 & 750 \\
\hline 18 & 2000 \\
\hline 19 & 2000 \\
\hline 20 & 2000 \\
\hline 21 & 500 \\
\hline 22 & 2500 \\
\hline 23 & 2000 \\
\hline 24 & 10 \\
\hline 25 & 500 \\
\hline 26 & 500 \\
\hline 27 & 500 \\
\hline 28 & 500 \\
\hline 29 & 80 \\
\hline 30 & 500 \\
\hline 31 & 500 \\
\hline 32 & 500 \\
\hline 33 & 500 \\
\hline 34 & 200 \\
\hline 35 & 30 \\
\hline 36 & 3 \\
\hline 37 & 150 \\
\hline 38 & 20 \\
\hline 39 & 5 \\
\hline 40 & 50 \\
\hline 41 & 100 \\
\hline 42 & 100 \\
\hline 43 & 1000 \\
\hline 44 & 1000 \\
\hline 45 & 1000 \\
\hline 46 & 1000 \\
\hline 47 & 800 \\
\hline 48 & 500 \\
\hline 49 & 500 \\
\hline 50 & 500 \\
\hline 51 & 500 \\
\hline 52 & 500 \\
\hline 53 & 5 \\
\hline 54 & 25 \\
\hline 55 & 25 \\
\hline 56 & 25 \\
\hline 57 & 25 \\
\hline 58 & 25 \\
\hline 59 & 500 \\
\hline 60 & 500 \\
\hline 61 & 500 \\
\hline 62 & 500 \\
\hline 63 & 250 \\
\hline 64 & 250 \\
\hline 65 & 250 \\
\hline 66 & 500 \\
\hline 67 & 500 \\
\hline 68 & 500 \\
\hline 69 & 250 \\
\hline 70 & 250 \\
\hline 71 & 250 \\
\hline 72 & 1000 \\
\hline 73 & 1400 \\
\hline 74 & 700 \\
\hline 75 & 1000 \\
\hline 76 & 1400 \\
\hline 77 & 1000 \\
\hline 78 & 40 \\
\hline 79 & 50 \\
\hline 80 & 10 \\
\hline 81 & 10 \\
\hline 82 & 5 \\
\hline 83 & 5 \\
\hline 84 & 50 \\
\hline 85 & 10 \\
\hline 86 & 25 \\
\hline 87 & 10 \\
\hline 88 & 3 \\
\hline 89 & 3 \\
\hline 90 & 3 \\
\hline 91 & 2 \\
\hline 92 & 2 \\
\hline 93 & 10 \\
\hline 94 & 80 \\
\hline 95 & 10 \\
\hline 96 & 50 \\
\hline
\end{tabular}




\begin{tabular}{|c|c|c|c|}
\hline Reage & Buffe & Buffer & Buffer \\
\hline$\#$ & & units & \\
\hline 1 & & & \\
\hline 2 & 0,2 & M & Sodium acetate trihydrate \\
\hline 3 & 0,2 & M & Sodium citrate tribasic dihydrate \\
\hline 4 & 0,2 & M & Succinic acid \\
\hline 5 & 0,2 & M & MES monohydrate \\
\hline 6 & 0,2 & M & BIS-TRIS \\
\hline 7 & 0,2 & M & Imidazole \\
\hline 8 & 0,2 & M & HEPES \\
\hline 9 & 0,2 & M & Tris \\
\hline 10 & 0,2 & M & BIS-TRIS Propane \\
\hline 11 & 0,2 & M & AMPD \\
\hline 12 & 0,2 & M & Glycine \\
\hline 13 & & & \\
\hline 14 & 0,2 & M & Sodium acetate trihydrate \\
\hline 15 & 0,2 & M & Sodium citrate tribasic dihydrate \\
\hline 16 & 0,2 & M & Succinic acid \\
\hline 17 & 0,2 & M & MES monohydrate \\
\hline 18 & 0,2 & $M$ & BIS-TRIS \\
\hline 19 & 0,2 & M & Imidazole \\
\hline 20 & 0,2 & $M$ & HEPES \\
\hline 21 & 0,2 & M & Tris \\
\hline 22 & 0,2 & M & BIS-TRIS Propane \\
\hline 23 & 0,2 & M & AMPD \\
\hline 24 & 0,2 & M & Glycine \\
\hline 25 & & & \\
\hline 26 & 0,2 & M & Sodium acetate trihydrate \\
\hline 27 & 0,2 & $M$ & Sodium citrate tribasic dihydrate \\
\hline 28 & 0,2 & M & Succinic acid \\
\hline 29 & 0,2 & M & MES monohydrate \\
\hline 30 & 0,2 & M & BIS-TRIS \\
\hline 31 & 0,2 & M & Imidazole \\
\hline 32 & 0,2 & M & HEPES \\
\hline 33 & 0,2 & M & Tris \\
\hline 34 & 0,2 & M & BIS-TRIS Propane \\
\hline 35 & 0,2 & M & AMPD \\
\hline 36 & 0,2 & M & Glycine \\
\hline 37 & & & \\
\hline 38 & 0,2 & M & Sodium acetate trihydrate \\
\hline 39 & 0,2 & M & Sodium citrate tribasic dihydrate \\
\hline 40 & 0,2 & M & Succinic acid \\
\hline 41 & 0,2 & M & MES monohydrate \\
\hline 42 & 0,2 & $M$ & BIS-TRIS \\
\hline 43 & 0,2 & M & Imidazole \\
\hline 44 & 0,2 & M & HEPES \\
\hline 45 & 0,2 & M & Tris \\
\hline 46 & 0,2 & M & BIS-TRIS Propane \\
\hline 47 & 0,2 & $M$ & AMPD \\
\hline 48 & 0,2 & M & Glycine \\
\hline 49 & & & \\
\hline 50 & 0,2 & M & Sodium acetate trihydrate \\
\hline 51 & 0,2 & M & Sodium citrate tribasic dihydrate \\
\hline 52 & 0,2 & M & Succinic acid \\
\hline 53 & 0,2 & M & MES monohydrate \\
\hline 54 & 0,2 & M & BIS-TRIS \\
\hline 55 & 0,2 & M & Imidazole \\
\hline 56 & 0,2 & M & HEPES \\
\hline 57 & 0,2 & M & Tris \\
\hline 58 & 0,2 & M & BIS-TRIS Propane \\
\hline 59 & 0,2 & M & AMPD \\
\hline 60 & 0,2 & M & Glycine \\
\hline 61 & & & \\
\hline 62 & 0,2 & M & Sodium acetate trihydrate \\
\hline 63 & 0,2 & M & Sodium citrate tribasic dihydrate \\
\hline 64 & 0,2 & M & Succinic acid \\
\hline 65 & 0,2 & M & MES monohydrate \\
\hline 66 & 0,2 & M & BIS-TRIS \\
\hline 67 & 0,2 & M & Imidazole \\
\hline 68 & 0,2 & M & HEPES \\
\hline 69 & 0,2 & M & Tris \\
\hline 70 & 0,2 & M & BIS-TRIS Propane \\
\hline 71 & 0,2 & M & AMPD \\
\hline 72 & 0,2 & M & Glycine \\
\hline 73 & & & \\
\hline 74 & 0,2 & M & Sodium acetate trihydrate \\
\hline 75 & 0,2 & $M$ & Sodium citrate tribasic dihydrate \\
\hline 76 & 0,2 & M & Succinic acid \\
\hline 77 & 0,2 & M & MES monohydrate \\
\hline 78 & 0,2 & M & BIS-TRIS \\
\hline 79 & 0,2 & M & Imidazole \\
\hline 80 & 0,2 & M & HEPES \\
\hline 81 & 0,2 & $M$ & Tris \\
\hline 82 & 0,2 & M & BIS-TRIS Propane \\
\hline 83 & 0,2 & M & AMPD \\
\hline 84 & 0,2 & M & Glycine \\
\hline 85 & & & \\
\hline 86 & 0,2 & M & Sodium acetate trihydrate \\
\hline 87 & 0,2 & M & Sodium citrate tribasic dihydrate \\
\hline 88 & 0,2 & M & Succinic acid \\
\hline 89 & 0,2 & M & MES monohydrate \\
\hline 90 & 0,2 & M & BIS-TRIS \\
\hline 91 & 0,2 & M & Imidazole \\
\hline 92 & 0,2 & M & HEPES \\
\hline 93 & 0,2 & M & Tris \\
\hline
\end{tabular}




\begin{tabular}{|c|c|}
\hline $\begin{array}{c}\text { Reagent } \\
\#\end{array}$ & [Additive] \\
\hline 1 & 0,1 \\
\hline 2 & 0,1 \\
\hline 3 & 0,1 \\
\hline 4 & 0,1 \\
\hline 5 & 0,1 \\
\hline 6 & 0,1 \\
\hline 7 & 0,1 \\
\hline 8 & 0,1 \\
\hline 9 & 0,1 \\
\hline 10 & 0,1 \\
\hline 11 & 0,1 \\
\hline 12 & 0,1 \\
\hline 13 & 0,1 \\
\hline 14 & 0,1 \\
\hline 15 & 1,0 \\
\hline 16 & 1,0 \\
\hline 17 & 1,0 \\
\hline 18 & 2,0 \\
\hline 19 & 0,5 \\
\hline 20 & 1,0 \\
\hline 21 & 2,0 \\
\hline 22 & 1,0 \\
\hline 23 & 1,0 \\
\hline 24 & 1,0 \\
\hline 25 & 1,0 \\
\hline 26 & 0,1 \\
\hline 27 & 0,1 \\
\hline 28 & 30 \\
\hline 29 & 0,1 \\
\hline 30 & 30 \\
\hline 31 & 30 \\
\hline 32 & 30 \\
\hline 33 & 30 \\
\hline 34 & 1,0 \\
\hline 35 & 0,3 \\
\hline 36 & 0,1 \\
\hline 37 & 0,1 \\
\hline 38 & 0,1 \\
\hline 39 & 0,1 \\
\hline 40 & 0,1 \\
\hline 41 & 0,1 \\
\hline 42 & 0,1 \\
\hline 43 & 1,0 \\
\hline 44 & 0,1 \\
\hline 45 & 0,1 \\
\hline 46 & 0,1 \\
\hline 47 & 0,1 \\
\hline 48 & 0,01 \\
\hline 49 & 0,1 \\
\hline 50 & 5 \\
\hline 51 & 30 \\
\hline 52 & 40 \\
\hline 53 & 10 \\
\hline 54 & 30 \\
\hline 55 & 30 \\
\hline 56 & 30 \\
\hline 57 & 30 \\
\hline 58 & 12 \\
\hline 59 & 30 \\
\hline 60 & 30 \\
\hline 61 & 30 \\
\hline 62 & 30 \\
\hline 63 & 3,0 \\
\hline 64 & 2,0 \\
\hline 65 & 2,0 \\
\hline 66 & 2,0 \\
\hline 67 & 1,0 \\
\hline 68 & 0,15 \\
\hline 69 & 20 \\
\hline 70 & 5 \\
\hline 71 & 5 \\
\hline 72 & 5 \\
\hline 73 & 30 \\
\hline 74 & 30 \\
\hline 75 & 30 \\
\hline 76 & 50 \\
\hline 77 & 50 \\
\hline 78 & 40 \\
\hline 79 & 40 \\
\hline 80 & 40 \\
\hline 81 & 30 \\
\hline 82 & 30 \\
\hline 83 & 30 \\
\hline 84 & 30 \\
\hline 85 & 10 \\
\hline 86 & 40 \\
\hline 87 & 40 \\
\hline 88 & 40 \\
\hline 89 & 40 \\
\hline 90 & 40 \\
\hline 91 & 5 \\
\hline 92 & 40 \\
\hline 93 & 0.25 \\
\hline 94 & 7 \\
\hline 95 & 40 \\
\hline 96 & 40 \\
\hline
\end{tabular}

Anhang 6.3. Originale Daten der Messungen der verschiedenen Assays von Hampton Research zur Löslichkeit und Stabilität. Die erste Tabelle sind die Ergebnisse des Solubility \& Stability Screen I, die zweite des Solubility \& Stability Screen II und die dritte des Additive Screen. Gezeigt sind die Temperaturen der Wendepunkte der einzelnen Kurven der Bedingungen. 


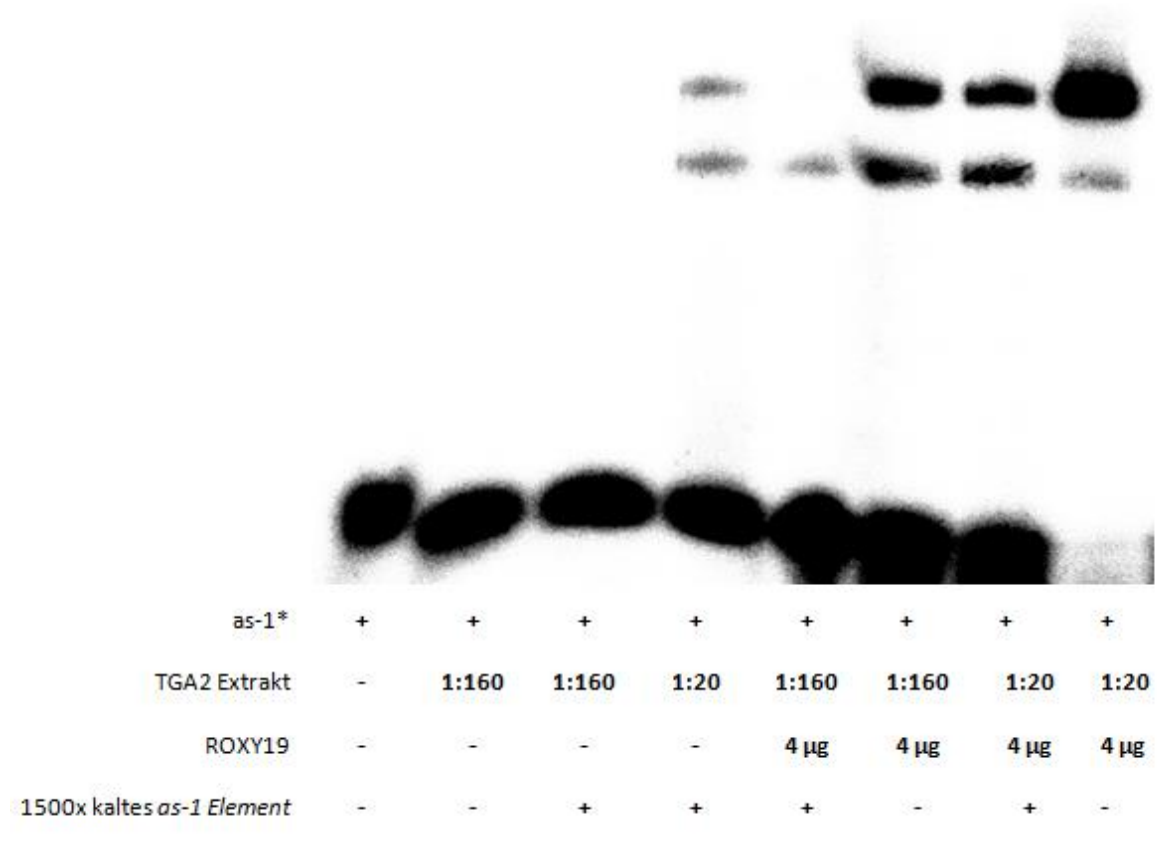

Anhang 6.4. Einfluss des kalten Fragments auf die Verstärkung der Bindung von TGA2 an as-1* durch ROXY19. EMSA mit radioaktiv markiertem as-1 Element von Gesamtzellextrakten von E. coli Expressionen von TGA2 (pAC28-TGA2) (1:160 Verdünnung) mit aus $E$. coli anaerob gereinigtem ROXY19, gemischt mit einem 1500x Überschuss an nicht radioaktiv markiertem (kaltes) as-1 Element, wenn angegeben (+). Anschließend wurden die Proben mit dem radioaktiv markiertem 88 bp as-1 element (as-1*) inkubiert. 


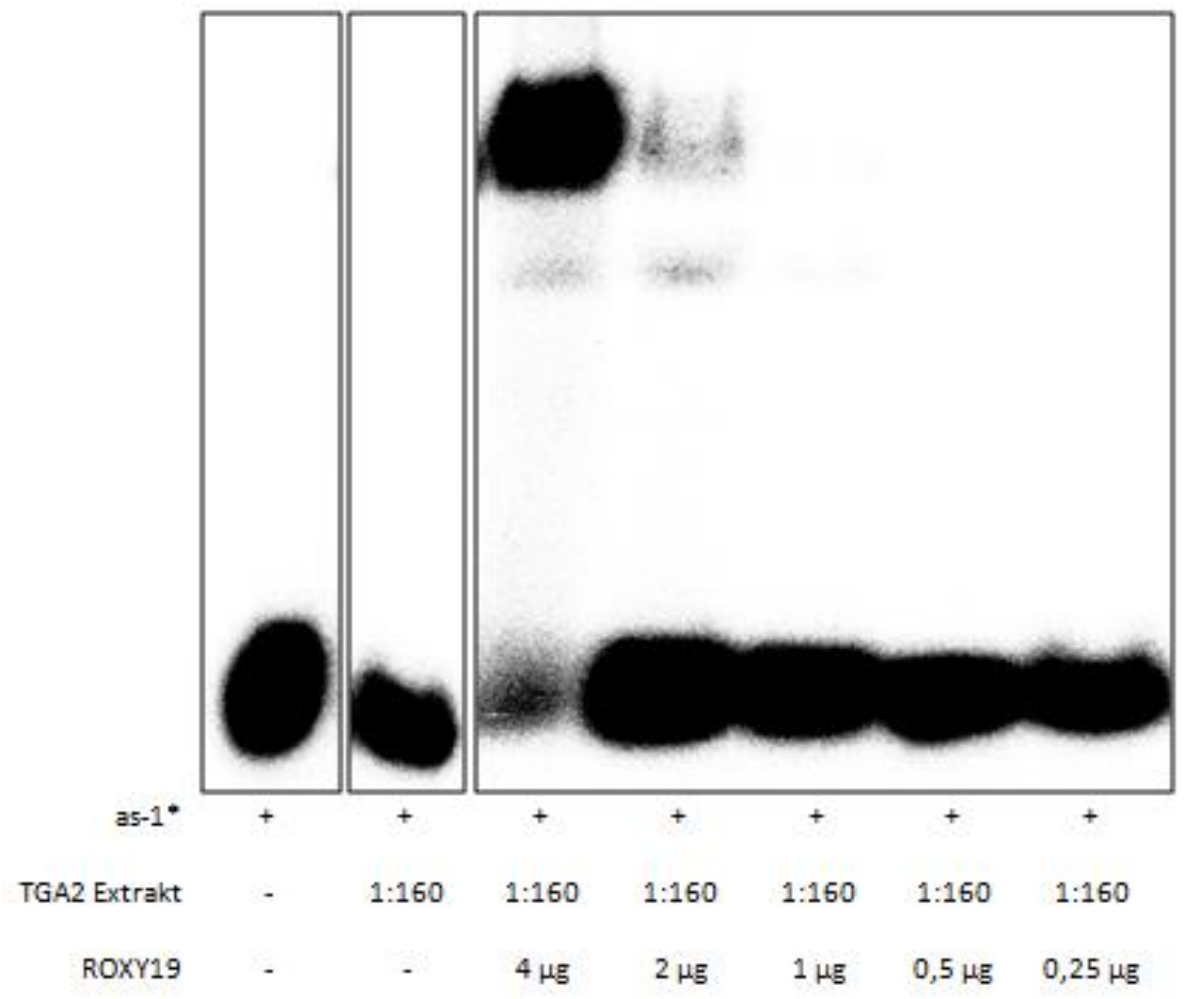

Anhang 6.5. Einfluss von ROXY19 Verdünnungen auf den TGA2-as-1* Komplex. EMSA mit radioaktiv markiertem as-1 Element von Gesamtzellextrakten von E. coli Expressionen von TGA2 (pAC28-TGA2) (1:160 Verdünnung) mit aus $E$. coli anaerob gereinigtem ROXY19, inkubiert mit dem radioaktiv markiertem 88 bp as-1 element (as-1*). Es wurden die jeweils angegebenen Mengen von ROXY19 eingesetzt. 


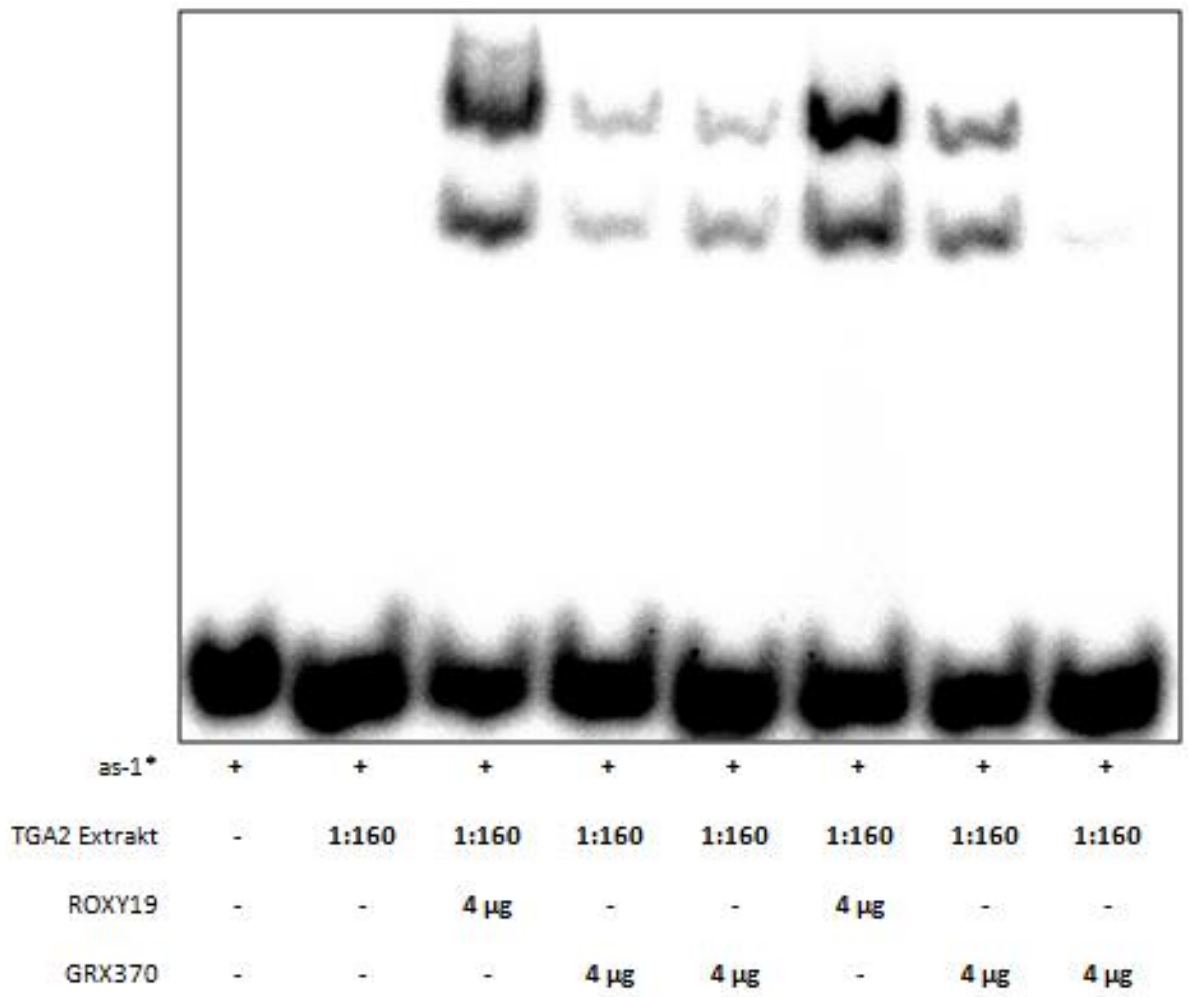

Anhang 6.6. Einfluss von ROXY19 und GRX370 auf den TGA2-as-1* Komplex. EMSA mit radioaktiv markiertem as-1 Element von Gesamtzellextrakten von E. coli Expressionen von TGA2 (pAC28-TGA2) (1:160 Verdünnung) mit aus $E$. coli anaerob gereinigtem ROXY19 und GRX370, inkubiert mit dem radioaktiv markiertem 88 bp as-1 element (as-1*). Es wurden je $4 \mu \mathrm{g}$ von ROXY19 und GRX370 eingesetzt. Es handelt sich in jeder Spur um eine unabhängige Expression von ROXY19 und GRX370. 


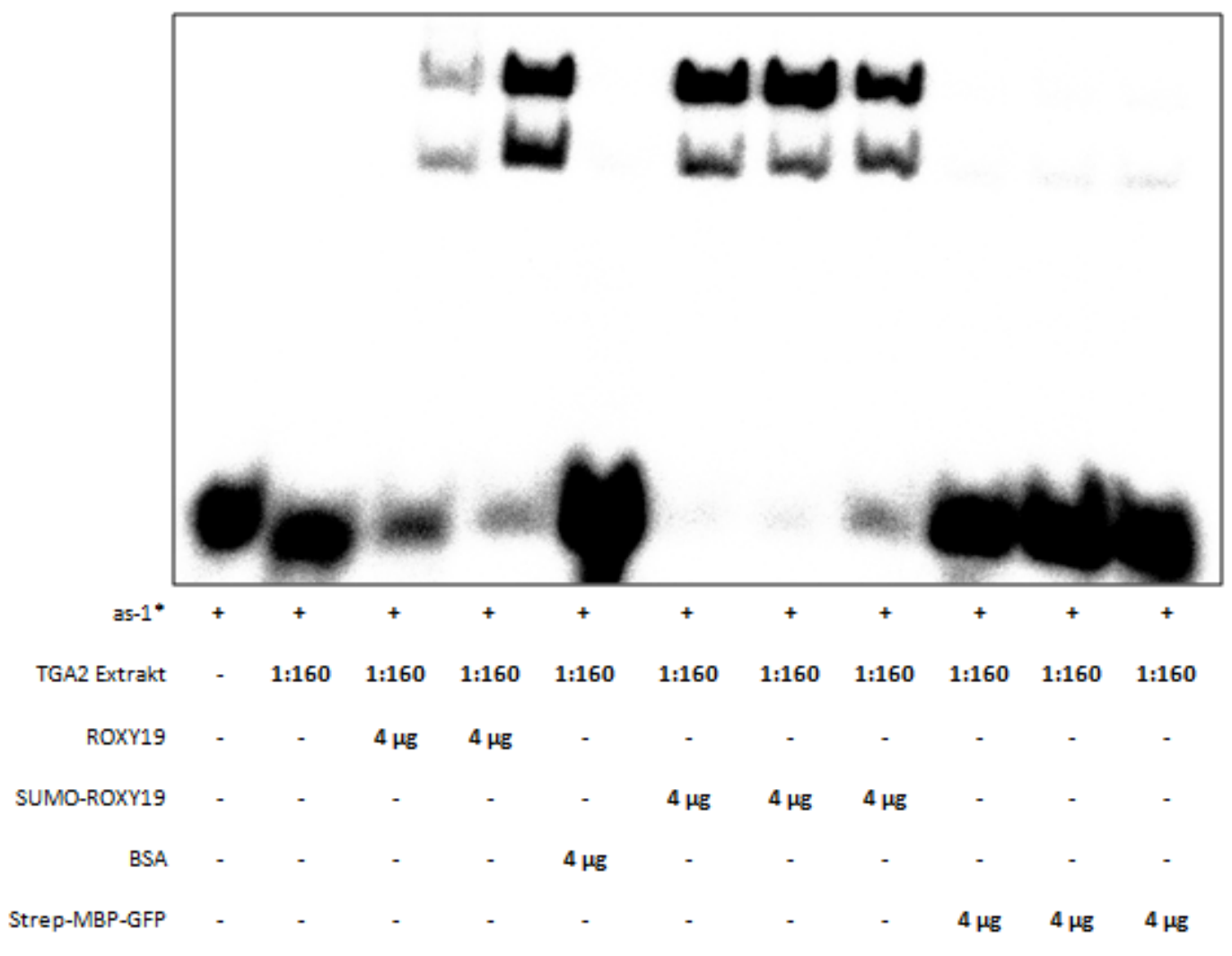

Anhang 6.7. Einfluss von ROXY19, BSA und GFP auf den TGA2-as-1* Komplex. EMSA mit radioaktiv markiertem as-1 Element von Gesamtzellextrakten von E. coli Expressionen von TGA2 (pAC28-TGA2) (1:160 Verdünnung) mit aus E. coli anaerob gereinigtem ROXY19 (mit Strep-MBP und Strep-SUMO tag) und GFP (Strep-MBP tag), inkubiert mit dem radioaktiv markiertem 88 bp as-1 element (as-1*). Es wurden je $4 \mu \mathrm{g}$ von ROXY19, GFP und BSA eingesetzt. Es handelt sich in jeder Spur um eine unabhängige Expression von ROXY19 und GFP. 


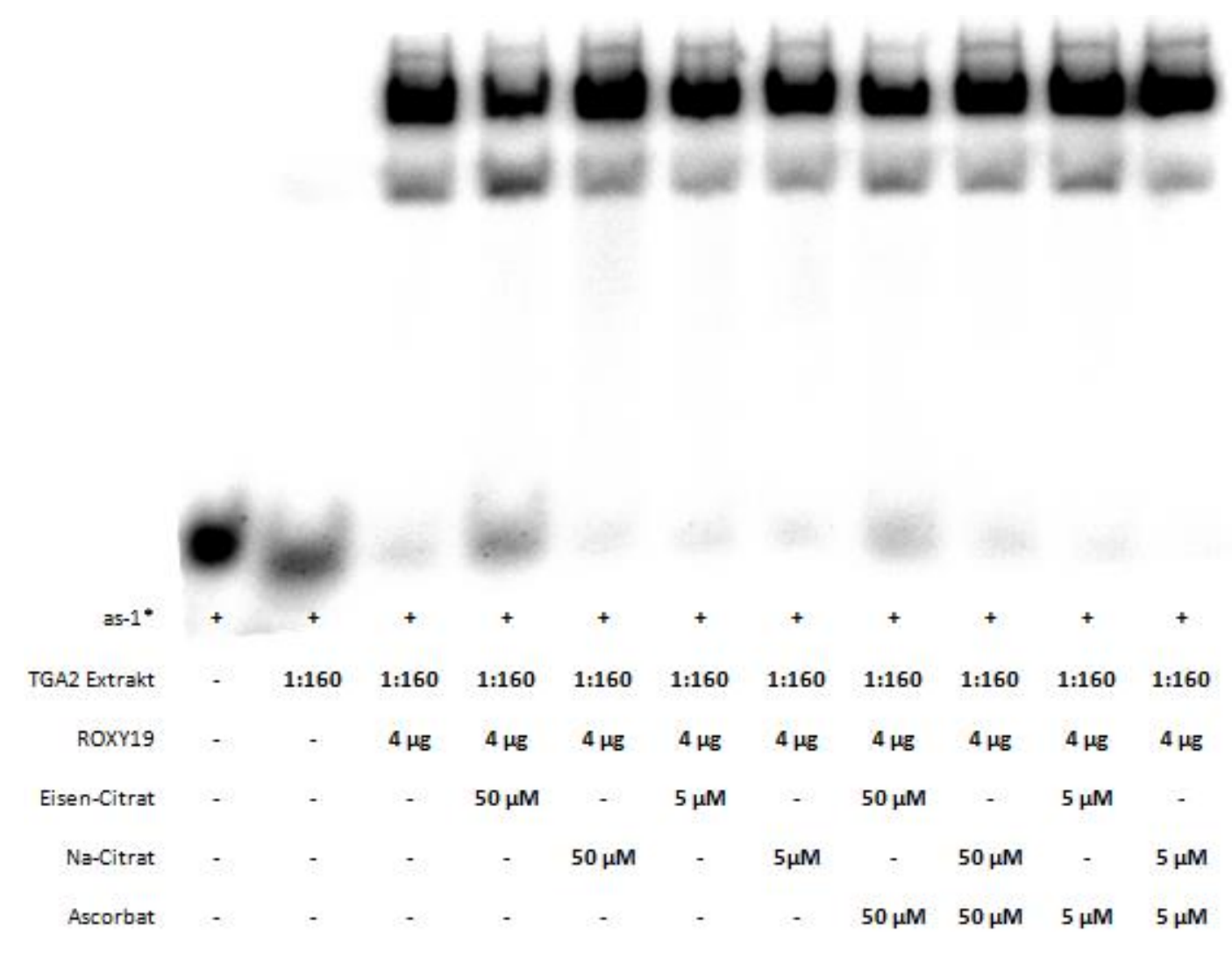

Anhang 6.8. Einfluss von Eisen auf die Bindungsverstärkung von ROXY19 auf den TGA2-as-1* Komplex. EMSA mit radioaktiv markiertem as-1 Element von Gesamtzellextrakten von $E$. coli Expressionen von TGA2 (pAC28TGA2) (1:160 Verdünnung) mit aus $E$. coli anaerob gereinigtem ROXY19, inkubiert mit dem radioaktiv markiertem 88 bp as-1 element (as- $1^{*}$ ). Es wurden je $4 \mu \mathrm{g}$ von ROXY19 eingesetzt. Es wurden die angegebenen Mengen an Eisen-Citrat $\left(\mathrm{Fe}^{3+}\right)$ oder der entsprechenden Kontrolle Na-Citrat, sowie Eisen-Citrat mit Ascorbat $\left(\mathrm{Fe}^{2+}\right)$ oder der entsprechenden Kontrolle mit Na-Citrat mit in den Reaktionsansatz gegeben. Der $\mathrm{pH}-\mathrm{Wert}$ betrug für alle Proben ca. 7,5. 


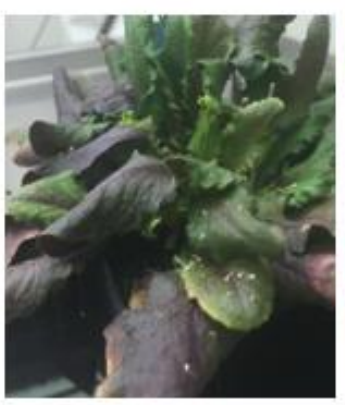

roxy18roxy19roxy20

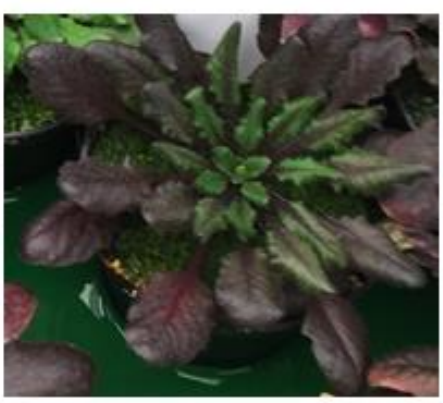

roxy18roxy19roxy20 pUBIGATOR

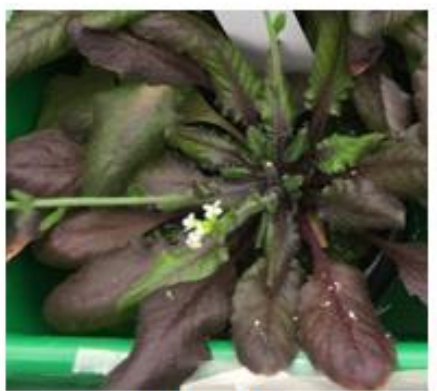

roxy18roxy19roxy20

pUBIGATOR-ROXY19

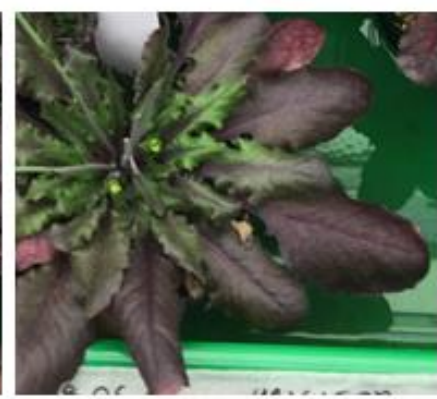

roxy18roxy19roxy20 PUBIGATOR

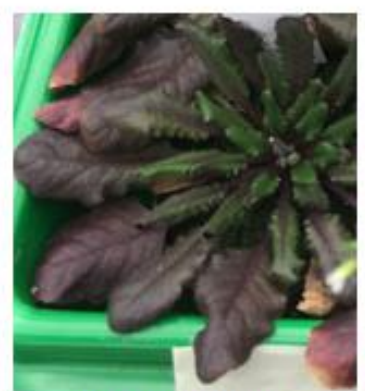

roxy18roxy19roxy20 pUBIGATOR-ROXY19

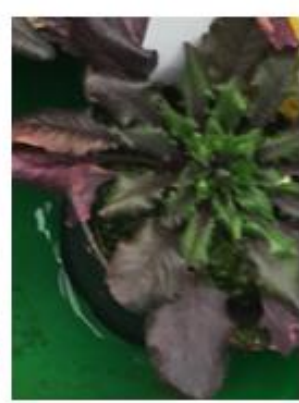

roxy18roxy19roxy20 pUBIGATOR

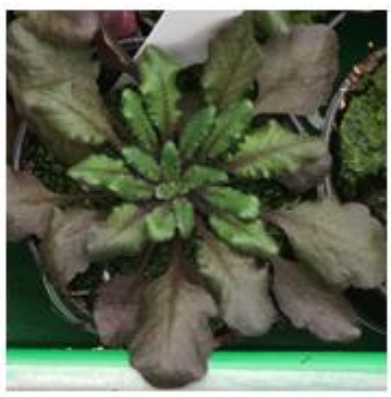

roxy18roxy19roxy20 pUBIGATOR-ROXY19

Anhang 6.9. Komplementation der roxy18roxy19roxy20 Mutante. Die roxy18roxy19roxy20 Mutante zeigte im Starklicht (160-190 $\mu \mathrm{mol} / \mathrm{m}^{2} / \mathrm{sek}$ ) einen Anthocyanin Phänotypen. Die Dreifachmutante wurde mit dem Vektor (pUBIGATOR) und ROXY19 (pUBIGATOR-ROXY19) komplementiert. Die Pflanzen wuchsen zunächst im Langtag (16 Stunden Licht / 8 Stunden Dunkelheit) unter normalen Lichtbedingungen $\left(80-100 \mu \mathrm{mol} / \mathrm{m}^{2} / \mathrm{sek}\right.$ ) für 4 Wochen und wurden dann für 2 weitere Wochen Starklicht (160-190 $\left.\mu \mathrm{mol} / \mathrm{m}^{2} / \mathrm{sek}\right)$ ausgesetzt. 


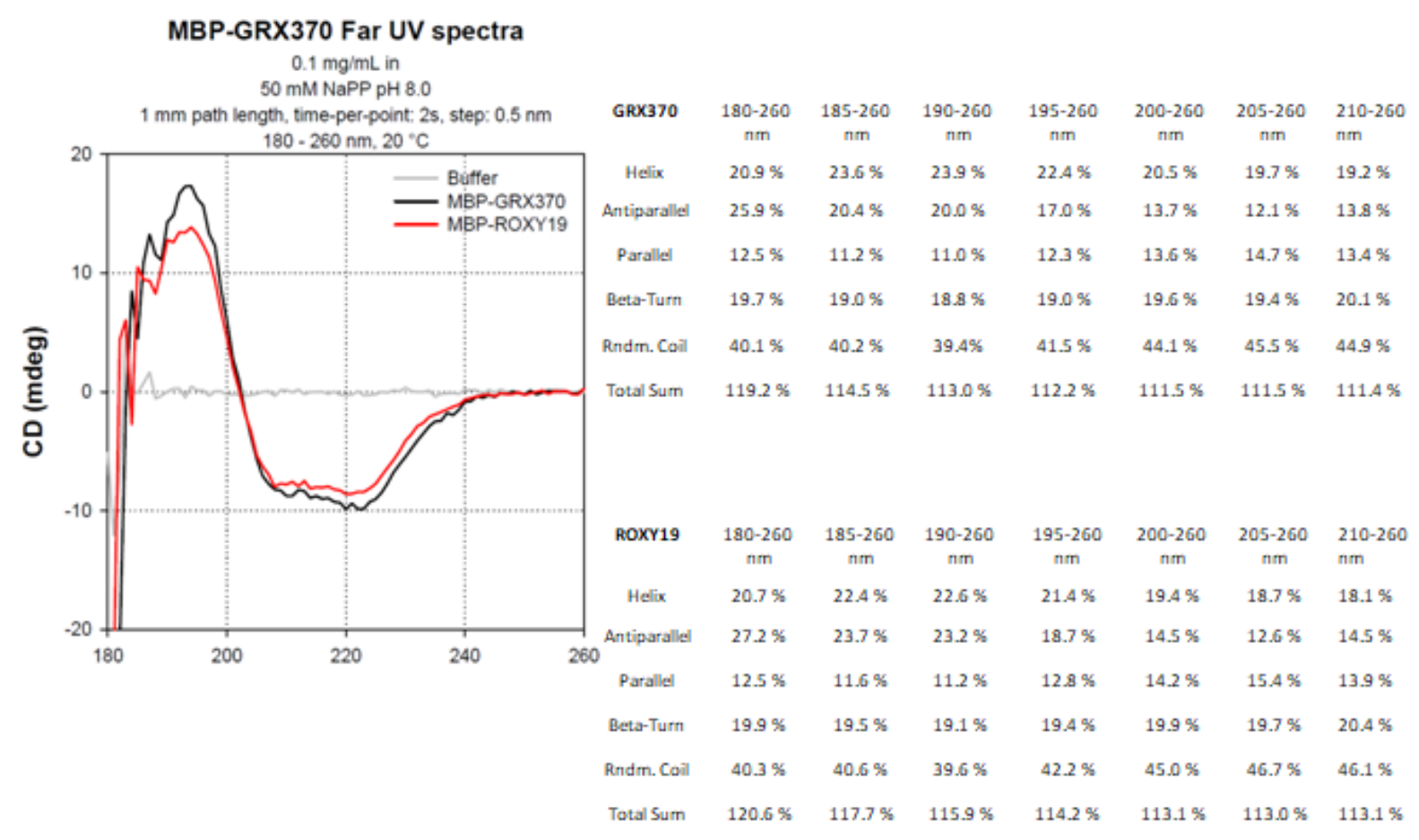

Anhang 6.10. CD-Spektren zur Faltung von ROXY19 und GRX370. Die gemessenen CD-Spektren von StrepMBP-ROXY19 und Strep-MBP-GRX370 zwischen $180 \mathrm{~nm}$ und $260 \mathrm{~nm}$ zeigen, dass beide Proteine eine sehr ähnliche Faltung aufweisen. 

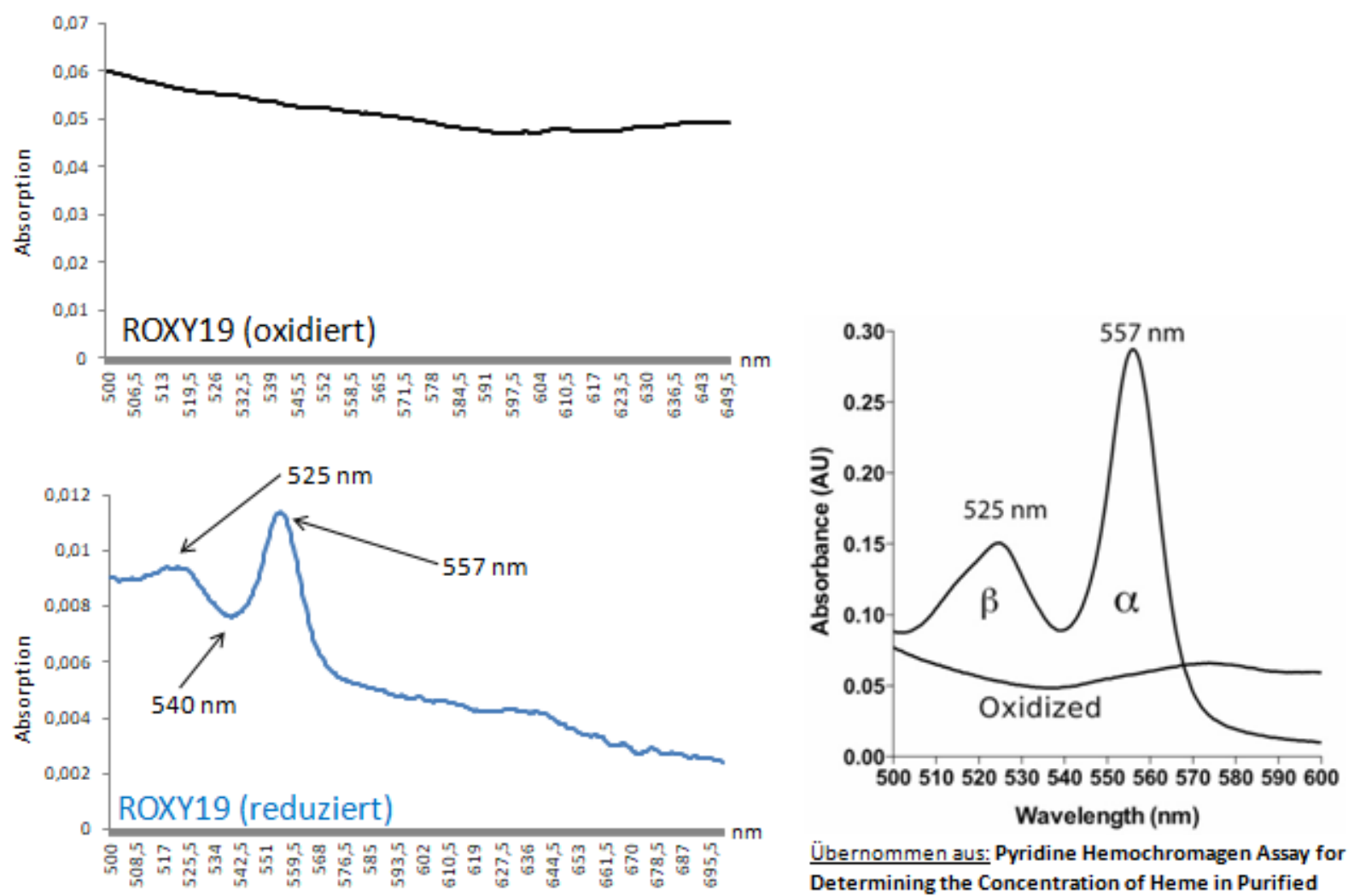

Übernommen aus: Pyridine Hemochromagen Assay for Determining the Concentration of Heme in Purified Protein Solutions

lan Barr and Feng Guo

Anhang 6.11. Häm-Bestimmung Spektren von ROXY19. Oben links: Gemessenes Spektrum für das oxidierte ROXY19 Oligomer (Peak 2). Unten links: Gemessenes Spektrum für das reduzierte ROXY19 Oligomer (Peak 2). Unten rechts: Abbildung aus (Barr and Guo, 2015) der Spektren für die Häm-Gruppe b. 


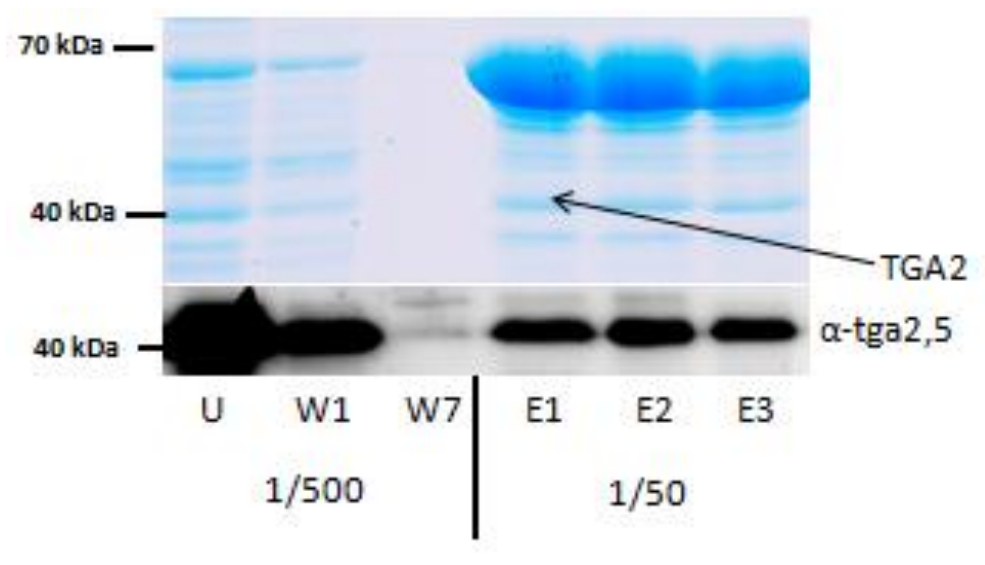

Anhang 6.12. Pull down von TGA2 mit ROXY19. Oben: Coomassie gefärbtes SDS-PAGE Gel von jeweils $1 / 500$ der Ungebundenen Fraktion (U) und Wasch-Schritte 1 und 7 (W), sowie 1/50 der Elutionen 1-3 (E) einer aeroben ROXY19 Co-Expression mit TGA2. Unten: : Western Blot Analyse der Fraktionen auf die Anwesenheit von TGA2. Der Nachweis erfolgte durch einen spezifisch gegen TGA2 und TGA5 gerichteten Antikörper ( $\alpha-$ tga2,5). Für den Western Blot wurden 1:100 Verdünnungen der Fraktionen verwendet, dies entspricht 1/50000 (U, W1, W7) und 1/5000 (E1-3). 


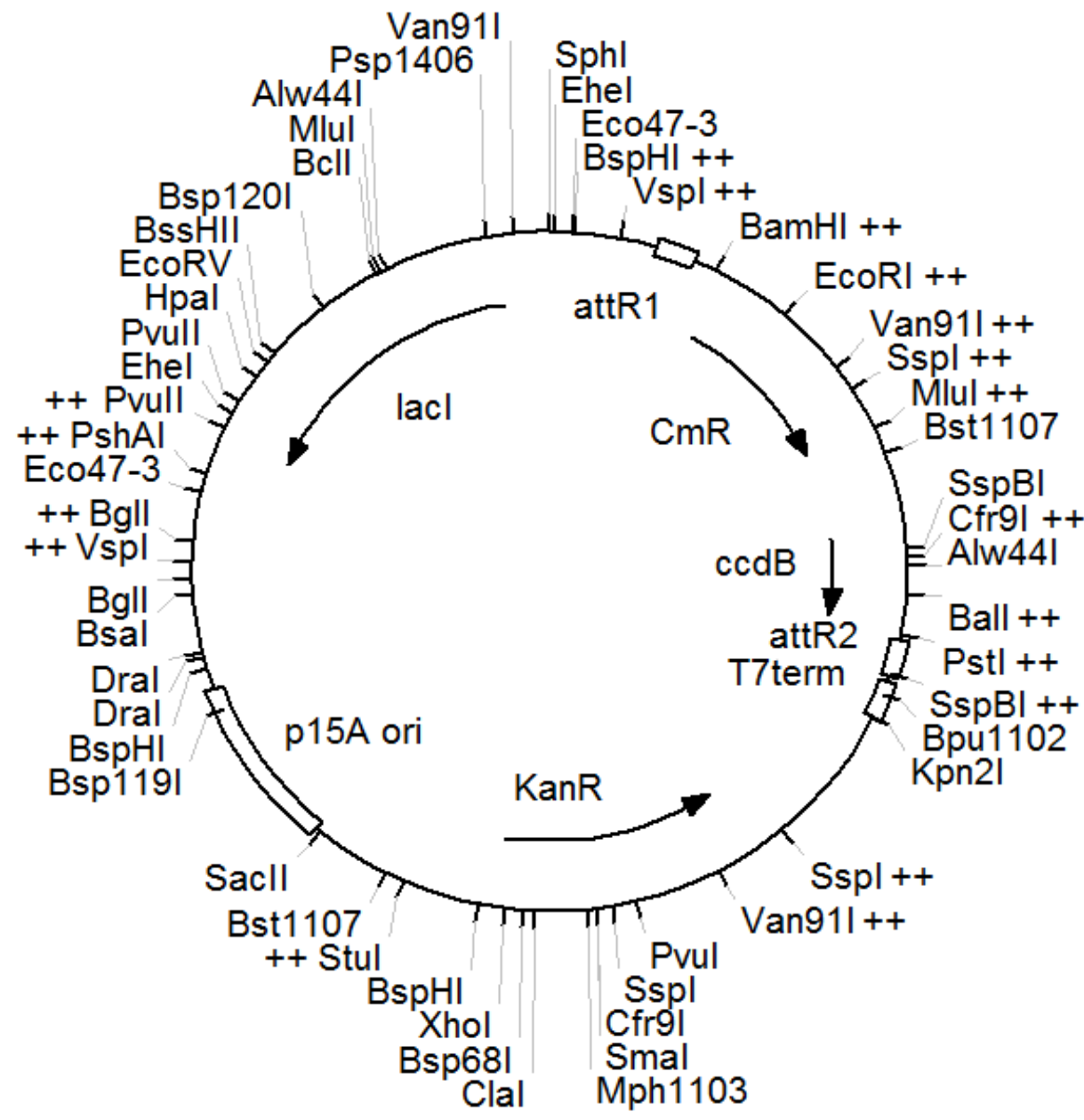

Anhang 6.13. Plasmidkarte für das Expressionsplasmid pAC28-GW. Über attR1 (332-455)und attR2 (19122036) kann die Gateway Kassette ( $C m R$ (565-1224) und $c c d B$ (1566-1871)) durch jedes beliebige Gen (durch attR1 und attR2 flankiert) durch eine LR Reaktion ausgetauscht werden. Für die Expression in E. coli ist ein T7 Promotor (214-230, nicht gezeigt), der lac Operator (233-256, nicht gezeigt), die Ribosomenbindestelle (287293, nicht gezeigt), der T7 Terminator (T7 term) (2050-2172) und der lac Inhibitor (lacl) (6586-5504) vorhanden. Das Plasmid besitzt einen p15A ori (Replikationsursprung) (4693-4147) und eine Kanamycin Resistenz Gen (KanR) (3553-2734). ++ = mehr Restriktionsenzyme vorhanden, als gezeigt. 


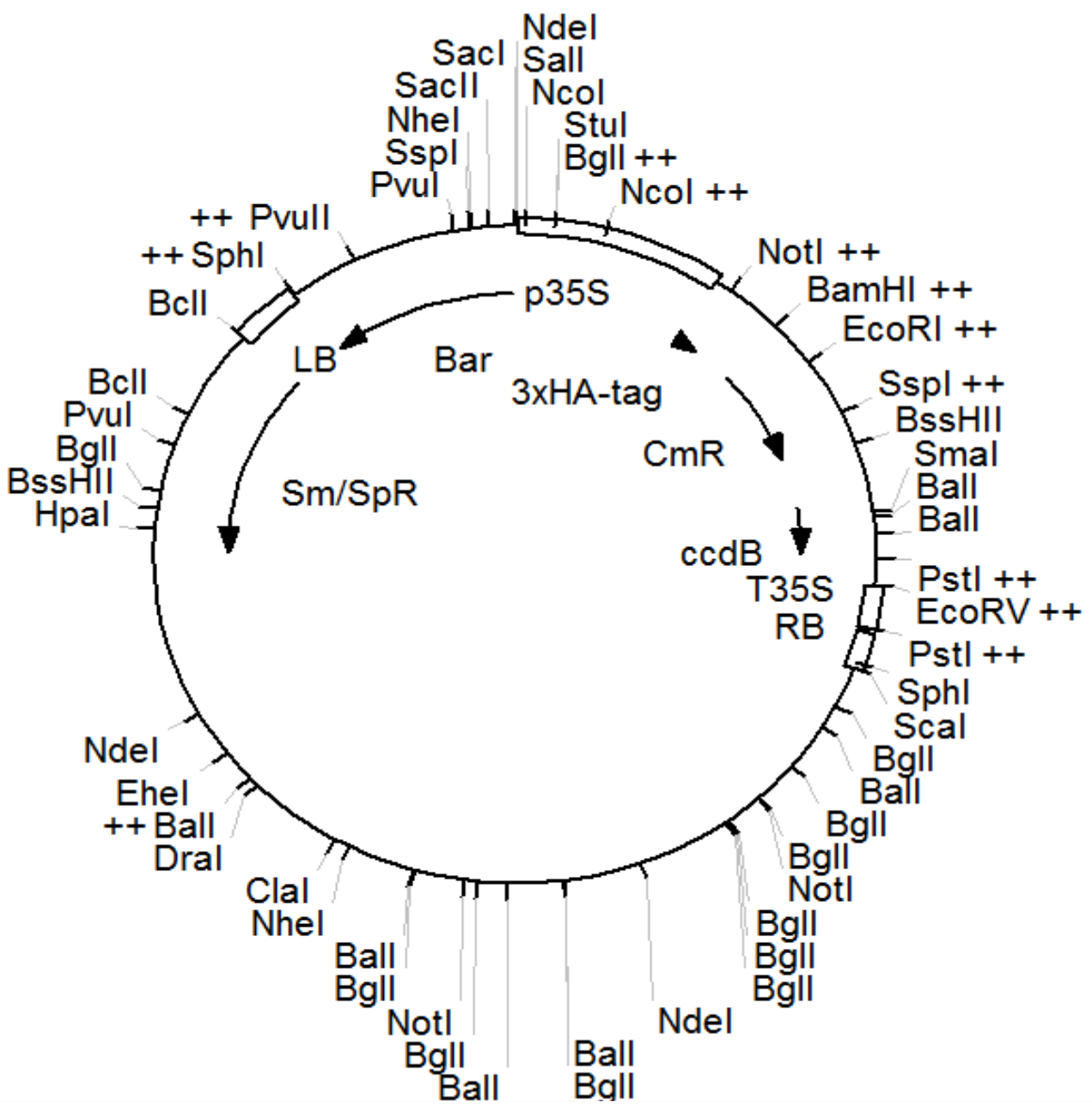

Anhang 6.14. Plasmidkarte für den Vektor pB2GW7-HA-GW. Über attR1 (1213-1336)und attR2 (2793-2917) kann die Gateway Kassette (CmR (1446-2105) und $\operatorname{ccdB}$ (2447-2757)) durch jedes beliebige Gen (durch attR1 und attR2 flankiert) durch eine LR Reaktion ausgetauscht werden. Das Gen wird durch den 35S Promotor (p35S) (15-1038) und 35S Terminator (T35S) (2927-3152) reguliert und besitzt ein N-terminales 3X HA-tag (1048-1194). Für die Integration in das Pflanzengenom sind die right border (RB) (3176-3375) und left border (LB) (9534-9866) vorhanden. In E. coli verleiht das Plasmid Spectinomycin Resistenz (Sm/SpR) (8528-8279) und in A. thaliana Basta Resistenz (Bar) (11017-9870). ++ = mehr Restriktionsenzyme vorhanden, als gezeigt. 


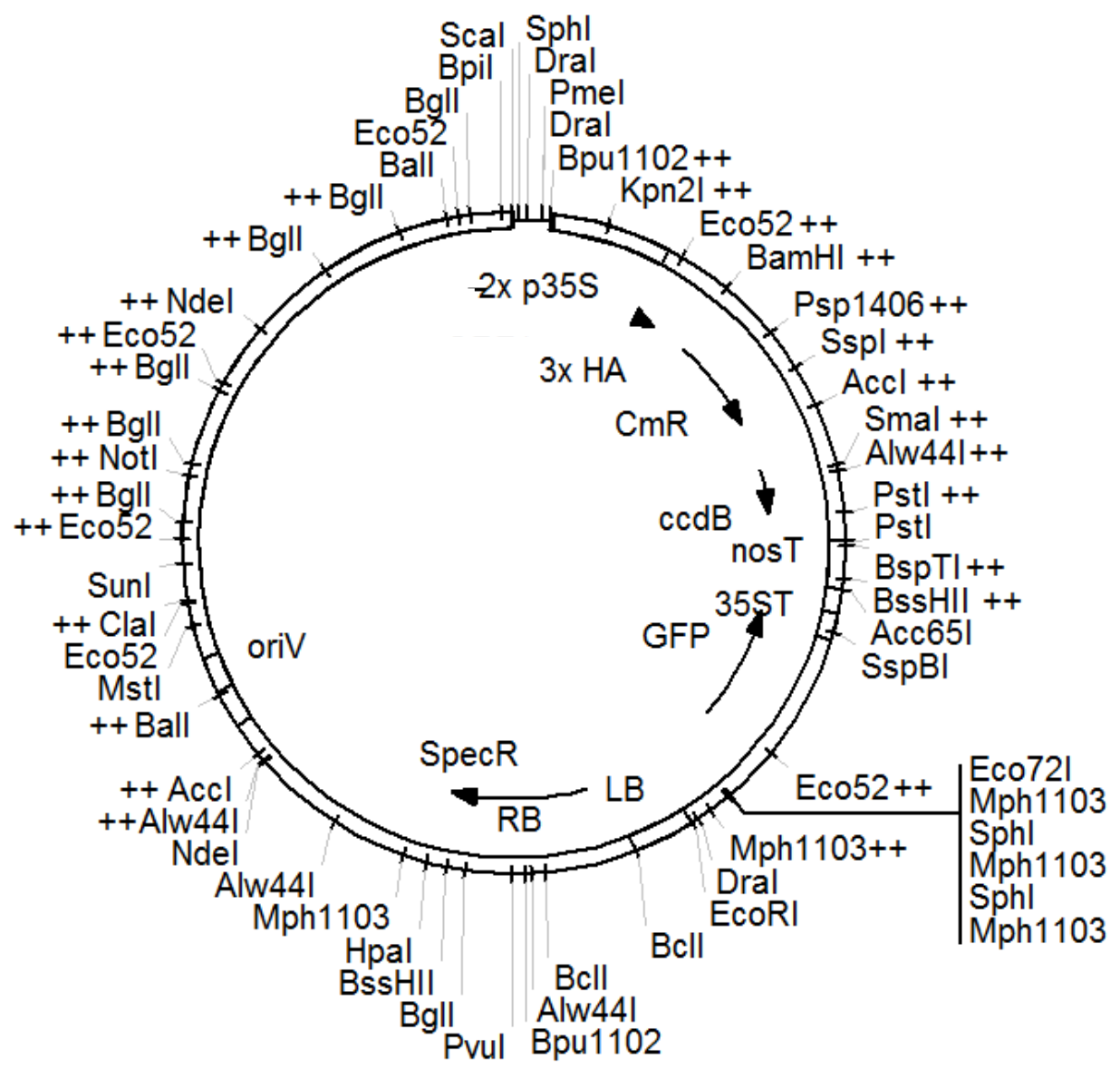

Anhang 6.15. Plasmidkarte für den Vektor pALLIGATOR2. Über attR1 (1017-1140)und attR2 (2721-2597) kann die Gateway Kassette (CmR (1250-1909) und ccdB (2251-2556)) durch jedes beliebige Gen (durch attR1 und attR2 flankiert) durch eine LR Reaktion ausgetauscht werden. Das Gen wird durch 2x 35S Promotor (2xp35S) (212-851) und den nos Terminator (nosT) (2743-2998) reguliert und besitzt ein N-terminales 3X HA-tag (8521004). Für die Integration in das Pflanzengenom sind die right border (RB) (11006-199) und left border (LB) (4847-4516) vorhanden. Der Vektor kodiert für ein GFP (4015-3218), welches durch den Samenspezifischen Promotor pAT253 (SESA3-Promotor, AT4G27160, -348 bis -1) und den 35S Terminator (T35S) (3124-3277) reguliert wird. In E. coli verleiht das Plasmid Spectinomycin Resistenz (SpecR) (4996-5928). Der Replikationsursprung oriV befindet sich bei 7630-7436. ++ = mehr Restriktionsenzyme vorhanden, als gezeigt. 


\section{Danksagungen}

An erster Stelle gilt mein Dank Frau Prof. Dr. Christiane Gatz für die Möglichkeit meine Dissertation in Ihrer Arbeitsgruppe anfertigen zu dürfen. Vor allem für die vielen Stunden des gemeinsamen Kopfzergrübelns wie das Projekt noch zu retten sei. Vielen Dank für die reichliche Menge an Geduld und konstruktive Kritik, sowie unzähligen aufschlussreichen Diskussionen, danke, dass Ihre Tür immer offen stand und Sie immer ein Ohr übrig hatten.

Desweiteren möchte ich Herrn Prof. Dr. Jörg Stülke für die Übernahme des Korreferenten danken. Vielen Dank für die konstruktiven Kritiken und Diskussionen nach jedem Thesis Comittee.

Ein Dank gilt auch allen weiteren Mitgliedern der Prüfungskommission, namentlich Herrn Prof. Dr. Volker Lipka, Herrn Prof. Dr. Ivo Feussner, Frau Prof. Dr. Andrea Polle und Herrn PD Dr. Thomas Teichmann.

Ein sehr großes Dankeschön geht an Herrn Dr. Sven Freibert und Herrn Prof. Dr. Roland Lill aus Marburg. Vielen Dank für die große Hilfe bei meinen Experimenten und die Bereitschaft Experimente für mich durchzuführen und auszuwerten. Außerdem danke ich für die Wochen in Marburg, in denen ich meine Experimente bei euch machen durfte. Außerdem danke ich euch für die freundliche und hilfsbereite Atmosphäre in der AG Lill, es war eine schöne und lehrreiche Zeit.

Natürlich möchte ich auch der ganzen Abteilung Gatz danken. Mein Dank gelten Frau Dr. Corinna Thurow und Herrn PD Dr. Joachim Uhrig für viele hilfreiche Tipps und Diskussionen in den letzten Jahren. Außerdem möchte ich Herrn Dr. Guido Kriete für seine Hilfe bei allen technischen Problemen danken. Dem technischen Personal der Abteilung gilt mein Dank für jede Hilfe die ich in Anspruch nahm bei Fragen zu Experimenten, danke Anna, Ronny und Kathi $;$, , bessere TAs gibt es nicht. Für die netten Jahre danke ich allen ehemaligen Mitgliedern der AG Gatz (Dr. Martin Muthreich, Dr. Alex Meier, Dr. Johanna Schmitz) und $\operatorname{der}$ AG Gleason (Dr. Nathannon Leelarasamee und Dr. Frederik Polzin), sowie den aktuellen Mitgliedern der AG Gatz (Dr. Li-Jun Huang, Dr. Ning Li, Dr. Armin Töller, Katrin Treffon, Aswin Nair, Jelena Budmir, Louisa Ulrich), meinem ehemaligen Bachelorstudenten Björn Richts und allen anderen Studenten(innen) der letzten Jahre. Ohne euch wäre alles bestimmt ganz anders verlaufen.

Ein Dank gilt auch unseren Gärtnern für das Stopfen zahlreicher Töpfe mit Erde und das Ernten von Samen, danke Feli und Susanne.

Zum Schluss danke ich meiner Familie und Freunden, danke für die Geduld und moralische Unterstützung. Besonderer Dank gilt meiner Schreibpartnerin der letzten Wochen: meiner Hündin Queeny. Ihr Kopf bekam besonders viel Zuneigung, wenn ich mal überlegen musste wie ich weiter schreiben kann. 


\section{Lebenslauf}

Jan Oberdiek

Geboren:

Staatsangehörigkeit:

Email:
23.06.1990 in Göttingen

Deutsch

janoberdiek@yahoo.de

\section{Bildungsweg}

seit $12 / 2014$

$10 / 2012-10 / 2014$

$10 / 2009-09 / 2012$

08/2002-07/2009

$08 / 2000-07 / 2002$
Promotion - Biologie

Georg-August-Universität (Göttingen, DE)

- Schwerpunkte: Molekularbiologie der Pflanze, Biochemie, Proteinexpression, Redoxchemie

- Abteilung: Frau Prof. Dr. Christiane Gatz

- Titel: Funktionale Analyse des CC-Typ Glutaredoxin ROXY19 in Arabidopsis thaliana

Master of Science - Biologie

Georg-August-Universität (Göttingen, DE)

- Schwerpunkte: Molekularbiologie, Mikrobiologie, Genetik und Biochemie

- Note: 1,6

- Titel: The role of nuclear export for the SCL14 function as an activator of detoxification genes (Abteilung: Frau Prof. Dr. Christiane Gatz, Note: 1,3)

Bachelor of Science - Biologie

Georg-August-Universität (Göttingen, DE)

- Schwerpunkte: Molekularbiologie, Genetik (humane und mikrobielle)

- Note: 1,6

- Titel: Identification of SCF (SkpA-CulA-Fbox) complexes in the filamentous fungus Aspergillus nidulans (Abteilung: Herr Prof. Dr. Gerhard Braus, Note: 1,3)

Abitur

Theodor-Heuss-Gymnasium (Göttingen, DE)

- Abschlussnote $(2,7)$

Orientierungsstufe Lutherschule (Göttingen, DE)

$08 / 1996-07 / 2000$
Erich-Kästner Grundschule (Göttingen, DE) 